\title{
Sympathetic nerves and alterations in vascular structure and reactivity
}

Citation for published version (APA):

Eerdmans, P. H. A. (1997). Sympathetic nerves and alterations in vascular structure and reactivity.

[Doctoral Thesis, Maastricht University]. Universiteit Maastricht. https://doi.org/10.26481/dis.19970206pe

Document status and date:

Published: 01/01/1997

DOI:

10.26481/dis.19970206pe

Document Version:

Publisher's PDF, also known as Version of record

\section{Please check the document version of this publication:}

- A submitted manuscript is the version of the article upon submission and before peer-review. There can be important differences between the submitted version and the official published version of record.

People interested in the research are advised to contact the author for the final version of the publication, or visit the DOI to the publisher's website.

- The final author version and the galley proof are versions of the publication after peer review.

- The final published version features the final layout of the paper including the volume, issue and page numbers.

Link to publication

\footnotetext{
General rights rights.

- You may freely distribute the URL identifying the publication in the public portal. please follow below link for the End User Agreement:

www.umlib.nl/taverne-license

Take down policy

If you believe that this document breaches copyright please contact us at:

repository@maastrichtuniversity.nl

providing details and we will investigate your claim.
}

Copyright and moral rights for the publications made accessible in the public portal are retained by the authors and/or other copyright owners and it is a condition of accessing publications that users recognise and abide by the legal requirements associated with these

- Users may download and print one copy of any publication from the public portal for the purpose of private study or research.

- You may not further distribute the material or use it for any profit-making activity or commercial gain

If the publication is distributed under the terms of Article $25 \mathrm{fa}$ of the Dutch Copyright Act, indicated by the "Taverne" license above, 
Sympathetic nerves and alterations in vascular structure and reactivity 
๑ P.H.A. Eerdmans, Maastricht 1997

ISBN 90-9010188-8

This thesis was supported by grants from the Royal Dutch Academy of Sciences (KNAW), the Netherlands Scientific Research Organisation (NWO) and the European Union (EU, Biomed 1).

Publication of this thesis was made possible by support of Medtronic Interstim, Pharmacia\&Upjohn, Yamanouchi and Zeneca. 


\section{Sympathetic nerves and alterations}

in

\section{vascular structure and reactivity}

\section{PROEFSCHRIFT}

Ter verkrijging van de graad van doctor aan de Universiteit Maastricht, op gezag van de Rector Magnificus, Prof. Mr. M.J. Cohen, volgens het besluit van het College van Decanen, in het openbaar te verdedigen op donderdag 6 februari 1997 om 16.00 uur

door

Pedro Henry Alfred Eerdmans geboren op 23 november 1961 te Alkmaar 


\section{Promotor}

Prof. dr. H.A.J. Struijker Boudier

Co-promotor

Dr. J.G.R. De Mey

Beoordelingscommissie

Prof. dr. R.A. Janknegt (voorzitter)

Prof. dr. C. Bruggeman

Prof. dr. S. de Lange

Prof. dr. M.C. Michel (Universitätsklinikum Essen, Duitsland)

Dr. M. Pfaffendorf (Universiteit van Amsterdam)

Financial support by the Netherlands Heart Foundation for the publication of this thesis is gratefully acknowledged. 
Aan mijn ouders Aan Caroline 



\section{Table of contents}

1. General introduction

2. Effects of chloroethylclonidine on prazosin binding and contractile responses to noradrenaline in large and small arteries of the rat

3. $\alpha_{2}$-adrenergic reactivity in resistance arteries of the adult spontaneously hypertensive rat

4. Regionally selective alterations of arterial structure after 4-week 83 treatment of juvenile SHR with prazosin, rilmenidine and azepexole

5. Regionally selective alterations of sympathetic nerves and their target organs in juvenile SHR after 4-week treatment with prazosin, rilmenidine and azepexole

6. Structure and reactivity of rat peripheral arteries 4 weeks after myocardial infarction

7. Impaired arterial reactivity following cytomegalovirus infection in the immunosuppressed rat

8. Summary and conclusions

Samenvatting 



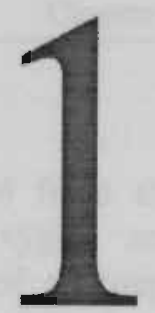

General introduction 


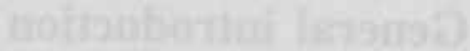




\section{Introduction}

The cardiovascular system distributes blood to and collects blood from the different organs to assure optimal exchange of nutrients, oxygen and metabolites from the tissues. The cardiovascular system consists of a pump, the heart, and an arterial tree starting with the aorta and resolving in a dense network of capillaries. These capillaries are connected to small venules which combine into veins. The veins end in the vena cava, which is connected to the heart, closing the vascular circle.

The control of the cardiovascular system is complex and consists of remote and local acute and chronic regulatory mechanisms.

Remote control systems of the vasculature include peptidergic and sympathetic nerves (Hirst \& Edwards, 1989) which release noradrenaline, ATP, peptidergic transmitters like CGRP and neuropeptide Y (Hirst \& Edwards, 1989; Lundberg et al., 1990; Eerdmans et al., 1991). Furthermore, dynamic changes in vasculature can be mediated by substances released in the circulation, like hormones (Grillone et al., 1988; Tabrichi \& Triggle, 1991), autocoids (De Mey \& Gray, 1985; Edwards, 1985; Lüscher \& Vanhoutte, 1988) and tissue metabolites (De Mey et al., 1979; Silver et al., 1984).

Local control of vascular function has been described on the basis of various mechanisms. Arteries have a basal tone, which does not depend on neurogenic or any of the other control mechanisms described above. This myogenic tone originates within the smooth muscle cells and is affected by pressure changes (Mellander, 1989; Falcone et al., 1991; Messing et al., 1991). Structural alterations due to pressure changes (Kitakaze et al., 1991) can be seen as an intrinsic long term control mechanism of the blood vessel wall to regulate wall stress and its local distribution. Other cell types in the arteries can also influence vascular tone locally. Endothelial cells have multiple modulatory effects on vascular smooth muscle function. Furchgott and Zawadski (Furchgott \& Zawadski, 1980) were the first to describe the endotheliumdependence of the vasodilator action of acetylcholine on smooth muscle cells. A vasodilator substance, endothelium derived relaxing factor (EDRF), is liberated by the endothelial cells. This substance was later found to be nitric oxide (Palmer et al., 1988; Moncada et al., 1989). Another relaxing substance released from the endothelium was later found, namely endothelium derived hyperpolarizing factor (EDHF) (Chen et al., 1988; Taylor \& Weston, 1988; Miller, 1991; Rubanyi, 1991). A third relaxing factor is prostacyclin (Moncada et al., 1976; Moncada \& Vane, 1979), which is released by the vascular endothelium in response to a number of stimuli like shear stress, 
hypoxia and receptor-operated mechanisms (Eldor et al., 1981). Recent research suggests the additional existence of endothelium derived constricting factors, most notably endothelin (Yanagisawa et al., 1988; Furchgott \& Vanhoutte, 1989; Highsmith et al., 1989; Lüscher et al., 1992; Hahn et al., 1993).

Cardiac function is regulated by two mechanisms; $i$. intrinsic autoregulation of pumping in response to changes in the volume of blood flowing into the heart and ii. extrinsic control of the heart by the sympathetic and parasympathetic nervous systems and several hormones.

The intrinsic autoregulation is needed to overcome variations in the venous return of blood; this autoregulation is called the Frank-Starling mechanism. In principle, the amount of stretching of the cardiac muscle is correlated with the force developed during contraction.

The major extrinsic form of control is exerted by the nerve endings of sympathetic fibers, which lie between the myocardial fibers and release noradrenaline. Both atria and ventricles contain $\beta_{1}$ and $\beta_{2}$-adrenoceptors, the relative density of $\beta$-adrenoceptors being highest in the atria. Stimulation of $\beta$ adrenoceptors causes increased atrial and ventricular contractility, increases the heart rate and speeds the spread of excitation through the AV node and, very slightly, through the ventricles. There is also evidence for the production of neuropeptides in the coronary vessels and heart muscle which can influence coronary vascular resistance and myocardial contractility (Gulbenkian et al., 1993). Vagal stimulation generally exerts effects opposite to those of sympathetic stimulation on the sinus node of the atria. The vagal parasympathetic stimulation normally predominates in the conscious state and maintains the usual resting heart rate of about 65 to 75 beats per minute. The resting bradycardia of exercise training is due predominantly to a slowing of the intrinsic rate of the sinus node pacemaker due to enhanced vagal activity in association with a decrease in the adrenergic influence. Furthermore, neural reflexes, particularly from stretch receptors in the carotid sinus and aorta, form a major extrinsic control mechanism that influences myocardial performance directly and indirectly. When carotid sinus stretch decreases, as with arterial hypotension, a reflex venoconstriction is produced by the sympathetic nervous system that increases venous return and thereby increases ventricular end-diastolic fiber length. Simultaneously, carotid sinus hypotension produces reflex arterial vasoconstriction, increasing peripheral vascular resistance and aortic impedance. In addition, carotid sinus hypotension elicits reflexes that increase atrial and ventricular contractility. 
Stimulation of the carotid sinus nerve, such as might occur with carotid sinus hypertension, produces the opposite effects.

\section{Sympathetic nervous system in relation to the vascular system}

In 1921, Loewi (Loewi, 1921) observed that stimulation of the cardiac sympathetic nerves of the isolated perfused turtle heart increased the heart rate and force of contraction. He also noted that, following stimulation of the nerves, the perfusate was capable of increasing the heart rate and contractile force of other isolated hearts. He concluded that stimulated cardiac nerves liberated a chemical substance that effects a chronotropic and inotropic response in the heart. This substance, noradrenaline, had already been identified in 1897 (Abel \& Crawford, 1897). Elliot in 1905 (Elliot, 1905) suggested a relationship between noradrenaline and the sympathetic nervous system, but Loewi was the first to establish the relation between noradrenaline, the sympathetic nervous system and the cardiovascular system.

Over the last decades, the importance of the sympathetic nervous system for the vasculature had become increasingly clear. Vascular control by the sympathetic nervous system is achieved in two ways; i.) by innervation of the blood vessel and ii.) by releasing catecholamines in the circulation which act from within the lumen of the target vessel.

The release of the sympathetic neurotransmitter noradrenaline at the nerve endings appears to be under a fine inhibitory and facilitatory control (figure 1). Noradrenaline release, by exocytosis, is inhibited by junctional presynaptic $\alpha_{2}$-adrenoceptors (Armstrong \& Boura, 1973; Langer, 1974; 1977; Medgett et al., 1978; Rump et al., 1991; Hauser et al., 1995). The same occurs after presynaptic receptor stimulation of $\mathrm{DA}_{2}$, muscarinic, adenosine and $\mathrm{PGE}_{2}$ receptors and various other receptors (figure 1 ). Noradrenaline release is enhanced by activating or engaging presynaptic $\beta_{2}$-adrenoceptors, angiotensin II receptors and other receptor types (see figure 1). Stimulation of postsynaptic $\alpha$-adrenoceptors leads to vasoconstriction by activating vascular smooth muscle (Raymond et al., 1990). 


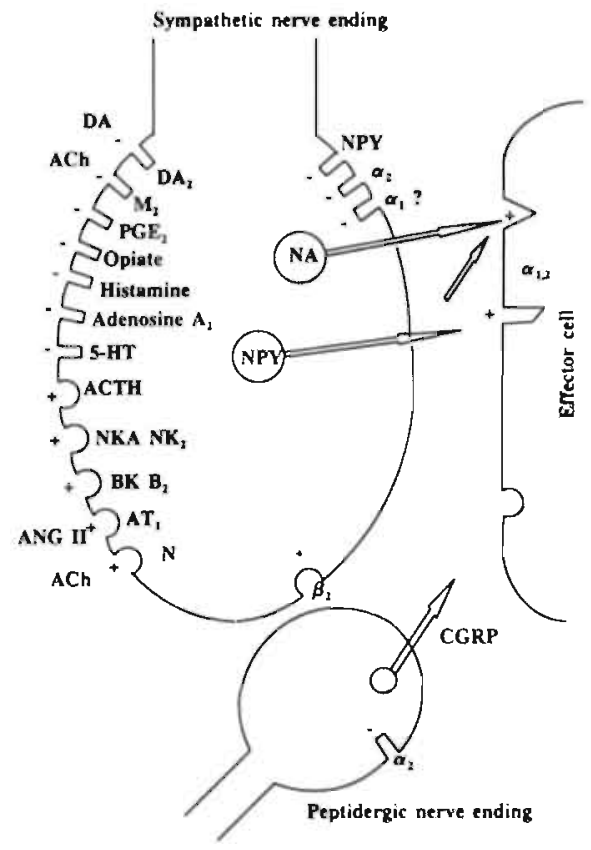

Figure 1

Schematic representation of presynaptic modulatory influences by autoreceptors and heteroceptors on noradrenaline and neuropeptide $\mathrm{Y}$ release.

Schematic representation of presynaptic modulatory influences by autoreceptors (right) and heteroceptors (left) on the liberation of the sympathetic neurotransmitters noradrenaline (NA) and neuropeptide Y (NPY). Inhibitory (-) influences are represented in the upper part and facilitatory $(t)$ influences in the lower part of the sympathetic nerve ending. In addition to its action on specific receptors NPY can also potentiate the effects of noradrenaline on adrenergic receptors. The peptidergic nerve ending seems to possess $\alpha_{2}$-adrenoceptors with inhibitory influences. DA, dopamine; $\mathrm{ACh}$, acetylcholine; $\mathrm{PGE}_{2}$, prostaglandin $\mathrm{E}_{2} ; 5-\mathrm{HT}$, serotonin; ACTH, adrenocorticotropine homone; BK, bradykinin; Ang II, angiotensin II.

The roles of the circulating catecholamines are diverse (see for example figure 2). Noradrenaline can play a role both in increasing and decreasing blood pressure. Stimulation of prejunctional, endothelial and $\alpha_{2}$-adrenoceptors in the vasomotor centre in the central nervous system (Van Zwieten et al., 1986) leads to a blood pressure reduction. Smooth muscle $\alpha_{1}$ and $\alpha_{2}$-adrenoceptor stimulation causes a blood pressure increase.

Furthermore, evidence exists of a trophic influence of the sympathetic nervous system in relation with the vasculature. In vitro administration of catecholamines to rat aortic smooth muscle cells (SMC) leads to DNA synthesis (Blaes \& Boissel, 1983; Yamori et al., 1987), mediated by $\alpha_{1}{ }^{-}$ adrenoceptors (Nakaki et al., 1990). Sympathetic nerves have been shown to stimulate arterial wall growth in young rabbits (Bevan \& Tsuru, 1979; 1981; Bevan et al., 1983). 

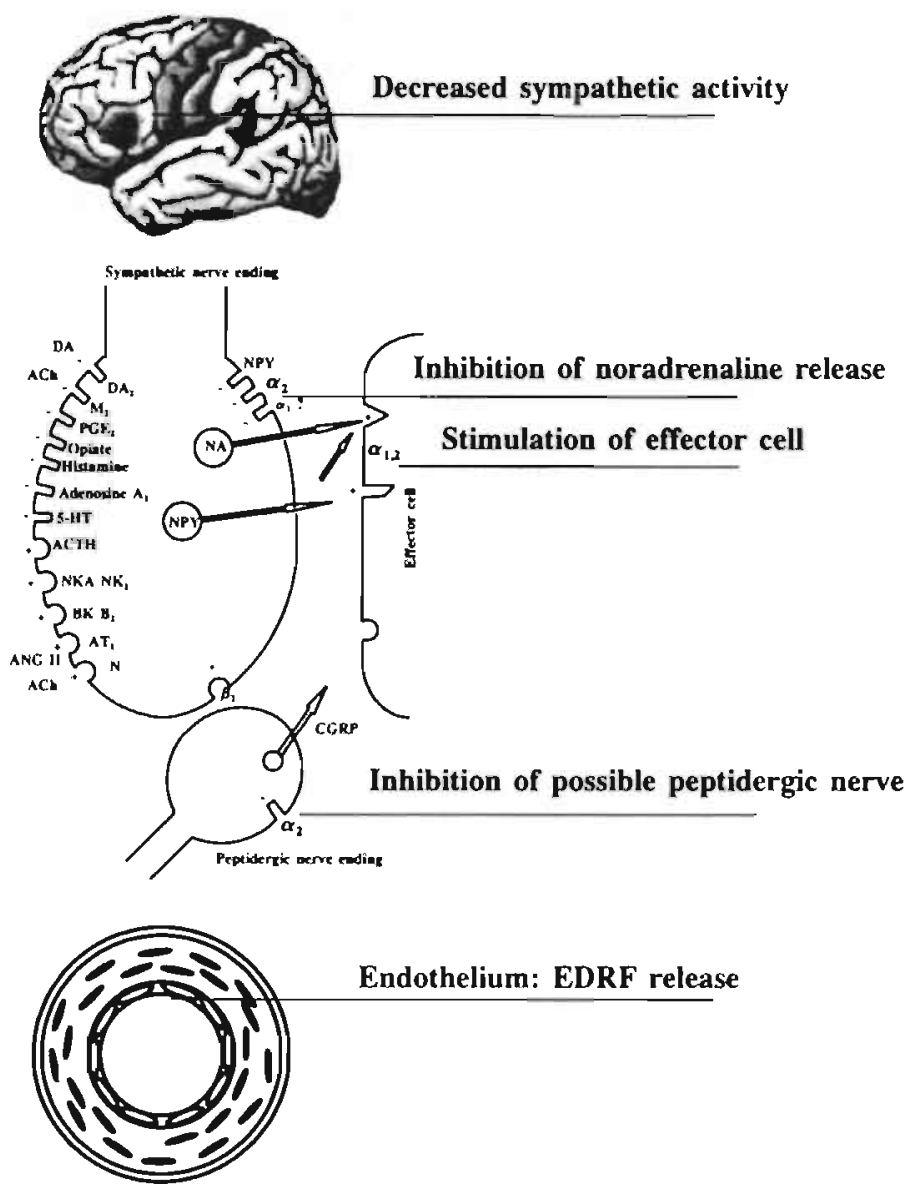

\section{Figure 2}

The possible mechanisms of action of $\alpha_{2}$-adrenoceptor agonists. $\alpha_{2}$-Adrenoceptor agonists can interact in several mechanisms. Stimulation of central $\alpha_{2}$-adrenoceptors leads to decreased sympathetic activity. In the sympathetic nerve ending stimulation induces decreased noradrenaline release and increased excitation of the effector cell. Furthermore, inhibition of peptidergic nerves is possible. In the artery, $\alpha_{2}$-adrenoceptor stimulation of the endothelium results in increased EDRF release, which in turn results in vasodilation.

Unilateral removal of the superior cervical ganglion in a four week old rabbit has been found to decrease the amount of SMC DNA synthesis, wall thickness and total weight of the denervated ear artery (Bevan \& Tsuru, 1979). Sympathectomy, using anti nerve growth factor (NGF) antibodies and guanethidine, partly prevented the development of resistance artery structure 
changes in the SHR (Lee et al., 1987; 1991; Korner, P. et al., 1993). The receptor or receptors responsible for the trophic changes are still unknown. Prazosin (Jonsson et al., 1992) administration significantly reduced aortic wall mass but did not modify resistance artery structure. This was in agreement with investigations performed by our group (Boonen et al., 1993) in which phenylephrine infusion led to a $15 \%$ increase in aortic wall mass but no changes in small resistance arteries.

Several differences in function and innervation have been found between large and small arteries. Small arteries play an important role in establishing resistance and regulating blood pressure. In larger arteries the compliance is of importance in relation to blood pressure (Barra et al., 1993) . Large vessels lack sympathetic innervation; the density of the innervation increases with the branching of the arterial tree. Furthermore, differences in innervation have been observed between different vascular beds. The response to nerve stimulation seems to be higher in mesenteric resistance arteries compared to intra-renal resistance arteries (Eerdmans et al., 1991). Furthermore, functional peptidergic (capsaicin sensitive) nerves were found to exist in the mesenteric resistance artery but not in the intra-renal resistance artery (McEwan et al., 1988; Edvinsson et al., 1989; Eerdmans et al., 1991).

Major differences in pharmacological profile between large and small arteries have been discribed in the literature. Differences in adrenergic sensitivity but also in the distribution of $\alpha$-adrenergic (sub)types (De Mey \& Vanhoutte, 1981; Daly et al., 1988; Faber, 1988; Heesen \& De Mey, 1990; Messing et al., 1990; Piascik et al., 1990) and $\beta$-adrenoceptors (Heesen et al., 1989) have been observed in various vascular beds. The physiological role of the differences between the (large and small) arteries and vascular beds, especially with respect to $\alpha_{1}$-adrenoceptor subtypes, remains largely unknown.

\section{Adrenoceptor pharmacology}

\section{Adrenoceptor classification}

Fifty years after the discovery of noradrenaline (Abel \& Crawford, 1897) and after numerous pharmacological studies of metabolic effects provoked by adrenoceptor agonists, Ahlquist (Ahlquist, 1948) proposed a division of adrenoceptors into two general classes, $\alpha$ and $\beta$ adrenoceptors. Since this original distinction between $\alpha$-and $\beta$-adrenoceptor responses, extensive studies of adrenoceptor pharmacology have pointed to further subdivision of each family into subtypes. $\alpha$-Adrenoceptor-mediated responses have been 
subdivided into two types, $\alpha_{1}$ and $\alpha_{2}$ (Langer, 1974). The $\beta$-adrenoceptor responses were divided into two classes, termed $\beta_{1}$ and $\beta_{2}$, based on the relative potencies of isoproterenol, adrenaline and noradrenaline (Lands et al., 1967). Furthermore, evidence has accumulated over the years for the existence of a $\beta$-adrenoceptor that is insensitive to the commonly used antagonists, the $\beta_{3}$-adrenoceptor. Insight into $\alpha$ - and $\beta$-adrenoceptor (sub)types has accelerated over the last decade, with the progress of molecular biology and the development of potent antagonists that are highly selective for the adrenoceptor subtypes (for an overview, see tables 1 and 2). Radioligand-binding and molecular studies have identified several $\alpha_{1}$-adrenoceptor subtypes. The initial subdivision of the $\alpha_{1}$-adrenoceptor into the $\alpha_{1 \mathrm{~A}}$ and $\alpha_{1 \mathrm{~B}}$ classes was based on differential affinity of the competitive antagonist WB 4101 and the alkylating agent chloroethylclonidine (CEC) (Johnson \& Minneman, 1987). At present $\alpha_{1 \mathrm{~A}}, \alpha_{1 \mathrm{~B}}$ and $\alpha_{\mathrm{ID}}$ have been identified as subtypes, with CEC seeming to alkylate both $\alpha_{1 \mathrm{~B}}$ and $\alpha_{1 \mathrm{D}^{-}}$adrenoceptors (Han \& Minneman, 1991; Bylund, 1992; Aboud et al., 1993; Michel et al., 1993a; b).

With the aid of radioligand-binding studies and by correlating the affinities for a series of $\alpha$-adrenoceptor antagonists as inhibitors of $\left[{ }^{3} \mathrm{H}\right]$ rauwolscine binding in different tissues, four types of $\alpha_{2}$-adrenoceptors have been identified (Bylund, 1985; Kawahara \& Bylund, 1985; Bylund et al., 1988; Minneman, 1988; Murphy \& Bylund, 1988; McClue \& Milligan, 1991; Simonneaux et al., 1991; Pepperl \& Regan, 1993; Ren et al., 1993; Devedjian et al., 1994).

\section{Signal transduction}

Binding of an agonist to its vascular receptor induces a cascade of biochemical events, ultimately leading to relaxation or contraction. $\alpha$ - and $\beta$-adrenergic receptors are all coupled to a specific intracellular second messenger system via guanine nucleotide (GTP, GDP) binding proteins. These proteins consist of three subtypes, $\alpha, \beta$ and $\gamma$. Receptor activation can induce the replacement of GDP by GTP in the $\alpha$ subunit, thereby altering the conformation of the protein and making the active site of the G-protein available for activation or inhibition of enzymes or ion channels. 
Table 1. $\alpha$-Adrenoceptors

$a_{1}$

Nomenclature

Potency order

Selective agonists

$$
\begin{aligned}
& \alpha_{\mid A} \\
& \text { NA } \geq \text { adrenaline } \\
& \text { A61603 } \\
& \text { SDZNV } 1085 \\
& \text { WB } 4101(9.5) \\
& 5 \text {-methyluradipil( }(9.2) \\
& (+) \text { niguldipine( } 10.0) \\
& \mathrm{G}_{q^{\prime \prime 1}} \\
& \alpha_{1 ;} \text { chr } 8 \\
& 466 \text { da human } 7 \mathrm{TM}
\end{aligned}
$$

Selective antagonists

Effector

Gene*

Structural information

\section{$\alpha_{2}$}

Nomenclature

Potency order

Selective agonists

Sclective antagonists

\section{Effector}

Gene

Siructural information

$$
\begin{aligned}
& \alpha_{2 \mathrm{~A}} \\
& \text { adrenaline } \geq \mathrm{NA} \\
& \text { oxymetazoline }
\end{aligned}
$$$$
\text { - }
$$

$G_{i: n}$ $\alpha 2 \mathrm{~A}$; chr 10

450 aa human P08913 7TM 450 aa mouse Q01338 7TM 450 aa rat $P 229097 \mathrm{TM}$

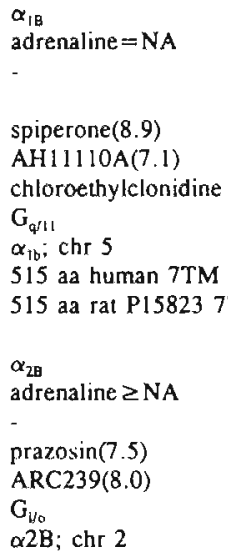

$\alpha_{\text {IB }}$

adrenaline $=\mathrm{NA}$

$-$

spiperone(8.9)

AH11110A(7.1)

chloroethylclonidine

$\mathrm{G}_{\mathrm{q} / \mathrm{I}}$

$\alpha_{+b}$; chr 5

515 aa human $7 T M$

$\alpha_{2 \mathrm{~B}}$
adrenaline $\geq N A$
-
prazosin(7.5)
ARC239(8.0)
$\mathrm{G}_{\mathrm{H}_{0}}$

Q2B; chr 2

515 aa rat $\mathrm{P} 158237 \mathrm{TM}$

450 aa human P18825 7TM 455 aa mouse P30545 7TM 453 a a rat P19328 7TM $\alpha_{10}$

adrenaline $=$ NA

BMY 7378(8.4)

$\mathrm{G}_{\psi / 1}$

$\alpha_{1 d ;}$ chr 20

560 aa rat $\mathrm{P} 23944$ 7TM

\begin{tabular}{|c|c|c|c|}
\hline Nomenclature & $\beta_{1}$ & $\beta_{2}$ & $\beta_{3}$ \\
\hline Potency order & NA $\geq$ adrenaline & adrenaline $>$ NA & adrenaline $>$ NA \\
\hline \multirow[t]{3}{*}{ Selective agonists } & noradrenaline & procaterol & BRL37344 \\
\hline & xamoterol & & CL.316243 \\
\hline & & & CGP12177A \\
\hline \multirow[t]{3}{*}{ Selective antagonists } & CGP20712A(8.5-9.3) & ICII1855I(8.3-9.2) & bupranolol(7.3) \\
\hline & betaxolol( 8.5$)$ & butaxamine $(6.2)$ & \\
\hline & atenolol $(7.0)$ & $\alpha$-methylpropranolol(8.5) & \\
\hline Effector & $\mathrm{G}_{3}$ & $G_{*}$ & $\mathrm{G}_{\mathrm{s}}$ \\
\hline Gene & $\beta 1$ & $\beta 2$ & $\beta 3$ \\
\hline \multirow[t]{2}{*}{ Structural information } & 477 aa human P08588 7TM & 413 aa human P07550 7TM & 408 aa human P13945 7TM \\
\hline & 466 aa rat $\mathrm{P} 180907 \mathrm{TM}$ & 418 aa rat PI0608 7TM & 400 aa rat $\mathrm{P} 262557 \mathrm{TM}$ \\
\hline
\end{tabular}

$\alpha_{2 c}$

adrenaline $\geq N A$

$\operatorname{prazosin}(7.5)$

ARC239(8.0)

$\mathrm{G}_{\mathrm{i}, \mathrm{B}}$ $\alpha 2 \mathrm{C}$; chr 4

461 aa human P19328 $7 \mathrm{TM}$

458 aa mouse Q01337 7TM

450 aa rat P18089 7TM

${ }^{*} \alpha_{1,}$ previously $\alpha_{1 c} ; \alpha_{1 \mathrm{~d}}$ previously $\alpha_{1 \mathrm{~A}}$

(aa: aminoacids, P: accession number for protein sequence, TM: transmembrane)

\section{Table 2. $\quad \beta$-adrenoceptors}

\section{Chemical names}

AH11110A: 1-(biphenyl-2-yloxy)-4-imino-4-piperidin, ARC239: 2-(2.4-[0-methoxyphenyl]-piperazin)-1-yl

BMY7378: 8-[2-[4-(2-methoxyphenyl)-]-piperazinyl]cthyl]-8-azaspiro[4.5]decane-7,9-dione

BRL 37344: sodium-4-(2-[2-hydroxy-\{3-chlorophenyl\}echylamino]propyl)phenoxyacetate

CGP12177: (-)-4-(3-tert-burylamino-2-hydroxypropoxy)-benzimidazol-2-one

CGP20712A: 2-hydroxy-5-(2-I\{2-hydroxy-3-(4-[1-methyl-4-trifluoromethyl-2-imidazolyl]phenoxy)propyl\} amino]ethoxy)benzamide

CL316243: disodium (R,R)-5-(2-\{[2-(3-chlorophenyl)-2-hydroxyethyl]-amino\}propyl)-1,3-benzodioxole-2,2-dicarboxylate IC11 18551: erythro-DL-1-(7-methylindan-4-yloxy)-3-isopropyl-aminobutane-2-ol

WB4101: 2-(2.6-dimethoxyphenoxyethyl) aminoethyl-1,4-benzodioxane hydrochloride

'based on: TIPS 1996 Receptor and ion channel nomenclature supplement 
$\alpha$-Adrenoceptor signal transduction mechanisms

\section{Calcium translocation}

In 1978, Casteels (Casteels, 1978) and van Breemen (Van Breemen et al., 1978) demonstrated the involvement of calcium ions in $\alpha_{2}$-adrenoceptormediated vasoconstriction. The role of an influx of extracellular calcium ions in $\alpha_{2}$-adrenoceptor-mediated vasoconstriction has been firmly established in, for example, arterioles (Van Meel et al., 1981), rat isolated tail artery (Medgett \& Rajanayagam, 1984) and canine saphenous veins (Matthews et al., 1984; Cooke et al., 1985).

The relative roles of extracellular calcium influx and intracellular calcium release in the coupling of $\alpha_{1}$-adrenoceptor activation to responses has been the subject of much controversy in recent years. Most studies, using vascular smooth muscle of both arterial and venous origin, found that $\alpha_{1}$-adrenoceptormediated responses were not reduced by calcium channel antagonists (Van Meel et al., 1981; Cavero et al., 1984). However, not all selective $\alpha_{1^{-}}$ adrenoceptor agonists produced vasoconstriction in vivo that is resistant to inhibition by calcium channel blockers. This has been found with the $\alpha_{1}$ adrenoceptor agonists St 587, Sgd 1-1/75 and (-)-dobutamine in pithed rats (Ruffolo et al., 1984). It would appear that some $\alpha_{1}$-adrenoceptor agonists produce vasoconstriction via an influx of extracellular calcium, whereas others do not.

\section{Membrane phospholipid metabolism}

In most systems, calcium translocation produced by agonist interaction with $\alpha_{1}$-adrenoceptors is believed to be secondary to enhanced phosphatidylinositol (PtdIns) turnover due to activation of phospholipase $\mathrm{C}$, in the so-called "PI response" (Michell, 1979). This pathway is shown in figure 3. In some cases, however, it appears that $\alpha_{2}$-adrenoceptor-mediated responses are not the result of an increase in PtdIns (Reese \& Mathews, 1986) but seems to be associated with the inhibition of adenyl cyclase. 


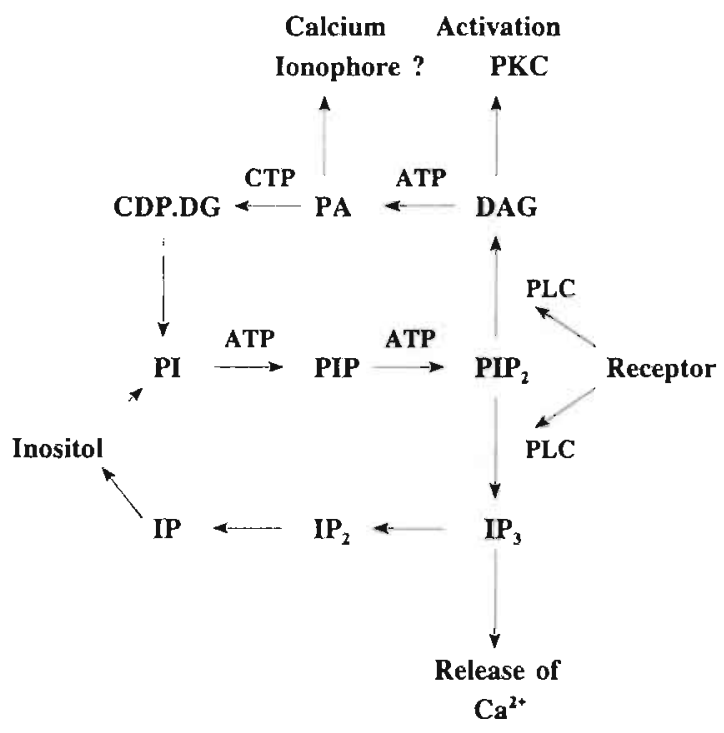

\section{Figure 3}

Schematic diagram of the cyclic nature of PtdIns turnover showing the potential role of various metabolites in signal transduction pathways. Inhibition of adenyl cyclasePIP,phosphatidylinositol-4phosphate; IP2, inositol-1,4-bis-phosphate; IP, inositol-1-phosphate; CDP.DG, cytidine diphosphate diacyglycerol; PKC, protein kinase C; PLC, phospholipase C; ATP, adenosine triphosphate; CTP, cytidine triphosphate.

Evidence of the inhibition of adenyl cyclase with $\alpha_{2}$-adrenoceptor stimulation has been observed in several cell types (Mills, 1975; Sabol \& Nirenberg, 1979; Woodcock \& Johnston, 1982; Yamazaki et al., 1982; Schoffelmeer \& Mulder, 1983; Muraki et al., 1984) and after postjunctional vascular $\alpha_{2}$ adrenoceptor activation in pithed rats (Boyer et al., 1983). $\alpha_{2}$-Adrenoceptors are coupled by an inhibitory G-protein to adenyl cyclase. Stimulation of $\alpha_{2}$ adrenoceptors induces calcium ion influx. It also induces a decrease in cytosolic cAMP concentration, which leads to a decreased activity of the enzyme protein kinase $A$ and thus to a diminished inhibitory influence on the contractile apparatus (Murray, 1990).

Sodium/hydrogen exchange.

Limbird and coworkers (Limbird \& Speck, 1983; Limbird, 1984; Sweatt et al., 1985) postulated the theory that $\alpha_{2}$-adrenoceptor activation stimulates a plasma membrane-bound $\mathrm{Na}^{+} / \mathrm{H}^{+}$exchange (antiporter) system which leads to 
an increase in intracellular $\mathrm{pH}$, resulting from the enhanced extrusion of intracellular $\mathrm{H}^{+}$, and a concomitant release of plasma membrane bound calcium into the cell. Elevation of both intracellular $\mathrm{pH}$ and calcium ion concentration leads to a cascade of intracellular reactions, resulting in activation of phospholipase $\mathrm{C}$ and eventually release of calcium ions from the sacroplasmatic reticulum.

\section{$\beta$-Adrenoceptor signal transduction mechanism}

The $\beta$-adrenoceptor signal transduction mechanism is less complex than the $\alpha$ adrenoceptors and consists, in the smooth muscle cell, of a $\beta$-adrenoceptor coupled to a stimulatory G-protein. This G-protein is coupled to adenyl cyclase, and its activation leads to an activation of protein kinase $\mathrm{C}$, causing inhibition of the contractile apparatus.

\section{Cardiovascular diseases and the sympathetic nervous system}

Cardiovascular diseases are the most common cause of death in the Western world. In the Netherlands, $40 \%$ of the total 1992 death count was due to cardiovascular disorders (The Netherlands Heart Foundation, 1994). $40 \%$ of those who died of cardiovascular disease, died of heart failure, whereas death was due to cerebrovascular accidents in $24 \%$. Ischemic heart disease is the major cause of failing pump function. Since 1972, the age-related death rate due to ischemic heart disease has shown impressive decrease of $43 \%$ for males and $44 \%$ for females. In contrast, the standardized hospital admission rate has shown a constant increase since 1972. The combination of a decreased death rate and an increase in hospital admissions may point to improved survival rates of acute myocardial infarctions and to an increase in the number of admissions for diagnostic or interventional purposes.

The three main risk factors for ischemic heart disease are dyslipidaemia, smoking and hypertension. Hypertension has been shown to predispose for coronary atherosclerosis (Koren et al., 1991).

Although a beneficial effect of lowering blood pressure on the incidence of stroke has now been firmly established, the impact on ischemic heart disease is much less pronounced (Paul, 1986). It is beyond the scope of this introduction to discuss in detail all possible pathogenic mechanisms in heart failure, hypertension or other cardiovascular disorders. The discussion limits itself to the potential role of the sympathetic nervous system. 
Heart failure: pathophysiology

The heart has 2 primary functions: to provide cardiac output sufficient to meet all physiologic and metabolic demands, and to generate arterial pressure sufficient to perfuse the organs. Cardiac failure can be defined as a state in which the heart fails to meet the variable oxygen and metabolic needs of the body under different circumstances, or a state in which cardiac output is reduced relative to the metabolic demands of the body, assuming the existence of adequate venous return.

In the presence of a disturbance in myocardial contraction, or an excessive hemodynamic burden placed on the ventricle, or both, the heart depends upon three principal compensatory mechanisms for maintenance of its pumping function: 1) the Frank-Starling mechanism, in which an increased preload (lengthening of sacromeres to provide optimal overlap between thick and thin myofilaments and to increase activation) acts to sustain cardiac performance; 2) increased sympathetic nervous system activity, which increases the force of contraction at any fiber length without increasing the filling pressure, stimulates the renin-angiotensin-aldosterone system(Sigurdsson et al., 1993) and raises the heart rate and the systemic vascular resistance to maintain arterial pressure (Remme, 1986); 3) myocardial hypertrophy, with or without cardiac chamber dilatation, by which the mass of contractile tissue is augmented.

Initially, these three compensatory mechanisms may be adequate to maintain the overall pumping performance of the heart at a relatively normal level for submaximal workloads, although the performance may be reduced at maximum workload. However, each of these three compensatory mechanisms has a limited potential, and each of them is subject to negative feedback control. If the disturbance in myocardial contraction and/or the excessive hemodynamic burden persists, the heart ultimately fails.

\section{Alterations in the sympathetic nervous system during heart failure.}

As was mentioned above, one of the three compensatory mechanisms in heart failure consists of increasing sympathetic nervous activity. This has been directly demonstrated by studies using peroneal nerve recordings of sympathetic nerve traffic in patients with chronic heart failure (Leimbach et al., 1986). Furthermore, patients with heart failure generally show circulating noradrenaline and NPY concentrations two to three times the level in normal subjects (Chidsey et al., 1962; Cohn et al., 1984; Esler et al., 1984; Hasking et al., 1986a; b; Leimbach et al., 1986; Jennings \& Esler, 1990; Sigurdsson et 
al., 1993). These are accompanied by elevation of circulating dopamine and sometimes adrenaline, reflecting increased adrenomedullary activity (Hasking et al., 1986b). Alterations in the sympathetic nervous system during the later stages of heart failure can be extremely dangerous for the patient and may lead to death.

There is evidence that in patients with heart failure $\beta$-adrenoceptors in circulating lymphocytes (Colucci et al., 1981) and $\alpha_{2}$-adrenoceptors on platelets (Weiss et al., 1983) are down-regulated. More important is the finding that ventricles obtained from patients with heart failure demonstrated a marked reduction of $\beta$-adrenoceptor density, isoproterenol-mediated adenylate cyclase stimulation, and myocardial contractility (Sibley \& Lefkowitz, 1985; Brodde, 1991; Kiuchi et al., 1993). Furthermore, Brodde has described a decoupling of the $\beta$-adrenoceptors from adenylate cyclase in the atria and ventricles in heart failure patients (Brodde, 1991)

Ventricular hypertrophy in heart failure is associated with a reduction of the inotropic response to $\alpha_{1}$-adrenoceptor agonists and a reduction of $\alpha_{1}$-adrenergic cardiac receptor numbers (Fouad et al., 1985). Further abnormalities of adrenergic nervous activity are reflected by the very low concentration of noradrenaline in atrial tissue or papillary muscles (Chidsey et al., 1966) removed from patients with heart failure. As a possible mechanism for cardiac noradrenaline depletion, reduced activity of tyrosine hydroxylase (Pool et al., 1967; Sole, 1982) (decreased biosynthesis and dopamine up-take) has been described.

The peripheral effect of increased sympathetic activity is responsible for one of the most important compensatory mechanisms in heart failure. Increased sympathetic activity causes vasoconstriction, resulting in increased arterial resistance being needed to maintain arterial pressure (Remme, 1986). Failure of this peripheral effect will lead to decreasing arterial pressure and can cause congestive heart failure ending with the death of the individual. Exhaustion of sympathetic nerve endings and down-regulation of adrenoceptors can result in a decreased vasoconstrictor response. Long-term increased sympathetic activity can lead to structural vascular alterations, changes in sympathetic innervation or modifications in the contractile apparatus. The peripheral vascular effects of the increased sympathetic activity developed after myocardial infarction are still largely unknown. In summary, a raised sympathetic activity may represent an initial compensatory mechanism in heart failure, but may -in the long runbe detrimental to the progression of the disease. 


\section{Hypertension}

Hypertension is classified as primary or secondary hypertension. A state of chronically increased blood pressure with a known cause like renal insufficiency or hyperaldosteronism is called secondary hypertension. Removing the cause will usually lead to a normalized pressure. In the case of primary or essential hypertension no (exact) cause of the increased blood pressure has been found.

Hypertension: pathophysiology

The factors responsible for the development of essential hypertension are still not clear. Some authors (Borst \& Borst-de Geus, 1963; Guyton et al., 1974) have put special emphasis on renal abnormalities in hypertension, while others, like Folkow, Lever and Mulvany allocate a central role to vascular changes.

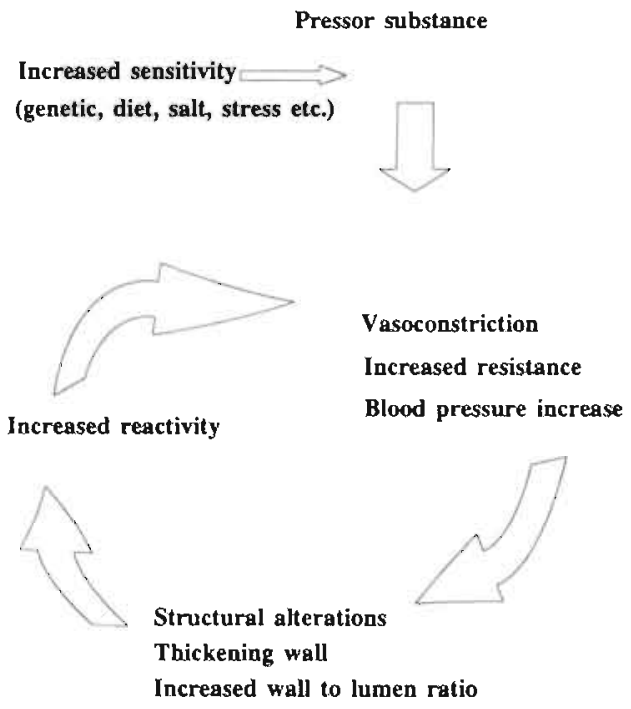

Figure 4

A hypothesis of the development of hypertension.

Folkow et al. (Folkow et al., 1958) proposed a hypothesis suggesting that environmental and genetic factors predispose an individual to become hypertensive. A pressor substance preset in the blood plasma in concentrations that does not normally affect vascular tone is assumed to induce a small but sustained vasoconstriction in subjects that have an increased susceptibility to the pressor substance due to altered environmental (Folkow et al., 1958; Folkow, 1982) or genetic factors. The global vasoconstriction would in turn 
increase total peripheral resistance and hence blood pressure. The persistent small but significantly raised blood pressure would then lead to a structural adaptation of the resistance vasculature so as to unload the active components of the vascular smooth muscle cells and redistribute and normalise wall stress. This results in a thickening of the wall and a narrowing of the lumen of resistance-sized vessels within the arterial tree or in an increase in muscle mass. An increase in the wall to lumen ratio has been suggested to affect the reactivity of the vessel. The increased reactivity to vasopressor substances subsequently leads to a further narrowing of the vessel diameter. Finally, this vicious circle (see figure 4) of positive feedback results in an upward resetting of blood pressure. Various investigators have refined this original hypothesis by stressing the amplifier properties of the vasculature (Korner, P.J. \& Angus, 1992), the role of mitogenic slow pressure substances (Lever, 1986), the role of vascular remodeling (Mulvany \& Aalkjaer, 1990; Mulvany, 1993) or the contribution of microcirculatory structural adaptions (Struijker Boudier et al., 1992).

The role of the sympathetic nervous system in hypertension.

The sympathetic nervous system plays an important role in blood pressure control by modulating venous capacity, heart rate, cardiac contractility and arteriolar resistance. Although it has frequently been assumed that a disturbed function of the autonomic system is involved in the pathogenesis of essential hypertension, convincing evidence for such a claim is lacking. One major drawback is the problem of reliable quantification of the activity of the sympathetic nervous system. Nerve activity recording, as performed by Wallin et al. (Wallin \& Sundlof, 1979; Wallin \& Nerhed, 1982; Wallin et al., 1983; Leimbach et al., 1986), can be used to evaluate sympathetic nervous tone. The development of sensitive methods to measure catecholamines in biological fluids has enabled closer monitoring of adrenergic function, but there is still no proof that this really reflects sympathetic nervous activity. Specifically, plasma concentrations may reflect the integral of noradrenaline overflow from many different tissues over time. Many investigators have measured circulating levels of noradrenaline and adrenaline in normotensive and hypertensive individuals (for review see Goldstein, 1981; 1983).

A second option is to measure NPY, which is liberated at the same time as noradrenaline. Possible re-uptake mechanisms, as seen with noradrenaline, do not exist for NPY, making the latter a more reliable parameter for measuring increased sympathetic activity. Although a number of studies have shown that 
hypertensives appear to have slightly elevated levels of catecholamines, statistically significant differences were found in only a minority of these studies (Goldstein, 1981). It should be noted, however, that a variety of environmental factors may influence circulating catecholamines, and careful matching for such factors (sodium intake, smoking, caffeine, etc.) is necessary. Furthermore, day-to-day variability, circadian variations (Turton $\&$ Deegan, 1974; Prinz et al., 1979; Levin \& Natelson, 1980; Zadik et al., 1980) and effects of physical and mental activity (De Leeuw et al., 1984) on plasma catecholamines concentrations make it difficult to investigate the role of the sympathetic nervous system in hypertension using the catecholamine plasma concentrations as a tool.

A role for the sympathetic nervous system in hypertension has been firmly established in experimental animal models of essential hypertension. The Kyoto strain of spontaneously hypertensive rat (SHR), with a genetic predisposion for hypertension, is often used as an animal model for investigating essential hypertension. At 3-5 weeks of age, the blood pressure levels of these rats are similar to those of normotensive Wistar-Kyoto control (WKY) rats (Okamoto, 1969; Lais et al., 1977). At 5-6 weeks of age, depending on the individual colony, the blood pressure of the SHR begins to increase significantly in comparison to WKY. Results of functional (Shibata et al., 1973; Lais \& Brody, 1978; Eccleston-Joyner \& Gray, 1988) and biochemical (Kwan et al., 1979) studies suggest that some changes have already taken place in the vasculature of SHR at the prehypertensive stage. Sympatholytic interventions in young spontaneously hypertensive rats prevent the development of hypertension and arterial structural changes (Nyborg et al., 1986; Lee et al., 1987). Even neonatal immunosympathectomy with anti-nerve growth factor (NGF) and guanethidine prevents the development of high blood pressure in SHR and SHRSP (stroke-prone SHR) (Lee et al., 1987; Mangiarua \& Lee, 1992)

Structural changes, such as increased wall to lumen ratio and media thickness in the SH rats have been described in several studies (Lee \& Smeda, 1985; Mangiarua \& Lee, 1992). Hypersensitivity to catecholamines seems to be common in the spontaneously hypertensive rat (Lais \& Brody, 1978; Mulvany, 1983; Aqel et al., 1987). Functional changes like postsynaptic desensitized $\alpha_{2^{-}}$ adrenoceptors and hypersensitive presynaptic $\beta_{2}$-adrenoceptors have been described (Tsuda et al., 1987; de Champlain, 1990)

In experimental models of secondary hypertension, sympathetic nerves could play a trophic role (Bevan et al., 1976; Lee \& Smeda, 1985).

In cultured smooth muscle cells, noradrenaline stimulates cell proliferation and 
the synthesis of enzymes that play a key role in DNA, RNA and protein synthesis (Kanbe et al., 1983; Mano et al., 1986).

\section{Septic shock}

Septic shock can be defined as a widely disseminated infection in many areas of the body, the infection being transported through the blood from one tissue to another, causing extensive damage. Features often seen in septic shock include i) high fever, ii) marked vasodilation throughout the body, especially in the infected tissues., iii) increased cardiac output and iv) increased red cell agglutination in response to degenerating tissues.

Cardiocirculatory insufficiency, with vascular hyporesponsiveness, is a hallmark of human septic shock. Endotoxin (LPS) as well as other bacterial toxins activate various cascade systems that lead to a final common pathway of injury. Interaction between cytokines and cardiovascular wall contributes to the pathological responses to infection, in particular to the deregulation of cardiac and vascular contractile function. Cytokines such as interleukin 1 and tumour necrosis factor have been shown to induce NO synthase activity in vascular smooth muscle (Moncada et al., 1989; Moncada \& Higgs, 1991; Schini et al., 1992). This seems to underlie hypotonic shock (Lin et al., 1994) during bacterial endotoxemia. Endotoxin is thought to stimulate cytokine production and subsequently elevate intravascular levels of NO, leading to profound vasodilation (Julou-Schaeffer et al., 1990; Moncada \& Higgs, 1991; Wakabayashi et al., 1991; Mombouli \& Vanhoutte, 1995).

The role of the sympathetic nervous system in septic shock.

The vasodilation, with its resulting decreased blood pressure, is accompanied by marked baroreflex-mediated stimulation of sympathetic nerve traffic to the heart and blood vessels (Groeneveld et al., 1986). With time the reflex may adapt (Salgado \& Krieger, 1978) which could result in the precipitous uncontrolled fall of blood pressure that characterizes septic shock (Groeneveld et al., 1986; Julou-Schaeffer et al., 1990; Wakabayashi et al., 1991). 


\section{The aim of this thesis}

The sympathetic nervous system is an important control mechanism in the cardiovascular system and plays an important role in overcoming flow problems like those found after myocardial infarction or during septic shock. In the long run, however, the sympathetic nervous system often cannot correct the hemodynamic abnormalities in these situations. This can lead to congestive heart failure or decreased blood pressure ending in death. The positive responses of long-term increased sympathetic tone seem to become attenuated due to alterations in adrenoceptors or through structural changes in the vasculature. Furthermore, there are also indications that enhanced sympathetic nervous activity can lead to the development of hypertension, as increased sympathetic activity has been observed in hypertension. Furthermore, hypertension is characterized by major structural alterations and changes in reactivity. The relationship with the sympathetic activity and the chronological order in which these changes occur are still unknown.

The aim of this thesis is to investigate the relationship between the sympathetic nervous system, blood pressure, the pathological changes in arterial structure and reactivity to adrenergic responses in large and small arteries. We chose for the study of different arteries in view of the potential differences with respect to structure, function, receptor populations and modifications during pathological conditions.

Experimental models were used with alterations in one of the four variables: increased blood pressure with decreased sympathetic tone (spontaneously hypertensive rats treated with $\alpha_{2}$-adrenoceptor stimulants), normal blood pressure with increased sympathetic tone (rats with a four week old myocardial infarction) and decreased blood pressure with increased sympathetic tone (CMV-infected rats). Furthermore, we investigated the "peripheral control" of circulating plasma catecholamines by evaluating the existence and functionality of $\alpha_{1}$-adrenoceptor subtypes in large and small arteries.

In chapters 2 and 3 we question the local role of the sympathetic nervous system using circulating catecholamines to control vasculature locally, the relevant questions being whether vascular $\alpha_{1}$-adrenoceptor subtypes play a role in local vascular control and whether $\alpha_{2}$-adrenoceptor stimulation in the vasculature leads to vasoconstriction or vasodilation.

The trophic properties of the sympathetic nervous system in relation to the vasculature constitute the subject of chapter 3, which discusses whether a normalized sympathetic nervous system in the hypertensive rat leads to positive structural alterations in the vasculature. 
Not only structural changes but also functional alterations of adrenoceptors have been regarded as one of the causes of the development of hypertension. Decreased sympathetic activity can lead to increased sensitivity, increased sympathetic activity can lead to down-regulation of $\alpha$ - and $\beta$-adrenoceptors. How sensitive are the vascular adrenoceptors to sympathetic alterations? This question was investigated using several experimental models; the results are discussed in chapters 4,5 and 6 .

This thesis investigates the importance of the sympathetic nervous system in relation to structure and vascular control. The outcome of this investigation may contribute to the development of selective antihypertensive drugs acting not only on the blood pressure but also on the mechanisms primarily responsible for the increased blood pressure and the pathological state of the vasculature. 


\section{References}

Abel J.J. \& Crawford A.C. (1897). On the blood pressure raising constituent of the suprarenal capsule, Bull Johns Hopkins Hosp 8, 151.

Aboud R., Shafii M. \& Docherty J.R. (1993). Investigation of the subtypes of $\alpha 1$ adrenoceptor mediating contractions of rat aorta, vas deferens and spleen, $\mathrm{Br} . \mathrm{J}$. Pharmacol., 109, 80-87.

Ahlquist R.P. (1948). A study of the adrenergic receptors, Am. J. Physiol., 153. 586-600.

Aqel M.B., Sharma R.V. \& Bhalla R.C. (1987). Increased norepinephrine sensitive intracellular $\mathrm{Ca} 2+$ pool in the caudal artery of spontaneously hypertensive rats, J. Hypertension., 5, 249-253.

Armstrong L.M. \& Boura A.L.A. (1973). Effects of clonidine and guanethidine on peripheral sympathetic nerve function in the pithed rat, Br. J. Pharmacol., 47, 850-852.

Barra J.G., Armentano R.L., Levenson J., Fischer E.I.C., Pichel R.H. \& Simon A. (1993). Assessment of smooth muscle contribution to descending thoracic aortic elastic mechanics in conscious dogs, Circ. Res., 73, 1040-1050.

Bevan R.D. \& Tsuru H. (1979). Long term denervation of vascular smooth muscle causes not only functional but structural change, Blood. Vessels., 16, 109-112.

Bevan R.D. \& Tsuru H. (1981). Functional and structural changes in the rabbit ear artery after sympathetic denervation, Circ. Res., 49, 478-485.

Bevan R.D., Marthens E. \& Bevan J.A. (1976). Hyperplasia of vascular smooth muscle in experimental hypertension in the rabbit, Circ. Res., 38, II58-II62.

Bevan R.D., Tsuru H. \& Bevan J.A. (1983). Cerebral artery mass in the rabbit is reduced by chronic sympathetic denervation, stroke, 14, 393-396.

Blaes N. \& Boissel J.P. (1983). Growth-stimulating effect of cathecholamines on rat aortic smooth muscle cells in culture, J. Cell. Physiol., 116, 167-172.

Boonen H.C.M., Daemen M.J.A.P., Eerdmans P.E., Fazzi G.E., van Kleef E., Schiffers P.M.H. \& De Mey J.G.R. (1993). Mesenteric small artery changes following vasoconstrictor infusion in young rats. J. Cardiovasc. Pharmacol., 22, 388-395.

Borst J.C.G. \& Borst-de Geus A. (1963). Hypertension explained by Starling's theory of circulatory homeostasis, Lancet., 1, 677-682.

Boyer J.L., Cardenas C., Posadas C. \& Garcia-Sainz J.A. (1983). Pertussis toxin induces tachcardia and impairs the increase in blood pressure produced by $\alpha_{2}$-adrenergic agonists, Life. Sci., 33, 2627-2633.

Brodde O.E. (1991). Beta-1 and beta-2 adrenoceptors in the human heart: properties, function, and alterations in chronic heart failure, Pharmacol. Rev., 43, 203-242.

Bylund D.B. (1985). Heterogeneity of $\alpha_{2}$ adrenergic receptors, Pharmacol. Biochem. Behav., 22, 835-843.

Bylund D.B. (1992). Subtypes of $\alpha_{1}$-and $\alpha_{2}$-adrenergic receptors, Faseb. J., 6, 832-839.

Bylund D.B., Ray-Prenger C. \& Murphy T.J. (1988). $\alpha_{1 \mathrm{~A}}$ and $\alpha_{1 \mathrm{~B}}$ adrenergic receptor subtypes: antagonist binding in tissues and cell lines containing only one subtype, $J$. Pharmacol. Exp. Therap., 245, 600-607.

Casteels R. (1978). Electro- and pharmacomechanical coupling in vascular smooth muscle, Chest., 78(suppl), 150-156. 
Cavero I., Shepperson N., Lefevre-Borg F. \& Langer S.Z. (1984). Differential inhibition of vascular smooth muscle responses for $\alpha_{1}$ and $\alpha_{2}$-adrenoceptor agonists by diltiazem. and verapamil, Circ. Res., 52 (suppl I), 69-87.

de Champlain J. (1990). Pre- and postsynaptic adrenergic dysfunctions in hypertension, J. Hypertension., 8, S77-S85.

Chen G., Suzuki H. \& Weston A.H. (1988). Acetylcholine releases endothelium-derived hyperpolarizing factor and EDRF from rat blood vessels, Br. J. Pharmacol., 95, 11651174.

Chidsey C.A., Harrison D.C. \& Braunwald E. (1962). Augmentation of plasma norepinephrine response to exercise in patients with congestive heart failure, New. Engl. J. Med., 267, 650 .

Chidsey C.A., Sonnenblick E.H., Morrow A.G. \& Braunwald E. (1966). Noradrenaline stores and contractile force of papillary muscle from the failing human heart, Circulation., 33, 43-51.

Cohn J.N., Levine T.B., Olivari M.T., Garberg V., Lura D., Francis G.S., Simon A.B. \& Rector T. (1984). Plasma norepinephrine as a guide to prognosis in patients with chronic congestive heart failure, New. Engl. J. Med., 311, 819-823.

Colucci W.S., Alexander R.W., Williams G.H., Rude R.E., Holman B.L., Konstam M.A., Wynne J., Mudge G.H. \& Braunwald E. (1981). Decreased lymphocyte beta-adrenergicreceptor density in patients with heart failure and tolerance to the beta-adrenergic agonist pirbuterol, New. Engl. J. Med., 305, 185-190.

Cooke J.P., Rimele T.J., Flavahan N.A. \& Vanhoutte P.M. (1985). Nimodipine and inhibition of $\alpha$-adrenergic activation of the isolated canine saphenous vein, J. Pharmacol. Exp. Therap., 234, 598-602.

Daly C.J., McGrath J.C. \& Wilson V.G. (1988). An examination of the postjunctional $\alpha$ adrenoceptor subtypes for (-)-noradrenaline in several isolated blood vessels from the rabbit, Br. J. Pharmacol., 95, 473-484.

De Leeuw P.W., van Leeuwen S.J. \& Willemse P.J. (1984). Spontaneous and induced variations in adrenergic activity, Ned. Tijdschr. Geneeskd., 27, 136-139.

De Mey J.G.R. \& Gray V.S.D. (1985). Endothelium dependent reactivity in resistance vessels, Prog. Appl. Microcirc., 8, 181-187.

De Mey J.G.R. \& Vanhoutte P.M. (1981). Uneven distribution of postjunctional $\alpha_{1-1}$ and $\alpha_{2}$ - like adrenoceptors in canine arterial and venous smooth muscle, Circ. Res., 48, 875884

De Mey J.G.R., Burnstock G. \& Vanhoutte P.M. (1979). Modulation of the evoked release of noradrenaline in canine saphenous vein via presynaptic receptors for adenosine but not ATP, Eur. J. Pharmacol., 55, 401-405.

Devedjian J.-C., Esclapez F., Denis-Pouxviel C. \& Paris H. (1994). Further characterization of human $\alpha_{2}$-adrenoceptor subtypes: [3H]RX821002 binding and definition of additional selective drugs, Eur. J. Phamnacol., 252, 43-49.

Eccleston-Joyner C.A. \& Gray S.D. (1988). Arterial hypertrophy in the fetal and neonatal spontaneously hypertensive rats, Hypertension., 12, 513-518.

Edvinsson L., Gulbenkian S., Wharton J., Jansen I. \& Polak J.M. (1989). Peptide containing nerves in the rat femoral artery and vein. An immunocytochemical and vasomotor study, Blood. Vessels., 26, 254-271. 
Edwards R.M. (1985). Response of isolated renal arterioles to acetylcholine, dopamine and bradykinin, Am. J. Physiol., 248, F183-F189.

Eerdmans P.H.A., Heesen B.J., Struijker Boudier H.A.J. \& De Mey J.G.R., 1991, Sympathetic heterogeneity in mesenteric and renal resistance arteries, in: Resistance Arteries. Structure and Function, Mulvany M.J., Aalkjaer C., Heagerty A.M., Nyborg N.C.B. \& Strandgaard S., Excerpta Medica, Amsterdam, The Netherlands, 156-159.

Eldor A., Falcone D.J., Hajjar D.P., Minick C.R. \& Weksler B.B. (1981). Recovery of prostacyclin production by deendothelialized rabbit aorta: critical role of the neointimal smooth muscle cells, J. Clin. Invest., 67, 735-741.

Elliot T.R. (1905). The action of adrenalin, J. Physiol., 32, 401.

Esler M., Jennings G., Korner P., Blombery P., Sacharias N. \& Leonard P. (1984). Measurement of total and organ-specific noradrenaline kinetics in humans, Am. J. Physiol., 247, E21-E28.

Faber J.E. (1988). In situ analysis of $\alpha$-adrenoceptors on arteriolar and venular smooth muscle in rat skeletal muscle microcirculation, Circ. Res., 62, 37-50.

Falcone J.C., Davis M.J. \& Meininger G.A. (1991). Endothelial independence of myogenic response in isolated skeletal muscle arterioles, Am. J. Physiol., 260, H130-H135.

Folkow B. (1982). Physiological aspects of primary hypertension, Physiol. Rev., 62, 347 504.

Folkow B., Grimby G. \& Thulesius O. (1958). Adaptive structural changes of the vascular walls in hypertension and their relation to the control of peripheral resistance, Acta. Physiol. Scand., 44, 255-272.

louad F.M., Shimamatsu K., Hanna M.M., Khairallah P.A. \& Tarazi R.C. (1985). Impaired inotropic responses to $\alpha$-adrenergic stimulation in experimental left ventricular hypertrophy, Circulation., 71, 1023-1028.

Furchgott R.F. \& Vanhoutte P.M. (1989). Endothelium-derived relaxing and contracting factors, Faseb. J., 3, 2007-2018.

Furchgott R.F. \& Zawadski J.V. (1980). The obligatory role of endothelial cells in the relaxation of arterial smooth muscle by acetylcholine, Nature., 288, 373-376.

Goldstein D.S. (1981). Plasma norepinephrine in essential hypertension. A study of the studies, Hypertension., 3, 48-52.

Goldstein D.S. (1983). Plasma catecholamines and essential hypertension- an analytical review, Hypertension., 5, 86-99.

Grillone L.R., Clark M.A., Godfrey R.W., Stassen F. \& Crooke S.T. (1988). Vasopressin induces $\mathrm{V} 1$ receptors to activate phosphatidylinositol and phosphatidylcholine-specific phospholipase $\mathrm{C}$ and stimulates the release of arachidonic acid by at least two pathways in the smooth muscle cell line, A-1, J. Biol. Chem., 263, 2658-2663.

Groeneveld A.B.J., Bronsveld W. \& Thijs L.G. (1986). Hemodynamic determinants of mortality in human septic shock, Surgery, 99, 140-152.

Gulbenkian S., Saetrum Opgaard O., Ekman R., Costa Andrade N., Wharton J., Polak J.M., Queiroz e Melo J. \& Edvinson L. (1993). Peptidergic innervation of human epicardial coronary arteries, Circ. Res., 73, 579-588.

Guyton A.C., Cowley A.W., Coleman T.G., DeClue J.W., Norman R.A. \& Manning R.D. (1974). Hypertension: a disease of abnormale circulatory control, Chest., 65, 328338. 
Hahn A.W.A., Resink T.J., Kern F. \& Buhler F.R. (1993). Peptide vasoconstrictors, vessel structure, and vascular smooth-muscle proliferation, J. Cardiovasc. Pharmacol., 22, S37-S43.

Han C. \& Minneman K.P. (1991). Interaction of subtype-selective antagonists with $\alpha_{1}$ adrenergic receptor binding sites in rat tissues, J. Pharmacol. Exp. Therap., 40, 531538.

Hasking G.J., Esler M.D., Jennings G.L., Burton D., Johns J.A. \& Komer P.I. (1986a). Noradrenaline spillover to plasma in congestive heart failure: evidence of increased cardiorenal and total sympathetic nerve activity. Circulation., 73, 615-621.

Hasking G.J., Esler M.D., Jennings G.L., Burton D. \& Korner P. (1986b). Norepinephrine spillover to plasma in patients with congestive heart failure: Evidence of increased overall and cardiorenal sympathetic nervous activity. Circulation., 73, 615-621.

Hauser W., Gutting J., Nguyen T. \& Dominiak P. (1995). Influence of imidazolines on catecholamine release in pithed spontaneously hypertensive rats, Ann. N.Y. Acad. Sci., $763,573-579$.

Heesen B.J. \& De Mey J.G.R. (1990). Effects of cyclic AMP-affecting agents on contractile reactivity of isolated mesenteric and renal resistance arteries of the rat, $\mathrm{Br}$. J. Pharmacol., 101, 859-864.

Heesen B.J., Struyker-Boudier H.A.J. \& De Mey J.G. (1989). Absence of $\beta$-adrenergic relaxing responses in isolated renal resistance arteries, The Pharmacologist, 31, 170.

Highsmith R.F., Pang D.C. \& Rapopor R.M. (1989). Endothelial cell-derived vasoconstrictors: Mechanism of action in vascular smooth muscle, J. Cardiovasc. Pharmacol., 13, S36-S44.

Hirst G.D.S. \& Edwards F.R. (1989). Sympathetic neuroeffector transmission in arteries and arterioles, Physiol. Rev., 69, 546-604.

Jennings G.L. \& Esler M.D. (1990). Circulatory regulation at rest and exercise and the functional assessment of patients with congestive heart failure, Circulation., 81, II5-II13.

Johnson R.D. \& Minneman K.P. (1987). Differentiation of $\alpha_{1}$-adrenergic receptors linked to phosphatidylinositol turnover and cyclic AMP accumulation in rat brain, Mol. Pharmacol., 31, 239-246.

Jonsson J.R., Head R.J. \& Frewin D.B. (1992). Effect of $\alpha_{1}$-adrenoceptor blockade on the development of hypertension in the spontaneously hypertensive rat, Eur. J. Pharmacol., 211, 263-268.

Julou-Schaeffer G., Gray G.A., Fleming I., Schott C., Parratt J.R. \& Stoclet J.-C. (1990). Loss of vascular responsiveness induced by endotoxin involves L-arginine pathway, Am. J. Physiol., 259, H1038-H1043.

Kanbe T., Nara Y., Tagami M. \& Yamori Y. (1983). Studies of hypertension-induced vascular hypertrophy in cultured smooth muscle cells from spontaneously hypertensive rats, Hypertension., 5, 887-892.

Kawahara R.S. \& Bylund D.B. (1985). Solubilization and characterization of putative $\alpha_{2}$ adrenergic isoceptors from the human platelet and the rat cerebral cortex, J. Pharmacol. Exp. Therap., 233, 603-610.

Kitakaze M., Hori M., Sato H., Iwakura K., Gotoh K., Inoue M., Kitabatake A. \& Kamada T. (1991). Beneficial effects of $\alpha_{1}$-adrenoceptor activity on myocardial stunning in dogs, Circ. Res., 68, 1322-1339. 
Kiuchi K., Sato N., Shannon R., Vatner D.E., Morgan K. \& Vatner S.F. (1993). Depressed $\beta$-adrenergic receptor- and endothelium-mediated vasodilation in conscious dogs with heart failure, Circ. Res., 73, 1013-1023.

Koren M.J., Devereux R.B., Casale P.N., Savage D.D. \& Laragh J.H. (1991). Relation of left ventricular mass and geometry to morbidity and mortality in uncomplicated essential hypertension, Annals Int. Med., 114, 345-352.

Korner P., Bobik A., Oddie C. \& Friberg P. (1993). Sympathoadrenal system is critical for structural changes in genetic hypertension, Hypertension., 22, 243-252.

Korner P.J. \& Angus J.A. (1992). Structural determinants of vascular resistance properties in hypertension. Hemodynamic and model analysis, J. Vasc. Res, 29, 293-312.

Kwan C.Y., Belbeck L. \& Daniel E.E. (1979). Abnormal biochemistry of vascular smooth muscle plasma membrane as an important factor in the initiation and maintenance of hypertension in rats, Blood. Vessels., 16, 259-268.

Lais L.T. \& Brody M.J. (1978). Vasoconstrictor hyperresponsiveness: an early pathogenic mechanism in the spontaneously hypertensive rat, Eur. J. Pharmacol., 47, 177-189.

Lais L.T., Rois L.L., Boutelle S., DiBona G.F. \& Brody M.J. (1977). Arterial pressure development in neonatal and young spontaneously hypertensive rats, Blood. Vessels., 14, 277-284.

Lands A.M., Arnold A., McAuliff J.P., Luduena F.P. \& Brown T.G. (1967). Differentation of receptor systems activated by sympathomimetic amines, Nature., 214, 597-598.

Langer S.Z. (1974). Presynaptic regulation of catecholamine release, Biochem. Pharmacol., $23,1793-1800$.

Langer S.Z. (1977). Presynaptic receptors and their role in the regulation of transmitter release, Br. J. Pharmacol., 60, 481-497.

Lee R.M.K.W. \& Smeda J.S. (1985). Primary versus secondary structural changes of the blood vessels in hypertension, Can. J. Physiol. Pharmacol., 63, 392-401.

Lee R.M.K.W., Triggle C.R., Cheung D.W.T. \& Coughlin M.D. (1987). Structural and functional consequences of neonatal sympathectomy on the blood vessels of spontaneously hypertensive rats, Hypertension., 10, 328-338.

Lee R.M.K.W., Borokowski K.R., Leenen F.H.H., Tsoporis J. \& Coughlin M. (1991). Combined effect of neonatal sympathectomy and adrenal demedullation on blood pressure and vascular changes in spontaneously hypertensive rats, Circ. Res., 69, 714-721.

Leimbach W.N., Wallin G., Victor R.G., Aylward P.E., Sundlof G. \& Mark A.L. (1986). Direct evidence from intraneuronal recordings for increased central sympathetic outflow in patients with heart failure, Circulation., 73, 913-919.

Lever A.F. (1986). Slow pressor mechanisms in hypertension: a role for hypertrophy of resistance vessels ?. J. Hypertension., 4, 515-524.

Levin B.E. \& Natelson B.H. (1980). The relation of plasma norepinephrine and epinephrine levels over time in humans, J. Auton. Nerv. Syst.. 2, 315-325.

Limbird L.E. (1984). GTP and $\mathrm{Na}+$ modulate receptor-adenyl cyclase coupling and receptor-mediated function, Am. J. Physiol., 247, E59-E68.

Limbird L.E. \& Speck J.L. (1983). N-ethylmaleimide, elevated temperature and digitonin solubilization eliminate guanine nucleotide but not sodium effects on human platelet $\alpha_{1}{ }^{-}$ adrenergic receptor agonist interactions, J.Cycl. Nucl.Prot.Phosphoryl.Res., 9, 191-201. 
Lin P.J., Chang C.H. \& Chang J.P. (1994). Reversal of refractory hypotension in septic shock by inhibitor of nitric oxide synthase, Chest., 106, 626-629.

Loewi O. (1921). Uber humorale ubertragbarkeit der herznervenwirkung, Pfluegers Arch, $189,239$.

Lüscher T.F. \& Vanhoutte P.M. (1988). Endothelium-dependent responses in human blood vessels, TIPS, 9, 181-184.

Lüscher T.F., Boulanger C.M., Dohi Y. \& Yang Z. (1992). Endothelium-derived contracting factors, Hypertension., 19, 117-130.

Lundberg J.M., Franco-Cereda A., Hemsen A., Lacroix J.S. \& Pernow J. (1990). Pharmacology of noradrenaline and neuropeptide tyrosine (NPY)-mediated sympathetic cotransmission, Fund. Clin. Pharmacol., 4, 373-391.

Mangiarua E.I. \& Lee R.M.K.W. (1992). Morphometric study of cerebral arteries from spontaneously hypertensive stroke-prone hypertensive rats, J. Hypertension., 10, 11831190.

Mano M., Nara Y., Tsubouchi T., Horie R. \& Yamori Y. (1986). Effect of noradrenaline exposure on polyploidy formation in cultured smooth muscle cells from nomotensive Wistar-Kyoto rats, J. Hypertension., 4, 113-114.

Matthews W.D., Jim K.F., Hieble J.P. \& DeMarinis R.M. (1984). Postsynaptic $\alpha$ adrenoceptors on vascular smooth muscle, Fedn Proc, 43, 2923-2928.

McClue S.J. \& Milligan G. (1991). Molecular interaction of the human $\alpha_{7}$-C10-adrenergic receptor, when expressed in rat-1 fibroblasts, with multiple pertussis toxin sensitive guanine nucleotide-binding proteins: studies with site-directed antisera, Mol. Pharmacol., $40,627-632$.

McEwan J.R., Benjamin N., Larkin S., Fuller R.W., Dollery C.T. \& MacIntyrel Path F.R.C. (1988). Vasodilatation by calcitonin gene-related peptide and by substance P:a comparison of their effects on resistance and capacitance vessels of human forearm, Circulation., 77, 1072-1080.

Medgett I.C. \& Rajanayagam M.A.S. (1984). Effects of reduced calcium ion cuncentration and of diltiazem on vasoconstrictor responses to noradrenaline and sympathetic nerve stimulation in rat isolated tail artery, Br. J. Pharmacol., 83, 889-898.

Medgett I.C., McCulloch M.W. \& Rand M.J. (1978). Partial agonist action of clonidine on prejunctional and postjunctional alpha-adrenoceptors, Naunyn. Schmiedeberg's. Arch. Pharmacol., 304, 215-221.

Mellander S. (1989). Functional aspects of myogenic vascular control, J. Hypertension., 7, S21-S30.

Messing M.W.J., van Essen H. \& Struijker Boudier H.A.J. (1990). Effects of $\alpha$ adrenoceptor antagonists on striated muscle microcirculation of conscious rats, Drugs.. 40, 31-33.

Messing M., Van Essen H., Smith T.L., Smits J.F.M. \& Struijker Boudier H.A.J. (1991). Microvascular actions of calcium channel antagonists, Eur. J. Pharmacol., 198, 189-195.

Michel M.C., Buscher R., Kerker J., Kraneis H., Erdbrugger W. \& Brodde O.-E. (1993a). Alphal-adrenoceptor subtype affinities of drugs for the treatment of prostatic hypertrophy. Evidence for heterogeneity of chloroethylclonidine-resistant rat renal alphal-adrenoceptors, Naunyn. Schmiedeberg's. Arch. Pharmacol., 348, 385-395. 
Michel M.C., Buscher R., Philipp T. \& Brodde O.-E. (1993b). $\alpha_{1 \mathrm{~A}}$ and $\alpha_{1 \mathrm{~B}^{-}}$adrenoceptors enhance inositol phosphate generation in rat renal cortex, Naunyn. Schmiedeberg's. Arch. Pharmacol., 347, 180-185.

Michell R.H. (1979). Inositol phospholipids in membrane function, Trends Biochem. Sci., 4, 128-131.

Miller V.M. (1991). Interaction between neural and endothelial mechanisms in control of vascular tone, NIPS, 6, 60-63.

Mills D.C.B. (1975). Initial biochemical responses of platelets to stimulation, CIBA Found. Symp., 35, 443-453.

Minneman K.P. (1988). $\alpha_{1}$-Adrenergic receptor subtypes, inositol phosphates and sources of cell calcium, Pharmacol. Rev., 40, 87-119.

Mombouli J.V. \& Vanhoutte P.M. (1995). Kinins and endothelial control of vascular smooth muscle, Ann. Rev. Pharmacol. Toxicol., 35, 679-705.

Moncada S. \& Higgs E.A. (1991). Endogenous nitric oxide: physiology, pathology and clinical relevance, Eur. J. Clin. Invest., 21, 361-374.

Moncada S. \& Vane J.R. (1979). Pharmacology and endogenous roles of prostaglandin endoperoxides, thromboxane A2 and prostacyclin, Pharmacol. Rev., 30, 293-331.

Moncada S., Gryglewski R., Bunting S. \& Vane J.R. (1976). An enzyme isolated from arteries transforms prostaglandin endoperoxides to an unstable substance that inhibits platelet aggregation, Nature., 263, 663-665.

Moncada S., Palmer R.M.J. \& Higgs E.A. (1989). Biosynthesis of nitric oxide from Larginine. A pathway for the regulation of cell function and communication, Biochem. Pharmacol., 38, 1709-1715.

Mulvany M.J. (1983). Do resistance vessel abnormalities contribute to the elevated blood pressure of spontaneously-hypertensive rats?, Blood. Vessels., 20, 1-22.

Mulvany M.J. (1993). Resistance vessel structure in hypertension: Growth or remodeling, J. Cardiovasc. Pharmacol., 22, S44-S47.

Mulvany M.J. \& Aalkjaer C. (1990). Structure and function of small arteries, Physiol. Rev., 70, 921-961

Muraki T., Nakaki T. \& Kato R. (1984). Predominance of $\alpha_{2}$-adrenoceptors in porcine thyroid: biochemical and pharmacological correlations, Endocrinology., 114, 1645-1651.

Murphy T.J. \& Bylund D.B. (1988). Characterization of $\alpha_{2}$ adrenergic receptors in the OK cell, an opossum kidney cell line, J. Pharmacol. Exp. Therap., 244, 571-578.

Murray K.J. (1990). Cyclic AMP and mechanisms of vasodilation, Pharmac. Ther., 47, 329-345.

Nakaki T., Nakayama M., Yamamoto S. \& Kato R. (1990). $\alpha_{1}$-Adrenergic stimulation and $\beta 2$-adrenergic inhibition of DNA synthesis in vascular smooth muscle cells, Mol. Pharmacol., 37, 30-36.

Nyborg C.B., Korsgaard N. \& Mulvany M. (1986). Neonatal sympathectomy of normotensive wistar-kyoto and spontaneously hypenensive rats with 6-hydroxydopamine : effects on resistance vessel structure and sensitivity to calcium, J. Hypertension., 4, 455-461.

Okamoto K. (1969). Spontaneous hypertension in rats, Int. Rev. exp. Path., 7, 227-270. 
Palmer R.M.J., Rees D.D., Ashton D.S. \& Moncada S. (1988). L-arginine is the physiological precursor for the formation of nitric oxide in endothelium-dependent relaxation, Biochem. Biophys. Res. Commun., 153, 1251-1256.

Paul O. (1986). The medical research council trial, Hypertension., 8, 733-736.

Pepperl D.J. \& Regan J.W. (1993). Selective coupling of $\alpha_{2}$-adrenergic receptor subtypes to cyclic AMP-dependent reporter gene expression in transiently transfected JEG-3 cells, Mol. Pharmacol., 44, 802-809.

Piascik M.T., Butler B.T. \& Pruitt T.A. (1990). The role of $\alpha_{1}$-adrenoceptor subtypes in the regulation of arterial blood pressure, Eur. J. Pharnacol., 180, 381-386.

Pool P.E., Covell J.W., Levitt M., Gibb J. \& Braunwald E. (1967). Reduction of cardiac tyrosine hydroxylase activity in experimental congestive heart failure, Circ. Res., 20. 349-353.

Prinz P.N., Halter J., Benedetti C. \& Raskind M. (1979). Circadian variation of plasma catcholamines in young and old men: relation to rapid eye movement and slow wave sleep, J. Clin. Endocrinol. Metab., 49, 300-304.

Raymond J.R., Hnatowich M., Lefkowitz R.J. \& Caron M.G. (1990). Adrenergic receptors: Models for regulation of signal transduction processes, Hypertension., 15, 119-131.

Reese J.B. \& Mathews W.D. (1986). $\alpha$-Adrenergic agonists stimulate phosphatidylinositol (PI) hydrolysis in canine saphenous vein, The Phamacologist, 28, 161.

Remme W.J. (1986). Congestive heart failure. Pathophysiology and medical treatment, J. Cardiovasc. Pharmacol., 8, S36-S52.

Ren Q., Kurose H., Lefkowitz R.J. \& Cotecchia S. (1993). Constitutively active mutants of the $\alpha_{2}$-adrenergic receptor, J. Biol. Chem., 268, 16483-16487.

Rubanyi G.M. (1991). Endothelium-derived relaxing and contracting factors, J Cell Biochem., 46, 27-36.

Ruffolo R.R., Messick K. \& Horng J.S. (1984). Interactions of three inotropic agents, ASL-7022, dobutamine and dopamine, with $\alpha_{1}$ and $\alpha_{2}$-adrenoceptors in vitro, Naunyn. Schmiedeberg's. Arch. Pharmacol., 326, 317-326.

Rump L.C., Ruff G., Wolk V. \& Schollmeyer P. (1991). $\alpha_{2}$-adrennceptor activation inhibits noradrenaline release in human and rabbit isolated renal aneries, Eur. J. Pharmacol., 196, 277-283.

Sabol S.L. \& Nirenberg M. (1979). Regulation of adenylate cyclase of neuroblastoma $x$ glioma hybrid cells by $\alpha$-adrenergic receptors. I. Inhibition of adenylate cyclase mediated by $\alpha 2$-receptors, J. Biol. Chem., 254, 1913-1920.

Salgado H.O. \& Krieger E.M. (1978). Time-course of baroreceptor resetting in short-term hypotension in the rat, Am. J. Physiol., 234, H552-H556.

Schini V.B., Durante W., Elizondo E., Scott-Burden T., Junquero D.C., Schafer A.I. \& Vanhoutte P.M. (1992). The induction of nitric oxide synthase activity is inhibited by TGF-bl, PDGF-AB and PDGF-BB in vascular smooth muscle cells, Eur. J. Pharmacol., 216. 379-383.

Schoffelmeer A.N.M. \& Mulder A.H. (1983). 3H-Noradrenaline release from rat neocortical slices in the absence of extracellular calcium and its presynaptic $\alpha_{2}$-adrenergic modulation. A study on the possible role of cyclic AMP. Naunyn. Schmiedeberg's. Arch. Pharmacol., 323. 188-192. 
Shibata S., Kurahashi K. \& Kuchii M. (1973). A possible etiology of contractility impairment of vascular smooth muscle from spontaneously hypertensive rats, $\mathbf{J}$. Pharmacol. Exp. Therap., 185, 406-417.

Sibley D.R. \& Lefkowitz R.J. (1985). Molecular mechanisms of receptor desensitization using the beta-adrenergic receptor-coupled adenylate cyclase system as a model, Nature., 317, 124-129.

Sigurdsson A., Held P. \& Swedberg K. (1993). Short- and long-term neurohormonal activation following acute myocardial infarction, Am. Heart. J., 126 (5), 1068-1076.

Silver P.J., Walus K. \& Disalvo J. (1984). Adenosine-mediated relaxation and activation of cyclic AMP-dependent protein kinase in coronary arterial smooth muscle, J. Pharmacol. Exp. Therap., 228, 342-347.

Simonntaux V., Ebadi M. \& Bylund D.B. (1991). Identification and characterization of $\alpha 2 \mathrm{D}$-adrenergic receptors in bovine pineal gland, Mol. Pharmacol., 40, 235-241.

Sole M.J. (1982), Alterations in sympathetic and parasympathetic neurotransmitter activity, Congestive Heart Failure: Current research and clinical applications. New York, Grune and Stratton, 101.

Struijker Boudier H.A.J., le Noble J.L.M.L., Messing M.W.J., Huijberts M.S.P., le Noble F.A.C. \& van Essen H. (1992). The microcirculation and hypertension, J. Hypertension., 10(suppl 7), S147-S156.

Sweatt J.D., Johnson S.L., Cragoe E.J. \& Limbird L.E. (1985). Inhibitors of $\mathrm{Na}+/ \mathrm{H}+$ exchange block stimulus-provoked arachidonic acid release in human platelets, J. Biol. Chem., 260, 12910-12918.

Tabrichi R. \& Triggle C.R. (1991). Pressor actions of arginine vasopressin in pithed Sprague-Dawley, Wistar Kyoto and spontaneously hypertensive rats before and after treatment with nifedipine or pertussis toxin, J. Hypertension., 9, 813-818.

Taylor S.G. \& Weston A.H. (1988). Endothelium derived hyperpolarizing factor:a new endogenous inhibitor from the vascular endothelium, TIPS, 9. 272-274.

The Netherlands Heart Fondation (1994). De Nederlandse Hartstichting, Hart en vaatziekten in Nederland, The Hague, The Netherlands,

Tsuda K., Kuchii M., Nishio L. \& Masuyama Y. (1987). Presynaptic $\alpha_{2}$-adrenoceptors mediated regulation of norepinephrine release in perfused mesenteric vasculatures in young and adult spontaneously hypertensive rats, Jpn. Circ. J., 51, 25-32.

Turton M.B. \& Deegan T. (1974). Circadian variations of plasma catecholamine, cortisol and immunoreactive insulin concentrations in supine subjects, Clin. Chem. Acta., 55, 389-397.

Van Breemen C., Aaronson P., Loutzenhiser R. \& Meisheri K. (1978). Ca2+ movements in smooth muscle, Chest., 78, 157-165.

Van Meel J.C.A., De Jonge A., Kalkman H.O., Wilffert B., Timmermans P.B.M.W.M. \& Van Zwieten P.A. (1981). Organic and inorganic calcium antagonists reduce vasoconstriction in vivo mediated by postsynaptic $\alpha_{2}$-adrenoceptors, Naunyn. Schmiedeberg's. Arch. Pharmacol., 316, 288-293.

Van Zwieten P.A., Thoolen M.J.M.C., Jonkman F.A.M., Wilffert B., De Jonge A. \& Timmermans P.B.M.W.M. (1986). Central and peripheral effects of $S 3341$ [(Ndicyclopropylmethyl)-amino-2-oxazoline] in animal models, Arch. Int. Pharmacodyn. Ther., 279, 130-149. 
Wakabayashi G., Gelfand J.A., Burke J.F., Thompson R.C. \& Dinarello C.A. (1991). A specific receptor antagonist for interleukin 1 prevents escherichia coli-induced shock in rabbits, Faseb. J., 5, 338-343.

Wallin B.G. \& Nerhed C. (1982). Relationship between spontaneous variations of muscle sympathetic activity and succeeding changes of blood pressure in man, J. Auton. Nerv. Syst., 6, 293-302.

Wallin B.G. \& Sundlof G. (1979). A quantitative study of muscle nerve sympathetic activity in resting normotensive and hypertensive subjects, Hypertension., 1, 67-77.

Wallin B.G., Blumberg H. \& Hynninen P. (1983). Intraneural stimulation as a method to study sympathetic function in the human skin, Neurosci. Let., 36, 189-194.

Weiss R.J., Tobes M., Wertz C.E. \& Smith C.B. (1983). Platelet $\alpha_{2}$ adrenoceptors in chronic congestive heart failure, Am. J. Cardiol., 52, 101-105.

Woodcock E.A. \& Johnston C.I. (1982). Selective inhibition by epinephrine of parathyroid hormone-stimulated adenylate cyclase in rat renal cortex. Am. J. Physiol., 242, F721F726.

Yamazaki S., Katada T. \& Ui M. (1982). $\alpha_{2}$-adrenergic inhibition of insulin secretion via interference with cyclic AMP generative in rat pancreatic islets. Mol. Pharmacol., 21. $648-653$

Yamori Y., Mano M., Nara Y. \& Horie R. (1987). Catecholamine induced polyploidization in vascular smooth muscle cells, Circulation., 75, 192-195.

Yanagisawa M., Inoue A., Ishikawa $\Upsilon$., Kasuya Y., Kimura S., Kamagaye S., Nakajima K., Watanabe T., Sakakibara S., Goto K. \& Masaki T. (1988). Primary structure, synthesis, and biological activity of rat endothelin, an endothelium-derived vasoconstrictor peptide, Proc. Natl. Acad. Sci. USA., 85, 6964-6967.

Zadik Z., Hamilton B.P., Kowarski A.A. \& Lukas K. (1980). Integrated concentration of epinephrine and norepinephrine in normal subjects and in patients with mild essential hypertension, J. Clin. Endocrinol. Metab., 50, 842-845. 



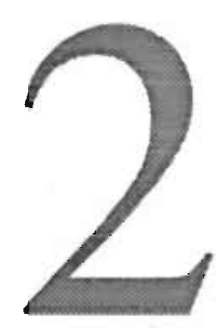

Effects of chloroethylclonidine on prazosin binding and contractile responses to noradrenaline in large and small arteries of the rat

P.H.A. Eerdmans, H.C.M. Boonen, G.M.J. Janssen and J.G.R. De Mey 



\section{Abstract}

We evaluated effects of the $\alpha_{1 B^{-}}$and $\alpha_{1 D^{-}}$adrenoceptor (AR) blocking agent chloroethylclonidine (CEC) in isolated large and small arteries of the rat. Pretreatment with $100 \mu \mathrm{M}$ CEC reduced specific $\left[{ }^{3} \mathrm{H}\right]$-prazosin binding more markedly in thoracic aorta (Ao; $100 \%$ ) and superior mesenteric artery (SMA; $85 \%$ ) than in mesenteric resistance-sized arteries (MrA; 38\%). CEC also reduced the sensitivity to the contractile effect of noradrenaline (NA) more markedly in Ao and SMA than in MrA. It did not reduce maximal responses to the agonist in the presence of calcium, but reduced in both SMA and MrA the responses to $10 \mu \mathrm{M} \mathrm{NA}$ in the absence of calcium. The order of apparent affinity $\left(\mathrm{pK}_{\mathrm{B}}\right.$ ) for competitive antagonists was WB4101 $>$ prazosin $>5-\mathrm{CH}_{3}-$ urapidil in MrA and WB4101 = prazosin > 5- $\mathrm{CH}_{3}$-urapidil in SMA; with the $\mathrm{pK}_{\mathrm{B}}$ for prazosin being similar in MrA and SMA and the $\mathrm{pK}_{\mathrm{B}}$ 's for WB4101 and 5- $\mathrm{CH}_{3}$-urapidil being larger in $\mathrm{MrA}$ than SMA. CEC did not modify antagonist action in MrA but reduced the $\mathrm{pK}_{\mathrm{B}}$ for prazosin in SMA. Responses to NA (i) were reduced more markedly by phenoxybenzamine in MrA than SMA or Ao; (ii) were similarly affected by felodipine in MrA, SMA and Ao and (iii) were more potently inhibited by Na-nitroprusside in Ao and SMA than MrA. This was not modified by CEC. These findings indicate that in rat aorta and superior mesenteric artery $\alpha_{1}$-AR subtypes that are susceptible to blockade by $\mathrm{CEC}$, mediate contractile responses to low concentrations of NA. In rat mesenteric resistance arteries these $\alpha_{1}$-AR subtypes are less prominent and though seemingly linked to intracellular calcium release are of minor importance for sustained contractile responses to NA. Differences between types of artery as regards effects of irreversible antagonists, calcium channel blockers and vasodilators cannot be attributed to regional differences in $\alpha_{1}$-AR subtypes. Furthermore, arterial actions of CEC seemed not to be restricted to blockade of $\alpha_{1}$-AR subtypes.

\section{Introduction}

Several lines of evidence indicate that $\alpha_{1}$-adrenoceptors $\left(\alpha_{1}\right.$-AR) are a family of subtypes (Flavahan \& Vanhoutte, 1987; Minneman, 1988; Muramatsu et al., 1990b; Ruffolo et al., 1991) comprising members with a high affinity for prazosin and members with a relatively low affinity for this antagonist. The former property is shared by $\alpha_{1 A^{-}}, \alpha_{1 B^{-}}$and $\alpha_{1 D^{-}}$AR (Cotecchia et al., 1990; Lomasney et al., 1991; Perez et al., 1991) which differ, among others, in 
terms of amino acid sequence and affinity for selected ligands such as WB4101, 5- $\mathrm{CH}_{3}$-urapidil, (+)-niguldipine and BMY 7378 (Minneman, 1988; Goetz et al., 1995). It was originally proposed that these $\alpha_{1}$-AR subtypes also differ with respect to the G-proteins and signal transduction pathway which they activate (Han et al., 1987; Minneman, 1988; Michel et al., 1990). In more recent experiments, involving extremely high receptor densities in transfected cell lines, all three $\alpha_{1}$-AR subtypes were shown to stimulate both calcium-influx and phospholipase activity (Wilson \& Minneman, 1990; Esbenshade et al., 1993; 1994). The efficacy may, however, differ between subtypes. Furthermore, the alkylating agent chloroethylclonidine (CEC) irreversibly blocks $\alpha_{1 \mathrm{~B}^{-}}$and $\alpha_{1 \mathrm{D}^{-}} \mathrm{AR}$ more readily than $\alpha_{1 \mathrm{~A}^{-}} \mathrm{AR}$ (Minneman, 1988; Perez et al., 1991).

While non -subtype- selective $\alpha_{1}$-antagonists lower blood pressure, administration of CEC does not modify blood pressure in anaesthetized rats despite marked reduction of contractile responses of the isolated aorta to $\alpha_{1}$ agonists (Piascik et al., 1990; 1993). This suggests that $\alpha_{1 \mathrm{~A}}$-AR may be more prominent in arteries that are small enough to regulate resistance, than in large conduit vessels such as the aorta. In line with this are observations that contractile responses to noradrenaline are highly sensitive to inhibition by calcium-antagonists and pertussis toxin in rat mesenteric resistance arteries but not in rat aorta (Boonen \& De Mey, 1990a; b; Ruffolo et al., 1991).

In this study we compared effects of CEC on prazosin binding and contractile effects of noradrenaline in thoracic aorta, superior mesenteric artery and mesenteric resistance arteries of the rat. The goal was to verify whether $\alpha_{1}$-AR subtypes are unevenly distributed along the arterial tree and to evaluate whether this contributes to regional differences in the mechanism of $\alpha_{1}$ adrenergic vasoconstriction.

\section{Materials \& methods}

\section{Animals and tissues}

Adult male Wistar-Kyoto rats (local inbred, Maastricht University, Maastricht, The Netherlands) were killed by cervical dislocation and exsanguination. The thoracic aorta (Ao) and superior mesenteric artery (SMA) were carefully cleaned from adhering fat and isolated. From the mesentery, 1st order sidebranches (binding) and 3rd to 4th order side-branches (reactivity) of the superior mesenteric artery (MrA) were isolated. 


\section{Pretreatments}

All experiments involved segments of the same arteries that had been pretreated with either CEC or its solvent (saline). Vessels were therefore incubated for $30 \mathrm{~min}$ at $37^{\circ} \mathrm{C}$ in $1 \mathrm{ml} \mathrm{KRB}$ in the absence or presence of 100 $\mu \mathrm{M}$ CEC. This duration and concentration have previously been observed to be supramaximal for irreversible blockade of $\alpha_{1 \mathrm{~B}}$-AR and $\alpha_{1 \mathrm{D}}$-AR (Piascik et al., 1990; Han \& Minneman, 1991; Michel et al., 1994). After exposure to $\mathrm{CEC}$, vessel segments were rinsed in two times $100 \mathrm{ml} \mathrm{KRB}$ at $37^{\circ} \mathrm{C}$ during $30 \mathrm{~min}$. From Ao preparations that were used for $\left[{ }^{3} \mathrm{H}\right]$-prazosin-binding, the adventitia was mechanically removed to decrease non-specific binding.

Part of the experiments were performed in vessels that had been sympathectomized by 10 min incubation in bicarbonate-free KRB solution ( $\mathrm{pH}$ 4.0 with glutathione) containing $300 \mu \mathrm{g} / \mathrm{ml}$ 6-hydroxydopamine (Aprigliano \& Hermsmeyer, 1977). In some experiments, restricted to Ao and SMA, the endothelium was mechanically removed by sliding the arterial segments over the shaft of an hypodermic injection needle (outer diameter 1.5 and $0.9 \mathrm{~mm}$ for Ao and SMA, respectively). Removal of endothelium was confirmed by absence of relaxing responses to $3 \mu \mathrm{M}$ acetylcholine during contraction induced by $10 \mu \mathrm{M}$ noradrenaline (De Mey et al., 1982).

\section{Ligand binding}

Analysis of $\left[{ }^{3} \mathrm{H}\right]$-prazosin binding was performed essentially as described by Michel et al. (Michel et al., 1990) and Jackson et al. (Jackson et al., 1992) with the exception that instead of microsomes derived from tissue homogenates, we used intact arterial segments. For this purpose we adapted the method developed by Morel and Godfraind (Morel \& Godfraind, 1989). In brief, intact arterial segments (2, 3 and $15 \mathrm{~mm}$ long for aorta, superior mesenteric artery and mesenteric small artery, respectively), that had or had not been pretreated with CEC, were incubated for $60 \mathrm{~min}$ at $37^{\circ} \mathrm{C}$ in $50 \mathrm{mM}$ Tris. $\mathrm{HCl}, 10 \mathrm{mM} \mathrm{MgCl}$ ( $\mathrm{pH} 7.4$ ) containing 0.016 to $0.40 \mathrm{nM}\left[{ }^{3} \mathrm{H}\right]$-prazosin. Parallel incubations were performed in the presence of $25 \mu \mathrm{M}$ phentolamine to determine non-specific binding. Following incubation, arterial segments were gently blotted, rinsed during vortexing for $30 \mathrm{sec}$ in $5 \mathrm{ml}$ incubation buffer and subsequently filtered over Whatman filters under vacuum with three 5-ml washes with ice-cold Tris. $\mathrm{HCl} / \mathrm{MgCl}_{2}$. Arterial segments were recovered from the filters and solubilized in $200 \mu \mathrm{l} 1 \mathrm{~N} \mathrm{NaOH} .100 \mu \mathrm{l}$ of this extract was added to $5 \mathrm{ml}$ Formula 989 and the radioactivity was determined by liquid scintillation. To the remaining $100 \mu \mathrm{l}, 900 \mu \mathrm{l} \mathrm{H}_{2} \mathrm{O}$ was added and the protein and DNA content were determined as described by Bradford (Bradford, 1976) 
and Labarca and Paigen (Labarca \& Paigen, 1980), using bovine serum albumin and calf thymus DNA as internal standards, respectively.

\section{Contractile reactivity}

Arterial segments (1.5 to $2.0 \mathrm{~mm}$ long) were mounted horizontally in an organ chamber with the use of two stainless steel wires (diameter $40 \mu \mathrm{m}$ ) between a displacement device and an isometric force transducer (Kistler Morse DSC6 or Statham UC)(Boonen \& De Mey, 1990a; b). In all cases a CEC-treated and a control segment of the same artery were mounted in parallel in the same chamber that was filled with $\mathrm{KRB}$ maintained at $37^{\circ} \mathrm{C}$ and aerated with $95 \%$ $\mathrm{O}_{2}-5 \% \mathrm{CO}_{2}$. Prior to experimentation, Ao and SMA segments were stretched radially to an internal diameter previously observed to be optimal for isometric force development (1.65 and $1.2 \mathrm{~mm}$ respectively). For MrA the optimal internal diameter was determined for each individual vessel (Boonen \& De Mey, 1990a; b). For this purpose, internal circumference was increased in steps of $50 \mu \mathrm{m}$ every $10 \mathrm{~min}$ with intermittent exposure of the preparations to $\mathrm{K}-\mathrm{KRB}$ until a maximal response to the depolarizing stimulus was obtained. Optimal diameter was not influenced by prior CEC-treatment or sympathectomy. It averaged $218 \pm 4 \mu \mathrm{m}(\mathrm{n}=50)$.

All experiments started with recording of three contractile responses to K-KRB (125 $\mathrm{mM}$ ) followed by three exposures to $10 \mu \mathrm{M}$ noradrenaline separated by 30 and $10 \mathrm{~min}$ in large and small arteries, respectively, which ensured reproducibility of subsequent noradrenaline concentration-response curves. These were constructed in a cumulative way (3-fold and 2 -fold increments in agonist concentration in aorta and the other vessels, respectively). They were repeated in the presence of $1 \mu \mathrm{M}$ propranolol plus $1 \mu \mathrm{M}$ yohimbine, $0.1 \mu \mathrm{M}$ prazosin, $0.1 \mu \mathrm{M}$ WB4101, $0.3 \mu \mathrm{M}$ 5- $\mathrm{CH}_{3}$-urapidil, $1 \mathrm{nM}$ felodipine, $10 \mathrm{nM}$ to $10 \mu \mathrm{M}$ Na-nitroprusside, or after exposure for 10 or $30 \mathrm{~min}$ to 0.1 to 100 nM phenoxybenzamine.

Prazosin, WB4101 and 5- $\mathrm{CH}_{3}$-urapidil caused, at the concentrations used in the three types of vessel, a reversible and parallel rightward shift of the concentration-response curves for the $\alpha_{1}$-adrenergic effect of noradrenaline without modification of the maximal response. To compare effects between types of vessel and between antagonists, the $E_{50}$ for noradrenaline was determined in the absence $\left(\mathrm{EC}_{50 \mathrm{c}}\right)$ and presence $\left(\mathrm{EC}_{50 \mathrm{~b}}\right)$ of antagonist and these values were used along with the concentration of antagonist ([B]) to calculate an index of apparent antagonist affinity according to the formula: 
[B]

$$
\mathrm{pK}_{\mathrm{B}}=-\log \frac{}{\left(\mathrm{EC}_{50 \mathrm{c}} / \mathrm{EC}_{50 \mathrm{~b}}\right)-1}
$$

This $\mathrm{pK}_{\mathrm{B}}$ is not intended to represent true affinity of receptors for the antagonist because (i) the antagonists may bind with different affinity to $\alpha_{1}$-AR subtypes, (ii) different $\alpha_{1}$-AR subtypes may be present in different types of blood vessel, and (iii) because the agents may affect other types of receptors in addition to $\alpha_{1}$-AR (Han \& Minneman, 1991; Jackson et al., 1992). The apparent affinity index is, however, in the same format as true receptor affinity to allow comparisons of the present findings with earlier findings in isolated tissues that did not take into account the possibility of multiple $\alpha_{1}$-AR subtypes. Furthermore, antagonist action expressed in this way can be compared in tissues with and without pretreatment with CEC, irrespective of the effect of the alkylating agent on the sensitivity to noradrenaline.

To evaluate the actions of phenoxybenzamine and of the functional antagonists Na-nitroprusside and felodipine, the concentration of these compounds that was required to reduce the maximal response to noradrenaline was determined. Subsequently, a double reciprocal plot of equieffective concentrations of noradrenaline was constructed on the basis of agonist concentration-response curves before and after exposure to phenoxybenzamine or in absence and presence of the appropriate concentration of functional antagonist. From these double reciprocal plots, an index of apparent agonist affinity was calculated according to the formula:

$$
\mathrm{pK}_{\mathrm{A}}=-\log \frac{\text { slope }-1}{\text { intercept }}
$$

Also this parameter may not be regarded as a measure of true receptor affinity for noradrenaline in view of the heterogeneity of $\alpha_{1}$-AR and because it cannot a priori be excluded that certain interventions, such as pretreatment with CEC, interfere with signal transduction phenomena distal from the receptor.

It is controversial to treat agonist concentration-response curves obtained in the presence of functional antagonist in the same way as those obtained after partial receptor inactivation (Furchgott, 1966). This procedure has, however, been proposed for receptor systems for which no irreversible antagonist is available yet (Leff et al., 1985). Because it has been demonstrated that CEC renders rat aorta insensitive to irreversible blockade by phenoxybenzamine 
(Oriowo \& Bevan, 1990), we used besides the alkylating agent two different directly vasodilating agents to approach apparent agonist affinity. Phenoxybenzamine, Na-nitroprusside and felodipine yielded qualitatively similar results in this respect.

If in the present study, all assumptions of "receptor occupation theory" are met except for homogeneity of receptors, then differences in apparent antagonist affinity and in apparent agonist affinity between preparations with and without pretreatment with CEC suggest the presence of multiple $\alpha_{1}$-AR subtypes.

\section{Drugs and solutions}

Chloroethylclonidine (CEC), 5- $\mathrm{CH}_{3}$-urapidil, WB4101 (2-(2,6-dimethoxyphenoxyethyl) aminoethyl-1,4-benzodioxane hydrochloride), and phentolamine were purchased from Research Biochemicals Inc (Natick, MA, USA). 6Hydroxydopamine, l-noradrenaline, l-prazosin, dl-propranolol, yohimbine, bovine serum albumin and calf thymus DNA were obtained from Sigma Chemicals (Saint Louis, Mo, USA); [7-methoxy- $\left.{ }^{3} \mathrm{H}\right]$-prazosin $(79.2 \mathrm{Ci} /$ mmole) from NEN ('s Hertogenbosch, The Netherlands) and acetylcholine and Nanitroprusside from Janssen Chimica (Geel, Belgium). Felodipine and phenoxybenzamine were gifts from Hässle (Gothenburg, Sweden) and Smith Kline \& Beecham (King of Prussia, PA, USA), respectively.

Krebs-Ringer-bicarbonate solution (KRB) had the following composition (in $\mathrm{mM}): \mathrm{NaCl}, 118.5 ; \mathrm{KCl}, 4.7 ; \mathrm{MgSO}_{4}, 1.2 ; \mathrm{NaHCO}_{2}, 25.0 ; \mathrm{CaCl}_{2}, 2.5 ;$ glucose 11.1. For high potassium solution (K-KRB) all $\mathrm{NaCl}$ in $\mathrm{KRB}$ was replaced by an equimolar concentration of $\mathrm{KCl}$. $\mathrm{KRB}$ containing $20 \mathrm{mM} \mathrm{KCl}$ was prepared by mixing 8.8 volumes $\mathrm{KRB}$ with 1.2 volumes $\mathrm{K}-\mathrm{KRB}$. Calcium-free solution was prepared by omitting $\mathrm{CaCl}_{2}$ in $\mathrm{KRB}$ and adding 0.3 mM EGTA.

\section{Data analysis}

Specific $\left[{ }^{3} \mathrm{H}\right]$-prazosin binding was determined by subtracting non-specific from total binding. The dissociation constant $\left(\mathrm{K}_{\mathrm{D}}\right)$ and receptor density $\left(\mathrm{B}_{\max }\right)$ were determined by Scatchard analysis (Michel et al., 1990; Jackson et al., 1992) of the mean saturation binding curves. Curves were fitted better by a model based on a single class of binding sites than by models based on multiple sites with different affinity for the ligand. Determination of concentrations of noradrenaline required to induce $50 \%$ of the maximal contractile response $\left(\mathrm{EC}_{50}\right)$, and equi-effective concentrations before and after partial receptor inactivation with phenoxybenzamine (Furchgott, 1966) or in the absence and presence of functional antagonist were performed by 
interpolation on a least square sigmoidal curve fit of concentration-response curves, using Graphpad Inplot software of Jandell (San Diego, Ca, USA).

Data are shown as means \pm SEM. Evaluation of drug effects were performed by Student's t-test for paired observations; comparison between types of artery by analysis of variance followed by a modified t-test as introduced by Bonferroni (Wallenstein et al., 1980).

\section{Results}

\section{$\left[{ }^{3} \mathrm{H}\right]-$ Prazosin binding}

Figure 1 illustrates binding of $\left[{ }^{3} \mathrm{H}\right]$-prazosin in segments of small mesenteric arteries (MrA) of the rat. Non-specific binding was low and increased linearly with increasing concentration of $\left[{ }^{3} \mathrm{H}\right]$-prazosin. Specific binding tended to saturate between 0.25 and $0.40 \mathrm{nM}\left[{ }^{3} \mathrm{H}\right]$-prazosin. The affinity $\left(\mathrm{K}_{\mathrm{D}}, 105 \mathrm{pM}\right)$ was comparable to that previously reported for $\left[{ }^{3} \mathrm{H}\right]$-prazosin binding to cerebral, cardiac and renal membrane preparations (Han \& Minneman, 1991; Jackson et al., 1992; Knowlton et al., 1993; Minneman \& Atkinson, 1993), but higher than that observed in aortic microsomes $\left(\mathrm{K}_{\mathrm{D}}, 199 \mathrm{pM}\right)$.

At $0.3 \mathrm{nM},\left[{ }^{3} \mathrm{H}\right]$-prazosin also displayed specific binding in SMA and Ao segments (figure 2). The number of sites specifically labelled by $0.3 \mathrm{nM}\left[{ }^{3} \mathrm{H}\right]$ prazosin was significantly larger in $\mathrm{MrA}$, than Ao when expressed relative to the total protein content or to the total DNA content of the arterial preparations (figure 2).

In MrA segments, pretreatment with CEC (100 $\mu \mathrm{M}$ during $30 \mathrm{~min})$ did not affect non-specific binding but reduced specific $\left[{ }^{3} \mathrm{H}\right]$-prazosin binding (figure 1). $B_{\max }$ was reduced from 49 to $39 \mathrm{fmol} / \mathrm{mg}$ total protein, while affinity was not modified $\left(\mathrm{K}_{\mathrm{D}}, 108 \mathrm{pM}\right.$ versus $\left.105 \mathrm{pM}\right)$.

Figure 2 summarizes effects of pretreatment with CEC on specific binding in presence of $0.3 \mathrm{nM}[3 \mathrm{H}]$-prazosin in the three types of artery. CEC reduced binding less markedly in MrA $(37.5 \pm 3.4 \%)$ than SMA $(84.5 \pm 3.0 \%)$. In Ao segments, pretreatment with CEC abolished specific $\left[{ }^{3} \mathrm{H}\right]$-prazosin-binding. 


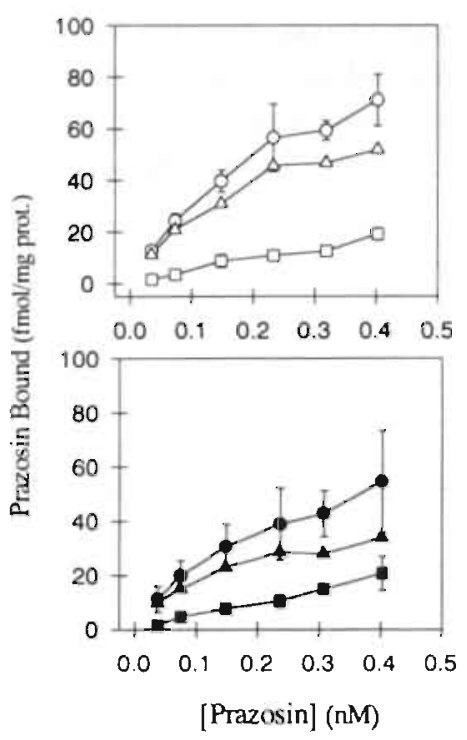

\section{Figure 1}

Binding of $\left[{ }^{3} \mathrm{H}\right]-$ prazosin in intact segments of small mesenteric arteries as a function of prazosin concentration. Binding was carried out in the absence (circle) and presence (square) of $25 \mu \mathrm{M}$ phentolamine to determine specific binding (triangle).

Top: preparations that had not been exposed to chloroethylclonidine (CEC); bottom: preparations that had been pretreated with CEC (100 $\mu \mathrm{M}$, during $30 \mathrm{~min})$. Data shown as mean $\pm \operatorname{SEM}(n=5-7)$.
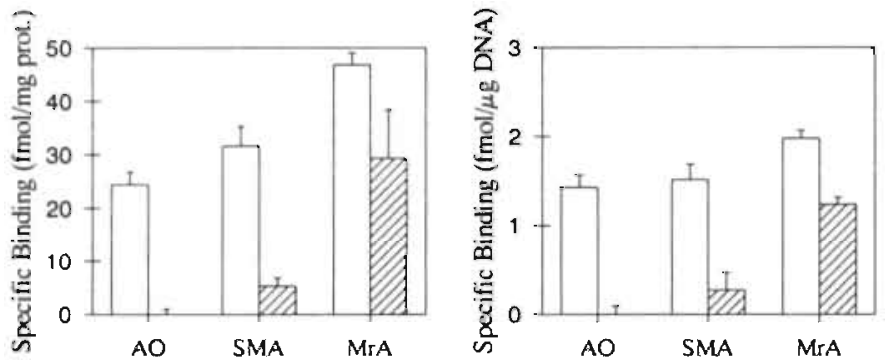

\section{Figure 2}

Effect of pretreatment with CEC on specific binding of prazosin in segments of rat thoracic aorta (Ao), superior mesenteric artery (SMA) and mesenteric small arteries (MrA). Specific binding, observed in the presence of $0.3 \mu \mathrm{M}\left[{ }^{3} \mathrm{H}\right]$-prazosin, was expressed relative to total protein content (left) and relative to DNA content (right) and is shown as mean \pm SEM $(n=5-7)$. Open bars, without: hatched bars, with pretreatment with CEC. The effects of CEC are statistically significant $(\mathrm{p}<0.05)$. 


\section{Contractile responses}

Sensitivity and maximal responses to noradrenaline in Ao, SMA, and MrA pretreatment with CEC (100 $\mu \mathrm{M}$ during $30 \mathrm{~min})$ did not significantly modify the amplitude of contractile responses to $125 \mathrm{mM}$ potassium (not shown) or maximal contractile responses to noradrenaline. (table 1). CEC. however, reduced the sensitivity to the catecholamine (table 1, figure 3). This was more pronounced in Ao and SMA than in MrA.

\section{Table 1}

Effects of chloroethylclonidine (CEC) on sensitivity and maximal responses to noradrenaline in rat arteries

$\begin{array}{lllllll}\begin{array}{l}\text { Vessel } \\ \text { Pretreatment }\end{array} & \begin{array}{l}\text { Ao } \\ \text { No additional treatment }\end{array} & \begin{array}{l}\text { Ao } \\ \text { +CEC }\end{array} & \begin{array}{l}\text { SMA } \\ \text {-CEC }\end{array} & \begin{array}{l}\text { SMA } \\ + \text { CEC }\end{array} & \begin{array}{l}\text { MrA } \\ \text {-CEC }\end{array} & \begin{array}{l}\text { MrA } \\ + \text { CEC }\end{array} \\ \mathrm{pD}_{2} & 6.5 \pm 0.2 & 5.7 \pm 0.3^{*} & 6.3 \pm 0.2 & 5.1 \pm 0.4^{*} & 5.5 \pm 0.2 & 5.3 \pm 0.1^{*} \\ \mathrm{E}_{\operatorname{mix}}(\mathrm{mN} / \mathrm{mm}) & 4.3 \pm 0.6 & 3.9 \pm 0.4 & 8.0 \pm 0.5 & 7.1 \pm 0.7 & 2.9 \pm 0.3 & 3.0 \pm 0.3 \\ \mathbf{6 - O H D A}, \text { propranolol } & & & & & & \\ \mathrm{pD}_{2} & \text { n.t. } & \text { n.t. } & 6.4 \pm 0.2 & 5.7 \pm 0.1^{*} & 6.4 \pm 0.1 & 6.3 \pm 0.1^{*} \\ \mathrm{E}_{\max }(\mathrm{mN} / \mathrm{mm}) & \text { n.t. } & \text { n.t. } & 7.9 \pm 0.6 & 6.9 \pm 0.9 & 3.0 \pm 0.2 & 2.7 \pm 0.2^{2} \\ \mathbf{6 - O H D A}, \text { propranolol, yohimbine } & & & & & \\ \mathrm{pD}_{2} & 6.6 \pm 0.2 & 5.7 \pm 0.3^{*} & 6.4 \pm 0.2 & 5.5 \pm 0.2^{*} & 6.3 \pm 0.1 & 6.1 \pm 0.1^{*} \\ \mathrm{E}_{\max }(\mathrm{mN} / \mathrm{mm}) & 4.9 \pm 0.3 & 4.3 \pm 0.4 & 7.5 \pm 0.6 & 6.8 \pm 0.7 & 3.0 \pm 0.2 & 3.0 \pm 0.3\end{array}$

6-OHDA, propranolol, yohimbine, -endothelium
$\mathrm{pD}_{2}$
$7.0 \pm 0.2$
$6.2 \pm 0.2^{*} \quad 6.9 \pm 0.2$
$5.8 \pm 0.2 * \quad$ n.t.
n.t.
$\mathrm{E}_{\max }(\mathrm{mN} / \mathrm{mm})$
$4.5 \pm 0.6$
$4.5 \pm 0.4$
$7.1 \pm 0.5$
$7.1 \pm 0.7 \quad$ n.t
n.t.

Concentration-response curves for noradrenaline were constructed in thoracic aorta (AO), superior mesenteric artery (SMA), and mesenteric resistance artery (MrA), that had (+CEC) or had not been (-CEC) pretreated with chloroethylclonidine (100 $\mu \mathrm{M}, 30 \mathrm{~min})$. Part of the experiments were performed after chemical sympathectomy, in the presence of $1 \mu \mathrm{M}$ propranolol and $1 \mu \mathrm{M}$ yohimbine and after mechanical removal of endothelium. Data were expressed as $\mathrm{pD}_{2}\left(-\log E \mathrm{C}_{\mathrm{s}_{0}}\right)$ and maximal response $\left(E_{n+1 x}\right)$ as increase in wall tension; they are shown as mean $\pm \operatorname{SEM}(n=8-40)$. "The effect of CEC is statistically significant $(p<0.05)$. n.t., not tested

Similar findings were obtained in the presence of $1 \mu \mathrm{M}$ propranolol and $1 \mu \mathrm{M}$ yohimbine and after chemical sympathectomy of the preparations with 6hydroxydopamine. Also under these conditions, pretreatment with CEC (i) did not modify maximal responses to noradrenaline in large or small arteries and (ii) reduced sensitivity to noradrenaline more markedly in Ao and SMA than in MrA (table 1, figure 3). Removal of endothelium did not modify the effect of CEC on sensitivity to noradrenaline in Ao or SMA (table 1). 


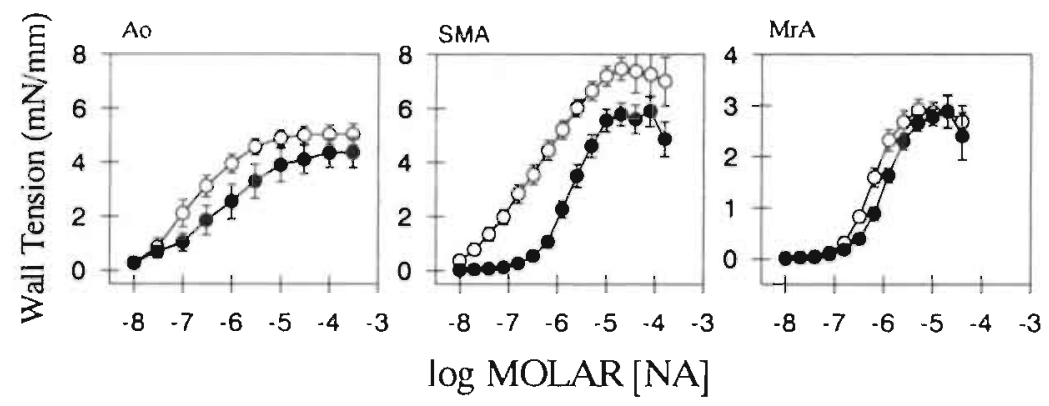

Figure 3

Effects of CEC on contractile responses to noradrenaline in thoracic aorta (left), superior mesenteric artery (middle) and mesenteric resistance artery (right) segments. Arterial preparations were chemically sympathectomized with 6-OHDA and were subsequently pretreated with CEC (100 $\mu \mathrm{M}$ during $30 \mathrm{~min}$, closed symbols) or its solvent (open symbols). Cumulative concentration response curves for noradrenaline were constructed in the presence of $1 \mu \mathrm{M}$ propranolol and $1 \mu \mathrm{M}$ yohimbine. Responses are shown as mean \pm SEM increase in wall tension $(n=10-18)$. For statistical analysis, see table 1.

\section{Calcium-free solution}

When SMA and MrA were incubated for $3 \mathrm{~min}$ in calcium-free solution, 10 $\mu \mathrm{M}$ noradrenaline induced a transient contractile response. In both the large and the small artery, pretreatment with CEC significantly reduced the amplitude of this transient response to noradrenaline, which has been attributed to release of intracellular calcium (Boonen \& De Mey, 1990a; b) (figure 4).

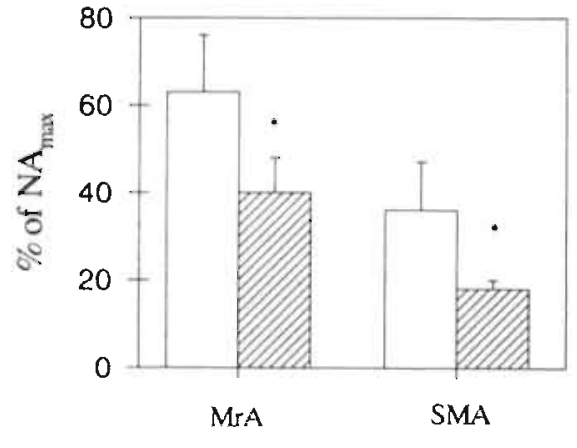

\section{Figure 4}

Contractile responses to $10 \mu \mathrm{M}$ noradrenaline in the mesenteric resistance artery (MrA) and superior mesenteric artery (SMA) in the absence of extracellular calcium. Open bars, control preparations; hatched bars, vessels pretreated with CEC (100 $\mu \mathrm{M}$ during $30 \mathrm{~min}$ ). Data were expressed as percentage of the contractile response observed in the presence of $2.5 \mathrm{mM}$ calcium, and are shown as mean \pm $\operatorname{SEM}(n=6-8) .^{*}$, the difference from control is statistically significant $(p<0.05)$. 


\section{Competitive antagonists}

In SMA and MrA that had not been pretreated with CEC, $0.1 \mu \mathrm{M}$ prazosin $0.1 \mu \mathrm{M}$, WB4101 and $0.3 \mu \mathrm{M} 5-\mathrm{CH}_{3}$-urapidil reduced the sensitivity but not the maximal response to noradrenaline. The shift of the concentration-response curve for noradrenaline was parallel and fully reversible after washout of the antagonists. Estimated affinity for prazosin was comparable in both types of vessel (table 2). The $\mathrm{pK}_{\mathrm{B}}$ 's for $\mathrm{WB} 4101$ and $5-\mathrm{CH}_{3}$-urapidil were significantly larger in MrA than SMA (table 2). In control superior SMA, the $\mathrm{pK}_{\mathrm{B}}$ for WB4101 did not differ significantly from that for prazosin; that for 5- $\mathrm{CH}_{3}$ urapidil was significantly smaller than that for prazosin (table 2). In control MrA, the apparent affinity for WB4101 was significantly higher and that for 5$\mathrm{CH}_{3}$-urapidil significantly lower than that for prazosin (table 2).

In $\mathrm{MrA}$, pretreatment with $\mathrm{CEC}$ did not significantly modify the $\mathrm{pK}_{\mathrm{B}}$ 's for the three antagonists (table 2). In SMA, however, CEC reduced apparent affinity for prazosin without modifying the $\mathrm{pK}_{\mathrm{B}}$ for $\mathrm{WB} 4101$ or $5-\mathrm{CH}_{3}$-urapidil (table 2). CEC reduced the $\mathrm{pK}_{\mathrm{B}}$ for prazosin in SMA by 0.5 to $1.0 \log$ unit. This was reproduced in separate experiments in the presence of $1 \mu \mathrm{M}$ yohimbine and after removal of the endothelium (table 2).

Table 2

Effects of chloroethylclonidine (CEC) on apparent antagonist affinities in superior mesenteric artery (SMA) and mesenteric resistance artery (MrA)

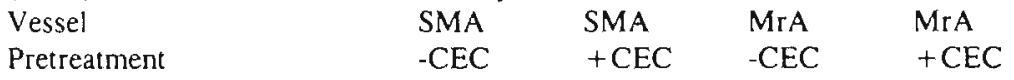

6-OHDA, propranolol

$\begin{array}{lllll}\text { Prazosin } & 8.5 \pm 0.2 & 8.0 \pm 0.2^{*} & 8.8 \pm 0.1 & 8.5 \pm 0.1 \\ \text { WB4101 } & 8.3 \pm 0.2 & 8.1 \pm 0.2 & 9.2 \pm 0.1 \# \$ & 8.9 \pm 0.2 \# \$ \\ 5-\mathrm{CH}_{3} \text { urapidil } & 7.6 \pm 0.1 \# & 7.7 \pm 0.4 & 8.3 \pm 0.2 \# \$ & 8.1 \pm 0.1 \#\end{array}$

6-OHDA, propranolol, yohimbine
Prazosin
$8.3 \pm 0.2 \quad 7.3 \pm 0.1^{*} \quad$ n.t.
n.t.

6-OHDA, propranolol, yohimbine, - endothelium

Prazosin

$8.7 \pm 0.2 \quad 7.7 \pm 0.4^{*} \quad$ n.t.

n.t.

Estimated apparent affinities are shown as $\mathrm{pK}_{\mathrm{B}}{ }^{\prime}$ 's (mean $\pm \mathrm{SEM} ; n=6$ ). Concentration-response curves for noradrenaline were constructed in sympathectomized vessels (6-OHDA) in the presence of I $\mu \mathrm{M}$ propranolol and with additional presence of $1 \mu \mathrm{M}$ yohimbine and endothelium removal as indicated. Curves were then repeated in the presence of $0.1 \mu \mathrm{M}$ prazosin, $0.1 \mu \mathrm{M}$ WB4101 or 0.3 $\mu \mathrm{M} 5-\mathrm{CH}_{3}$-urapidil. Controls (-CEC) and preparations that had been pretreated with CEC $(+\mathrm{CEC})$ were used in parallel. * The difference from control $(-C E C)$ is statistically significant $(\mathrm{p}<0.05)$. \# The difference from prazosin is statistically significant $(p<0.05)$. $\$$ The difference from SMA is statistically significant $(p<0.05)$ 


\section{Phenoxybenzamine}

Phenoxybenzamine irreversibly antagonized contractile responses to noradrenaline in Ao, SMA and MrA. Following $30 \mathrm{~min}$ of exposure to $1 \mu \mathrm{M}$ phenoxybenzamine, up to $300 \mu \mathrm{M}$ noradrenaline failed to elicit contraction in either type of vessel (not shown). Susceptibility to this alkylating agent differed, however, markedly between the types of artery. In Ao and SMA, approximately $50 \%$ of the maximal response to the catecholamine persisted after $30 \mathrm{~min}$ exposure to $100 \mathrm{nM}$ and $20 \mathrm{nM}$ phenoxybenzamine, respectively (figure 5). In mesenteric resistance arteries, however, responses to noradrenaline were already abolished following $30 \mathrm{~min}$ of incubation with 2 $\mathrm{nM}$ phenoxybenzamine. In view of this high sensitivity, MrA were sequentially exposed for $10 \mathrm{~min}$ to $0.1,0.2,0.4,0.8$ and $1.6 \mathrm{nM}$ phenoxybenzamine with intermittent construction of concentration-response curves for noradrenaline.

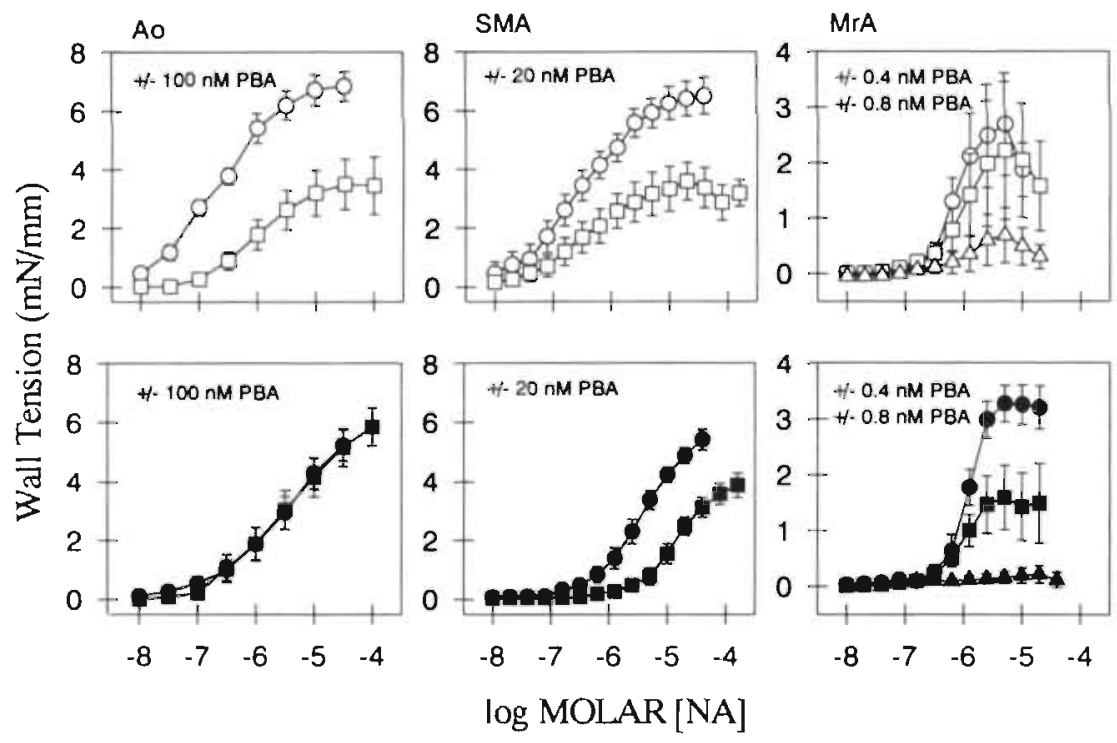

\section{Figure 5}

Effects of phenoxybenzamine on contractile responses to noradrenaline in thoracic aorta (left), superior mesenteric artery (middle) and mesenteric resistance artery (right) segments that had been sympathectomized and studied in the presence of $1 \mu \mathrm{M}$ propranolol and $1 \mu \mathrm{M}$ yohimbine. The experiments were performed in control preparations (top; open symbols) and in preparations that had been pretreated with CEC (bottom: closed symbols). Mean \pm SEM $(n=6-10)$. Note the different concentrations of phenoxybenzamine that were used; circles, prior to exposure 10 phenoxybenzamine; squares, after exposure to phenoxybenzamine ( $100 \mathrm{nM}, 20 \mathrm{nM}$, and $0.4 \mathrm{nM}$ for aorta, superior mesenteric artery, and mesenteric resistance artery, respectively); triangles, after exposure of the resistance arteries to 0.4 and $0.8 \mathrm{nM}$ phenoxybenzamine. 
Using this approach, it was observed that maximal responses to the catecholamine were reduced by approximately $50 \%$ following $0.8 \mathrm{nM}$ phenoxybenzamine (figure 5). After treatment with CEC, $100 \mathrm{nM}$ phenoxybenzamine no longer reduced responses of Ao to noradrenaline (figure 5). In SMA and MrA, pretreatment with CEC did not significantly modify subsequent actions of phenoxybenzamine (figure 5).

\section{Functional antagonists}

Figure 6 summarizes responses to noradrenaline in absence and presence of 1 $\mathrm{nM}$ felodipine. The dihydropyridine calcium antagonist reduced sensitivity and maximal responses to noradrenaline. The effect on sensitivity to the catecholamine was more marked in SMA $\left(\Delta \mathrm{pD}_{2} 0.9\right)$ than in Ao $\left(\Delta \mathrm{pD}_{2} 0.5\right)$ and $\operatorname{MrA}\left(\Delta \mathrm{pD}_{2} 0.15\right)$. In vessels that had been pretreated with CEC, effects of $1 \mathrm{nM}$ felodipine on sensitivity and maximal responses to noradrenaline did not differ significantly from those in control vessels with the exception of the sensitivity in SMA which was reduced to a smaller extent $\left(\Delta \mathrm{pD}_{2} 0.5\right)$.
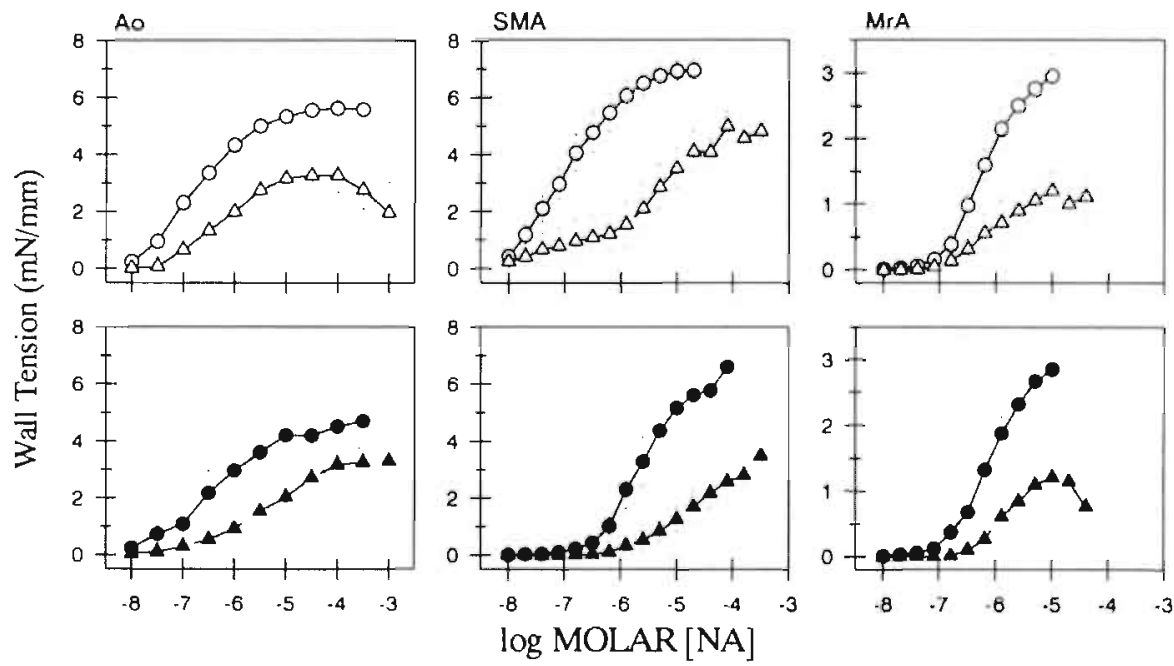

Figure 6

Responses to noradrenaline in thoracic aorta (left), superior mesenteric artery (middle) and mesenteric resistance artery (right) in the absence (circle) and presence of $1 \mathrm{nM}$ felodipine (triangle). Both control preparations (top) and preparations that had been pretreated with CEC (bottom) were used. All preparations had been symparhectomized and were studied in the presence of $1 \mu \mathrm{M}$ propranolol and $1 \mu \mathrm{M}$ yohimbine. Means $\pm \operatorname{SEM}(n=6-8)$. 
The direct vasodilator Na-nitroprusside was more potent in reducing responses to noradrenaline in Ao than in SMA and, especially MrA (figure 7). At 0.1 $\mu \mathrm{M}, \mathrm{Na}$-nitroprusside reduced the maximal response to noradrenaline by $33 \pm 9 \%$ and $17 \pm 4 \%$ in Ao and SMA, respectively, but even $10 \mu \mathrm{M} \mathrm{Na}$ nitroprusside did not alter the maximal response to the catecholamine in MrA (figure 7). Similar observations were obtained in arteries that had been pretreated with CEC (figure 7).
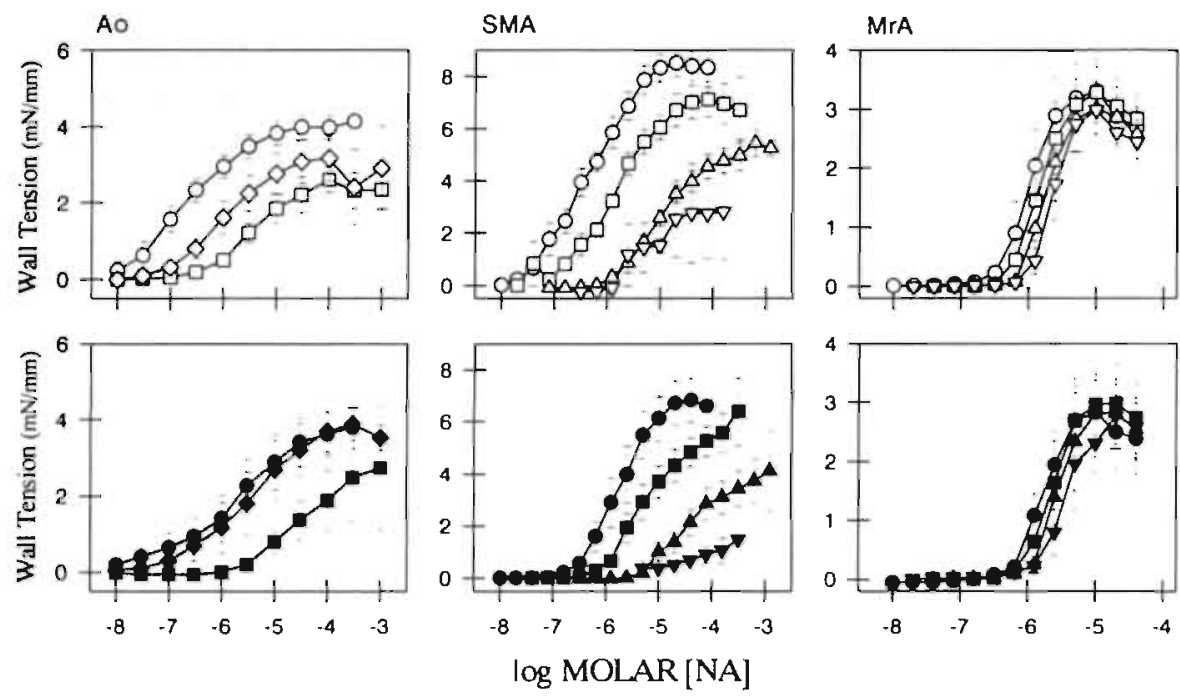

\section{Figure 7}

Contractile responses to noradrenaline in thoracic aorta (left), superior mesenteric artery (middle) and mesenteric resistance artery (right) in the absence (circles) and presence of Na-nitroprusside (diamond, $10 \mathrm{nM}$; square, $100 \mu \mathrm{M}$; triangle, I $\mu \mathrm{M}$; inverse triangle, $10 \mu \mathrm{M}$ ). Both control preparations (top) and preparations that had been pretreated with CEC (bottom) were used. All preparations had been sympathectomized and were studied in the presence of $1 \mu \mathrm{M}$ propranolol and $1 \mu \mathrm{M}$ yohimbine. Means $\pm \operatorname{SEM}(\mathrm{n}=6)$. 
Agonist affinity

In control preparations, the affinity for noradrenaline cannot be estimated because of the possible presence of receptor subtypes. After pretreatment with $\mathrm{CEC}$, however, calculated agonist affinity is representative for $\alpha_{1 \mathrm{~A}}$-AR provided CEC irreversibly blocks $\alpha_{1 \mathrm{~B}}$-AR and $\alpha_{1 \mathrm{D}}$-AR but not $\alpha_{1 \mathrm{~A}}$-AR (Minneman, 1988; Perez et al., 1991), and does not interfere with signal transduction. Differences in estimated agonist affinity between control and CEC-treated preparations then offer additional support for the presence of $\alpha_{1}$ AR subtypes. Estimates of receptor reserve $\left(\mathrm{pD}_{2}-\mathrm{pK}_{\mathrm{A}}\right)$ depend on the same assumptions.

The responses to noradrenaline obtained before and after partial receptor inactivation with phenoxybenzamine and those observed in absence and presence of felodipine or Na-nitroprusside were further used to estimate agonist affinity for noradrenaline (Furchgott, 1966; Leff et al., 1985)(table 3). With the partial receptor inactivation method (phenoxybenzamine) apparent agonist affinity was comparable in SMA and MrA but lower in Ao. Receptor reserve was, however, more marked in Ao than in the other vessels (table 3 ). In SMA and MrA, pretreatment with CEC (i) reduced apparent agonist affinity by 1.4 to $0.8 \log$ unit and (ii) paradoxically increased receptor reserve. For instance, in MrA there was hardly any receptor reserve before exposure to CEC, while after pretreatment with CEC sensitivity to noradrenaline significantly exceeded apparent affinity for the catecholamine (table 3). In Ao, effects of CEC on affinity and efficacy of noradrenaline could not be evaluated with phenoxybenzamine, because CEC blunted subsequent actions of phenoxybenzamine (see figure 5).

Estimates of affinity for noradrenaline were larger when using the calcium antagonist felodipine, than following partial receptor alkylation with phenoxybenzamine (table 3). Findings were, however, qualitatively similar with this approach. Before pretreatment with $\mathrm{CEC}$, a significant receptor reserve was present in Ao but not MrA. Following pretreatment with CEC estimated affinity for noradrenaline was reduced and receptor reserve increased in both Ao and MrA (table 3). Similarly, the use of Na-nitroprusside, which resulted in lower estimates of affinity than phenoxybenzamine, indicated that in SMA CEC reduced affinity for noradrenaline (table 3 ). 


\section{Table 3}

Effects of chloroethylclonidine (CEC) on apparent affinity and apparent receptor reserve for noradrenaline in large and small arteries of the rat evaluated with phenoxybenzamine and functional antagonists

\begin{tabular}{|c|c|c|c|c|c|c|}
\hline Vessel & $\mathrm{AO}$ & $\mathrm{AO}$ & SMA & SMA & $\mathrm{MrA}$ & MrA \\
\hline Pretreatment & $-\mathrm{CEC}$ & $+\mathrm{CEC}$ & $-\mathrm{CEC}$ & $+\mathrm{CEC}$ & $-\mathrm{CEC}$ & $+\mathrm{CEC}$ \\
\hline \multicolumn{7}{|c|}{ Phenoxybenzamine } \\
\hline $\mathrm{pK}_{\mathrm{A}}$ & 5.77 & n.a. & 6.31 & 3.69 & 6.21 & 5.40 \\
\hline $\mathrm{pD}_{2}-\mathrm{pK}_{\mathrm{A}}$ & 0.63 & n.a. & 0.08 & 0.76 & 0.00 & 0.55 \\
\hline \multicolumn{7}{|l|}{ Felodipine } \\
\hline $\mathrm{pK}_{\mathrm{A}}$ & 6.53 & 5.39 & n.d. & 5.33 & 6.50 & 5.60 \\
\hline $\mathrm{pD}_{2}-\mathrm{pK}_{\lambda}$ & 0.17 & 1.30 & n.d. & 0.42 & 0.00 & 0.53 \\
\hline \multicolumn{7}{|c|}{ Na-nitroprusside } \\
\hline $\mathrm{pK}_{\mathrm{A}}$ & 4.03 & n.d. & 5.21 & 4.50 & n.a. & n.a. \\
\hline $\mathrm{pD}_{2}-\mathrm{pK}$ & 2.67 & n.d. & 0.86 & 0.95 & n.a. & n.a. \\
\hline
\end{tabular}

$\mathrm{pK}_{\mathrm{A}}$ for noradrenaline was calculated from double reciprocal plots of equi-effective agonist concentrations derived from mean concentration-response curves for noradrenaline ( $n=6-10)$ before and after exposure to phenoxybenzamine, in absence and presence of $1 \mathrm{nM}$ felodipine and in absence and presence of $0.1 \mu \mathrm{M} \mathrm{Na-nitroprusside.} \mathrm{The} \mathrm{experiments} \mathrm{were} \mathrm{performed} \mathrm{in} \mathrm{sympathectomized}$ arta (AO), superior mesenteric artery (SMA) and mesenteric resistance artery (MrA), in the presence of $1 \mu \mathrm{M}$ propranolol and $1 \mu \mathrm{M}$ yohimbine; control preparations (-CEC) and preparations that had been pretreated with chloroethylclonidine ( $+\mathrm{CEC}$ ) were obtained from the same arteries. As an estimate of receptor reserve, the difference between the sensitivity $\left(\mathrm{pD}_{2}\right)$ and affinity for the agonist $\left(\mathrm{pK}_{\mathrm{A}}\right.$ ) was determined. n.a., not available because of lack of effect of the antagonist on the maximal response to noradrenaline, n.d., not determined because of a negative intercept of the double reciprocal plot.

\section{Discussion}

Effects of chloroethylclonidine on prazosin binding and sensitivity to the contractile effect of noradrenaline, along with estimates of apparent affinity for subtype selective $\alpha_{1}$-AR antagonists, suggest that $\alpha_{1 \mathrm{~A}}$-AR are more prominent in small mesenteric resistance-sized arteries than in large conduit vessels such as superior mesenteric artery and thoracic aorta. This does not suffice to explain differences between the $\alpha_{1}$ - adrenergic responses of these vessels as regards receptor reserve and effects of vasodilator drugs.

Multiple subtypes of $\alpha_{1}$-AR seem to exist (Flavahan \& Vanhoutte, 1987; Cotecchia et al., 1988; Minneman, 1988; Muramatsu et al., 1990b; Ruffolo et al., 1991; Schwinn et al., 1991). Of these, only the subtypes with a high 
affinity for prazosin have been characterized in great detail. Molecular biological approaches, ligand binding experiments and functional studies indicate that these $\alpha_{1 \mathrm{~A}^{-}}, \alpha_{\mathrm{IB}^{-}}$, and $\alpha_{1 \mathrm{D}^{-}} \mathrm{AR}$ coexist in several organs including the vasculature (Muramatsu et al., 1990a; b; Ohmura et al., 1992; Kohno et al., 1994; Piascik et al., 1995). The arterial tree is, however, a highly heterogeneous structure and differences between vascular beds and between branches of a given vascular bed have repeatedly been noted for various vasoactive agents (De Mey \& Vanhoutte, 1981; Daly et al., 1988; Faber, 1988; Heesen et al., 1989; Heesen \& De Mey, 1990; Messing et al., 1990; Piascik et al., 1990; Eerdmans et al., 1991; Testa et al., 1995). We evaluate whether $\alpha_{1 \mathrm{~A}}$-AR are unevenly distributed along the rat arterial tree and whether this may help explain regional differences in $\alpha_{1}$-adrenergic vasoconstrictor responses. CEC, an agent that has been shown to irreversibly block $\alpha_{1 \mathrm{~B}}$-AR and $\alpha_{1 \mathrm{D}}$-AR more readily than $\alpha_{1 \mathrm{~A}}$-AR (Minneman, 1988; Perez et al., 1991), reduced the specific binding of subnanomolar concentrations of $\left[{ }^{3} \mathrm{H}\right]$-prazosin less markedly in mesenteric resistance arteries than superior mesenteric artery and aorta. CEC also reduced the sensitivity to the $\alpha_{1}$-adrenergic vasoconstrictor effect of noradrenaline less markedly in the small arteries $\left(\Delta \mathrm{pD}_{2}: 0.2\right)$ than in the conduit vessels $\left(\Delta \mathrm{pD}_{2}: 0.8-1.2\right)$. Moreover, the apparent affinity for the $\alpha_{1 \mathrm{~A}}$-AR preferring antagonists WB4101 and 5- $\mathrm{CH}_{3}$ urapidil was significantly larger in the mesenteric resistance vessels than in the mesenteric feeding vessel. Collectively these findings indicate that $\alpha_{1 \mathrm{~A}}$-AR are more prominent and more involved in $\alpha_{1}$-adrenergic responses in mesenteric vessels than in the larger arteries of the rat.

While the mesenteric resistance arteries seem to rely primarily on $\alpha_{A \mathrm{~A}}$-AR in the presence of extracellular calcium, a role for CEC-sensitive sites became clear in the absence of the divalent cation. Recent observations indicate that mesenteric resistance arteries display a particularly low affinity for the $\alpha_{1 D}$-AR selective ligand BMY 7378 (Piascik et al., 1995). We therefore propose that rat mesenteric resistance arteries contain besides $\alpha_{1 \mathrm{~A}}$-AR a subpopulation of $\alpha_{1 \mathrm{~B}}$-AR that are preferentially coupled to intracellular calcium release.

In view of the different effects of CEC on prazosin-binding and sensitivity to $\alpha_{1}$-adrenergic effects of noradrenaline in different rat arteries, we evaluated whether the alkylating agent modified regional differences as regards receptor reserve and effects of vasodilator drugs during $\alpha_{1}$-adrenergic vasoconstriction. With the use of phenoxybenzamine we noted a marked difference in receptor reserve between types of vessel as indicated by the difference between sensitivity and affinity (table 3 ) and by the shape of the curves relating relative receptor occupancy to relative effect. We furthermore confirmed a marked 
regional difference in the inhibitory effect of Na-nitroprusside on $\alpha_{1}$-adrenergic contractions. Though various separate studies indicated that rat aorta is considerably less susceptible to dihydropyridine calcium antagonists than mesenteric resistance arteries (Boonen \& De Mey 1990a, b; Ruffolo et al., 1991; Videbaek et al., 1995), $1 \mathrm{nM}$ felodipine reduced contractile responses to $\alpha_{1}$-stimulation to roughly the same extent in aorta, superior mesenteric artery and mesenteric resistance arteries. Irreversible blockade of $\alpha_{1 B^{-}}$and $\alpha_{\mathrm{ID}}$-AR by CEC did not normalise differences between types of vessel as regards sensitivity to inhibition of phenoxybenzamine, estimates of receptor reserve and the relaxing effect of Na-nitroprusside. Thus, the heterogeneous distribution of $\alpha_{1 \mathrm{~B}^{-}}$and $\alpha_{1 \mathrm{D}} \mathrm{-AR}$ along the rat arterial tree seems not to be the major determinant of the distinct characteristics of $\alpha_{1}$-adrenergic responses at specific locations in the system.

Various previous and present findings question that the currently cloned $\alpha_{1 \mathrm{~A}^{-}}$, $\alpha_{1 \mathrm{~B}^{-}}$and $\alpha_{1 \mathrm{D}^{-}}$-AR subtypes would suffice to explain arterial $\alpha_{1}$-adrenergic responses (Yu et al., 1993; McGrath \& Daly, 1995). For instance, although CEC effectively blocked all specific high affinity prazosin binding in the aorta this was not accompanied by a drastic reduction of the maximal $\alpha_{1}$-adrenergic response in the tissue. Also, CEC reduced the apparent affinity for prazosin in the superior mesenteric artery despite near-identical affinity of the presently cloned $\alpha_{1}$-AR subtypes for this ligand. Furthermore, as reported earlier pretreatment with CEC prevented inhibitory effects of phenoxybenzamine in the aorta but not in the other types of vessel (Oriowo \& Bevan, 1990). Last but not least, CEC was found to have opposing effects on agonist affinity (reduced) and efficacy (increased). Neither of these observations are compatible with the properties of the cloned $\alpha_{1}$-AR subtypes. Whether this is due to other $\alpha_{1}$-AR subtypes (for instance those proposed to exhibit a comparatively low affinity for prazosin) or whether some of these are due to irreversible effects of CEC other than those on $\alpha_{1 \mathrm{~B}^{-}}$and $\alpha_{1 \mathrm{D}^{-}} \mathrm{AR}$ (Schwietert et al., 1992; Nunes \& Guimaraes, 1993).

In conclusion, chloroethylclonidine was found to affect prazosin binding and noradrenaline action more markedly in rat aorta and superior mesenteric artery than in mesenteric resistance arteries. Consequently $\alpha_{1 A^{-}}$seem to be more prominent in the distal small artery than in the proximal conduit vessels. This does not appear to be a major determinant of regional differences along the arterial tree as regards $\alpha_{1}$-adrenergic receptor reserve and vasodilator responses. 


\section{References}

Aprigliano O. \& Hermsmeyer K. (1977). Trophic influences of the sympathetic nervous system on the rat portal vein, Circ. Res., 41, 198-206.

Boonen H.C.M. \& De Mey J.G.R. (1990a). G-proteins are involved in contractile responses of isolated mesenteric resistance arteries to agonists, Naunyn. Schmiedeberg's. Arch. Pharmacol., 342, 462-468.

Boonen H.C.M. \& De Mey J.G.R. (1990b). Increased calcium sensitivity in isolated resistance arteries from spontaneously hypertensive rats: effects of dihydropyridines, Eur. J. Pharmacol., 179, 403-412.

Bradford M.M. (1976). A rapid and sensitive method for the quantitation of microgram quantities of protein utilizing the principle of protein-dye binding, Anal. Biochem., 72, 248-254.

Cotecchia S., Schwinn S.D., Randall R.R., Lefkowitz R.J., Caron M.G. \& Koblika B.K. (1988). Molecular cloning and expression and expression of the cDNA for the hamster alpha1-adrenergic receptor, Proc. Natl. Acad. Sci. USA., 85, 7159-7163.

Cotecchia S., Exum S., Caron M.G. \& Lefkowitz R.J. (1990). Regions of the alpha1adrenergic receptor involved in coupling to phosphatidylinositol hydrolysis and enhanced sensitivity of biological function, Proc. Natl. Acad. Sci. USA., 87, 2896-2900.

Daly C.J., McGrath J.C. \& Wilson V.G. (1988). An examination of the postjunctional $\alpha$ adrenoceptor subtypes for (-)-noradrenaline in several isolated blood vessels from the rabbit, Br. J. Pharmacol., 95, 473-484.

De Mey J.G.R. \& Vanhoutte P.M. (1981). Uneven distribution of postjunctional $\alpha_{1}-$ and $\alpha_{2}$ - like adrenoceptors in canine arterial and venous smooth muscle, Circ. Res., 48, 875884.

De Mey J.G.R., Claeys M. \& Vanhoutte P.M. (1982). Endothelium-dependent inhibitory effects of acetylcholine, adenosine triphosphate, thrombin and arachidonic acid in the canine femoral artery, J. Pharmacol. Exp. Therap., 222, 166-173.

Eerdmans P.H.A., Heesen B.J., Struijker Boudier H.A.J. \& De Mey J.G.R., 1991, Sympathetic heterogeneity in mesenteric and renal resistance arteries, in: Resistance Arteries. Structure and Function, Mulvany M.J., Aalkjaer C., Heagerty A.M., Nyborg N.C.B. \& Strandgaard S., Excerpta Medica, Amsterdam, The Netherlands, 156-159

Esbenshade T.A., Han C., Murphy T.J. \& Minneman K.P. (1993). Comparison of $\alpha_{1}{ }^{*}$ adrenergic receptor subtypes and signal transduction in SK-N-MC and NB41A3 Neuronal cell lines, Mol. Pharmacol., 44, 76-86.

Esbenshade T.A., Theroux T.L. \& Minneman K.P. (1994). Increased voltage-dependent calcium influx produced by $\alpha_{1 \mathrm{~B}}$-adrenergic receptor activation in rat medullary thyroid carcinoma 6-23 cells, Mol. Pharmacol., 45, 591-598

Faber J.E. (1988). In situ analysis of $\alpha$-adrenoceptors on arteriolar and venular smooth muscle in rat skeletal muscle microcirculation, Circ. Res., 62, 37-50.

Flavahan N.A. \& Vanhoutte P.M., 1987, Heterogeneity of $\alpha$-adrenergic responsiveness in vascular smooth muscle : Role of receptor subtype and receptor reserve, in: The $\alpha_{1^{-}}$ adrenergic receptors, Ruffolo Jr. R.R., Humana Press, Clifton, New Jersey, 351-403. 
Furchgott R.F., 1966, The use of beta-haloalkylamines in the differentiation of receptors and in the determination of dissociation constants of receptor-agonist complexes, in: Advances in Drug Reserach, Harper N.J. \& Simmonds A.B., Academic Press, New York, 21-55.

Goetz A.S., King H.K., Ward S.D., True T.A., Rimele T.J. \& Saussy D.L.J. (1995). BMY 7378 is a selective antagonist of the D subtype of $\alpha$ ladrenoceptors, Eur. J. Pharmacol., 272, R5-R6.

Graham R.M., Perez D.M., Hwa J. \& Piascik M.T. (1996). Alpha 1-adrenergic receptor subtypes. Molecular structure, function, and signaling, Circ. Res., 78, 737-749.

Han C. \& Minneman K.P. (1991). Interaction of subtype-selective antagonists with $\alpha_{1}{ }^{-}$ adrenergic receptor binding sites in rat tissues, J. Pharmacol. Exp. Therap., 40, 531538.

Han C., Abel P.W. \& Minneman K.P. (1987). $\alpha_{1}$-adrenoceptor subtypes linked to different mechanisms for increasing intracellular Ca2 + in smooth muscle, Nature., 329, 333-335.

Heesen B.J. \& De Mey J.G.R. (1990). Effects of cyclic AMP-affecting agents on contractile reactivity of isolated mesenteric and renal resistance arteries of the rat, $\mathrm{Br} . \mathrm{J}$. Pharmacol., 101, 859-864.

Heesen B.J., Struyker-Boudier H.A.J. \& De Mey J.G.R. (1989). Absence of $\beta$-adrenergic relaxing responses in isolated renal resistance arteries, The Pharmacologist, 31, 170.

Jackson C.A., Michel M.C. \& Insel P.A. (1992). Expression of renal $\alpha_{1}$-adrenergic receptor subtypes in established hypertension, J. Cardiovasc. Pharmacol., 19, 857-862.

Knowlton K.U., Michel M.C., Itani M., Shubeita H.E., Ishihara K., Heller Brown J. \& Chien K.R. (1993). The $\alpha_{1 \mathrm{~A}}$-adrenergic receptor subtype mediates biochemical,molecular and morphological features of cultured myocardial cell hypertrophy, J. Biol. Chem., 268, 15374-15380.

Kohno Y., Saito H., Takita M., Kigoshi S. \& Muramatsu I. (1994). Heterogeneity of $\alpha_{1}$ adrenoceptor subtypes involved in adrenergic contractions of dog blood vessels, $\mathrm{Br}$. J. Pharmacol., 112, 1167-1173.

Labarca C. \& Paigen K. (1980). A simple, rapid and sensitive DNA assay procedure, Anal. Biochem., 102, 344-352.

Leff P. . Martin G.R. \& Morse J.M. (1985). Application of the operational model of agonism to establish conditions when functional antagonism may be used to estimate agonist dissociation constants, $\mathrm{Br}$. J. Pharmacol., 85, 655-663.

Lomasney J.W., Cotecchia S., Lorenz W., Leung W.-Y., Schwinn D.A., Yang-Feng T.L., Brownstein M., Lefkowitz R.J. \& Caron M.G. (1991). Molecular cloning and expression of the cDNA for the alphalA-adrenergic receptor. The gene for which is located on human chromosome 5. J. Biol. Chem.. 266, 6365-6369.

McGrath J.C. \& Daly C.J. (1995). Viewing adrenoceptors: past, present and future; commentary and a new technique, Pharm. Comm., 6. 269-279.

Messing M.W.J., van Essen H. \& Struijker Boudier H.A.J. (1990). Effects of $\alpha$ adrenoceptor antagonists on striated muscle microcirculation of conscious rats, Drugs., $40,31-33$.

Michel M.C., Hanft G. \& Gross G. (1990). $\alpha_{1 \mathrm{~B}}$ but not $\alpha_{1 \mathrm{~A}}$ adrenoceptors mediate inositol phosphate generation, Naunyn. Schmiedeberg's. Arch. Pharmacol., 341, 385-387. 
Minneman K.P. (1988). $\alpha_{1}$-Adrenergic receptor subtypes, inositol phosphates and sources of cell calcium, Pharmacol. Rev., 40, 87-119.

Minneman K.P. \& Atkinson B. (1993). Interaction of subtype-selective antagonists with $\alpha_{1}$ adrenergic receptor-mediated second messenger responses in rat brain, Mol. Pharmacol., 40, 523-530.

Morel N. \& Godfraind T. (1989). Pharmacological properties of voltage-dependent calcium channels in functional microvessels isolated from rat brain, Naunyn. Schmiedeberg's. Arch. Pharmacol., 140, 442-451.

Muramatsu I., Kigoshi S. \& Oshita M. (1990a). Two distinct $\alpha_{1}$-adrenoceptor subtypes involved in noradrenaline contraction of the rabbit thoracic aorta, Br. J. Pharmacol., $101,662-666$.

Muramatsu I., Ohmura T., Kigoshi T., Hashimoto S. \& Oshita M. (1990b). Pharmacological subclassification of $\alpha_{1}$-adrenoceptors in vascular smooth muscle, $\mathrm{Br} . \mathrm{J}$. Pharmacol., 99, 197-201.

Nunes J.P. \& Guimaraes S. (1993). Chloroethylclonidine irreversibly activates postjunctional $\alpha_{2}$-adrenoceptors in the dog saphenous vein, Naunyn. Schmiedeberg's. Arch. Pharmacol., 348, 264-268.

Ohmura T., Oshita M., Kigoshi S. \& Muramatsu I. (1992). Identification of $\alpha_{1}$ adrenoceptor subtypes in the rat vas deferens: binding and functional studies, $\mathrm{Br}$. J. Pharmacol., 107, 697-704.

Oriowo M.A. \& Bevan J.A. (1990). Chloroethylclonidine unmasks a non- $\alpha$-adrenoceptor noradrenaline binding site in the rat aorta, Eur. J. Pharmacol., 178, 243-246.

Perez D.M., Piascik M.T. \& Graham R.M. (1991). Solution-phase library screening for the identification of rare clones: isolation of an $\alpha_{1 D}$ receptor cDNA, Mol. Pharmacol., 40, 876-883.

Piascik M.T., Butler B.T. \& Pruitt T.A. (1990). The role of $\alpha_{1}$-adrenoceptor subtypes in the regulation of arterial blood pressure, Eur. J. Pharmacol., 180, 381-386.

Piascik M.T., Sparks M.S. \& Pruitt T.A. (1993). Effect of chloroethylclonidine on arterial blood pressure and heart rate, J. Pharmacol. Exp. Therap., 262, 901-906.

Piascik M.T., Guarino R.D., Smith M.S., Soltis E.E., Saussy D.L.J. \& Perez D.M. (1995). The specific contribution of the novel $\alpha_{1 \mathrm{D}}$ adrenoceptor to the contraction of vascular smooth muscle, J. Pharmacol. Exp. Therap., 275, 1583-1589.

Ruffolo R.R., Nichols A.J., Stadel J.M. \& Hieble J.P. (1991). Structure and function of $\alpha-$ adrenoceptors, Pharmacol. Rev., 43, 475-505.

Schwinn D.A., Page S.O., Middleton J.P., Lorenz W., Liggett S.B., Yamamoto K., Lapetina E.G., Caron M.G., Lefkowitz R.J. \& Cotecchia S. (1991). The $\alpha_{1 C^{-a d r e n e r g i c}}$ receptor: characterization of signal transduction pathways and mammalian tissue heterogeneity, J. Pharmacol. Exp. Therap., 40, 619-626.

Schwietert H.R., Mathy M.J., Wilhelm D., Wilfert B., Pfaffendorf M. \& van Zwieten P.A. (1992). $\alpha_{1}$-adrenoceptor-mediated $\mathrm{Ca}^{2+}$-entry from the extracellular fluid and $\mathrm{Ca}^{2+}$. release from intracellular stores: no role for $\alpha_{1 \mathrm{~A} . \mathrm{B}}$-adrenoceptor subtypes in the pithed rat, J. Auton. Pharmacol., 12, 125-136.

Testa R., Destefani C., Guarneri L., Poggesi E., Simonazzi I., Taddei C. \& Leonardi A. (1995). The $\alpha_{1 \mathrm{D}}$ adrenoceptor subtype is involved in the noradrenaline induced contractions of rat aorta, Life. Sci., 57, PL153-163. 
Videbaek L.M., Kvist S. \& Mulvany M.J. (1995). Time course of action of amlodipine and felodipine in the rat is most rapid in small arteries, Eur. J. Pharmacol., 274, 109-115.

Wallenstein S., Zucker C.L. \& Fleiss J.L. (1980). Some statistical methods useful in circulation research, Circ. Res., 47, 1-9.

Wilson K.M. \& Minneman K.P. (1990). Different pathways of 3H inositol phosphate formation mediated by $\alpha_{1 \mathrm{~A}}$-adrenergic and $\alpha_{1 \mathrm{~B}}$-adrenergic receptors, J. Biol. Chem., 265, $17601-17606$.

Yu G.S., Han Q.D. \& Chen M.Z. (1993). A new $\alpha_{1}$-adrenergic receptor subtype with low affinity for 5-methyl-urapidil but insensitive to chloroethylclonidine, Chung Kuo Yao Li Hsueh Pao, 14, 492-495. 


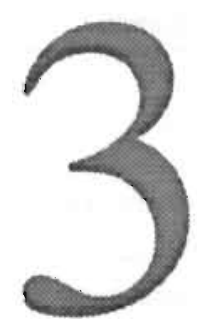

$\alpha_{2}$ - adrenergic reactivity in resistance arteries of the adult spontaneously hypertensive rat.

P.H.A. Eerdmans, H.A.J. Struijker Boudier and J.G.R. De Mey. 



\section{Abstract}

We compared acute effects on resistance artery reactivity for three compounds that share agonistic properties at $\alpha_{2}$-adrenoceptors: azepexole, clonidine and rilmenidine. Experiments were performed in mesenteric and renal resistance arteries isolated from adult spontaneously hypertensive rats. Comparable findings were obtained in mesenteric and renal artery preparations. Azepexole and rilmenidine (up to $10 \mu \mathrm{M}$ ) did not modify (i) basal tone, (ii) contractile responses to $30 \mathrm{mM}$ potassium, (iii) contractile responses to 0.1 to $20 \mu \mathrm{M}$ phenylephrine or (iv) relaxing responses to isoproterenol $1 \mathrm{nM}$ to $10 \mu \mathrm{M}$. At $10 \mu \mathrm{M}$, rilmenidine, but not azepexole, increased the sensitivity of mesenteric vessels to nerve stimulation. Clonidine, on the other hand, while having minimal effects on basal tone or isoproterenol-induced relaxations, increased contractile responses to $30 \mathrm{mM}$ potassium and reduced contractile responses to phenylephrine. Contractile effects of clonidine in partly depolarised preparations could be antagonised by $1 \mu \mathrm{M}$ prazosin. Thus, $\alpha_{2}$-adrenoceptor stimulation failed to influence resistance artery contractile reactivity and both rilmenidine and clonidine elicited effects that cannot be attributed to $\alpha_{2}$ adrenoceptor stimulation. For rilmenidine this may involve an effect on sensory-motor nerves; in the case of clonidine, partial $\alpha_{1}$-adrenoceptor agonism seems to be involved.

\section{Introduction}

Experimental evidence in vivo and vitro suggests that sympathetic nerves play an important role in the development of essential hypertension. Sympatholytic interventions in young spontaneously hypertensive rats prevent the development of hypertension and arterial structural changes (Lee, R.M.K.W. \& Smeda, 1985; Nyborg et al., 1986; Lee, R.M.K.W. et al., 1987; Mangiarua \& Lee, 1992). Furthermore, drugs influencing sympathetic activity have antihypertensive properties, as has been demonstrated with both $\alpha_{1}$-adrenoceptor antagonists and $\alpha_{2}$-adrenoceptor agonists. $\alpha_{2}$-Adrenoceptor agonists lower blood pressure primarily by pre-synaptic (Isaac, 1980; Head et al., 1983; Head \& Burke, 1991) or central nervous system mediated (Zwieten van, 1975; Kobinger, 1978; Bousquet et al., 1984; 1989; Van Zwieten et al., 1986; Coupry \& Lachaud, 1989; Verbeuren et al., 1990) inhibition of sympathetic activity. In addition, the involvement of imidazoline-binding sites (Bousquet \& Feldman, 1987; Ernsberger et al., 1987) has been proposed for some of these drugs (clonidine, rilmenidine). $\alpha_{2}$-Adrenoceptors are present in the vasculature, as has been 
proven by ligand-binding studies (Schmitz et al., 1981; Pettinger et al., 1987; Shi et al., 1990; Elhawary et al., 1992). Stimulation of presynaptic $\alpha_{2}$ adrenoceptors inhibits adrenergic (Armstrong \& Boura, 1973; Langer, 1974; 1977; Medgett et al., 1978; Rump et al., 1991; Hauser et al., 1995) and nonadrenergic neurotransmission (Mione et al., 1990; Friedman \& Duckles, 1995).

Several postjunctional $\alpha_{2}$-adrenergic mechanisms have been observed in the vasculature: i) stimulation of $\alpha_{2}$-adrenoceptors on vascular smooth muscle cells can result in vasoconstriction (Drew \& Whiting, 1979; Ress et al., 1979; De Mey \& Vanhoutte, 1981; Daly et al., 1988; Verbeuren et al., 1989), ii) stimulation of $\alpha_{2}$-adrenoceptors on endothelial cells can increase EDRF release (Angus et al., 1988; Vanhoutte \& Miller, 1989) and iii) adenylate cyclase is inhibited (Pettinger et al., 1987; Limbird, 1988; Heesen \& De Mey, 1990) by $\alpha_{2}$-adrenoceptors on vascular smooth muscle cells.

In this chapter we investigate the acute effects of 3 different $\alpha_{2}$-adrenoceptor agonists, azepexole, clonidine and rilmenidine, in mesenteric and renal resistance arteries in spontaneously hypertensive rats. The $\alpha_{2}$-adrenoceptor agonists differ in several aspects. Azepexole (BHT-933) is an experimental $\alpha_{2}$-adrenoceptor agonist often used in in vivo and in vitro studies (Nielsen et al., 1990; BlochlDaum et al., 1991; Messing, 1992; Schwietert et al., 1992). Clonidine is one of the oldest $\alpha_{2}$-adrenoceptor agonists and became the prototype of all centrally acting hypotensive drugs (Hoefke \& Kobinger, 1966; Schmitt, 1978; Christersson et al., 1979; Isaac, 1980). In addition to its $\alpha_{2}$-adrenoceptor properties, other effects have been described (Medgett et al., 1978; Ress et al., 1979; Verbeuren et al., 1989; Xiao \& Rand, 1989). Rilmenidine is an nsubstituted oxazoline with some important differences in pharmacological profile to that of clonidine. Rilmenidine has a higher affinity than clonidine for both $\alpha_{2}$ adrenoceptors (Van Zwieten et al., 1986; Verbeuren et al., 1989; 1990) and imidazoline receptors (Bricca et al., 1989; Gomez et al., 1991; Schafer et al., 1995).

Our specific goal was to study the precise mechanisms of action of the three agonists in the peripheral vasculature and their contribution to the antihypertensive properties of these drugs. A hypertensive animal model was used to mimic the target group of these types of drug. 


\section{Materials \& methods}

Experiments were performed in 12 weeks old male specific pathogen-free Spontaneously Hypertensive rats (SHR) of the Okamoto strain (Central Animal Facilities; University of Limburg, Maastricht, The Netherlands). The animals were maintained on 12 hour dark - 12 hour light cycles and had free access to standard lab food and tap water. The rats were killed by stunning and exsanguination and the mesentery and left kidney were isolated. The mesentery was pinned out on a petri dish coated with Silgard (Dow Corning Corp.) and a fourth order resistance-sized side branch of the superior mesenteric artery (diameter approximately $200 \mu \mathrm{m}$ ) was dissected. The kidney was cut in half, one side was pinned on a petri dish and a small intra-lobar artery was isolated.

All arteries were mounted in a myograph (JP Trading Corp., Risskov, Denmark) (Mulvany \& Halpern, 1977; Heesen \& De Mey, 1990) to measure arterial reactivity. In the myograph the vessels were mounted horizontally in an organ chamber between an isometric force transducer (Statham UC3 and Kistler Morse DSC6 for large and small vessels, respectively) and a displacement device using 2 stainless steel wires (diameter $0.04 \mathrm{~mm}$ ). The organ chamber was filled with Krebs-Ringer bicarbonate solution (KRB, 25 and $10 \mathrm{ml}$ for large and small vessels, respectively) that was maintained at $37^{\circ} \mathrm{C}$ and aerated with $95 \% \mathrm{O}_{2}$ and $5 \% \mathrm{CO}_{2}$. The mesenteric and renal resistance arteries were stretched to their individual optimal internal circumference for isometric force development by an active length-tension protocol (Boonen \& De Mey, 1990; 1991; Heesen \& De Mey, 1990; Eerdmans et al., 1991). For this purpose their circumference was increased by $60 \mu \mathrm{m}$ every $5 \mathrm{~min}$, with intermittent exposure to $10 \mu \mathrm{M}$ noradrenaline. This length-tension protocol was continued until maximal contractile responses were obtained (internal diameter: MrA $195 \pm 11 \mu \mathrm{m}, \operatorname{RrA}$ $214 \pm 21 \mu \mathrm{m})$. Part of the experiment was performed in vessels that had been sympathectomized by $10 \mathrm{~min}$ incubation in bicarbonate-free KRB solution ( $\mathrm{pH}$ 4.0 with glutathione) containing $300 \mu \mathrm{g} / \mathrm{ml} \mathrm{6-hydroxydopamine} \mathrm{(Aprigliano} \mathrm{\&}$ Hermsmeyer, 1977). To stimulate the sympathetic nerves in the mesenteric resistance arteries, 2 platinum electrodes connected to a constant current source (amplitude $85 \mathrm{~mA}$ ) were placed longitudinally across the mounted vessel segments and frequency response curves ( 1 to $32 \mathrm{~Hz}$, pulse duration $2 \mathrm{msec}$ ) were constructed (Nilsson, 1985; Eerdmans et al., 1991). In order to unmask potential contractile effects of the agonist, concentration response curves were constructed in vessels that had been made to contract with an intermediate concentration of potassium ( $30 \mathrm{mM} \mathrm{K-KRB}$ solution). 


\section{Drugs and Solutions}

During dissection, mounting and experimentation the preparations were immersed in a Krebs bicarbonate buffered physiological salt solution (KRB). $\mathrm{KRB}$ had the following millimolar composition: $\mathrm{NaCl} 118.3, \mathrm{KCl} 4.7, \mathrm{CaCl}_{2}$ 2.5. $\mathrm{MgSO}_{4} .7 \mathrm{H}_{2} \mathrm{O}$ 1.2, $\mathrm{KH}_{2} \mathrm{PO}_{4}$ 1.2, $\mathrm{NaHCO}_{3}$ 25.0, glucose 11.1. High potassium solution (K-KRB) was prepared by replacing all $\mathrm{NaCl}$ in normal $\mathrm{KRB}$ with an equimolar amount of $\mathrm{KCl}$.

L-isoproterenol hydrochloride, L-phenylephrine hydrochloride, L-prazosin hydrochloride and 6-hydroxydopamine were obtained from Sigma Chemical Co (Saint Louis, Mo USA). Rilmenidine was obtained from Servier (France). Azepexole was obtained from Boehringer Ingelheim and yohimbine hydrochloride from Roussel (France).

\section{Data Analysis}

Contractile responses of isolated blood vessels to agonists were expressed as increases in wall tension (increases in isometric force divided by twice the segment length) and relative to the amplitude of the contraction induced by 125 $\mathrm{mM}$ potassium, $30 \mathrm{mM}$ potassium, $3 \mu \mathrm{M}$ phenylephrine or $10 \mu \mathrm{M}$ noradrenaline. Sensitivity for the contractile effects of agonists or nerve stimulation was determined by interpolation on a least square sigmoidal curve fit of the individual concentration response curves (Inplot, GraphPad, San Diego, $\mathrm{Ca}$, USA). $50 \%$ of the maximal contraction induced by electrical field stimulation was noted as $E_{50}$. Data are shown as mean \pm SEM. Statistical significance of effects and of differences between treatment groups was evaluated by Student's t-test for paired observations, Student's t-test for unpaired observations or analysis of variance followed by Bonferroni's t-test where appropriate (Wallenstein et al., 1980) using commercially available software (Crunch, Software Corp., San Francisco, Ca USA).

\section{Results}

\section{General vessel characteristics.}

The diameters at which mesenteric and renal resistance arteries responded maximally to $125 \mathrm{mM}$ potassium were comparable: $195 \pm 11$ and $214 \pm 21 \mu \mathrm{m}$, respectively. The maximal response to the depolarising stimulus was significantly larger in sympathectomized mesenteric vessels $(2.8 \pm 0.5 \mathrm{~N} / \mathrm{m})$ than in sympathectomized renal vessels $(0.7 \pm 0.2 \mathrm{~N} / \mathrm{m})$. In both types of vessels 30 $\mathrm{mM}$ potassium induced a contraction that averaged $25-35 \%$ of the response to 
$125 \mathrm{mM}$ of the cation.

Phenylephrine induced concentration-dependent contractions in both types of vessels. The sensitivity to the agonist and the relative amplitude of the maximal response, did not differ significantly between mesenteric and renal vessels. During contractions induced by $30 \mathrm{mM}$ potassium, isoproterenol caused mesenteric resistance arteries to relax but failed to affect renal artery contractions.

In intact, but not sympathectomized, mesenteric resistance arteries electrical tield stimulation caused frequency-dependent contractions. Half of maximum responses were obtained between 4 and $8 \mathrm{~Hz}$; the maximum response did not differ significantly from that induced by exogenous noradrenaline.

\section{Effects of $\alpha_{2}$-agonists.}

Azepexole, clonidine and rilmenidine (10 $\mathrm{nM}$ to $10 \mu \mathrm{M})$ did not modify basal tone in mesenteric or renal vessels (data not shown). During contraction induced by $30 \mathrm{mM} \mathrm{K}^{+}$, azepexole and rilmenidine hardly affected contractile reactivity. Clonidine, on the other hand, induced further increases in tone under this condition (table 1, figure 1) an effect which was more pronounced in mesenteric vessels than in renal resistance arteries.

\section{Table 1}

Contractile properties of azepexole, rilmenidine and clonidine in the presence of $30 \mathrm{mM} \mathrm{K} \mathrm{K}^{+} \mathrm{KRB}$, and clonidine in the presence of $30 \mathrm{mM} \mathrm{K}{ }^{+} \mathrm{KRB}$ with prazosin or yohimbine.

\begin{tabular}{|l|l|l|l|l||}
\hline Agonist & Emax $\left(/ 30 \mathrm{mM} \mathrm{K}^{+}\right)$ & $\mathrm{p}$-value * & Emax $\left.(/ 30 \mathrm{mM} \mathrm{K})^{+}\right)$ & $\mathrm{p}$-value * \\
\hline Azepexole $(1 \mu \mathrm{M})$ & $1.24 \pm 0.22$ & $\mathrm{p}=0.0008$ & $0.89 \pm 0.11$ & $\mathrm{p}=0.01$ \\
\hline Rilmenidine $(10 \mu \mathrm{M})$ & $2.10 \pm 0.31$ & $\mathrm{p}=0.007$ & $1.13 \pm 0.12$ & $\mathrm{p}=0.01$ \\
\hline Clonidine $(10 \mu \mathrm{M})$ & $4.54 \pm 0.83$ & & $2.20 \pm 0.26$ & \\
\hline Clonidine+Yoh & $3.23 \pm 1.02$ & $\mathrm{NS}$ & $1.59 \pm 0.18$ & $\mathrm{p}=0.044$ \\
\hline Clonidine + Praz & $1.39 \pm 0.20$ & $\mathrm{p}=0.0024$ & $1.29 \pm 0.12$ & $\mathrm{p}=0.007$ \\
\hline
\end{tabular}

Maximal contractile properties of azepexole, rilmenidine or clonidine in mesenteric (MrA) and renal resistance arteries ( $\mathrm{RrA}$ ) precontracted with $30 \mathrm{mM} \mathrm{K} \mathrm{K}^{+}$Krebs solution. In addition, maximal contractile properties of $30 \mu \mathrm{M}$ clonidine are given in the presence of $1 \mu \mathrm{M}$ yohimbine (Yoh) or $1 \mu \mathrm{M}$ prazosin (Praz). Data are mean \pm SEM and are related to the contractile properties of $30 \mathrm{mM} \mathrm{K}$ * Krebs solution. ${ }^{*} \mathrm{p}$-value: unpaired t-test comparing agonist with clonidine. NS: $p>0.05$ 

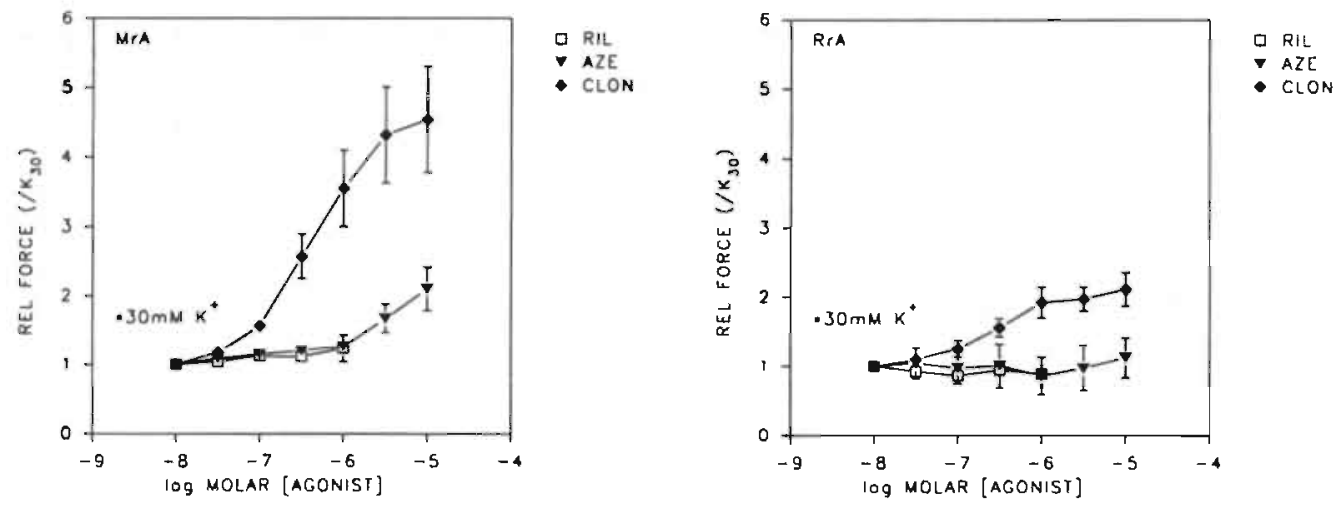

Figure 1

Effects of azepexole, clonidine and rilmenidine in mesenteric and renal resistance aneries made to constrict with potassium. Concentration response curves for azepexole (AZE), clonidine (CLON) and rilmenidine (RIL) were constructed in mesenteric (MrA) and renal resistance arteries (RrA) precontracted with a $30 \mathrm{mM}$ potassium KRB solution. Data are shown as mean $\pm \mathrm{SEM}$.
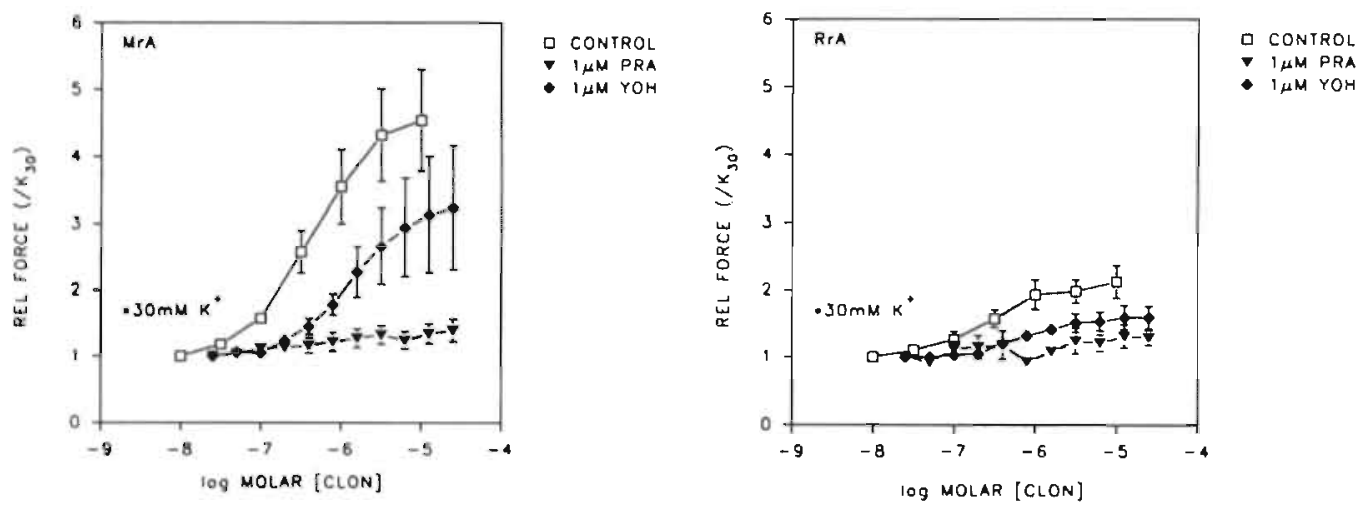

Figure 2

Effects of clonidine in the absence or presence of prazosin and yohimbine in mesenteric and renal resistance arteries made to constrict with potassium. Concentration response curves for clonidine (CL.ON) were constructed in the absence or presence of $1 \mu \mathrm{M}$ prazosin or $1 \mu \mathrm{M}$ yohimbine in mesenteric and renal resistance arteries precontracted with $30 \mathrm{mM} \mathrm{K} \mathbf{K}^{+}$. Data are shown as mean $\pm S E M$. 
Yohimbine at $1 \mu \mathrm{M}$ reduced this potentiating action of clonidine, while $1 \mu \mathrm{M}$ prazosin prevented the effect of even $30 \mu \mathrm{M}$ clonidine (figure 2).

During contractions induced by $3 \mu \mathrm{M}$ phenylephrine, neither azepexole nor rilmenidine $(10 \mathrm{nM}$ to $10 \mu \mathrm{M})$ influenced mesenteric or renal vessels (data not shown). Also, azepexole $(1 \mu \mathrm{M})$ nor rilmenidine $(1 \mu \mathrm{M})$ modified concentration response curves for phenylephrine in these vessels (figure 4). Clonidine, on the other hand, reduced the responses to $\alpha_{1}$-agonist in both types of vessel (figure 3). Mesenteric vessels were more sensitive to this relaxing effect than renal vessels; maximal relaxation could, however, be obtained in both. Clonidine furthermore shifted concentration-response curves for phenylephrine in an apparently competitive manner (table 2 , figure 4 ). In this respect too, renal vessels were less sensitive to clonidine than mesenteric vessels.
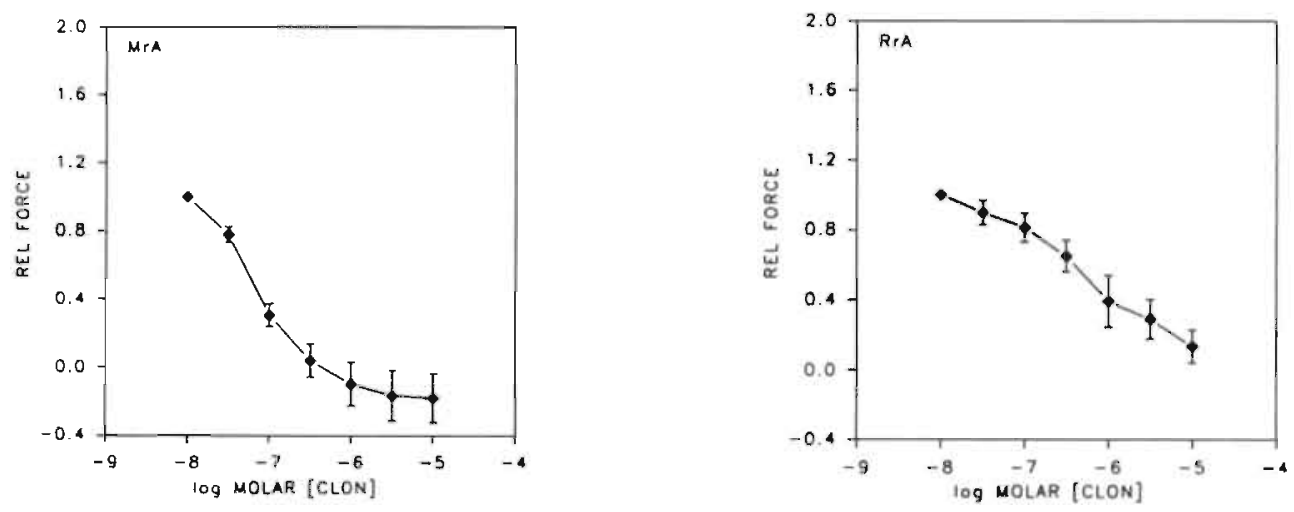

Figure 3

Concentration response curves for clonidine in mesenteric and renal resistance arteries precontracted with $3 \mu \mathrm{M}$ phenylephrine. Concentration response curves for clonidine (CLON) were constructed in mesenteric (MrA) and renal resistance arteries (RrA) precontracted with $3 \mu \mathrm{M}$ phenylephrine (PHE).

Data are shown as mean \pm SEM (related to the maximal response to $3 \mu \mathrm{M}$ PHE). 

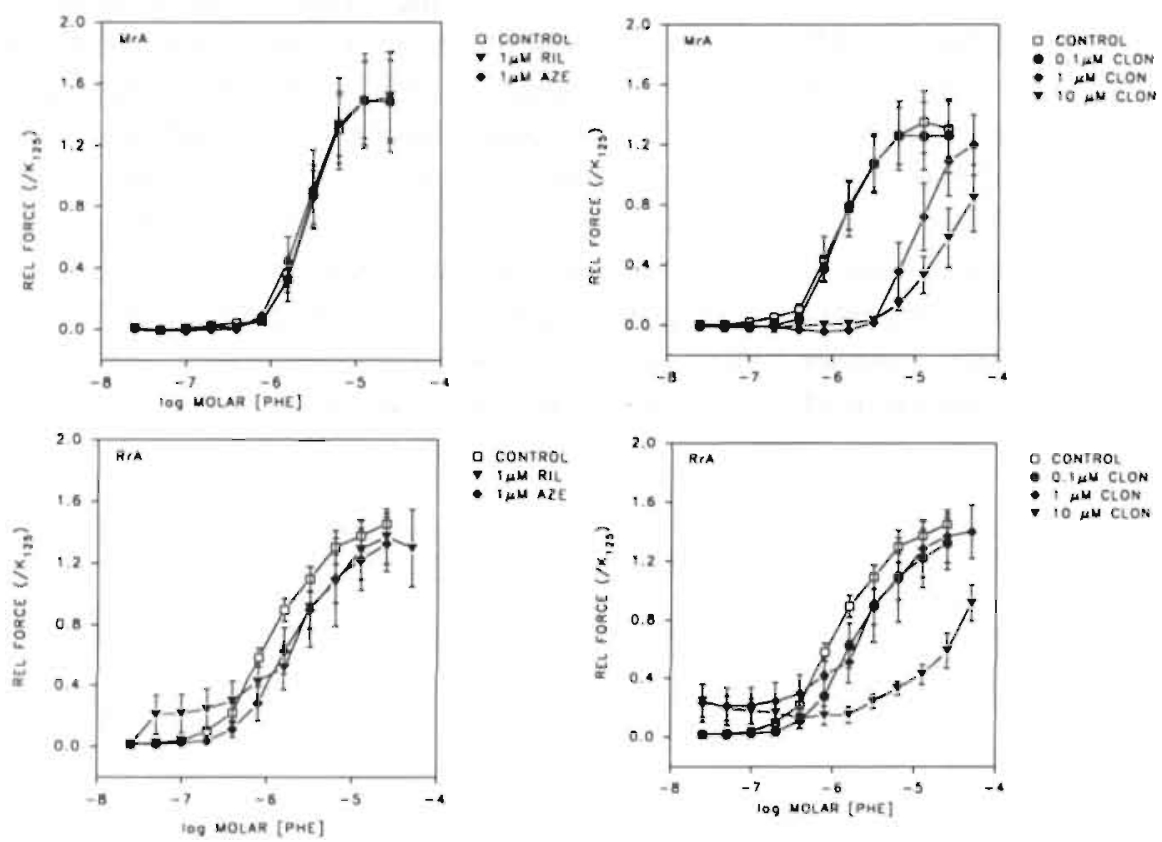

- CONTROL - i MM RJL

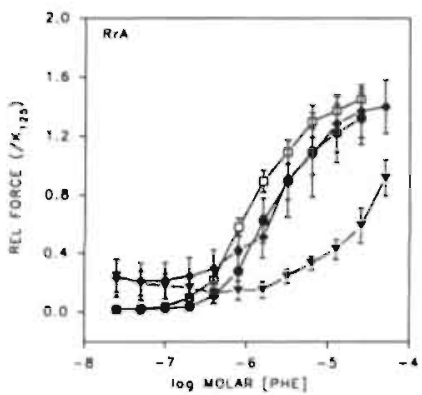

D. Contrial

e O lign CLON

- incLon

\section{Figure 4}

Effects of azepexole, clonidine and rilmenidine in concentration response curves for phenylephrine inmesenteric and renal resistance arteries. Concentration response curves for phenylephrine (PHE) were constructed in the presence of $1 \mu \mathrm{M}$ rilmenidine (RIL), $1 \mu \mathrm{M}$ azepexole (AZE) (top left MrA, bottom left $\operatorname{RrA}$ ) and increasing concentrations of clonidine (CLON) (top right MrA, bottom right $\operatorname{RrA}$ ). Data are shown as mean \pm SEM and related to the contractile response to K-KRB solution. 
Table 2

Contractile properties of mesenteric and renal resistance arteries of phenylephrine in the presence of increasing clonidine concentrations.

\begin{tabular}{|l|l|l|l|l||}
\hline \multicolumn{2}{l}{ Mra } & RrA \\
\hline Phenylephrine & $\begin{array}{l}\text { Emax }(/ \mathrm{K}-\mathrm{KRB}) \\
\mathrm{pD}_{2}\end{array}$ & $\mathrm{p}$-value * & $\begin{array}{l}\text { Emax }(/ \mathrm{K}-\mathrm{KRB}) \\
\mathrm{pD}_{2}\end{array}$ & $\mathrm{p}$-value * \\
\hline $\begin{array}{l}1.30 \pm 0.18 \\
\mathrm{pD}_{2}\end{array}$ & $5.77 \pm 0.12$ & & $\begin{array}{l}1.45 \pm 0.07 \\
5.88 \pm 0.07\end{array}$ & \\
\hline$+0.1 \mu \mathrm{M}$ clonidine & $1.26 \pm 0.24$ & $\mathrm{NS}$ & $1.32 \pm 0.18$ & $\mathrm{NS}$ \\
$\mathrm{pD}_{2}$ & $5.87 \pm 0.07$ & $\mathrm{NS}$ & $5.62 \pm 0.13$ & $\mathrm{p}=0.028$ \\
\hline$+1 \mu \mathrm{M}$ clonidine & $1.20 \pm 0.20$ & $\mathrm{NS}$ & $1.40 \pm 0.18$ & $\mathrm{NS}$ \\
$\mathrm{pD}_{2}$ & $4.11 \pm 0.44$ & $\mathrm{p}<0.001$ & $5.40 \pm 0.21$ & $\mathrm{p}=0.009$ \\
\hline$+10 \mu \mathrm{M}$ clonidine & $0.84 \pm 0.22$ & $\mathrm{NS}$ & $0.91 \pm 0.12$ & $\mathrm{NS}$ \\
$\mathrm{pD}_{2}$ & $3.86 \pm 0.31$ & $\mathrm{p}<0.001$ & $4.48 \pm 0.99$ & $\mathrm{p}=0.025$ \\
\hline
\end{tabular}

The arteries precontracted with $3 \mu \mathrm{M}$ phenylephrine. Maximal contractile responses of phenylephrine (PHE) in mesenteric and renal resistance arteries were obtained in the absence or presence of increasing clonidine concentrations. Furthermore $\mathrm{pD}_{2}$ values for $\mathrm{PHE}$ were calculated from concentration response curves with or without clonidine. Values are mean $\pm S E M$ and related to the maximal contractile responses to $\mathrm{K}-\mathrm{KRB}$ solution. ${ }^{*} \mathrm{p}$-values are calculated using an unpaired t-test comparing PHE (control) with PHE + clonidine. NS: $p>0.05$

Relaxing effects of isoproterenol in mesenteric resistance arteries were not significantly altered by the presence of $1 \mu \mathrm{M}$ azepexole, clonidine or rilmenidine (figure 5).

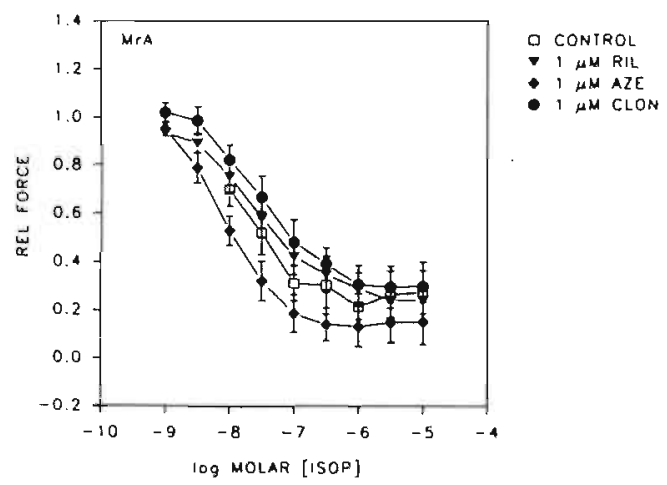

\section{Figure 5}

Effects of azepexole, clonidine and rilmenidine on concentration response curves for isoproterenol in mesenteric resistance arteries.

Concentration response curves for isoproterenol (ISOP) were constructed in mesenteric resistance arteries precontracted with $30 \mathrm{mM} \mathrm{K}-\mathrm{KRB}$ in the absence $\left(\mathrm{pD}_{2}=7.68 \pm 0.36\right)$ and presence of 1 $\mu \mathrm{M}$ azepexole (AZE, $\mathrm{pD}_{2}=7.68 \pm 0.36$ ), I $\mu \mathrm{M}$ clonidine (CLON, $\mathrm{pD}_{2}=7.56 \pm 0.09$ ) or $1 \mu \mathrm{M}$ rilmenidine ( $\mathrm{RIL}, \mathrm{pD}_{2}=7.67 \pm 0.20$ ).

All experiments were performed in the presence of $1 \mu \mathrm{M}$ prazosin to rule out possible $\alpha_{1}$ adrenergic properties of the evaluated agonists. Data are shown as mean \pm SEM and related to the contractile response to $30 \mathrm{mM} \mathrm{K-KRB}$ solution. 
Figure 6 summarizes the effects of azepexole and rilmenidine on responses of mesenteric resistance arteries to adrenergic nerve stimulation. Clonidine was not evaluated in this respect because it was noted that the agent interfered with postjunctional adrenergic responses. At $10 \mu \mathrm{M}$, rilmenidine but not azepexole significantly increased the sensitivity of the vessels to nerve stimulation without modifying the maximal response. For the sake of comparison, effects of $3 \mu \mathrm{M}$ cocaine and $1 \mu \mathrm{M}$ yohimbine were also evaluated. The former slightly increased the sensitivity to nerve stimulation and the latter caused a further elevation of the responses to low frequency stimulation (figure 6).
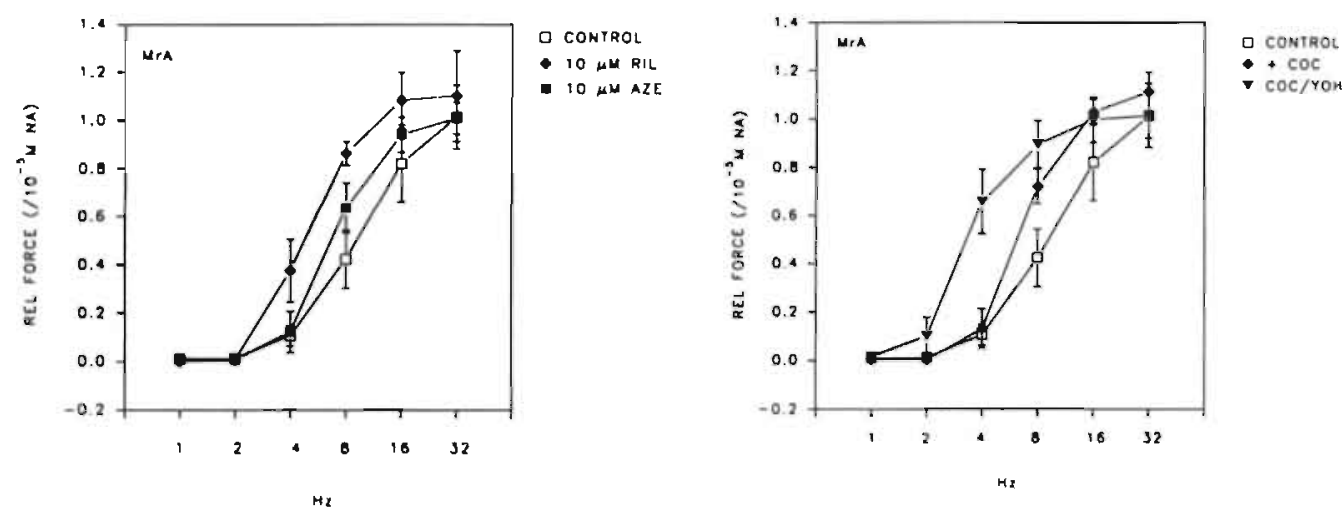

Figure 6

Effects of azepexole and rilmenidine on frequency response curves in mesenteric resistance arteries in the presence of cocaine or yohimbine. Frequency response curves were constructed in mesenteric resistance arteries in the presence of rilmenidine (RIL) or azepexole (AZE) (right-hand figure). Furthermore, frequency response curves were constructed (different groups of animals) in the absence or presence of $3 \mu \mathrm{M}$ cocaine (COC) and $3 \mu \mathrm{M}$ cocaine $+1 \mu \mathrm{M}$ yohimbine (YOH) (left figure). Data are shown as mean $\pm \mathrm{SEM}$ and related to the response to $10 \mu \mathrm{M}$ noradrenaline. Significant differences in $\mathrm{EF}_{50}$ were found comparing control with rilmenidine $(10.8 \pm 2.4$ versus $5.33 \pm 0.8 \mathrm{~Hz}, p=0.034)$. Frequency response curves in the absence or presence of cocaine showed significant differences $\left(E_{50}\right)$ in control versus cocaine/yohimbine $(8.3 \pm 0.7$ versus $3.7 \pm 0.5 \mathrm{~Hz}, p=0.0001)$ and cocaine versus cocaine/yohimbine $(6.7 \pm 0.9$ versus $3.7 \pm 0.5 \mathrm{~Hz}, \mathrm{p}=0.005)$. 


\section{Discussion}

In this study we investigated the acute effects of $\alpha_{2}$-adrenoceptor agonists on mesenteric and renal resistance arteries in adult spontaneously hypertensive rats. Observations differed considerably for azepexole, clonidine and rilmenidine. The effects of postsynaptic $\alpha_{2}$-adrenoceptor stimulation in resting arteries of all three agents were minor. Arteries in precontracted state, however, were very sensitive to clonidine and to some extent also to azepexole. The contractile effects of cionidine in precontracted arteries could be reduced completely by $\alpha_{1}$-adrenergic blockade (prazosin) but not by $\alpha_{2}$-adrenergic blockade (yohimbine). Only clonidine reduced the contractile effects of phenylephrine. The same kind of observations has been described for rabbit pulmonary arteries (Lee, T.S. \& Hou, 1995). Clonidine caused vasoconstriction in resting and $\mathrm{KCl}$ precontracted pulmonary arteries and dose-dependent vasodilation in arteries precontracted with noradrenaline. This indicates that the so called $\alpha_{2}$-adrenoceptor agonist clonidine has additional partial $\alpha_{1}$-adrenoceptor agonist properties.

The $\alpha_{2}$-adrenoceptor effects of the drugs studied could be caused by a post- or prejunctional effect. With respect to the postjunctional effect, it has been documented that $\alpha_{2}$-adrenoceptor stimulation can lead to inhibition of adenylate cyclase (Pettinger et al., 1987; Limbird, 1988). The same adenylate cyclase plays a role in the $\beta$-adrenoceptor stimulation cascade (Gilman, 1987). In other words, $\alpha_{2}$-adrenoceptor stimulation can lead to decreased $\beta$-adrenoceptor agonist responses. Renal resistance arteries lack functional $\beta$-adrenoceptors, as was described earlier by our group (Heesen et al., 1989; Heesen \& De Mey, 1990; Eerdmans et al., 1991) and were not investigated. The relaxing responses to isoproterenol in mesenteric resistance arteries were not altered by $\alpha_{2}$-adrenergic stimulation. The lack of effect of the three drugs we studied on resting tone as well as on isoproterenol induced relaxation suggests that mesenteric resistance arteries do not contain functional $\alpha_{2}$-adrenoceptors.

Presynaptic $\alpha_{2}$-adrenoceptor mediated inhibition of noradrenaline release by postganglionic sympathetic nerves has been described as one of the mechanisms of $\alpha_{2}$-adrenoceptor agonists, resulting in a decreased sympathetic tone (Szabo \& Urban, 1995). In our study no changes in nerve stimulation (noradrenaline release) were found in the presence of azepexole. However, an increased $E_{50}$ was found after rilmenidine. Clonidine was not evaluated, since its $\alpha_{1}$ adrenoceptor properties could bias the results. The lack of effects of azepexole does not necessarily imply the absence of functional presynaptic $\alpha_{2}$ adrenoceptors; the increased nerve stimulation response in the presence of 
yohimbine supports their existence. It is possible that most of the presynaptic $\alpha_{2}$ adrenoceptors are already occupied by endogenous noradrenaline. The maximal occupation of pre-synaptic $\alpha_{2}$-adrenoceptors implies that azepexole or rilmenidine cannot inhibit noradrenaline release any further. Similar results were obtained by Rump et al. (Rump et al., 1991) in a study in which they investigated human and rabbit renal arteries (strips). In their study, clonidine inhibited stimulation induced noradrenaline release only at low frequency ( $2 \mathrm{~Hz}$ ), whereas at higher frequency no inhibition was found either. We actually found an unexpectedly increased sensitivity of nerve stimulation in the presence of rilmenidine. A possible explanation for this finding can be found in the work of Burnstock et al. (Burnstock, 1990; Mione et al., 1990; Friedman \& Duckles, 1995) who described the possible existence of $\alpha_{2}$-adrenoceptors on peptidergic nerves. Stimulation of those receptors inhibits the release of peptidergic transmitters like calcitonin gene related peptide (CGRP). These peptidergic nerves are present in the mesenteric resistance artery and inhibition leads to increased nerve stimulation, as has already been described by our group (Eerdmans et al., 1991).

Most studies over the past two decades suggest that $\alpha_{2}$-adrenoceptor agonists primarily reduce blood pressure by central inhibition of the sympathetic activity (Zwieten van, 1975; Kobinger, 1978; Van Zwieten et al., 1986). The lack of pre- and postjunction $\alpha_{2}$-adrenoceptor activity of the drugs used in our study in resistance arteries confirms the dominant role of central mechanisms. In addition, our study shows that clonidine must be classified as a partial $\alpha_{1}$ adrenoceptor agonist. The peripheral vascular effect of this agent may contribute to its antihypertensive properties. 


\section{References}

Angus J.A., Broughton A. \& Mulvany M.J. (1988). Role of $\alpha$-adrenoceptors in constrictor responses of rat, guinea-pig and rabbit small arteries to neural activation, J. Physiol., 403, 495-510.

Aprigliano O. \& Hermsmeyer K. (1977). Trophic influences of the sympatheric nervous system on the rat portal vein, Circ. Res., 41, 198-206.

Armstrong L.M. \& Boura A.L.A. (1973). Effects of clonidine and guanethidine on peripheral sympathetic nerve function in the pithed rat, Br. J. Pharmacol., 47, 850-852.

Blochl-Daum B., Korn A., Wolzt M., Schmidt E. \& Eichler H.G. (1991). In vivo studies on alpha-adrenergic receptor subtypes in human veins, Naunyn. Schmiedeberg's. Arch. Pharmacol., 344, 302-307.

Boonen H.C.M. \& De Mey J.G.R. (1990). Increased calcium sensitivity in isolated resistance arteries from spontaneously hypertensive rats: effects of dihydropyridines, Eur. $J$. Pharmacol., 179, 403-412.

Boonen H.C.M. \& De Mey J.G.R. (1991). Effects of a phorbol ester and staurosporine on electro- and pharmacomechanical coupling in a resistance artery, Eur. J. Pharmacol, 202, 25-32.

Bousquet P. \& Feldman J. (1987). The blood pressure effects of alpha-adrenoceptor antagonists injected in the medullary site of action of clonidine: The nucleus reticularis lateralis, Life. Sci., 40, 1045-1052.

Bousquet P., Feldman J. \& Schwartz J. (1984). Central cardiovascular effects of alpha adrenergic drugs: differences between catecholamins and imidazolines, J. Pharmacol. Exp. Therap., 230, 232-236.

Bousquet P., Feldman J., Tibirica E., et al. (1989). New concepts on the central regulation of blood pressure. $\alpha_{2}$-adrenoceptors and imidazoline receptors. Am. J. Med., 87, 10-13S.

Bricca G., Dontenwill M. \& Molines A. (1989). Rilmenidine selectivity for imidazoline receptors in human brain, Eur. J. Pharmacol., 163, 373-377.

Burnstock G. (1990). Local mechanisms of blood flow control by perivascular nerves and endothelium, J. Hypertension., 8, S95-S106.

Christersson S., Frisk-Holmberg M. \& Paalzow L. (1979). Steady state plasma concentration of clonidine and its relation to the effects on blood pressure in nomotensive and hypertensive rats, J. Pharmacol., 31, 418-419.

Coupry I. \& Lachaud V. (1989). Different affinities of $\alpha_{2}$ agonists for imidazoline and $\alpha_{2}$ adrenergic receptors, Am. J. Hypertension., 2, 468-470.

Daly C.J., McGrath J.C. \& Wilson V.G. (1988). An examination of the postjunctional $\alpha$ adrenoceptor subtypes for (-)-noradrenaline in several isolated blood vessels from the rabbit, Br. J. Pharmacol., 95, 473-484.

De Mey J.G.R. \& Vanhoutte P.M. (1981). Uneven distribution of postjunctional $\alpha_{1^{-}}$and $\alpha_{2}$ like adrenoceptors in canine arterial and venous smooth muscle, Circ. Res., 48, 875-884.

Drew G.W. \& Whiting S.B. (1979). Evidence for two distinct types of postsynapticadrenoceptors in vascular smooth muscle in vivo, Br. J. Pharmacol., 67, 207-215.

Eerdmans P.H.A., Heesen B.J., Struijker Boudier H.A.J. \& De Mey J.G.R., 1991, Sympathetic heterogeneity in mesenteric and renal resistance arteries, in: Resistance Arteries. Structure and Function, Mulvany M.J., Aalkjaer C., Heagerty A.M., Nyborg N.C.B. \& Strandgaard S., Excerpta Medica, Amsterdam, The Netherlands, 156-159. 
Elhawary A.M., Pettinger W.A. \& Wolff D.W. (1992). Subtype-selective $\alpha_{1}$ adrenoceptor alkylation in the rat kidney and its effect on the vascular pressor response, J. Pharmacol. Exp. Therap., 260, 709-713.

Ernsberger P., Meeley M.P., Mann J.J. \& Reis D.J. (1987). Clonidine binds to imidazole binding sites as well as $\alpha 2$-adrenergic receptors in the ventrolateral medulla, Eur. $J$. Pharmacol., 134, 1-13

Friedman D.J. \& Duckles S.P. (1995). Prejunctional interaction of $\alpha_{2}$-adrenoceptors and D2 dopamine receptors on perivascular sympathetic nerves, J. Auton. Pharmacol., 15, 27-35.

Gilman A.G. (1987). G proteins: transducers of receptor-generated signals, Ann. Rev. Biochem., 56, 615-649.

Gomez R.E., Ernsberger P., Feinland G. \& Reis D.J. (1991). Rilmenidine lowers blood pressure via imidazoline receptors in the brain-stem $\mathrm{Cl}$ area, Eur. J. Pharmacol., 195, 181191.

Hauser W., Gutting J., Nguyen T. \& Dominiak P. (1995). Influence of imidazolines on catecholamine release in pithed spontaneously hypertensive rats, Ann. N.Y. Acad. Sci., 763, 573-579.

Head G.A. \& Burke S. (1991). Importance of central noradrenergic and serotonergic pathways in the cardiovascular actions of rilmenidine and clonidine, J. Cardiovasc. Pharmacol., 18, 819-826.

Head G.A., Korner P.I., Lewis S.L. \& Badoer E. (1983). Contribution of noradrenergic and serotonergic neurons to the circulatory effects of centrally acting clonidine and $\alpha$ methyldopa in rabbits, J. Cardiovasc. Pharmacol., 5, 945-953.

Heesen B.J. \& De Mey J.G.R. (1990). Effects of cyclic AMP-affecting agents on contractile reactivity of isolated mesenteric and renal resistance arteries of the rat, $\mathrm{Br}$. J. Pharmacol., $101,859-864$.

Heesen B.J., Struyker-Boudier H.A.J. \& De Mey J.G.R. (1989). Absence of beta-adrenergic relaxing responses in isolated renal resistance arteries, The Pharmacologist, 31, 170.

Hoefke W. \& Kobinger W. (1966). Pharmakologischen wirkungen des 2-(2,6-Dichlorophenylamino)-2-imidazolin hydrochlorids, einer neuen antihypertensiver substantz, Arzneim. Forsch., 16, 1038-1050.

Isaac L. (1980). Clonidine in the central nervous system: Site and mechanism of hypotensive action, J. Cardiovasc. Pharmacol., 2, S5-S19.

Kobinger W. (1978). Central alpha-adrenergic systems as targets for hypotensive drugs, Rev Physiol Biochem Pharnacol. 81, 40-100.

Langer S.Z. (1974). Presynaptic regulation of catecholamine release, Biochem. Pharmacol., $23,1793-1800$.

Langer S.Z. (1977). Presynaptic receptors and their role in the regulation of transmitter release, Br. J. Pharmacol., 60, 481-497.

Lee R.M.K.W. \& Smeda J.S. (1985). Primary versus secondary structural changes of the blood vessels in hypertension, Can. J. Physiol. Pharmacol., 63, 392-401.

Lee R.M.K.W., Triggle C.R., Cheung D.W.T. \& Coughlin M.D. (1987). Structural and functional consequences of neonatal sympathectomy on the blood vessels of spontaneously hypertensive rats, Hypertension., 10, 328-338.

Lee T.S. \& Hou X. (1995). Dual effect of clonidine on isolated rabbit pulmonary arteries, Chest., 107, 793-797. 
Limbird L.E. (1988). Receptors linked to inhibition of adenylate-cyclase: additional signaling mechanisms, Faseb. J., 2, 2686-2695.

Mangiarua E.I. \& Lee R.M.K.W. (1992). Morphometric study of cerebral arteries from spontaneously hypertensive stroke-prone hypertensive rats, J. Hypertension., 10, 11831190.

Medgett I.C., McCulloch M.W. \& Rand M.J. (1978). Partial agonist action of clonidine on prejunctional and postjunctional $\alpha$-adrenoceptors, Naunyn. Schmiedeberg's. Arch. Pharmacol., 304, 215-221.

Messing M.W.J. (1992). Antihypertensive drugs and the microcirculation, UPM, ISBN 90 9005095 7, 64-72.

Mione M.C., Ralevic V. \& Burnstock G. (1990). Peptides and vasomotor mechanisms, Pharmac. Ther., 46, 429-468.

Mulvany M.J. \& Halpern W. (1977). Contractile properties of small arterial resistance vessels in spontaneously hypertensive and normotensive rats, Circ. Res., 41, 19-26.

Nielsen H., Mortensen F.V. \& Mulvany M.J. (1990). Responses to noradrenaline in human subcutaneous resistance arteries are mediated by both $\alpha_{1}$ and $\alpha_{2}$-adrenoceptors, $\mathrm{Br} . \mathrm{J}$. Pharmacol., 99, 31-34.

Nilsson H. (1985). Adrenergic nervous control of resistance and capacitance vessels, Acta. Physiol. Scand., 124(suppl 541), 1-34.

Nyborg C. B., Korsgaard N. \& Mulvany M. (1986). Neonatal sympathectomy of normotensive wistar-kyoto and spontaneously hypertensive rats with 6-hydroxydopamine : effects on resistance vessel structure and sensitivity to calcium, J. Hypertension., 4, 455-461.

Pettinger W.A., Umemura, Smyth D.D. \& Jeffries W.B. (1987). Renal $\alpha_{2}$-adrenoceptors and the adenylate cyclase-cAMP system: biochemical and physiological interactions, Am. J. Physiol., 252, F199-F208.

Ress R.J., Field F.P., Lockley O.E. \& Fregly M.J. (1979). Effect of clonidine on the contractile responsiveness of aortic smooth muscle to norepinephrine, pharmacol., 18, 149154.

Rump L.C., Ruff G., Wolk V. \& Schollmeyer P. (1991). $\alpha_{2}$-adrenoceptor activation inhibits noradrenaline release in human and rabbit isolated renal arteries, Eur. J. Pharmacol,, 196. 277-283.

Schafer S.G., Kaan E.C., Christen M.O., Low-Kroger A., Mest H.J. \& Molderings G.J. (1995). Why imidazoline receptor modulator in the treatment of hypertension, Ann. N.Y. Acad. Sci., 763, 659-672

Schmitt H. (1978). The pharmacology of clonidine and related products, Handbook of experimental pharmacology, vol 39, Springer-Verlag, New York, 299-310.

Schmitz J.M., Graham R.M., Sagalowsky A. \& Pettinger W.A. (1981). Renal $\alpha_{1}$ and $\alpha_{2}$ adrenergic receptors : biochemical and pharmacological correlations, J. Pharmacol. Exp. Therap., 219, 400-407.

Schwietert H.R., Mathy M.J., Wilhelm D., Wilfert B., Pfaffendorf M. \& van Zwieten P.A. (1992). $\alpha_{1}$-adrenoceptor-mediated $\mathrm{Ca}^{2+}$-entry from the extracellular fluid and $\mathrm{Ca}^{2+}$-release from intracellular stores: no role for $\alpha_{1 \mathrm{~A}, \mathrm{~B}^{-}}$adrenoceptor subtypes in the pithed rat, J. Auton. Pharmacol., 12, 125-136. 
Shi A.G., Ahmad S., Kwan C.Y. \& Daniel E.E. (1990). Alpha-adrenoceptors in dog mesenteric vessels subcellular distribution and number of $[3 \mathrm{H}]$ prazosin and $[3 \mathrm{H}]$ rauwolscine binding sites, J. Cardiovasc. Pharmacol., 15, 515-526.

Szabo B. \& Urban R. (1995). Mechanism of sympathoinhibition by imidazolines, Ann. N.Y. Acad. Sci., 763, 552-565.

Vanhoutte P.M. \& Miller V.M. (1989). $\alpha_{2}$-adrenoceptors and endothelium-derived relaxing factor, Am. J. Med., 87, 1S-5S

Van Zwieten P.A., Thoolen M.J.M.C., Jonkman F.A.M., Wilffert B., De Jonge A. \& Timmermans P.B.M.W.M. (1986). Central and peripheral effects of S 3341 [(Ndicyclopropylmethyl)-amino-2-oxazoline] in animal models, Arch. Int. Pharmacodyn. Ther., 279, 130-149.

Verbeuren T.J., Koening-Berard E., Jordaens F.H., Van Hoydonck A.E., Verrelst J., Zonnekeyn L.L. \& Herman A.G. (1989). Interaction of rilmenidine and clonidine with preand postjunctional alpha-adrenoceptors in rat and rabbit blood vessels and in rat kidneys, Arch. Int. Pharmacodyn. Ther., 300, 114-139.

Verbeuren T.J., Tuan Dinh Xuan A., Koening-Berard E. \& Vitou P. (1990). Rilmenidine, Cardiovasc. Drug Rev., 8, 56-70.

Wallenstein S., Zucker C.L. \& Fleiss J.L. (1980). Some statistical methods useful in circulation research, Circ. Res., 47, 1-9.

Xiao X.H. \& Rand M.J. (1989). $\alpha_{2}$-adrenoceptor agonists enhance responses to certain other vasoconstrictor agonists in the rat tail artery, Br. J. Pharmacol., 96, 539-546.

Zwieten van P.A. (1975). Antihypertensive drugs with a central action, Prog. Pharmacol., 1, $1-63$. 
Regionally selective alterations of arterial structure after 4-week treatment of juvenile SHR with prazosin, rilmenidine and azepexole.

P.H.A. Eerdmans, C.M. Eerdmans-Tijssen, H.A.M.D. van der Heijden, G. Fazzi and J.G.R. De Mey 



\section{Abstract}

We evaluated effects of long-term treatment with $0.1 \mathrm{mg} / \mathrm{kg} /$ day prazosin (PRA), $6 \mathrm{mg} / \mathrm{kg} /$ day rilmenidine (RIL) or $60 \mathrm{mg} / \mathrm{kg} /$ day azepexole (AZE) on arteries of juvenile Spontaneously Hypertensive Rats (SHR). 8 weeks old male SHR were continuously infused with solvent or drug for 4 weeks. AZE and RIL transiently lowered blood pressure (BP) and heart rate (HR) and caused a persistent reduction of plasma noradrenaline levels ([NA]pl). PRA did not modify BP, HR or [NA]pl. At termination of the treatment, structural parameters and maximal contractile responses were recorded in thoracic aorta (AO), superior mesenteric artery (SMA) and in mesenteric and renal resistance arteries (MrA, RrA). PRA treatment resulted in a significant reduction of media cross sectional area (CSAm) in AO but not in the other vessels. AZE treatment caused a significant increase in CSAm in MrA, but not in the other vessels. RIL treatment did not modify CSAm in either type of vessel. Lumen diameter of resistance arteries was not modified by either treatment. Maximal active wall tension and maximal active wall stress in response to potassium and noradrenaline were not significantly modified by PRA or AZE treatment in either type of vessel. RIL treatment, however, resulted in a significant increase and decrease of active wall tension and stress in $\mathrm{AO}$ and $\mathrm{MrA}$, respectively. These observations indicate that long-term administration of PRA, AZE or RIL leads to regionally selective changes in arterial structure and function. This regionality and the type of changes differ for the three drugs, suggesting that effects of AZE are not solely due to reduced peripheral $\alpha_{1}$-adrenergic input and those of RIL are not restricted to consequences of chronic $\alpha_{2}$-adrenoceptor stimulation. Some of the long-term arterial effects which we observed may contribute to the limited anti-hypertensive potential of the these drugs in the SHR.

\section{Introduction}

Experimental evidence in vivo and in vitro suggests that sympathetic nerves plays an important role in the development of essential hypertension. Sympatholytic interventions in young spontaneously hypertensive rats prevent the development of hypertension and arterial structural changes (Lee \& Smeda, 1985; Nyborg et al., 1986; Lee et al., 1987; Mangiarua \& Lee, 1992). Sympathetic nerves could play a trophic role in experimental models of secondary hypertension (Bevan et al., 1976; Lee \& Smeda, 1985). In cultured 
smooth muscle cells, noradrenaline stimulates cell proliferation and synthesis of enzymes that play a key role in DNA-, RNA- and protein synthesis (Kanbe et al., 1983; Mano et al., 1986). Drugs influencing sympathetic activity, including $\alpha_{1}$-adrenoceptor antagonists or $\alpha_{2}$-adrenoceptor agonists, have been used as antihypertensive agents. $\alpha_{2}$-Adrenoceptor agonists lower elevated blood pressure primarily through an action in the central nervous system that results in reduced sympathetic vasomotor tone (Zwieten van, 1975; Kobinger, 1978; Van Zwieten et al., 1986). Whether they can alter structural properties of resistance arteries and whether this is due to the central action of the compounds or to their direct peripheral effects is largely unknown. In recent years it has furthermore become clear that certain $\alpha_{2}$-agonists may in addition occupy imidazoline-binding sites in the CNS and that this contributes to their blood pressure lowering effect (Bousquet et al., 1984; 1989; Coupry \& Lachaud, 1989; Verbeuren et al., 1990). In SHR the antihypertensive action of either type of drug is only modest during long-term treatment (Eerdmans et al., 1991b). The mechanisms that prevent the antihypertensive effects are not entirely clear. There may be resistance of structural vascular changes to the treatment, or development of adverse functional and structural alterations. Furthermore, adaptive changes in receptors in response to chronic stimulation or blockade may develop. Finally, adaptations of other blood pressure regulating systems may play an important role in preventing the antihypertensive effect of drugs acting on sympathetic activity. In the present study we evaluated these possibilities.

We determined structural parameters and maximal contractile responses of arteries from SHR that had been treated between the ages of 8 to 12 weeks with either prazosin ( a prototype antagonist of $\alpha_{1}$-adrenoceptors)(Brogden, 1977), azepexole (BHT-933, an $\alpha_{2}$-adrenoceptor agonist) or rilmenidine (an $\alpha_{2}$ adrenoceptor agonist that also displays a high affinity for imidazoline-binding sites) (Louis et al., 1988; Galitzky et al., 1989; Verbeuren et al., 1990). Treated animals were compared with control animals that has been infused $(120 \mu \mathrm{l} /$ day $)$ with solvent $\left(\mathrm{H}_{2} \mathrm{O}\right)$. The experiments were performed in juvenile SHR in an attempt to prevent the structural vascular changes that occur during development of hypertension.

The purpose of the present study was to investigate the effect of a decreased sympathetic tone on the structure and contractile properties of different types of arteries, because in hypertension primary and secondary vascular changes are not uniformly distributed over different vascular beds and over vessels of different caliber (Lee \& Smeda, 1985; Boonen et al., 1990; Eerdmans et al., 1991a). The thoracic aorta, the superior mesenteric artery, mesenteric 
resistance arteries and renal resistance arteries were chosen because of differences with respect to innervation density (Nilsson et al., 1986; Eerdmans et al., 1991a), responsiveness to adrenergic stimuli (De Mey \& Vanhoutte, $1981 ; 1982$ ) and presence of $\alpha_{1}$-adrenoceptor subtypes (Jackson et al., 1992; Feng et al., 1993).

\section{Materials \& methods}

\section{Animals \& treatment}

Experiments were performed in 8 weeks old male specific pathogen-free Spontaneously Hypertensive rats (SHR) of the Okamoto strain (Central Animal Facilities; University of Limburg, Maastricht, The Netherlands). The animals were maintained on 12 hours dark - 12 hours light cycles and had free access to standard lab food and tap water. Four groups of animals ( $n=40,10$ each) were defined: 1) treatment with solvent $\left(\mathrm{H}_{2} \mathrm{O}\right)$, 2) treatment with 0.1 $\mathrm{mg} / \mathrm{kg} /$ day prazosin, 3) treatment with $6 \mathrm{mg} / \mathrm{kg} /$ day rilmenidine and 4) treatment with $60 \mathrm{mg} / \mathrm{kg} /$ day azepexole. The drugs were administered with the aid of a subcutaneously implanted osmotic minipump (Alzet 2ML2; Alza Co, Palo Alto, Ca USA). These osmotic minipumps, which deliver $120 \mu \mathrm{l} /$ day, remain functional for two weeks. After two weeks of treatment they were replaced, to ensure 4 weeks of continuous drug treatment.

\section{Blood pressure measurements}

\section{Tail cuff blood pressure measurement}

Between 6 and 8 weeks of age, the rats were accustomed to the restraining, heating and experimental conditions used to measure systolic blood pressure (sBP) by tailcuff. The rats were placed in a constant temperature chamber where 8 rats could be measured simultaneously. The blood pressure measuring equipment was obtained from IITC Inc / Life Science Instruments, (Woodland Hills CA, USA). Average systolic blood pressure and heart rate were calculated from at least 5 representative blood pressure readouts. These data were obtained just prior to the treatment and after 7 and 14 days of treatment.

\section{Intra arterial blood pressure measurement}

After two and a half weeks of treatment the animals were equipped with an intra-arterial catheter for invasive blood pressure recording (Smits et al., 1982). Surgery was performed under ketamine/xylazine (5 and $1 \mathrm{mg} / \mathrm{kg} \mathrm{im}$ ) anaesthesia. Polyethylene tubing (PE 10) was inserted via a femoral artery into 
the abdominal aorta. The tube was guided under the dorsal skin, exteriorized and sutured to the neck musculature. The arterial catheter was connected to a miniature low volume displacement pressure transducer (CP-01, Century Technology $\mathrm{Co}$, Inglewood $\mathrm{Ca}$, USA) and the signal was recorded on a polygraph (Grass model 7D; Grass Instruments, Quincy MA, USA). Heart rate was determined from the pulsatile signal by a tachograph (Grass Instruments). Mean blood pressure (mBP) and heart rate (HR) were determined in conscious, freely moving animals at the end of the 4 weeks of treatment.

\section{Plasma catecholamine concentrations}

Sampling: $2 \mathrm{ml}$ blood were taken through the intra-arterial catheter from non disturbed animals and collected in chilled heparinized tubes containing $12 \mathrm{mg}$ of glutathione. Tubes were centrifuged at 3000 rotations per minute at $4{ }^{\circ} \mathrm{C}$ for 15 minutes and plasma was stored at $-20^{\circ} \mathrm{C}$ until use. High performance liquid chromatography (HPLC) with fluorometric detection according to the method developed by Van der Hoorn (Hoorn van der et al., 1989) was used to determine the plasma catecholamines concentrations. Catecholamines were extracted from the plasma samples by liquid-liquid extraction : $\alpha$ methylnoradrenaline (Sigma), $2 \mathrm{M}$ ammonia-ammonium chloride buffer $\mathrm{pH}$ 8.6 (Merck) and n-haptene (J.T. Baker, Deventer, The Netherlands) were added to the plasma. After shaking and centrifugation, the organic phase was separated from the aqueous layer. 0.01 M hydrochloric acid (Merck), 1octanol (Merck) and $0.08 \mathrm{M}$ acetic acid (Merck) were added to the organic phase, which was then shaken and centrifuged, after which the aqueous layer was again separated from the organic phase. This procedure was repeated twice. Acetonitrile (Fisons, Loughborough, U.K.) was added to the concentrate collected by the extraction procedure, together with $1.7 \mathrm{M}$ bicine pH 7.05 (Sigma) and the fluorescent agent 1,2-diphenylethylenediamine (DPE, Sigma). The derivation reaction was started by addition of potassium ferricyanide (Janssen, Beerse, Belgium).

Chromatography was performed by injection of $100 \mu \mathrm{l}$ of each concentrate in the HPLC with a sperisorb 5 ODS-2 column $(150 \mathrm{~mm} \times 4.6 \mathrm{~mm}$, Chromopack, Middelburg, The Netherlands). Fluorescent derivatives were monitored at an excitation wavelength of $350 \mathrm{~nm}$ and an emission wave length of $480 \mathrm{~nm}$. As an internal standard, $\alpha$-methylnoradrenaline was used.

\section{Body, heart and kidney weight}

Before and during the treatment, body weight was determined at weekly intervals. After sacrificing the animal the right kidney and heart were isolated 
and cleaned of adhering connective tissue and blood, and weights were determined. These weights were then divided by the total body weight of the animal.

\section{Myograph experiments}

After four weeks of treatment the rats were sacrificed by a sharp blow on the back of the head and exsanguinated. The thoracic aorta, superior mesenteric artery, mesentery and left kidney from each rat were isolated. Segments of approximately $2 \mathrm{~mm}$ were cut from the large vessels. The mesentery was pinned out on a petri dish coated with Silgard (Dow Corning Corp.) and a fourth order resistance-sized side branch of the superior mesenteric artery (diameter approximately $200 \mu \mathrm{m}$ ) was dissected. The kidney was cut in half, one side was pinned on a petri dish and a small interlobar artery was isolated. The arteries were mounted in a myograph (JP Trading Corp., Risskov, Denmark) (Mulvany \& Halpern, 1977; Heesen \& De Mey, 1990), in which the vessels are mounted horizontally in an organ chamber between an isometric force transducer (Statham UC3 and Kistler Morse DSC6 for large and small vessels, respectively) and a displacement device using 2 stainless steel wires (diameter $0.04 \mathrm{~mm}$ ). The organ chamber was filled with KrebsRinger bicarbonate solution (KRB, 25 and $10 \mathrm{ml}$ for large and small vessels, respectively) that was maintained at $37^{\circ} \mathrm{C}$ and aerated with $95 \% \mathrm{O}_{2}$ and $5 \%$ $\mathrm{CO}_{2}$. Prior to experimentation, the internal diameters of the thoracic aorta and superior mesenteric artery segments were set at 1675 and $1020 \mu \mathrm{m}$ respectively, which had been observed in preliminary experiments to yield strong and reproducible contractile responses. It was not possible to stretch these large vessels to their individual optimal diameters, as was normally done in the smaller arteries, as the time-span for contracting and relaxing the larger vessels is approximately 45 minutes. In other words, it would take a whole day to construct the full relationship between active wall tension and diameter. Furthermore, these relationships are too shallow in these vessels to allow accurate determination of optimal diameter. In contrast, mesenteric and renal resistance arteries were stretched to their individual optimal internal circumference for isometric force development (Boonen \& De Mey, 1990; 1991; Heesen \& De Mey, 1990; Eerdmans et al., 1991a). For this purpose their circumference was increased by $60 \mu \mathrm{m}$ every $5 \mathrm{~min}$, with intermittent exposure to $10 \mu \mathrm{M}$ serotonin. This length-tension protocol was continued until maximal contractile responses had been obtained. Contractile responses were subsequently induced in all vessels by means of receptor independent stimuli (high potassium) and receptor specific stimuli (noradrenaline, 5-hydroxytryp- 
tamine or Arg-vasopressin). To rule out effects of $\beta$ - and $\alpha_{2}$-adrenoceptor stimulation. all contractile responses were constructed in the presence of $1 \mu \mathrm{M}$ propranolol and $1 \mu \mathrm{M}$ yohimbine. The experiments in the isolated aorta, superior mesenteric artery and resistance artery segments took approximately 6 hours to perform.

\section{Morphology}

Arteries were fixed in the myograph at their working diameter, which was performed at $37{ }^{\circ} \mathrm{C}$ with phosphate buffered formalin $(\mathrm{pH}=7.4)$ for thirty minutes. The fixed arterial segments were embedded in paraffin (Paraplast ${ }^{+}$, Sherwood, St. Louis, USA) and cross sections of $4 \mu \mathrm{m}$ (microtome type 820 , American Optical, USA) were cut. Quantitative morphology was performed on the preparations after staining with Lawson's solution, a staining which highlights the elastic laminae. Measurements and calculations were performed using video images generated by a Zeiss Axioscope (Zeiss, Germany), a standard CCD camera (Stemmer, Germany) and commercial software (JAVA; Jandel Scientific Video Analysis Software, Jandel Scientific, Corte Madera, CA, USA). The internal circumference (IC), the length of the internal elastic lamina, was determined along with the cross sectional area of the tunica media (CSA), the area enclosed between the internal and external elastic laminas. IC was used to calculate the lumen radius ( $r$ ), assuming a circular configuration $(r=I C / 2 \pi)$. Mean media thickness (Mt) was obtained from the equation $\mathrm{CSA}=\pi(\mathrm{r}+\mathrm{Mt})^{2}-\pi \mathrm{r}^{2}$.

\section{Drugs and Solutions}

During dissection, mounting and experimentation, the preparations were immersed in a Krebs bicarbonate buffered physiological salt solution (KRB). $\mathrm{KRB}$ had the following millimolar composition: $\mathrm{NaCl} 118.3, \mathrm{KCl} 4.7, \mathrm{CaCl}_{2}$ 2.5, $\mathrm{MgSO}_{4} .7 \mathrm{H}_{2} \mathrm{O}$ 1.2, $\mathrm{KH}_{2} \mathrm{PO}_{4}$ 1.2, $\mathrm{NaHCO}_{3}$ 25.0, glucose 11.1. High potassium solution (K-KRB) was prepared by replacing all $\mathrm{NaCl}$ in normal $\mathrm{KRB}$ with an equimolar amount of $\mathrm{KCl}$. L-noradrenaline hydrochloride, Lprazosin hydrochloride and DL-propranolol hydrochloride were obtained from Sigma Chemical Co (Saint Louis, Mo USA). Serotonin creatinine sulphate monohydrate was purchased from Janssen Chimica (Beerse, Belgium) and Argvasopressin from Sandoz (Basel, Switzerland). Rilmenidine was obtained from Servier (France). Azepexole (BHT-933) was obtained from Boehringer Ingelheim and yohimbine hydrochloride from Roussel (France). 


\section{Data Analysis}

All experiments were performed in a blinded manner. Drug treatment, recording of blood pressure, reactivity studies and histology were performed by different individuals. The code was broken only after all the results has been obtained. Contractile responses of isolated blood vessels to agonists were expressed as increases in wall tension (WT i.e., increases in isometric force divided by twice the segment length) and as increases in wall stress $(\mathrm{Ws}=\mathrm{WT} / \mathrm{Mt})$. Data are shown as mean $\pm \mathrm{SEM}$. Statistical significance of effects and of differences between treatment groups was evaluated by Student's t-test for paired observations, Student's t-test for unpaired observations or analysis of variance followed by Bonferroni's t-test where appropriate (Wallenstein et al., 1980) using commercially available software (Crunch, Software Corp., San Francisco, Ca USA).

\section{Results}

\section{Plasma catecholamine concentrations}

Plasma noradrenaline concentrations were significantly reduced in the animals treated for 4 weeks with rilmenidine or azepexole compared with the control animals (figure 1). The plasma concentration of noradrenaline in the prazosin treated animals was not altered compared with the control animals (figure 1). No significant differences in adrenaline plasma concentrations were found between the various groups.

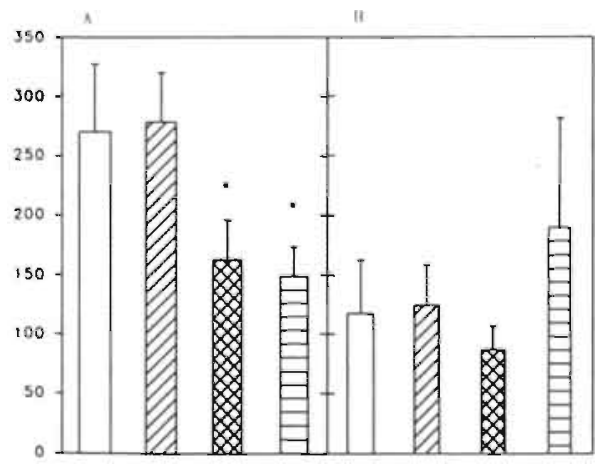

Jontrol DJaraz

\section{Figure 1}

Catecholamine concentrations in plasma blood samples of spontaneously hypertensive rats treated for four weeks with solvent (control), prazosin, rilmenidine or azepexole.

Concentrations $(\mathrm{pg} / \mathrm{ml})$ of noradrenaline (A) and adrenaline (B) in blood samples of spontaneously hypertensive rats after four weeks tre'utment with solvent (control, $n=7)$, prazosin $(n=10)$, rilmenidine $(n=7)$ or azepexole $(n=6)$. Bars are mean \pm SEM. * denotes statistical significance of difference with solvent treated rats (t-test, $\mathrm{p}<0.05$ ). 


\section{Hemodynamic properties}

To monitor drug effects during the treatments, heart rate, systolic blood pressure (indirect measurements; first two weeks) and mean blood pressure (direct measurements; after 4 weeks) were determined. Although systolic blood pressure values varied from $153 \pm 7$ (AZE) to $177 \pm 9$ (control) at the initiation of the study, these differences were not statistically significant. After 7 and 14 days a significant reduction of systolic blood pressure was observed in the rilmenidine and azepexole treated animals (figure 2), which was accompanied by bradycardia (figure 3). No significant alteration of SBP was found after four weeks. At the end of the treatment with prazosin, rilmenidine and azepexole the mean blood pressures were, respectively, $159 \pm 6,153 \pm 6$ and $134 \pm 7 \mathrm{mmHg}$. This represented no significant difference with the control group value: $149 \pm 4 \mathrm{mmHg}$. Heart rates were also normalized in all 4 groups (control $368 \pm 11$, prazosin $352 \pm 10$, rilmenidine $338 \pm 14$ and azepexole $341 \pm 13$ beats/minute).

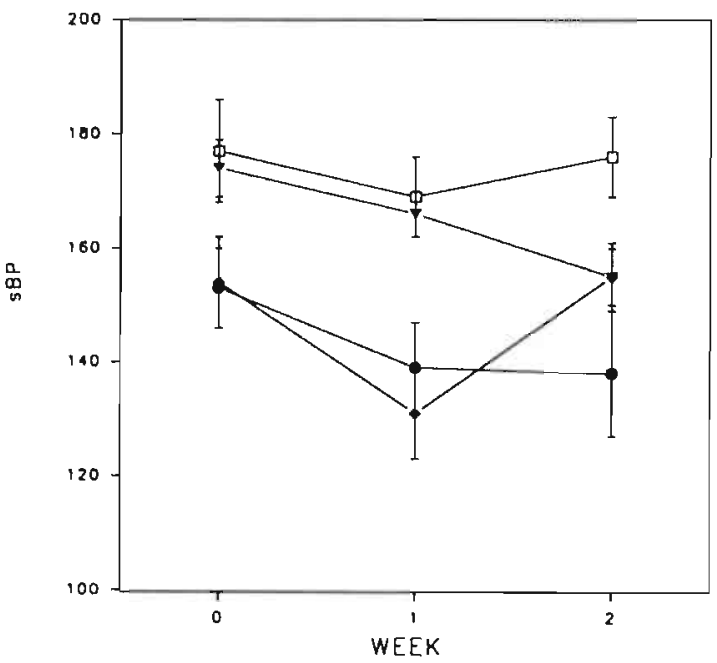

Figure 2

Systolic blood pressure measurements in spontaneously hypertensive rats recorded during two weeks of treatment with solvent, prazosin, rilmenidine or azepexole. Systolic blood pressure (mmHg) from week 0 to 2 in rats treated with solvent (open squares), $0.1 \mathrm{mg} / \mathrm{kg} / \mathrm{day}$ prazosin (filled triangle), 6 $\mathrm{mg} / \mathrm{kg} /$ day rilmenidine (filled diamond) or $60 \mathrm{mg} / \mathrm{kg} /$ day azepexole (filled circle). Data are shown as mean $\pm S E M$. 


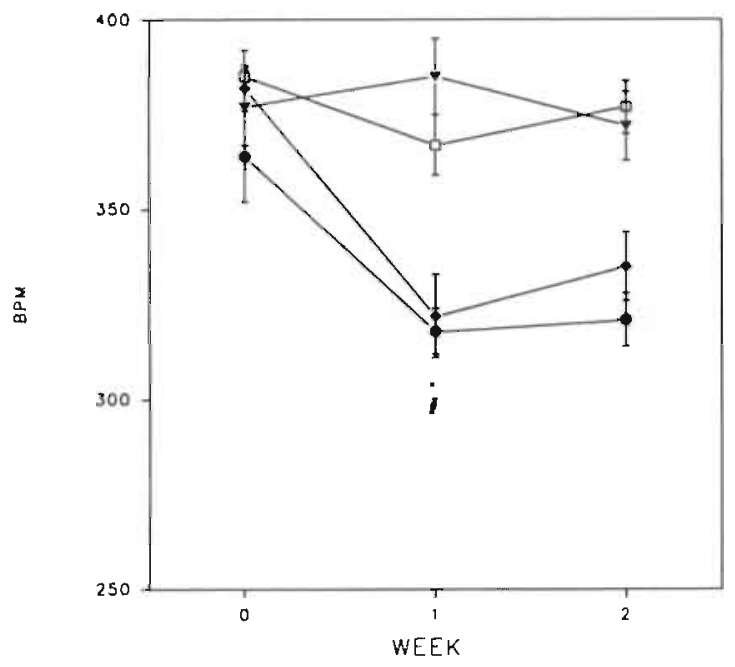

Figure 3

Heart rate in spontaneously hypertensive rats treated during two weeks with solvent, prazosin, rilmenidine or azepexole. Heart rate (beat/minute) from week 0 to 2 in rats treated with solvent (open squares), prazosin (filled triangle), rilmenidine (filled diamond) or azepexole (tilled circle) Data are shown as mean \pm SEM. * (rilmenidine) and \# (azepexole) denote statistical significance of difference with control rats (t-test, $\mathrm{p}<0.05$ ).

\section{Structural changes}

Body, heart and kidney weight.

After four weeks, the body weight of the animals treated with prazosin and azepexole did not significantly differ from that of control animals. However, the body weight of the rilmenidine treated animals was significantly decreased $(\mathrm{p}=0.036$, table 1$)$.

The relative kidney and heart weights were not significantly different between the control and drug treated animals (table 1). 


\section{Table 1}

Weight properties of spontaneously hypertensive rats after four weeks treatment with saline, prazosin, rilmenidine or azepexole

\begin{tabular}{lllll}
\hline & solvent & prazosin & rilmenidine & azepexole \\
\hline $\mathrm{n}$ & 12 & 10 & 10 & 8 \\
Body weight $(\mathrm{g})$ & $270 \pm 8$ & $258 \pm 7$ & $249 \pm 8^{*}$ & $263 \pm 4$ \\
heart weight $(\mathrm{g})$ & $1.19 \pm .05$ & $1.13 \pm .04$ & $1.02 \pm .03^{*}$ & $1.12 \pm .09$ \\
heart/body weight & $4.4 \pm .3$ & $4.4 \pm .2$ & $4.1 \pm 0$ & $4.2 \pm .2$ \\
(mg/g) & & & & \\
kidney weight (g) & $1.26 \pm .05$ & $1.23 \pm .06$ & $1.18 \pm .04$ & $1.23 \pm .02$ \\
kidney/body weight & $4.6 \pm .1$ & $4.8 \pm .3$ & $4.8 \pm 0$ & $4.7 \pm .1$ \\
(mg/g) & & & &
\end{tabular}

Total body, total and relative heart and kidney weights of spontaneously hypertensive rats measured after four weeks treatment with saline, prazosin, rilmenidine or azepexole. Body weight ( $\mathrm{g}$ ) was measured directly before sacrificing the animals. Values are means $\pm S E M$. (* $P<0.05$ ).

\section{Morphology}

Table 2 summarizes the effects of the drug treatments on the structure and model of the thoracic aorta, superior mesenteric artery, mesenteric resistance arteries and renal resistance arteries. Media cross sectional area was significantly reduced by prazosin in the thoracic aorta, while media cross sectional area was significantly increased by azepexole in mesenteric resistance arteries. Drug effects on media cross sectional area in other vessels were not statistically significant (table 2). Because the thoracic aorta and superior mesenteric artery were fixed at a preset and poorly defined diameter, drug effects on lumen diameter, media thickness and W/L could not be critically evaluated in these vessels. In both types of resistance arteries, however, an active length-tension protocol was used to critically define lumen diameter, allowing lumen diameter and derived variables such as media thickness and $\mathrm{W} / \mathrm{L}$ to be compared in these resistance arteries. Neither prazosin nor rilmenidine resulted in structural narrowing or in relative or absolute hypertrophy or hypotrophy of the resistance arteries (table 2). Azepexole, on the other hand, led to an increase in $\mathrm{W} / \mathrm{L}$ in mesenteric resistance arteries without modifying the lumen diameter, suggesting that the effect was exclusively due to the observed increase in media mass (table 2). Unlike the situation in mesenteric resistance vessels, azepexole reduced $\mathrm{W} / \mathrm{L}$ in the renal resistance arteries (table 2). 
Table 2

Morphological properties of the aorta, superior mesenteric artery, mesenteric and renal resistance arteries from spontaneously hypertensive rats treated for four weeks with either solvent, prazosin, rilmenidine or azepexole.

Aorta

$\begin{array}{ccccc} & \text { solvent } & \text { prazosin } & \text { rilmenidine } & \text { azepexole } \\ & 10 & 10 & 8 & 8 \\ \text { CSA }\left(\mathrm{mm}^{2 *} 1000\right) & 540 \pm 19 & 498 \pm 15^{*} & 507 \pm 10 & 549 \pm 9\end{array}$

Superior mesenteric artery

$\begin{array}{lcccc} & \text { solvent } & \text { prazosin } & \text { rilmenidine } & \text { azepexole } \\ \mathrm{n} & 10 & 10 & 8 & 8 \\ \mathrm{CSA}\left(\mathrm{mm}^{2 * 1000)}\right. & 140 \pm 5 & 133 \pm 8 & 142 \pm 6 & 141 \pm 9\end{array}$

Mesenteric resistance artery

$\begin{array}{lcccc} & \text { solvent } & \text { prazosin } & \text { rilmenidine } & \text { azepexole } \\ \mathrm{n} & 10 & 10 & 8 & 8 \\ \text { Radius }(\mu \mathrm{m}) & 118 \pm 3 & 119 \pm 3 & 115 \pm 5 & 115 \pm 4 \\ \text { CSA }\left(\mathrm{mm}^{2 *} 1000\right) & 9.5 \pm .4 & 10 \pm .5 & 9.6 \pm 1.3 & 11 \pm .8^{*} \\ \mathrm{M}_{1}(\mu \mathrm{m}) & 12 \pm .4 & 13 \pm .6 & 12 \pm 1 & 14 \pm .8^{*} \\ \text { W/L }(s) & 10.3 \pm .5 & 10.9 \pm .7 & 10.8 \pm .4 & 12.4 \pm .7^{*}\end{array}$

Renal resistance artery

$\begin{array}{lcccc} & \text { solvent } & \text { prazosin } & \text { rilmenidine } & \text { azepexole } \\ \mathrm{n} & 10 & 10 & 8 & 8 \\ \text { Radius }(\mu \mathrm{m}) & 127 \pm 4 & 132 \pm 8 & 128 \pm 6 & 133 \pm 6 \\ \mathrm{CSA}\left(\mathrm{mm}^{2 *} 1000\right) & 13 \pm 1 & 13 \pm 2 & 11 \pm 1 & 12 \pm 1 \\ \mathrm{M}_{\mathrm{t}}(\mu \mathrm{m}) & 15 \pm 1 & 14 \pm 1 & 13 \pm 1 & 13 \pm 1 \\ \mathrm{~W} / \mathrm{L}(\mathrm{l}) & 11.5 \pm .5 & 10.7 \pm .5 & 10.2 \pm .6 & 10 \pm .6^{*}\end{array}$

Morphological properties, radius, media cross sectional area (CSA), media thickness $\left(\mathrm{M}_{\mathcal{L}}\right)$ and wall 10 lumen ratio ( $\mathrm{W} / \mathrm{L}=\mathrm{M}_{\mathrm{t}} /$ radius) of large and small arteries from $\mathrm{SH}$ rats treated with solvent, prazosin, rilmenidine or azepexole. Values are mean $\pm S E M$. * indicates significance of difference with controls (t-test $\mathrm{P}<0.05$ )

\section{Maximal contractile responses}

In the aorta maximal contractile responses, induced by high potassium krebs solution, were increased in the animals treated with rilmenidine $(p=0.006)$ and azepexole $(p=0.057)$ (figure 4$)$. The maximal active wall stress calculations (individual wall tension/individual media thickness) indicated an increased maximal active wall stress in the aorta of these animals (figure 5). In the superior mesenteric arteries no differences were found for maximal responses to high potassium krebs solution (figure 4) and wall stress (figure 5). 

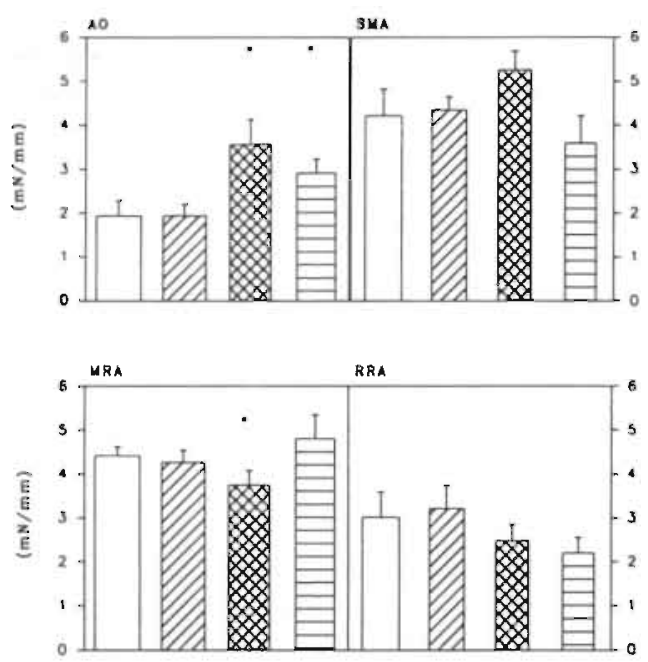

Figure 4

$\square$ cOntRoL RZPRAZ EAZEPEXLE

Maximal active wall tension determined for aorta, superior mesenteric artery, mesenteric and renal resistance artery. In the aorta and superior mesenteric artery, maximal wall tension was induced with high potassium Krebs solution. In the resistance arteries, maximal wall tension was induced with high potassium Krebs solution $+10 \mu \mathrm{M}$ noradrenaline. Bars are mean $\pm \mathrm{SEM}$. * denotes statistical significance of difference (t-test, $p<0.05$ ).
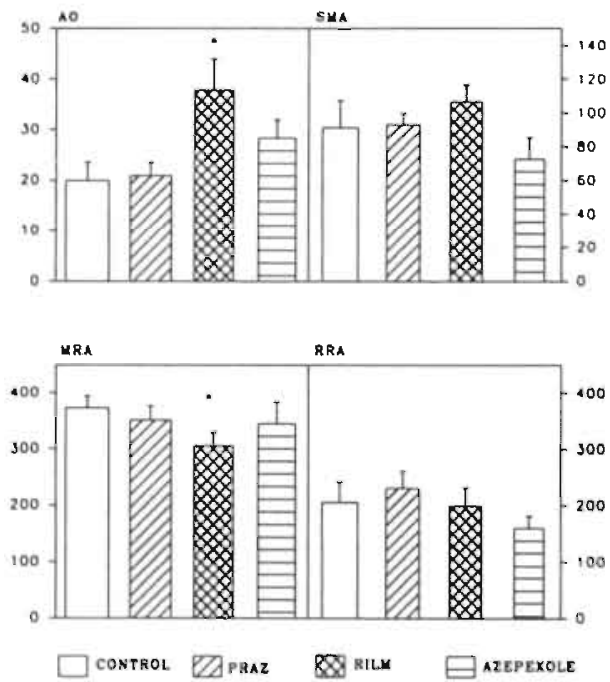

\section{Figure 5}

Maximal active wall stress ( $\mathrm{mN} / \mathrm{mm}^{2}$. wall tension / media thickness) was calculated for all types of arteries. Bars are mean \pm SEM. * denotes statistical significance of difference ( $t$-test, $p<0.05$ ). 
Although increases in maximal responses were found in larger arteries, the mesenteric resistance arteries showed contractile responses to high potassium krebs solution + noradrenaline which were significantly decreased in the rilmenidine treated animals (figure 4) This decrease in maximal contractile response in the rilmenidine treated animal was also reflected in the maximal active wall stress (figure 5). However, in the renal resistance arteries no changes were found as regards to maximal contractile responses (figure 4). This lack of reactivity changes were not shielded by structural changes, the maximal active wall stress did not differ between the control and the treated animals (figure 5).

\section{Discussion}

We evaluated structural vascular effects of pharmacological sympatholytic interventions in spontaneously hypertensive rats. For this purpose, we performed long-term continous treatments with either an $\alpha_{1}$-adrenergic antagonist or with centrally acting $\alpha_{2}$-adrenergic agonists. The vascular effects of these treatments differed between types of vessels and between the drugs that were used. In addition to changes in arterial structure, effects also included changes in arterial contractility.

Much is known about the role of the sympathetic nervous system in relation to blood pressure and vacular changes. A lot of work has been done in the past in which the sympathetic nervous system was deactivated chemically or mechanically in neonatal, young and adult rats.

Neonatal immunosympathectomy with anti-nerve growth factor and guanethidine has been found to prevent the development of hypertension in the SHR and SHRSP (Lee et al., 1987; Mangiarua \& Lee, 1992). Using the same methodology in neonatal WKY rats, Lee at al. (Lee et al., 1987) saw no structural changes in the superior mesenteric artery, but a decreased number of smooth muscle cells in the SHR. Mangiarua et al. (Mangiarua \& Lee, 1992) did not find any changes in the basilar artery of the WKY and SHR, while only a decreased smooth muscle cell size was found in the SHRSP rat. Bevan et al. (Bevan, 1975; Bevan \& Tsuru, 1981; Bevan et al., 1983) studied the effect of (surgical) sympathetic denervation in the growing rabbit ear artery. They found decreased ${ }^{3} \mathrm{H}$-thymidine incorporation, CSA and weight of the ear artery after denervation. The opposite was found in the adult animals. Various researchers have studied the ear artery, cerebral artery and thoracic aorta, and 
found increases in weight (Bevan \& Tsuru, 1981), smooth muscle cell size (Dimitriadou et al., 1988) and smooth muscle cell number (Froneck et al., 1978), as well as increased synthetic activity (Froneck, 1983; Branco et al., 1984; Dimitriadou et al., 1988). In the mesenteric artery (Azevedo \& Osswald, 1986) and saphenous vein (Branco et al., 1984; Albino-Teixeria et al., 1990) of the dog. mechanical denervation and chemical denervation by 6 hydroxydopamine were found to produce increased smooth muscle cell size and synthetic activity. Only in adult dogs chemically denervated with guanethidine (Branco et al., 1984) were no changes found in the saphenous vein. From these observations the picture emerges that the sympathetic nerves system seems to have an important role in stimulating the vascular smooth muscle in the developing animal. In the adult animal, the sympathetic nervous system is needed to control the smooth muscle cell: without its control the smooth muscle cell changes its phenotype.

We treated young adult male spontaneously hypertensive rats for 4 weeks with either solvent (control group), prazosin, rilmenidine or azepexole. We treated the animals with these drugs to induce a decreased sympathetic input to the vessels either by lowering the sympathetic tone centrally (azepexole, rilmenidine) or by blocking the $\alpha_{1}$ adrenoceptors (prazosin).

The effect of the treatment was evaluated by determining plasmacatecholamines at the end of the four-week treatment. Plasma concentrations of noradrenaline and adrenaline can be used as an index of sympathetic nervous system activity (Evenwel et al., 1982), although plasma catecholamine levels depend upon numerous processes such as release from and re-uptake by nerve endings, metabolic degradation and uptake into non-neural tissue (Goldstein, 1983). After 4 weeks of treatment the plasma noradrenaline concentrations were significantly reduced in the rilmenidine and azepexole treated animals, indicating a decreased sympathetic tone.

Prazosin causes an increased sympathetic tone (baroreflex), but after several days a resetting of the baroreflex develops and the sympathetic activity as well as the plasma noradrenaline concentration, are normalized.

The present study the adrenaline plasma concentrations were not found to be altered. Earlier studies in the SHR and in humans also failed to find changes in adrenaline concentrations after treatment with $\alpha_{2}$-adrenoceptor agonists or antagonists (Zech \& Pozet, 1986; Smemeredi et al., 1988). This indicates that the plasma concentration of adrenaline, released by the adrenal medullae, is not influenced by $\alpha_{1}$-adrenergic antagonists or $\alpha_{2}$-adrenergic agonists.

The drugs we evaluated were introduced for their antihypertensive properties: 
the $\alpha$-adrenoceptor antagonist prazosin has been used in the treatment of human hypertension for some years (Brogden, 1977). It acts as an arteriolar vasodilator, causing a fall in blood pressure associated with a reduction of peripheral vascular resistance. Interpretation of the effects of drugs that act on $\alpha_{2}$-adrenoceptors is rather complex, because of the various locations where this receptor occurs. A depressor effect can be mediated through stimulation of central $\alpha_{2}$-adrenoceptors. In addition, $\alpha_{2}$-adrenoceptor agonists elicit several direct effects on the peripheral vasculature, including endothelium-dependent dilation of large arteries (Cocks \& Angus, 1983), constriction of arteriolar (Faber, 1988) and venous smooth muscle (De Mey \& Vanhoutte, 1981) and presynaptic inhibition of adrenergic neurotransmission (Zech \& Pozet, 1986; Brown, 1988; Xiao \& Rand, 1989). In most animal models $\alpha_{2}$-adrenoceptor agonists, like rilmenidine and azepexole, exert an antihypertensive effect via stimulation of central $\alpha_{2}$-adrenoceptors (Van Zwieten, 1975; Kobinger, 1978; Van Zwieten et al., 1986) causing a decreased sympathetic tone (Ghaemmaghami et al., 1990). In addition to the $\alpha_{2}$-adrenoceptor interaction with rilmenidine, activity at an imidazoline receptor in the rostral ventrolateral medulla oblongata has been suggested as important in mediating the hypotension (Bousquet et al., 1984; 1989).

Until now, only acute and short-term (1-2 weeks) effects of $\alpha_{2}$-adrenoceptor agonists and $\alpha_{1}$-adrenoceptor antagonists has been investigated in experimental models of hypertension. Hardly any data are available about the effect of longterm treatment with these drugs (Callens-El Amrani et al., 1989). In our study, we only observed some antihypertensive effects in the first two weeks for both $\alpha_{2}$-adrenoceptor agonists. Earlier studies performed by our group with $\alpha_{2}$-adrenoceptor agonists did not reveal any long term antihypertensive effects of clonidine $(0.2 \mathrm{mg} / \mathrm{kg}$ / day) either (Eerdmans et al., 1991b).

The reasons for this lack of antihypertensive effect after 4 weeks of treatment may be multiple.

One hypothesis is that down-regulation of central $\alpha_{2}$-adrenoceptors or imidazoline-binding sites involved in the mechanism of anti-hypertensive action of azepexole and rilmenidine could explain the lack of antihypertensive effects of these compounds (Hamilton et al., 1990). The decreased plasmanoradrenaline concentrations found in our study, however, rule out this hypothesis. An alternative explanation may be that the initial lowering of blood pressure is compensated for by changes in other neuro-humoral mechanisms that regulate blood pressure. The present study was designed to define the nature of such counter-regulatory mechanisms. 
We evaluated the effects of chronic treatment with prazosin, rilmenidine and azepexole on the structure of elastic, muscular and resistance sized arteries of spontaneously hypertensive rats. Internal and external circumference, as well as the cross sectional area of the media were determined, allowing the lumen diameter, mean media thickness and wall to lumen ratios to be calculated. Since the large arteries were all stretched to the same diameter, only cross sectional area could be determined for these vessels, as all the other morphology parameters are extrapolated from the internal diameter, which is constant in all four groups. Only an antitrophic effect of prazosin (aorta) was found in the large vessels. In an earlier study, we observed that infusion of the $\alpha_{1}$-adrenoceptor agonist phenylephrine in the young SHR resulted in hypertrophy of the aorta, but not of mesenteric resistance-sized vessels (Boonen et al., 1993).

In contrast, a trophic effect of the azepexole treatment, increasing CSA, $M_{t}$ and $\mathrm{W} / \mathrm{L}$, was found in the mesenteric resistance arteries. One of the explanations for this trophic effect can be found in the work of Messing (Messing, 1992), whose study showed that azepexole constricted the entire arteriolar vasculature and also caused a significant constriction of the small venules. This was found during acute experiments with azepexole concentrations ranging from $30-300 \mu \mathrm{g} / \mathrm{kg} / \mathrm{min}$. The constriction induced by azepexole may cause a change in pressure gradient in the whole vascular tree. The vessels directly proximal from the arteriole, in other words the resistancesized arteries, will be most affected. This would imply that the azepexoleinduced trophic effect in the mesenteric resistance artery is due to the pressure increase.

With only minor structural changes, interesting changes were found in functional properties. We observed a significant increase in the maximal active wall stress, force development per square $\mathrm{mm}$, of the aorta in rilmenidine treated animals. In the mesenteric resistance artery, however, a decrease in maximal active wall stress was found. This is also reflected in the maximal contractile responses, which were increased in the aorta of rilmenidine treated animals and decreased in the mesenteric resistance arteries of the rilmenidine treated animals (figure 4).

Comparing the adrenergic control of the aorta and the mesenteric resistance arteries the major difference is the lack of sympathetic innervation of the aorta. In other words, modulations found in the aorta are either based on a direct effect of the drug or on changes in plasma noradrenaline, while modulations found in the mesenteric resistance artery are based on a direct 
effect of the drug. changes in plasma noradrenaline or changes in sympathetic nerve activity. A possible explanation of the decreased maximal wall stress in the mesenteric resistance artery is the following. Interference with the sympathetic nervous system not only changes the release of noradrenaline but can also modify sympathetic cotransmitters such as ATP, NPY and, indirectly, neurotransmitters released by peptidergic nerves. ATP and NPY in particular seem to play an important role in the sympathetic nervous system (Branco et al., 1984; Albino-Teixeria et al., 1990). As was discribed earlier (Branco et al., 1984) it is quite possible that structural modulation takes place in the mesenteric resistance artery, changing its phenotype from a contractile to a more synthetic one. Changes found in the aorta cannot be caused by modulation due to changes in co-transmitters, since this vessel is not innervated. What is left is a direct effect of rilmenidine and especially its imidazoline properties, in view of the fact that azepexole had no effect.

In conclusion, we can say that the mode of action of $\alpha_{2}$-adrenoceptor agonists which causes decreased sympathetic tone, is still active after 4 weeks of treatment in the SHR. No sustained decreased blood pressure was found, however, with either rilmenidine, azepexole or with the $\alpha_{1}$-adrenoceptor antagonist prazosin. The effect of a decreased sympathetic input seems to be compensated by other blood pressure regulating mechanisms. A possible positive effect on the pathological vascular structure in the SHR was not found. In the mesenteric resistance artery a change in phenotype was found upon treatment with rilmenidine, causing a decreased maximal contractile response. An explanation for this can be found in the decreased sympathetic tone, which results in decreased release of several cotransmitters. The possible role of rilmenidine in affecting the phenotype of the smooth muscle cell in the aorta is difficult to explain, and the direct effects of rilmenidine on the vascular smooth muscle cell remain to be further investigated. 


\section{References}

Alhinu-Teixeria A., A7tevedo I., Branco D. \& Osswald W. (1990). Purine agonists prevent trophic changes caused by sympathetic denervation, Eur. J. Pharmacol., 179, 141-149.

Azevedo I. \& Osswald W. (1986). Trophic role of the sympathetic innervation, Journal de Pharmacologie 17, SupplII, 30.

Bevan R.D. (1975). Effect of sympathetic denervation on smooth muscle cell proliferation in the growing rabbit ear artery, Circ. Res., 37, 14-19.

Bevan R.D. \& Tsuru H. (1981). Functional and structural changes in the rabbit ear artery after sympathetic denervation, Circ. Res., 49, 478-485.

Bevan R.D., Marthens E. \& Bevan J.A. (1976). Hyperplasia of vascular smooth muscle in experimental hypertension in the rabbit, Circ. Res., 38, II58-II62.

Bevan R.D., Tsuru H. \& Bevan J.A. (1983). Cerebral artery mass in the rabbit is reduced by chronic sympathetic denervation, stroke, 14, 393-396.

Boonen H.C.M. \& De Mey J.G.R. (1990). Increased calcium sensitivity in isolated resistance arteries from spontaneously hypertensive rats: effects of dihydropyridines, Eur.

J. Pharmacol., 179, 403-412.

Boonen H.C.M. \& De Mey J.G.R. (1991). Effects of a phorbol ester and staurosporine on electro- and pharmacomechanical coupling in a resistance artery, Eur. J. Pharmacol., 202, 25-32.

Boonen H.C.M., Struyker-Boudier H.A.J. \& De Mey J.G.R. (1990). Effects of tertatolol on the responsiveness of isolated femoral, mesenteric, and renal resistance aneries to adrenergic stimuli, J. Cardiovasc. Pharmacol., 15, 124-129.

Boonen H.C.M., Daemen M.J.A.P., Eerdmans P.H.A., Fazzi G.E., van Kleef E., Schiffers P.M.H. \& De Mey J.G.R. (1993). Mesenteric small artery changes following vasoconstrictor infusion in young rats, J. Cardiovasc. Pharmacol., 22, 388-395.

Bousquet P., Feldman J. \& Schwartz J. (1984). Central cardiovascular effects of $\alpha$ adrenergic drugs: differences between catecholamins and imidazolines, J. Pharmacol. Exp. Therap., 230, 232-236.

Bousquet P., Feldman J., Tibirica E., et al. (1989). New concepts on the central regulation of blood pressure. $\alpha 2$-adrenoceptors and imidazoline receptors, Am. J. Med., 87, 10$13 \mathrm{~S}$.

Branco D., Albino-Teixeira A., Azevedo I. \& Osswald W. (1984). Structural and functional alterations caused at the extraneuronal level by sympathetic denervation of blood vessels, Naunyn. Schmiedeberg's. Arch. Pharmacol., 326, 302-312.

Brogden R.N. (1977). Prazosin: A review of its pharmacological properties and therapeutic etticacy in hypertension, Drugs., 14, 163-197.

Brown M.J. (1988). Sites of action of $\alpha_{2}$ agonists and antagonists, Am. J. Cardiol., 61, 18D-21D.

Callens-El Amrani F. Paolaggi F. \& Swynghedauw B. (1989). Remodelling of the heart in DOCA-salt hypertensive rats by propranolol and by an $\alpha 2$ agonist, rilmenidine, J. Hypertension., 7, 947-954.

Cocks T.M. \& Angus J.A. (1983). Endothelium-dependent relaxation of coronary arteries by noradrenaline and serotonin, Nature., 305, 627-629.

Coupry I. \& Lachaud V. (1989). Different affinities of $\alpha 2$ agonists for imidazoline and $\alpha 2$ adrenergic receptors, Am. J. Hypertension., 2, 468-470. 
De Mey J.G.R. \& Vanhoutte P.M. (1981). Uneven distribution of postjunctional $\alpha 1$ - and $\alpha 2$ - like adrenoceptors in canine arterial and venous smooth muscle, Circ. Res., 48, 875884.

De Mey J.G.R. \& Vanhoutte P.M. (1982). Heterogeneous behavior of the canine anterial and venous wall. Importance of the endothelium, Circ. Res., 51, 439-447.

Dimitriadou V., Aubineau P., Taxi J. \& Seylaz J. (1988). Ultrastructural changes in the cerebral artery wall induced by long-term sympathetic denervation, Blood. Vessels., 25, 122-143.

Eerdmans P.H.A., Heesen B.J., Struijker Boudier H.A.J. \& De Mey J.G.R., 1991a, Sympathetic heterogeneity in mesenteric and renal resistance aneries, in: Resistance Arteries. Structure and Function. Mulvany M.J., Aalkjaer C.. Heagerty A.M., Nyborg N.C.B. \& Strandgaard S., Excerpta Medica, Amsterdam, The Netherlands, 156-159.

Eerdmans P.H.A., Struijker Boudier H.A.J. \& De Mey J.G.R. (1991b). Contractile reactivity of isolated resistance arteries after 4 weeks of treatment with rilmenidine. clonidine or hydralazine in spontaneously hypertensive rats, J. Hypertension., 9, S348S349.

Evenwel R.T., Vervoort-Peters L., Smits J.F.M. \& Struyker-Boudier H.A.J. (1982). Reduction of plasma noradrenaline in the spontaneously hypertensive rat by physical training, Hypertensive mechanisms,, 458-464.

Faber J.E. (1988). Effect of local tissue cooling on microvascular smooth muscle and postjunctional $\alpha 2$-adrenoceptors, Am. J. Physiol., 255, h121-H130.

Feng F., Abel P.W., Scofield M., Liu F., Wolff D.W. \& Jeffries W.B. (1993) Heterogenous expression of $\alpha_{1}$-adrenoceptor subtypes among rat nephon segments, Mol. Pharmacol., 44, 926-933.

Froneck K. (1983). Trophic effects of the sympathetic vervous system on vascular smooth muscle, An. Biomed. Engin., 11, 607-615.

Froneck K.. Bloor C.M., Amiel D. \& Chvapil M. (1978). Effect of long term sympathectomy on the arterial wall in rabbits and rats, Exp. Mol. Pathol., 28, 279-289.

Galitzky J., Mauriege P., Berlan M. \& Lafontan M. (1989). Human fat cell $\alpha_{2}$ adrenoceptors. I. Functional exploration and pharmacological definition with selected $\alpha_{2}$ agonists and antagonists, J. Pharmacol. Exp. Therap., 249, 583-591.

Ghaemmaghami F., Ibanez J., Geelen G., Vincent M., Frutoso J. \& Gharib C. (1990). Effects of swim training alone and in combination with clonidine and rilmenidine on blood pressure, plasma electrolytes. vasopressin, and renin activity in spontaneously hypertensive rats, J. Cardiovasc. Pharmacol., 15, 68-74.

Goldstein D.S. (1983). Plasma catecholamines and essential hypertension- an analytical review, Hypertension. 5, 86-99.

Hamilton C.A., Yakubu M.A., Howie C.A., Jardine E. \& Reid J.L. (1990). Desensitization and down-regulation of brain $\alpha_{2}$-adrenoceptors by centrally acting antihypertensive drugs, $\mathrm{Br}$. J. Clin. Pharmac., 30, 131s-134s.

Heesen B.J. \& De Mey J.G.R. (1990). Effects of cyclic AMP-affecting agents on contractile reactivity of isolated mesenteric and renal resistance arteries of the rat, $\mathrm{Br} . \mathrm{J}$. Pharmacol., 101, 859-864. 
Hoorn van der F.A.J., Boomsma F., Man in 't Veld A.J. \& Schalekamp M.A.D.H. (1989). Determination of catecholamines in human plasma by high-performance liquid chromotography: comparison between a new method with fluorescence detection and an established method with electrochemical detection, J. Chrom., 487, 17-28.

Jackson C.A., Michel M.C. \& Insel P.A. (1992). Expression of renal $\alpha_{1}$-adrenergic receptor subtypes in established hypertension, J. Cardiovasc. Pharmacol., 19, 857-862.

Kanbe T., Nara Y., Tagami M. \& Yamori Y. (1983). Studies of hypertension-induced vascular hypertrophy in cultured smooth muscle cells from spontaneously hypertensive rats, Hypertension., 5. 887-892.

Kobinger W. (1978). Central $\alpha$-adrenergic systems as targets for hypotensive drugs, Rev Physiol Biochem Pharmacol, 81, 40-100.

Lee R.M.K.W. \& Smeda J.S. (1985). Primary versus secondary structural changes of the blood vessels in hypertension, Can. J. Physiol. Pharmacol., 63, 392-401.

Lee R.M.K.W., Triggle C.R., Cheung D.W.T. \& Coughlin M.D. (1987). Structural and functional consequences of neonatal sympathectomy on the blood vessels of spontaneously hypertensive rats, Hypenension., 10, 328-338.

Louis W.J., Jarrott B. \& Conway E.L. (1988). Sites of actions of $\alpha_{2}$ agonists in the brain and periphery, Am. J. Cardiol., 61, 15D-17D.

Mangiarua E.I. \& Lee R.M.K.W. (1992). Morphometric study of cerebral arteries from spontaneously hypertensive stroke-prone hypertensive rats, J. Hypertension., 10, 11831190.

Mano M., Nara Y., Tsubouchi T., Horie R. \& Yamori Y. (1986). Effect of noradrenaline exposure on polyploidy formation in cultured smooth muscle cells from normotensive Wistar-Kyoto rats, J. Hypertension., 4, 113-114.

Messing M.W.J. (1992). Antihypertensive drugs and the microcirculation, UPM, ISBN 90 90050957, , 64-72.

Mulvany M.J. \& Halpern W. (1977). Contractile properties of small arterial resistance vessels in spontaneously hypertensive and normotensive rats, Circ. Res., 41, 19-26.

Nilsson H., Goldstein M. \& Nilsson O. (1986). Adrenergic innervation and neurogenic response in large and small arteries and veins from the rat, Acta. Physiol. Scand., 126, 121-133.

Nyborg C.B., Korsgaard N. \& Mulvany M. (1986). Neonatal sympathectomy of normotensive wistar-kyoto and spontaneously hypertensive rats with 6-hydroxydopamine : effects on resistance vessel structure and sensitivity to calcium, J. Hypertension., 4, 455-461.

Smemeredi K., Bagdy G., Stull R., Keiser H.R., Kopin I.J. \& Goldstein D.S. (1988). Sympathoadrenomedullary hyper-responsiveness to yohimbine in juvenile spontaneously hypertensive rats. Life. Sci.. 43, 1063-1068.

Smits J.F.M., Coleman T.G., Smith T.L., Kasbergen C.M., Essen van H. \& Struyker Boudier H.A.J. (1982). Antihypertensive effect of propranolol in conscious spontaneously hypertensive rats: central hemodynamics, plasma volume, and renal functiun during beta-blockade with propranolol, J. Cardiovasc. Pharmacol., 4, 903-914.

Van Zwieten P.A. (1975). Antihypertensive drugs with a central action, Prog. Pharmacol., $1,1-63$. 
Van Zwieten P.A., Thoolen M.J.M.C., Jonkman F.A.M., Wilffert B., De Jonge A. \& Timmermans P.B.M.W.M. (1986). Central and peripheral effects of S 3341 [(Ndicyclopropylmethyl)-amino-2-oxazoline] in animal models, Arch. Int. Pharmacodyn. Ther., 279, 130-149.

Verbeuren T.J., Tuan Dinh Xuan A., Koening-Berard E. \& Vitou P. (1990). Rilmenidine, Cardiovasc. Drug Rev., 8, 56-70.

Wallenstein S., Zucker C.L. \& Fleiss J.L. (1980). Some statistical methods useful in circulation research, Circ. Res., 47, 1-9.

Xiao X.H. \& Rand M.J. (1989). $\alpha_{2}$-adrenoceptor agonists enhance responses to certain other vasoconstrictor agonists in the rat tail artery, Br. J. Pharmacol., 96, 539-546.

Zech P. \& Pozet N. (1986). The effect of a new $\alpha_{2}$ agonist, oxaminozoline (S 3341), on renal function, renin-aldosterone system and plasma catecholamines during a two month treatment period, First International Symposium on Oximinozoline, Heidelberg,. 82.

Zwieten van P.A. (1975). Antihypertensive drugs with a central action, Prog. Pharmacol., $1,1-63$. 
Regionally selective alterations of sympathetic nerves and their target organs in juvenile SHR after 4-week treatment with prazosin, rilmenidine and azepexole.

P.H.A. Eerdmans, H.A.M.D. van der Heijden,

D. van Inge-Schenau and J.G.R. De Mey 



\section{Abstract}

In this study we treated young adult male spontaneously hypertensive rats for 4 weeks with solvent (control group), prazosin, rilmenidine or azepexole. We treated the animals with these drugs to induce a decreased sympathetic input at the vessels either by lowering the sympathetic tone centrally (azepexole, rilmenidine) or by blocking the $\alpha_{1}$-adrenoceptors (ргаzosin). We evaluated the effect of the above treatments on the arterial control of several types of arteries with the purpose of finding regulatory systems responsible for the transient effect of several antihypertensive drugs. We evaluated sympathetic nerve properties, adrenergic and non-adrenergic receptor properties in large and small arteries. Increased responses to electrical nerve stimulation were found in the mesenteric resistance arteries of all three treatments, but not in the renal arteries. This increased response may be caused by increased density or decreased activity of peptidergic nerves. No changes were found in the sensitivity of $\alpha$-and $\beta$-adrenoceptors in either large or resistance arteries. A significant decrease in sensitivity to acetylcholine was found in the aorta (all treatments) and superior mesenteric artery (prazosin, rilmenidine). Receptor binding studies of the $\alpha_{1}$-adrenoceptors of the kidney showed no changes in either subtype or affinity due to the treatments. The density of the sympathetic nerves did not alter in the femoral arteries, as was proven with a glyoxylic staining technique. Four weeks of treatment of SHR with prazosin, rilmenidine or azepexole did not change nerve density or cause up-regulation of adrenoceptors. The possible mechanisms responsible for the transient effect of some antihypertensive drugs may be found in down-regulation of vasoconstrictor inhibiting mechanisms such as the endothelium of the aorta and non-adrenergic nerves of the mesenteric resistance artery.

\section{Introduction}

Drugs influencing sympathetic activity, such as peripherally acting $\alpha_{1}$ adrenoceptor antagonists and centrally acting $\alpha_{2}$-adrenoceptor agonists are being used as antihypertensive agents. In spontaneously hypertensive rats the antihypertensive action of either type of drug is only modest in long-term treatment. The mechanisms that reduce the antihypertensive effect of these compounds are not entirely clear but may include adaptive changes in arterial structure and function. Functional alterations can be caused by changes in adrenoceptor properties such as modulation of the numbers, affinity or distribution of the receptors (DeMeyts, 1976; Pettinger et al., 1987). In the 
present study we investigated the effect of long-term reduction of sympathetic input on several arterial control mechanisms such as adrenoceptors, sympathetic innervation and endothelium. We evaluated these effects with the purpose of finding mechanisms responsible for the transience of the effect of several antihypertensive drugs.

We used $\alpha_{2}$-adrenoceptor agonists and an $\alpha_{1}$-adrenoceptor antagonist to reduce arterial sympathetic tone. Both azepexole and rilmenidine were used as pure $\alpha_{2}$-adrenoceptor agonists, while rilmenidine also seems to have imidazoline receptor stimulating properties. $\alpha_{2}$-Adrenoceptor agonists lower blood pressure by reducing the sympathetic input to the cardiovascular system, which is the result of inhibitory effects on the vasomotor centre in the central nervous system (Van Zwieten et al., 1986) and inhibitory effects on the neurotransmission by postganglionic sympathetic nerves (Langer, 1974; Vanhoutte et al., 1981). Postjunctional effects of $\alpha_{2}$-adrenoceptor agonists on vascular smooth muscle and endothelial cells in the vascular wall (Drew \& Whiting, 1979; De Mey \& Vanhoutte, 1981; Angus et al., 1988; Daly et al., 1988b; Vanhoutte \& Miller, 1989) can interfere with these actions.

Theoretically, the antihypertensive effects of $\alpha_{2}$-adrenoceptor agonists can be influenced by the following mechanisms: i) down-regulation of systemic $\alpha_{2}$ adrenoceptors; ii) up-regulation of central and systemic $\alpha_{1}$-adrenoceptors; and iii) adrenergic subtype changes. Other (non-adrenergic) blood pressure regulating mechanisms might play a role as well, but these will not be discussed.

Down-regulation has been firmly established in $\beta$-adrenoceptors (Sibley \& Lefkowitz, 1985), but this is less clear for $\alpha$-adrenoceptors (Michel et al., 1990). Several investigators have suggested the existence of multiple $\alpha_{1}$ adrenoceptor subtypes (Cotecchia et al., 1988; Minneman, 1988; Perez et al., 1991; Ruffolo et al., 1991; Schwinn et al., 1991). Our study focused on $\alpha_{1 \mathrm{~A}}$, $\alpha_{1 \mathrm{~B}}$ and $\alpha_{1 \mathrm{D}}$-adrenoceptors, in this chapter when discussing $\alpha_{1 \mathrm{~B}}$-adrenoceptors in relation to the antagonistic properties of chloroethylclonidine (CEC) $\alpha_{1 B^{-}}$ and $\alpha_{1 \mathrm{D}}$-adrenoceptors is ment. Investigations performed with $\mathrm{CEC}$ have suggested that $\alpha_{1 \mathrm{~B}}$-adrenoceptors are present in large arteries but are of minor importance for the regulation of blood pressure or peripheral resistance (Epand \& Lester, 1990; Piascik et al., 1990; 1993). In other words, the role of the $\alpha_{1 \mathrm{~B}}$-adrenoceptors seems to be more important in vessels which are not (aorta) or only sparsely (superior mesenteric arteries) innervated. Changes in $\alpha_{1}$ adrenergic subtypes, especially in innervated vessels, may constitute an explanation for the lack of long-term effects of $\alpha_{2}$-adrenoceptor agonists. 
In the present study, we treated young spontaneously hypertensive rats for 4 weeks with prazosin, rilmenidine or azepexole, with the purpose of decreasing the sympathetic input to the vascular system. We wanted to inquire into the possible arterial mechanisms that could be responsible for the transient antihypertensive effect found for several antihypertensive agents. The thoracic aorta, superior mesenteric artery, mesenteric resistance arteries and renal resistance arteries were chosen because of their differences with respect to the contribution to total peripheral resistance, role in the pathogenesis of hypertension, innervation density, responsiveness to adrenergic stimuli and presence of $\alpha_{2}$-adrenoceptor subtypes (De Mey \& Vanhoutte, 1981; 1982; Nilsson et al., 1986; Eerdmans et al., 1991; Jackson et al., 1992; Feng et al., 1993).

The adrenergic responses and adrenoreceptor subtype populations were extensively investigated using electrical nerve stimulation, pharmacological tools and receptor binding studies (whole kidney preparations).

\section{Materials \& methods}

\section{Animals \& treatment}

Experiments were performed in 8 weeks old male specific pathogen-free Spontaneously Hypertensive rats (SHR) of the Okamoto strain (Central Animal Facilities; University of Limburg, Maastricht, The Netherlands). The animals were maintained on 12 hour dark - 12 hour light cycles and had free access to standard lab food and tap water. Four groups of animals $(n=40,10$ each) were defined: 1) treatment with solvent $\left(\mathrm{H}_{2} \mathrm{O}\right)$ (control), 2) treatment with 0.1 $\mathrm{mg} / \mathrm{kg} /$ day prazosin, 3) treatment with $6 \mathrm{mg} / \mathrm{kg} /$ day rilmenidine and 4) treatment with $60 \mathrm{mg} / \mathrm{kg} /$ day azepexole. The drugs were administered with the aid of a subcutaneously implanted osmotic minipump (Alzet 2ML2; Alza Co, Palo Alto, Ca USA). These osmotic minipumps are functional for two weeks and release approximately $120 \mu \mathrm{l} /$ day. After two weeks of treatment they were replaced, to ensure 4 weeks of continuous drug treatment.

\section{Tissue preparation}

After four weeks of treatment with either solvent, prazosin, rilmenidine or azepexole, the rats were sacrificed by stunning and exsanguination. Femoral arterial segments, needed for nerve density measurements, were prepared from one of the legs, left or right at random. The right kidney was isolated and saved for the radioligand binding study. The thoracic aorta, superior mesenteric artery, mesentery and left kidney were isolated and two segments 
of approximately $2 \mathrm{~mm}$ were cut from the aorta and superior mesenteric artery. The mesentery was pinned out on a petri dish coated with Silgard (Dow Corning Corp.) and two fourth order resistance-sized side branches of the superior mesenteric artery (diameter approximately $200 \mu \mathrm{m}$ ) were dissected. The kidney was cut in half, one side was pinned on a petri dish, and two small intra-lobar arteries were isolated.

\section{Myograph experiments}

From each pair of isolated arteries, one preparation was treated for 30 minutes in aerated Krebs solution with $100 \mu \mathrm{M}$ chloroethylclonidine (CEC). This concentration and duration of exposure to CEC has previously been shown to irreversibly block $\alpha_{1 \mathrm{~B}}$ and $\alpha_{1 \mathrm{D}}$-AR (Piascik et al., 1990; Han \& Minneman, 1991; Michel et al., 1994). After the pretreated vessels had been rinsed, all arteries were mounted in a myograph (JP Trading Corp., Risskov, Denmark) (Mulvany \& Halpern, 1977; Heesen \& De Mey, 1990), with a CEC treated and a non-treated artery of the same type mounted in parallel in each myograph. The vessels were mounted horizontally in an organ chamber between an isometric force transducer (Statham UC3 and Kistler Morse DSC6 for large and small vessels, respectively) and a displacement device using 2 stainless steel wires (diameter $0.04 \mathrm{~mm}$ ). The organ chamber was filled with Krebs-Ringer bicarbonate solution (KRB, 25 and $10 \mathrm{ml}$ for large and small vessels, respectively) that was maintained at $37^{\circ} \mathrm{C}$ and aerated with $95 \% \mathrm{O}_{2}$ and $5 \% \mathrm{CO}_{2}$.

Prior to experimentation, the internal diameters of the thoracic aorta and superior mesenteric artery segments were set at 1675 and $1020 \mu \mathrm{m}$ respectively, values which had been found in preliminary experiments to yield strong and reproducible contractile responses. It was not possible to stretch these large vessels to their individual optimal diameters, as was normally done in the smaller arteries, as the time-span for contracting and relaxing the larger vessels is approximately 45 minutes. In other words, it would take a whole day to construct the full relationship between active wall tension and diameter. Furthermore, the relationship between diameter and active tension is too shallow in these vessels to allow accurate determination of optimal diameters. In contrast, mesenteric and renal resistance arteries were stretched to their individual optimal internal circumference for isometric force development by an active length-tension protocol (Boonen \& De Mey, 1990; 1991; Heesen \& De Mey, 1990; Eerdmans et al., 1991). For this their circumference was increased by $60 \mu \mathrm{m}$ every 5 minutes, with intermittent exposure to $10 \mu \mathrm{M}$ serotonin. This length-tension protocol was continued until maximal contractile 
responses had been obtained.

Contractile responses were induced with high potassium solution and with the agonists noradrenaline, phenylephrine, 5-hydroxytryptamine and Argvasopressin. Relaxing responses to isoproterenol or acetylcholine were induced after the preparations had been made to contract with $30 \mathrm{nM}$ Arg-vasopressin, or with $10 \mu \mathrm{M}$ phenylephrine if no sustained contraction could be obtained. To rule out effects of $\beta$ - and $\alpha_{2}$-adrenoceptor stimulation, all agonist concentration-response curves, except the concentration response curve of isoproterenol, were constructed in the presence of $1 \mu \mathrm{M}$ propranolol and $1 \mu \mathrm{M}$ yohimbine.

All agents were tested in the same vessels, but the order of testing was randomized to exclude the possibility that responses to a given agonist were influenced by pretreatment with another agent. To stimulate the sympathetic nerves in the superior mesenteric arteries and the mesenteric resistance and renal resistance arteries, 2 platinum electrodes connected to a constant current source (amplitude $85 \mathrm{~mA}$ ) were placed longitudinally across the mounted vessel segments, and frequency response curves $(1-32 \mathrm{~Hz}$, pulse duration 2 msec) were constructed (Nilsson, 1985; Eerdmans et al., 1991). The experiments in the isolated aorta, superior mesenteric artery and resistance artery segments took approximately 6 hours to perform.

\section{Nerve density}

We determined nerve density in the femoral artery. It was not possible to evaluate nerve density in smaller arteries like the mesenteric resistance artery because of their very high nerve density. Noradrenaline containing nerves were stained with a glyoxylic acid (Bjorklund et al., 1972; Cowen \& Burnstock, 1980) which causes a fluorescent staining of adrenergic nerves. The method used was as follows, the dissected femoral artery was rinsed in cold KREBS solution, and then incubated for thirty minutes at $37^{\circ} \mathrm{C}$ in a phosphate buffered solution ( $\mathrm{pH}=7.2$.) containing $2 \%$ glyoxylic acid and $10 \%$ sucrose. After incubation the vessel was rinsed with phosphate buffer solution, stretched on a microscopic slide and dried under a stream of room air for thirty minutes. The artery was heated to $100^{\circ} \mathrm{C}$ for four minutes, after which photographs, three of each vessel, were taken using fluorescence microscopy (microscope Nikon Diaphot, BA 470-DM 455 filter, Nikon FE2 camera). Nerve density was calculated using a curvilinear test system by MERZ (Merz, 1967; Weibel, 1989) The grid was placed and fixed over the photograph of a stained vessel. The inspected area of the vessel was determined by counting the test points $(\mathrm{Pt})$ of the grid. 


\section{Chapter 5}

The same number of testpoints was always used, so the area was the same in all vessels. The following equations were used to calculated the nerve density.

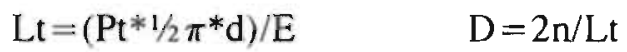

$\mathrm{Lt}=$ test line length, $\mathrm{Pt}=$ number of test points $(150), \mathrm{d}=$ diameter hemicircle $(10 \mathrm{~mm}), \mathrm{E}=$ enlargement $(115 \mathrm{X}), \mathrm{D}=$ nerve density (crossings $/ \mathrm{mm}$ testline), $\mathrm{n}=$ total number of nerve fibers crossing the grid lines.

Three pictures were screened in this way, after which the average was calculated.

A curvilinear test system by MERZ was used to determine the sympathetic nerve density of the femoral artery.

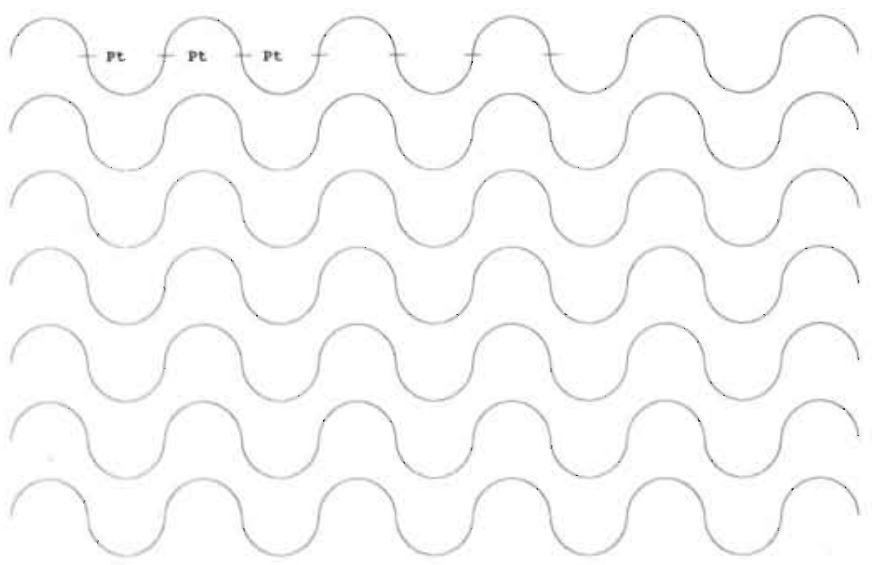

The grid, consisting of semicircles with a diameter of $10 \mathrm{~mm}$, was placed over the picture taken of a femoral artery stained with glyoxylic acid and examined with the aid of a fluorescence microscope. $\mathrm{Pt}$ are test points and have been counted over the whole grid.

\section{Ligand binding}

Radioligand binding was used to determine the number of $\alpha_{1}$-adrenoceptor subtypes in renal arteries. Sufficient material could only be obtained by pooling arteries from $\mathrm{X}$ to $\mathrm{Y}$ animals. Since this was not compatible with our study design, a maximum of 10 animals were used for each treatment, and sufficient amounts of tissue were obtained by using whole kidneys. Properties of vascular $\alpha$-adrenoceptors could be evaluated because it was known that only $\alpha_{12}$-adrenoceptor subtypes are found in intra-renal vessels (Ekblad et al., 1983; Owen, 1993). Discrimination of subtypes, in other words between vascular and renal tissue, was made possible by treatment with chloroethylclonidine. The kidneys used for ligand binding studies were minced and incubated for 30 minutes in $\mathrm{KRB}$ solution at $37^{\circ} \mathrm{C}$ to remove remaining blood cells. The kidney 
preparation was subsequently preincubated for another 30 minutes with 100 $\mu \mathrm{M}$ chloroethylclonidine, after which the alkylating agent was removed by repeated washing. The tissue samples were placed in tubes containing $0.25 \mathrm{M}$ ice-cold sucrose solution, homogenised (Ultra-Turrax, Omni 2000, Omni International, USA) and centrifuged at $1500 \mathrm{~g}$ for 20 minutes at $4{ }^{\circ} \mathrm{C}$. A microsomal preparation was pelleted from the resulting supernatant by 30 minutes centrifugation at $100.000 \mathrm{~g}$. The pellet was stored at $-70^{\circ} \mathrm{C}$ until further use. On the day of the assay, the pellet was resuspended in assay buffer (50 mM TRIS, $5 \mathrm{mM} \mathrm{MgCl}_{2}$, $\mathrm{pH} \mathrm{7.4)} \mathrm{and} \mathrm{centrifuged} \mathrm{for} 30$ minutes at $4^{\circ} \mathrm{C}$ at $100.000 \mathrm{~g}$. The resulting pellet was resuspended in assay buffer and subsequently diluted to make a final tissue protein concentration of $75-90 \mu \mathrm{g}$ of protein $/ 100 \mu \mathrm{l}$. The density and affinity of $\alpha_{1}$-adrenoceptors were determined in saturation binding experiments by incubating $100 \mu \mathrm{l}$ of the membrane preparation with increasing concentrations $(0.05-2 \mathrm{nM})$ of $\left[{ }^{3} \mathrm{H}\right]$ prazosin $(79.2$ $\mathrm{Ci} / \mathrm{mmol}$, New England Nuclear) for 40 minutes. Competition experiments were conducted by incubating $50 \mu \mathrm{l}$ of a single concentration of ${ }^{3} \mathrm{H}$ prazosin $(0.2 \mathrm{nM}), 100 \mu \mathrm{l}$ of membrane preparation, and $50 \mu \mathrm{l}$ of the competing drug (+)-niguldipine at concentrations of $10^{-11}-10^{-5} \mathrm{M}$. Parallel incubations were performed in the presence of $10 \mu \mathrm{M}$ phentolamine to determine nonspecific binding. All binding assays were performed in duplicate in a total volume of $250 \mu \mathrm{l}$ at $25^{\circ} \mathrm{C}$ for 40 minutes in a shaking bath. The reaction was terminated by adding $5 \mathrm{ml}$ ice-cold assay buffer, followed by rapid filtration under vacuum over Whatman GF/C fiber paper and rinsing twice with $5 \mathrm{ml}$ ice cold assay buffer. The bound radioligand retained on the filters was determined in a liquid scintillation counter.

\section{Drugs and Solutions}

During dissection, mounting and experimentation the preparations were immersed in a Krebs bicarbonate buffered physiological salt solution (KRB). $\mathrm{KRB}$ had the following millimolar composition: $\mathrm{NaCl} 118.3, \mathrm{KCl} 4.7, \mathrm{CaCl}_{2}$ 2.5, $\mathrm{MgSO}_{4} .7 \mathrm{H}_{2} \mathrm{O}$ 1.2, $\mathrm{KH}_{2} \mathrm{PO}_{4}$ 1.2, $\mathrm{NaHCO}_{3}$ 25.0, glucose 11.1. High potassium solution (K-KRB) was prepared by replacing all $\mathrm{NaCl}$ in normal $\mathrm{KRB}$ with an equimolar amount of $\mathrm{KCl}$. L-isoproterenol hydrochloride, Lnoradrenaline hydrochloride, L-phenylephrine hydrochloride, L-prazosin hydrochloride, DL-propranolol hydrochloride and glyoxylic acid were obtained from Sigma Chemical Co (Saint Louis, Mo USA). Acetylcholine hydrochloride and serotonin creatinine sulphate monohydrate were purchased from Janssen Chimica (Beerse, Belgium) and Arg-vasopressin from Sandoz (Basel, Switzerland). Rilmenidine was obtained from Servier (France). 
Azepexole (BHT-933) was obtained from Boehringer Ingelheim and yohimbine hydrochloride from Roussel (France). Chloroethylclonidine, $(+)$ niguldipine and phentolamine mesylate were obtained from Research Biochemicals International (USA), ${ }^{3} \mathrm{H}$-prazosin from NEN-Products Dupont (USA).

\section{Data Analysis}

Contractile responses of isolated blood vessels to agonists were expressed as increases in wall tension (increases in isometric force divided by twice the segment length) and relative to the amplitude of the contraction induced by $125 \mathrm{mM}$ potassium or $125 \mathrm{mM}$ potassium $+10 \mu \mathrm{M}$ noradrenaline (small arteries) in the same preparation. Sensitivity to the contractile effects of agonists or nerve stimulation was determined by interpolation on a least square sigmoidal curve fit of the individual concentration response curves (Inplot, GraphPad, San Diego, Ca, USA). Data are shown as mean \pm SEM. Statistical significance of effects and of differences between treatment groups was evaluated by Student's t-test for paired observations, Student's t-test for unpaired observations or analysis of variance followed by Bonferroni's t-test where appropriate (Wallenstein et al., 1980) using commercially available software (Crunch, Software Corp., San Francisco, Ca USA).

\section{Results}

\section{Ligand binding in kidney}

The affinity (Kd) and number (Bmax) of $\alpha_{1^{-}}$and CEC resistant $\alpha_{1}$ adrenoceptors in the kidney were measured by means of saturation curves (with/without CEC pretreatment) using the labelled $\alpha_{1}$-adrenoceptor antagonist ${ }^{3} \mathrm{H}$-prazusin. Figure la,b shows the affinity and number of $\alpha_{1^{-}}$and CEC resistant $\alpha_{1}$-adrenoceptors $\left(\alpha_{1 \mathrm{~A}}\right)$ in the kidney for the various treatments. The relation between $\alpha_{1 \mathrm{~A}}$ and $\alpha_{1 \mathrm{~B}}$ was also evaluated with a different method. We constructed displacement curves with (+)niguldipin. (+)Niguldipin is a well known $\alpha_{1}$-adrenoceptor agonist (Jackson et al., 1992; Michel et al., 1994) with a high affinity side for $\alpha_{1 \mathrm{~A}^{-}}$-adrenoceptors and a low affinity side for $\alpha_{1 \mathrm{~B}^{-}}$ adrenoceptors. The two component displacement curves were used to determine $\mathrm{Ki}$ (not shown) and the relation between $\alpha_{1 \mathrm{~A}}$ (high affinity) and $\alpha_{1 \mathrm{~B}}$ (low affinity) adrenoceptors in the kidneys. Ki values were the same for both $\alpha_{1}$-adrenoceptor subtypes. 

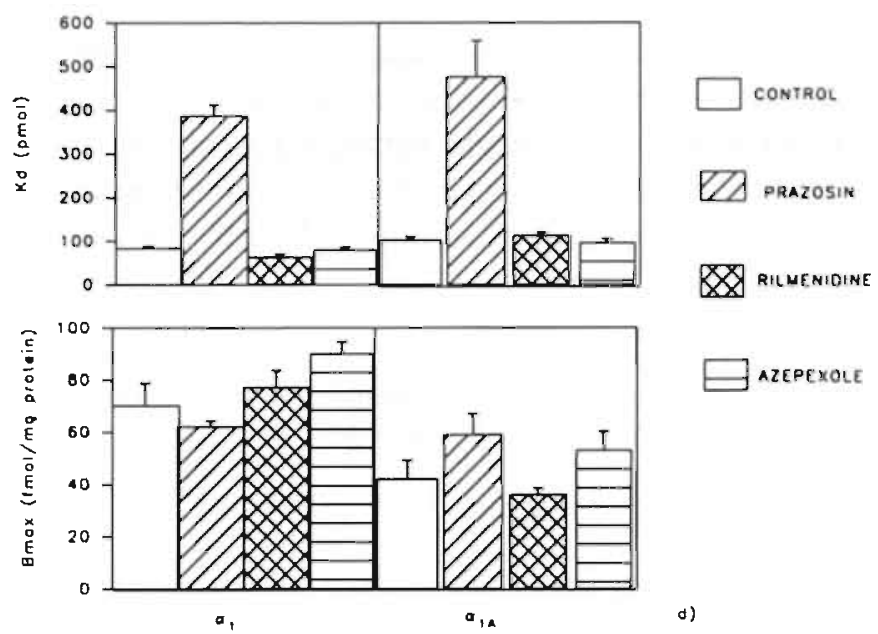

RILArNione

d)
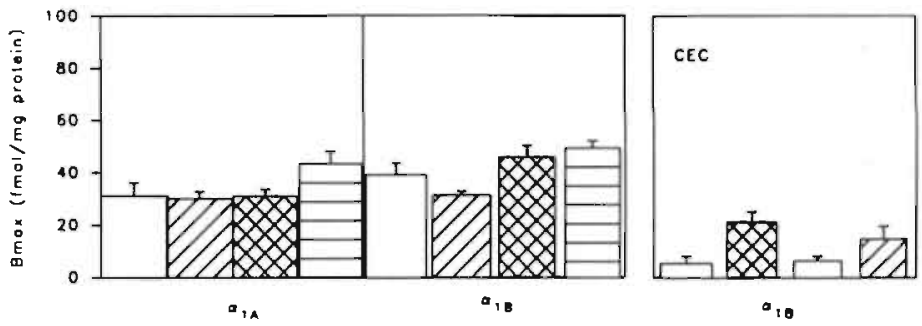

Figure 1

Affinity and numbers of $\alpha_{1^{-}}, \alpha_{1 A^{-}}$and $\alpha_{1 B^{-}}$adrenoceptors of whole kidneys from SHR rats treated for 4 weeks with solvent, prazosin, rilmenide or azepexole. Saturation curves with ${ }^{3} \mathrm{H}$-prazosin were obtained from microsomal preparations of whole kidneys from treated rats. From the curves, affinity (Kd, figure a) and numbers of receptors (Bmax, figure b) could be calculated. Pretreatment with chloroethylclonidine (CEC) before constructing the saturation curves made it possible to determine $\alpha_{1 A}$-adrenoceptors (receptors resistant to akylating by CEC). By constructing displacement curves with (+)-niguldipin and making use of the $\alpha_{1 A^{-}}$high and $\alpha_{1 B^{-}}$low affinity side of this compound it was possible to differentiate between the two subtypes (figure c). Furthermore the chloroethylclonidine properties were confirmed by calculating the Bmax of $\alpha_{1 \mathrm{H}^{-}}$adrenoceptors after pretreatment (figure d). No significant changes in $\mathrm{Kd}, \mathrm{Bmax}$ or the relation between $\alpha_{1 \mathrm{~A}^{-}}$and $\alpha_{1 \mathrm{~B}^{-}}$ adrenoceptors were found after the treatment. Data are shown as mean \pm SEM.

The $\alpha_{1}$-Bmax value calculated from saturation curves, and the relation between $\alpha_{1 \mathrm{~A}}$ and $\alpha_{1 \mathrm{~B}}$, calculated from displacement curves, were used to determine the Bmax value of $\alpha_{1 \mathrm{~A}}$ and $\alpha_{1 \mathrm{~B}}$ (figure 1c). By way of control $\alpha_{1 \mathrm{~B}}-\mathrm{Bmax}$ was determined after pretreatment with chloroethylclonidine (figure ld). 
Nerve density

The noradrenaline in the nerves surrounding the femoral artery was stained. The staining technique used only allows the amount of noradrenaline to be determined. No distinction can be made between the number of nerves or the concentration of noradrenaline per nerve. The density of the nerves calculated with the MERZ grid did not differ significantly for the various treatments (table 1).

Table 1.

Sympathetic nerve density in the femoral artery of spontaneously hypertensive rats after four weeks of treatment with solvent, prazosin, rilmenidine or azepexole.

\begin{tabular}{lllll}
\hline & solvent & prazosin & rilmenidine & azepexole \\
\hline $\mathrm{n}$ & 7 & 9 & 7 & 7 \\
nerve density & $43.7 \pm 1.6$ & $40.9 \pm 1.3$ & $44.4 \pm 2.1$ & $40.2 \pm 2.1$ \\
\hline
\end{tabular}

Nerve density in the femoral artery determined after glyoxylic acid staining. Values are meantSEM.

\section{Pharmacological evaluation}

\section{Thoracic aorta}

\section{Contractile responses}

Contractile responses induced by stimulating several receptor types were evaluated. Maximal contractile responses to several stimuli can be found in table 2, which shows that increased maximal responses were found in the arteries of rats treated with rilmenidine, while vessels pretreated with CEC showed no increased responses. CEC pretreatment significantly decreased maximal responses in the rilmenidine and azepexole treated animals. Figure 2 shows the concentration response curves for noradrenaline with or without CEC pretreatment and for serotonin. Responses to noradrenaline and serotonin did not differ after 4 weeks of treatment with prazosin, rilmenidine or arcpexole. 
Table 2

Contractile properties of the aorta.

\begin{tabular}{|c|c|c|c|c|}
\hline & saline: & prazosin & rilmenidine & azepexole: \\
\hline n & 10 & 10 & 8 & 8 \\
\hline $\begin{array}{l}125 \mathrm{mM} \mathrm{K}-\mathrm{KRB} \\
(\mathrm{mN} / \mathrm{mm})\end{array}$ & $1.94 \pm .34$ & $1.94 \pm .26$ & $3.56 \pm .57^{*}$ & $2.91 \pm .32$ \\
\hline $\begin{array}{l}10 \mu \mathrm{M} N A \\
(\mathrm{mN} / \mathrm{mm})\end{array}$ & $2.54 \pm .34$ & $2.51 \pm .28$ & $4.09 \pm .59^{*}$ & $3.27 \pm .41$ \\
\hline $\begin{array}{l}10 \mu \mathrm{M} 5-\mathrm{HT} \\
(\mathrm{mN} / \mathrm{mm})\end{array}$ & $2.41 \pm .53$ & $2.51 \pm .32$ & $4.85 \pm .67^{*}$ & $3.27 \pm .44$ \\
\hline $\begin{array}{l}30 \mathrm{nM} \text { AVP } \\
(\mathrm{mN} / \mathrm{mm})\end{array}$ & $2.26 \pm .29$ & $2.25 \pm .3$ & $3.42 \pm .54^{*}$ & $2.84 \pm .30$ \\
\hline
\end{tabular}

After CEC pretreatment.

\begin{tabular}{|c|c|c|c|c|}
\hline $\begin{array}{l}125 \mathrm{mM} \mathrm{K}-\mathrm{KRB} \\
(\mathrm{mN} / \mathrm{mm})\end{array}$ & $1.82 \pm .29$ & $1.61 \pm .23$ & $2.67 \pm .65$ & $1.99 \pm .23 \#$ \\
\hline $\begin{array}{l}10 \mu \mathrm{MNA} \\
(\mathrm{mN} / \mathrm{mm})\end{array}$ & $2.06 \pm .29$ & $2.15 \pm .28$ & $2.34 \pm .59 \#$ & 1.59 上. $22 \#$ \\
\hline
\end{tabular}

Contractile properties of the aorta of SH rats treated with saline, prazosin, rilmenidine or azepexole. Maximal contractions were produced with high potassium Krebs solution (125 mM K-KRB). noradrenaline (NA), serotonin (5-HT) and Arg-vasopressin (AVP), * indicates significance of difference compared to saline (t-test $\mathbf{P}<0.05$ ). \# indicates significance of difference compared to artery not pre-treated with CEC. Values are mean \pm SEM

\section{Figure 2}

Concentration response curves for noradrenaline, noradrenaline after pretreatment with CEC and serotonin in aorta.
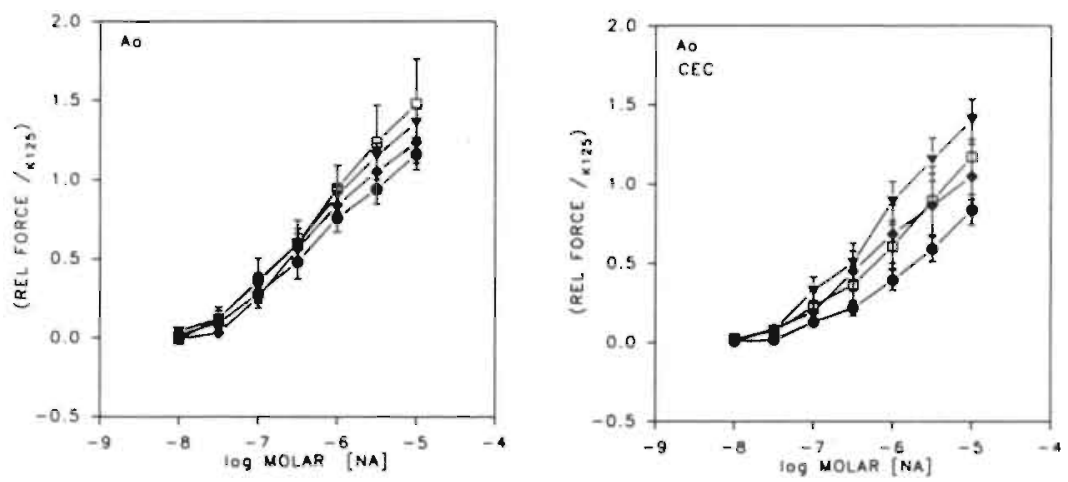


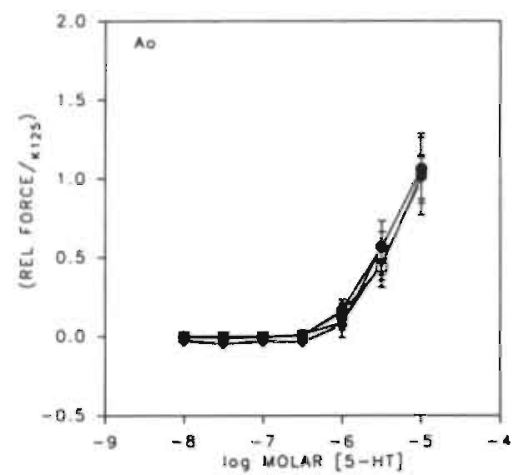

C CONTROL

- prazosin

- RILMENIDINE

- azEPEXole
Concentration response curves obtained using the aorta of SH rats treated for four weeks with either saline, prazosin. rilmenidine or azepexole. Concentration response curves were obtained for noradrenaline (NA) in normal vessels (previous page, left) and in vessels pretreated with chloroethylclonidine (CEC, previous page, right).

Furthermore, concentration response curves were obtained with serotonin (5$H T$ ). Data are shown as mean $\pm S E M$.

\section{Relaxing responses}

Not only receptors causing contraction were evaluated, but also receptor types causing relaxation. The aortas were brought into a contractile state with the aid of Arg-vasopressin. $\beta$ Adrenoceptor responses were evaluated with isoproterenol. As can be seen in figure 3 , hardly any $\beta$ adrenergic receptor relaxation occurred. Endothelium dependent relaxation was evaluated with acetylcholine (figure 3). Significant differences in $\mathrm{ED}_{50}$ were found in all three treatments compared to the control group. (control $\mathrm{ED}_{50}=0.38 \mu \mathrm{M}$, prazosin $\mathrm{ED}_{50}=1$ $\mu \mathrm{M}$, rilmenidine $\mathrm{ED}_{50}=2.7 \mu \mathrm{M}$, azepexole $\left.\mathrm{ED}_{50}=1.3 \mu \mathrm{M}\right)$.
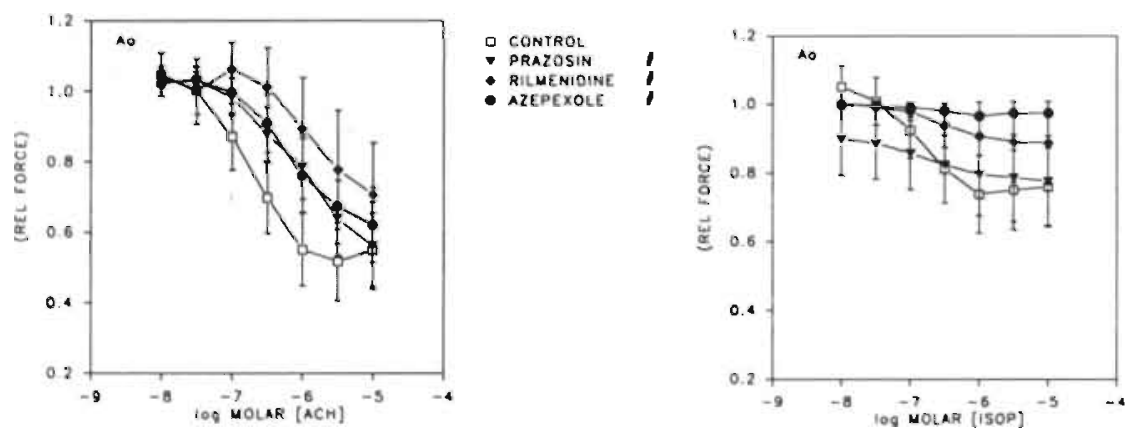

D. CONTROL

- prazosita

- azepexole

Figure 3

Concentration response curves for acetylcholine (left) and isoprenaline (right) were obtained in the aorta precontracted with Arg-vasopressin. \#p $<0.05$ compared to control. Data are shown as mean \pm SEM. 


\section{Superior mesenteric artery}

\section{Contractile responses}

Maximal responses to high potassium Krebs solution and contractile agents are shown in table 3. Adrenergic responses after pretreatment with chloroethylclonidine were significantly reduced in prazosin and rilmenidine treated animals.

Table 3

Contractile properties of the superior mesenteric artery.

\begin{tabular}{lllll}
\hline & saline & prazosin & rilmenidine & azepexole \\
\hline $\mathrm{n}$ & 10 & 8 & 8 & 8 \\
$\begin{array}{l}125 \mathrm{mM} \mathrm{K}-\mathrm{KRB} \\
(\mathrm{mN} / \mathrm{mm})\end{array}$ & $4.22 \pm .61$ & $4.35 \pm .30$ & $5.26 \pm .43$ & $3.59 \pm .63$ \\
$\begin{array}{l}10 \mu \mathrm{M} \mathrm{NA} \\
(\mathrm{mN} / \mathrm{mm})\end{array}$ & $4.68 \pm .50$ & $5.15 \pm .0 .55$ & $5.81 \pm .59$ & $3.61 \pm .51$ \\
$\begin{array}{l}10 \mu \mathrm{M} \mathrm{5-HT} \\
(\mathrm{mN} / \mathrm{mm})\end{array}$ & $4.32 \pm .50$ & $5.41 \pm .54$ & $6.41 \pm .60^{*}$ & $4.31 \pm .65$ \\
$\begin{array}{l}30 \mathrm{nM} \mathrm{AVP} \\
(\mathrm{mN} / \mathrm{mm})\end{array}$ & $3.72 \pm .42$ & $3.85 \pm .36$ & $4.64 \pm .45$ & $3.05 \pm .48$ \\
\hline
\end{tabular}

After CEC pretreatment.

$\begin{array}{lllll}125 \mathrm{mM} \mathrm{K}-\mathrm{KRB} & 4.31 \pm .89 & 2.51 \pm .41 \# & 3.34 \pm .72 & 3.37 \pm .46 \\ (\mathrm{mN} / \mathrm{mm}) & 3.85 \pm .69 & 2.45 \pm .33 \# & 3.37 \pm .66 \# & 3.59 \pm .47 \\ \begin{array}{l}10 \mu \mathrm{M} \mathrm{NA} \\ (\mathrm{mN} / \mathrm{mm})\end{array} & & & \end{array}$

Contractile properties of the superior mesenteric artery of SH rats treated with saline, prazosin, rilmenidine or azepexole. Maximal contractions were produced with high potassium Krebs solution (125 mM K-KRB), noradrenaline (NA), serotonin (5-HT) and Arg-vasopressin (AVP). * indicates: significance of difference compared to saline (t-test $P<0.05)$. \# indicates significance of difference compared 10 artery not pretreated with CEC $(t$-test $P<0.05)$. Values are mean $\pm S E M$.

Concentration response curves for noradrenaline in the absence or presence of cocaine (COC) and after pretreatment with CEC can be seen in figure 4. Concentration response curves for noradrenaline were the same in all groups. Reducing the noradrenaline re-uptake with cocaine did not reveal any discrepancies. Only prazosin treated animals showed increased sensitivity (control $\mathrm{ED}_{50}=0.34 \mu \mathrm{M}$, prazosin $\mathrm{ED}_{50}=0.21 \mu \mathrm{M}$ ) in the presence of cocaine, though the increase was not significantly. Phenylephrine concentration response curves (figure 4), however, showed increased sensitivity in both prazosin and rilmenidine treated animals (control $\mathrm{ED}_{50}=1.83 \mu \mathrm{M}$, prazosin $\mathrm{ED}_{50}=0.45 \mu \mathrm{M}$, rilmenidine $\mathrm{ED}_{50}=0.83 \mu \mathrm{M}$ ).

Electrical nerve stimulation was applied to investigate possible modification of the sympathetic nerve endings (figure 5). 
Frequency response curves were obtained in arteries in the absence or presence of cocaine. The outcome of this evaluation showed no indication of a modification of either receptor mediated responses or neuronal re-uptake.
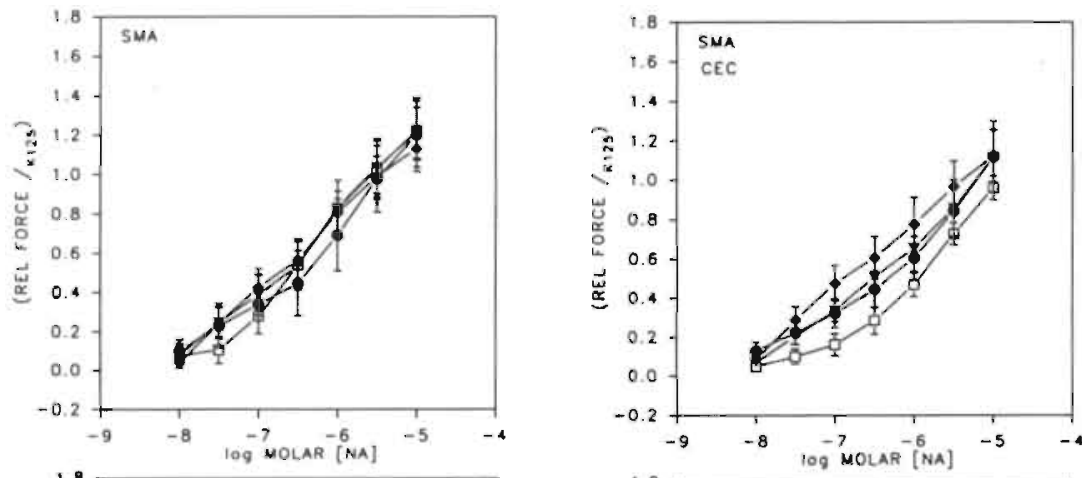

a CONTROL.

T PRAZOSIN

- rilnenidine

- aZEPEXOLE
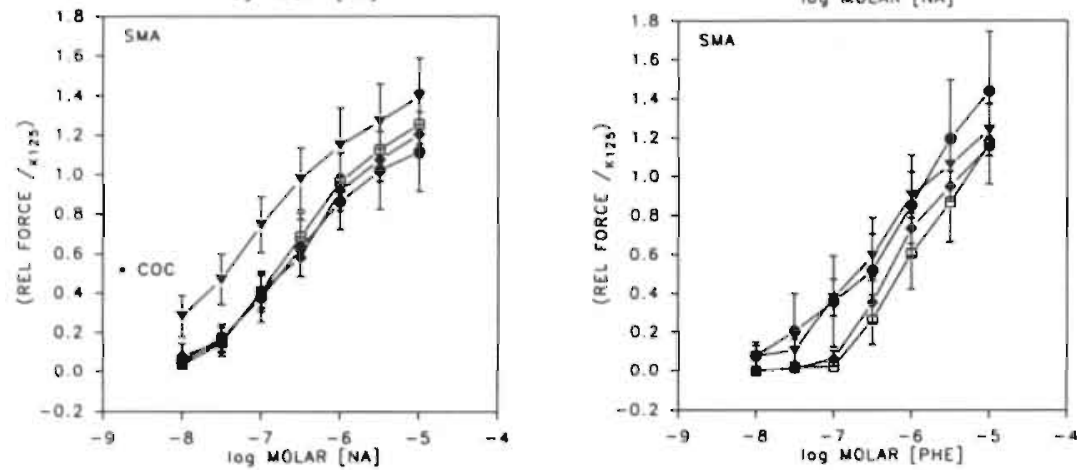

- CONIROL

- PRAROSIN

- riluenidine

- AZEPEXDLE.

Figure 4.

Concentration response curves obtained in superior mesenteric arteries of SH rats treated for four weeks with either saline, prazosin, rilmenidine or azepexole. Three different concentration response curves for noradrenaline (NA) were constructed: basic (top left), after pretreatment with chloroethylclonidine (CEC, top right) and in the presence of $3 \mu \mathrm{M}$ cocaine (bottom left). Furthermore, concentration response curves for phenylephrine were constructed (bottom right). The sensitivity to phenylephrine was significantly increased (t-test, $\mathrm{p}<0.05)$ in the prazosin $\left(E D_{50}=0.45\right.$ $\mu \mathrm{M})$ and rilmenidine $\left(E D_{50}=0.83 \mu \mathrm{M}\right)$ treated animals compared with the controls $\left(E_{50}=1.83\right.$ $\mu \mathrm{M})$. Data are shown as mean \pm SEM. 

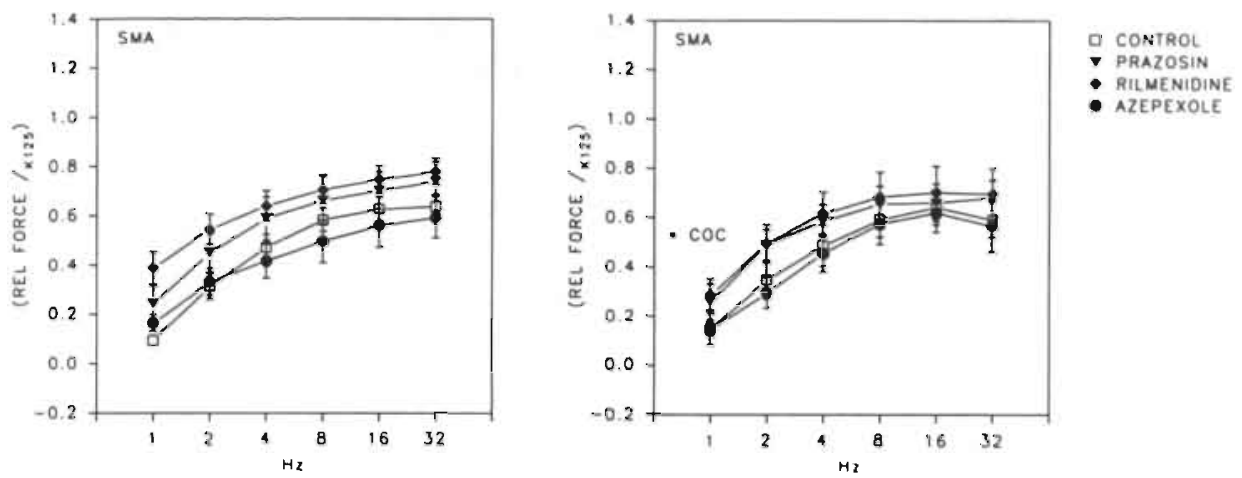

Figure 5

Frequency response curves constructed in superior mesenteric arteries. Frequency response curves constructed in superior mesenteric arteries of SH rats treated for four weeks with either solvent, prazosin, rilmenidine or azepexole. Frequencies from 1-32 Hz were induced with constant current ( $85 \mathrm{~mA}$ ) and variable voltage, under normal conditions (left) or in the presence of $3 \mu \mathrm{M}$ cocaine (right). Data are shown as mean $\pm \mathrm{SEM}$.

\section{Relaxing responses}

As with the aorta, endothelium dependent relaxations induced by acetylcholine (figure 6) were constructed in the vessels of the four treatments. Since hardly any relaxing effects were found in the rilmenidine treated animals, no $\mathrm{ED}_{50}$ could be calculated. However a significant decrease in maximal response was found in the superior mesenteric arteries of the rilmenidine $(p=0.007)$ and prazosin $(p=0.027)$ treated rats. Furthermore, relaxing responses due to $\beta$ adrenoreceptor stimulation with isoproterenol did not reveal any shifts in sensitivity (data not shown).

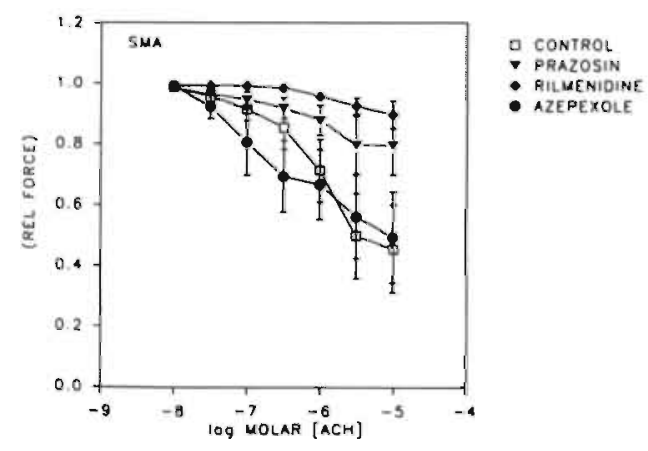

Figure 6

Concentration response curves for acetylcholine and isoprenaline in superior mesenteric arteries precontracted with Argvasopressin or phenylephrine.

Concentration response curves for acetylcholine were obtained in superior mesenteric arteries precontracted with Arg-vasopressin. Data are shown as mean \pm SEM. 


\section{Mesenteric resistance artery}

\section{Contractile responses}

The same properties evaluated in the superior mesenteric artery were investigated in smaller, resistance sized arteries. Maximal responses (table 4) did not differ for the various groups with or without pretreatment with CEC.

Table 4

Contractile properties of the mesenteric resistance artery.

\begin{tabular}{lllll}
\hline & saline & prazosin & rilmenidine & azepexole \\
\hline $\mathrm{n}$ & 9 & 10 & 8 & 8 \\
ID $(\mu \mathrm{m})$ & $243 \pm 9$ & $244 \pm 11$ & $238 \pm 13$ & $238 \pm 9$ \\
$\begin{array}{l}10 \mu \mathrm{M} \mathrm{NA}+\mathrm{K}-\mathrm{KRB} \\
(\mathrm{mN} / \mathrm{mm})\end{array}$ & $4.42 \pm .20$ & $4.26 \pm .28$ & $3.75 \pm .33^{*}$ & $4.80 \pm .54$ \\
$\begin{array}{l}10 \mu \mathrm{M} \mathrm{NA} \\
(\mathrm{mN} / \mathrm{mm})\end{array}$ & $4.54 \pm .24$ & $4.31 \pm .28$ & $3.90 \pm .48$ & $4.93 \pm .53$ \\
$\begin{array}{l}10 \mu \mathrm{M} \mathrm{5-HT} \\
(\mathrm{mN} / \mathrm{mm})\end{array}$ & $4.01 \pm .26$ & $3.98 \pm .34$ & $3.85 \pm .36$ & $4.61 \pm .53$ \\
$\begin{array}{l}30 \mathrm{nM} \mathrm{AVP} \\
(\mathrm{mN} / \mathrm{mm})\end{array}$ & $4.19 \pm .28$ & $4.04 \pm .28$ & $3.95 \pm .33$ & $4.31 \pm .34$ \\
\hline
\end{tabular}

After CEC pretreatment.

$\begin{array}{lllll}\text { ID }(\mu \mathrm{m}) & 264 \pm 10 & 256 \pm 7 & 231 \pm 10 & 251 \pm 13 \\ 10 \mu \mathrm{M} N A+K-K R B & 3.76 \pm .21 & 4.50 \pm .48 & 3.68 \pm .41 & 4.34 \pm .29 \\ 10 \mu \mathrm{M} N A & 3.80 \pm .21 & 4.55 \pm .51 & 3.63 \pm .34 & 4.18 \pm .34\end{array}$

$(\mathrm{mN} / \mathrm{mm})$

Contractile properties of mesenteric resistance arteries of SH rats treated with saline, prazosin, rilmenidine or azepexole. The arteries were stretched to their individual optimal diameter, (ID, internal diameter). Maximal contractions were produced with high potassium Krebs solution (125 $\mathrm{mM} \mathrm{K-KRB}$ ), noradrenaline (NA), serotonin (5-HT) and Arg-vasopressin (AVP). Values are mean $\pm S E M . *$ indicates significance of difference compared to saline (t-test $P<0.05$ )

Only in the rilmenidine treated animals was a significant decrease found in maximal response to high potassium Krebs with $10 \mu \mathrm{M}$ noradrenaline. Concentration response curves for noradrenaline under different conditions and for phenylephrine are shown in figure 7. As was also the case in the superior mesenteric artery, no differences were seen between the four groups for all conditions. Furthermore, responses to serotonin were the same after all treatments (data not shown).

Sympathetic nerve properties were investigated using electrical field stimulation, as can be seen in figure 8 . A significant increase in maximal responses was found in the prazosin and azepexole treated animals (top left). Frequency response curves were also obtained in the presence of cocaine (figure 8). The damping effect caused by re-uptake in the first frequency 
response curves disappeared, and even more pronounced differences were found. A significantly increased sensitivity to nerve stimulation was found in all three treatments $\left(\mathrm{ED}_{50} \pm 2,5 \mathrm{~Hz}\right.$, control $\mathrm{ED}_{50}=5,18 \mathrm{~Hz}$ ).
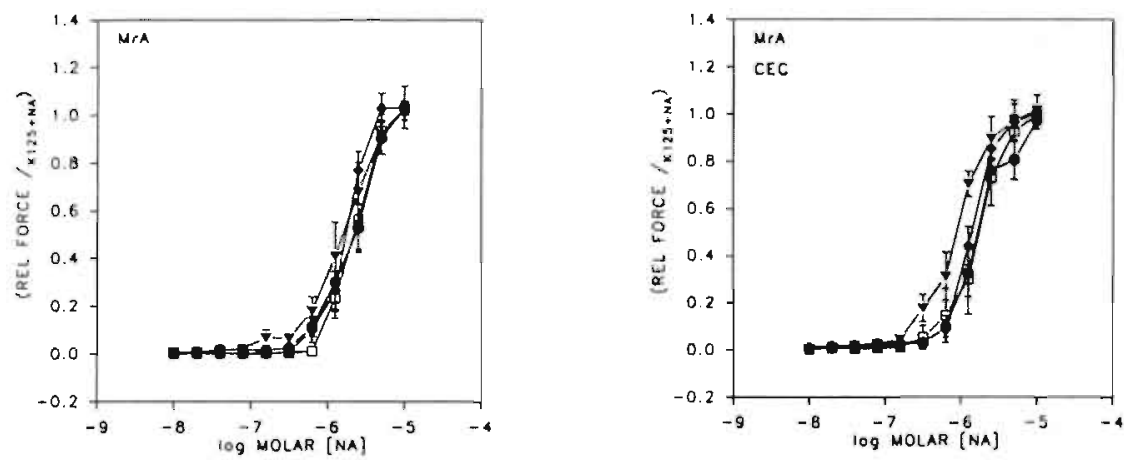

- CONIROL

- prazosin

- Rilmentoine

- azE.PEXole
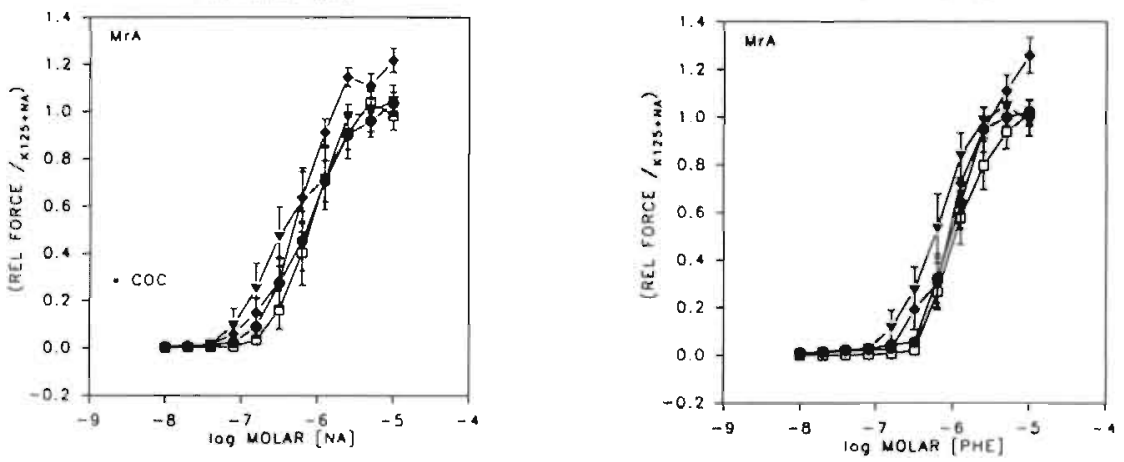

C. CORTROL

$\rightarrow$ PRAZOSIN

- RIL nenipine

- azepixole

\section{Figure 7}

Concentration response curves obtained in mesenteric resistance arteries of SH rats treated for four weeks with either saline, prazosin, rilmenidine or azepexole. Three different concentration response curves for noradrenaline (NA) were constructed; basic (top left), after pretreatment with chloroethylclonidine (CEC, top right), and in the presence of $3 \mu \mathrm{M}$ cocaine (bottom left). Furthermore, concentration response curves for phenylephrine were constructed (bottom right). Data are shown as mean \pm SEM. 

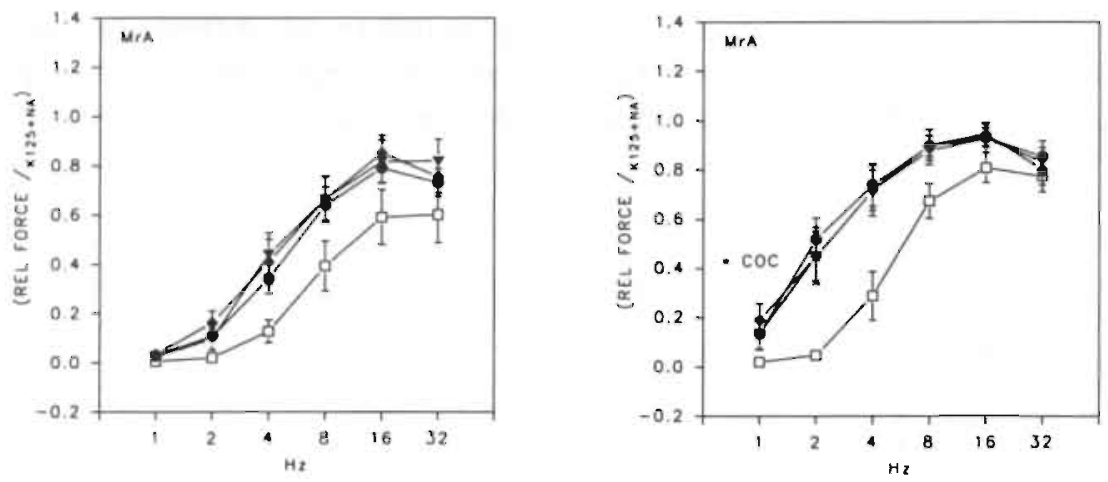

C CONTROL

- PRAZOSIN

- rilmenidine

- azEPExole

Figure 8

Frequency response curves in mesenteric resistance arteries were obtained under normal conditions and in the presence of $3 \mu \mathrm{M}$ cocaine. Frequencies of $1-32 \mathrm{~Hz}$ were induced with constant current $(85 \mathrm{~mA})$ and variable voltage. The frequency response curves of arteries without cocaine or CEC treatment showed significantly increased sensitivity comparing prazosin $\left(E D_{30}=4.01\right)$ and azepexole $\left(E D_{50}=4.60\right)$ with the controls $\left(E D_{50}=6.42\right)$ animals. In the presence of cocaine the increased sensitivity was even more pronounced: a significant increase was found in all three treatments compared to controls $\left(\mathrm{ED}_{50}=5,18\right)$, prazosin $\left(\mathrm{ED}_{50}=2,33\right)$, rilmenidine $\left(\mathrm{ED}_{50}=2,85\right)$ and azepexole $\left(E D_{50}=2,25\right)$ Data are shown as mean \pm SEM.

\section{Relaxing responses}

The relaxing responses to acetylcholine and isoproterenol did not differ for the various treatment groups (figure 9).
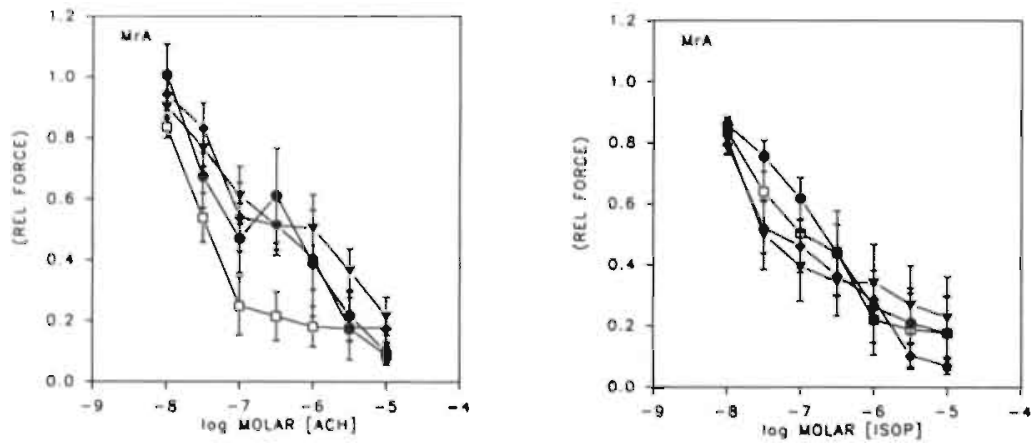

a CONTROL

- pRAZOOSIN

- RILMENioine

- AZEPEXOLE

\section{Figure 9}

Concentration response curves for acetylcholine $(\mathrm{ACH}$, left) and isoprenaline (ISOP, right) were obtained in mesenteric resistance arteries precontracted with Arg-vasopressin (ACH) or phenylephrine (ISOP). Data are shown as mean \pm SEM. 
Renal resistance artery

\section{Contractile responses}

Maximal responses (table 5) did not differ for the various groups with or without pretreatment with CEC. Concentration response curves of noradrenaline in the absence and presence of cocaine and after pretreatment with CEC are shown in figure 10. No significant changes were found for any of the three conditions, nor in the concentration response curve for phenylephrine (figure 10). Electrical nerve stimulation is shown in figure 11 . No significant changes were found after the 4 weeks of treatment.

Table 5

Contractile properties of renal resistance arteries.

\begin{tabular}{lllll}
\hline & saline & prazosin & rilmenidine & azepexole \\
\hline $\mathrm{n}$ & 9 & 10 & 8 & 8 \\
$\mathrm{ID}(\mu \mathrm{m})$ & $244 \pm 8$ & $245 \pm 13$ & $237 \pm 11$ & $259 \pm 13$ \\
$\begin{array}{l}10 \mu \mathrm{M} \mathrm{NA}+\mathrm{K}-\mathrm{KRB} \\
(\mathrm{mN} / \mathrm{mm})\end{array}$ & $3.01 \pm .58$ & $3.21 \pm .53$ & $2.48 \pm .37$ & $2.20 \pm .36$ \\
$\begin{array}{l}10 \mu \mathrm{M} \mathrm{NA} \\
(\mathrm{mN} / \mathrm{mm})\end{array}$ & $3.16 \pm .70$ & $2.88 \pm .54$ & $2.42 \pm .40$ & $2.20 \pm .33$ \\
$\begin{array}{l}10 \mu \mathrm{M} \mathrm{5-HT} \\
(\mathrm{mN} / \mathrm{mm})\end{array}$ & $2.90 \pm .59$ & $2.85 \pm .54$ & $2.43 \pm .36$ & $2.11 \pm .29$ \\
$\begin{array}{l}30 \mathrm{nM} \mathrm{AVP} \\
(\mathrm{mN} / \mathrm{mm})\end{array}$ & $2.68 \pm .47$ & $2.93 \pm .46$ & $2.35 \pm .38$ & $2.05 \pm .28$ \\
\hline
\end{tabular}

After CEC pretreatment.

$\begin{array}{lllll}\text { ID }(\mu \mathrm{m}) & 230 \pm 8 & 239 \pm 16 & 242 \pm 9 & 244 \pm 7 \\ 10 \mu \mathrm{M} \mathrm{NA}+\mathrm{K}-\mathrm{KRB} & 2.04 \pm .38 & 2.65 \pm .37 & 2.25 \pm .35 & 1.99 \pm .34 \\ (\mathrm{mN} / \mathrm{mm}) & & & & \\ 10 \mu \mathrm{M} \mathrm{NA} & 1.90 \pm .30 & 2.53 \pm .41 & 2.07 \pm .34 & 1.74 \pm .18 \\ (\mathrm{mN} / \mathrm{mm}) & & & & \end{array}$

Contractile properties of the renal resistance artery of SH rats treated with saline, prazosin, rilmenidine or azepexole. The arteries were stretched to their individual optimal diameter, (ID, internal diameter). Maximal contractions were produced with high potassium Krebs solution (125 $\mathrm{mM} \mathrm{K-KRB}$ ). Furthermore, maximal response to noradrenaline (NA), serotonin (5-HT) and Argvasopressin (AVP) were determined. Values are mean \pm SEM.

\section{Relaxing responses}

Concentration response curves for acetylcholine or for renal resistance arteries precontracted with Arg-vasopressin were the same in all four groups (data not shown). 

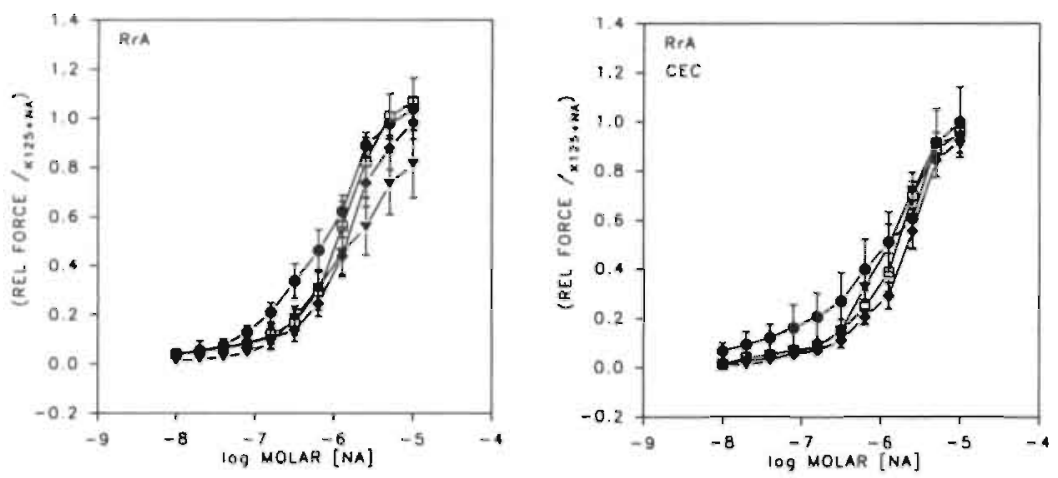

a CONTROL

- prazosia

- rilmenidine

- AZEPEXOLE
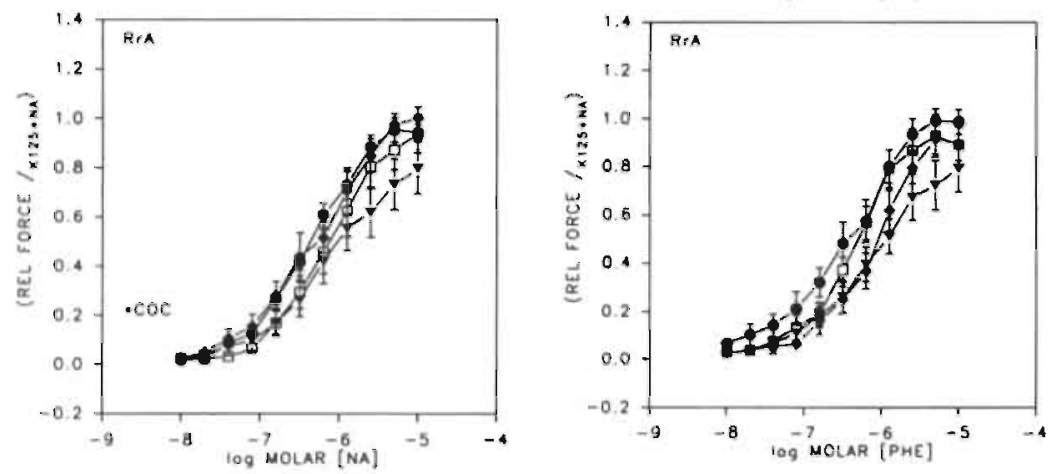

D CONTROL

- PRAZOSIN

- ril.menidine

- AZEPEXOLE.

\section{Figure 10}

Concentration response curves for noradrenaline and phenylephrine in renal resistance arteries. Concentration response curves obtained in renal resistance arteries of SH rats treated for four weeks with either saline, prazosin, rilmenidine or azepexole. Three different concentration response curves for noradrenaline (NA) were constructed: basic (top left), after pretreatment with chloroethylclonidine (CEC, top right), and in the presence of 3 $\mu \mathrm{M}$ cocaine (bottom left). Furthermore, concentration response curves for phenylephrine were obtained (bottom right). Data are shown as mean \pm SEM. 

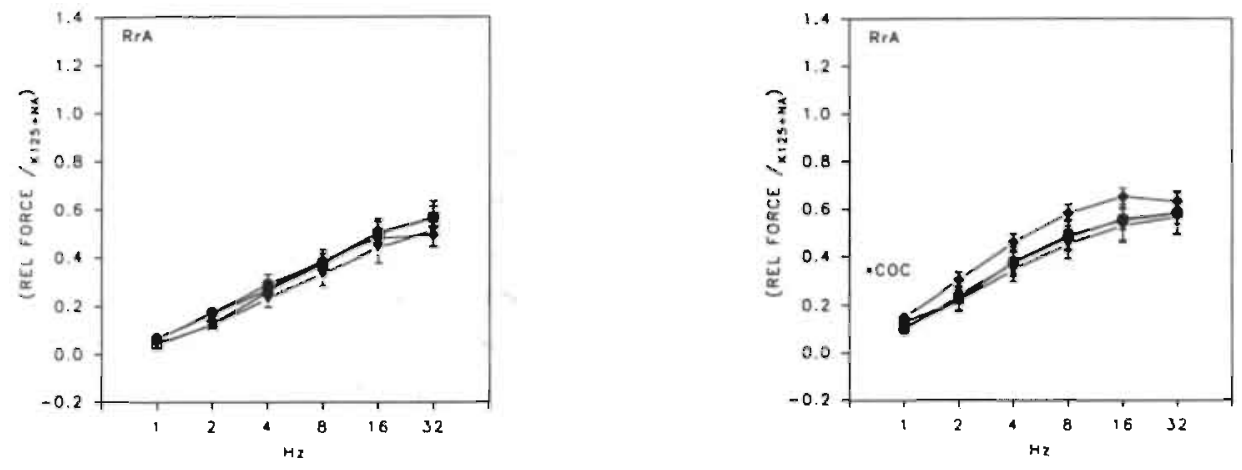

口 CONTROL

- PRAZOSIN

- rilmenidine

- aZEPEXOLE

\section{Figure 11}

Frequency response curves were obtained in the presence or absence of the $3 \mu \mathrm{M}$ cocaine (COC). Frequencies of $1-32 \mathrm{~Hz}$ were induced with constant current $(85 \mathrm{~mA})$ and variable voltage. Data are shown as mean \pm SEM.

\section{Discussion}

We investigated the effect of long-term decreased sympathetic activity on the adrenergic control of several types of arteries from SHR rats. Antihypertensive drugs that decrease sympathetic tone only have a transient effect on the blood pressure, and the mechanisms responsible for the increase in blood pressure during the treatment are unknown.

The purpose of the present study was to investigate the adrenergic pathway, trying to find the mechanism or mechanisms responsible for this effect. Although several blood pressure regulating systems exist, this discussion focuses on the sympathetic control mechanism only.

Basically the sympathetic blood pressure control consists of three parts; 1) a controller, 2) signal transporters 3) target organs. The signal transporters are the nerves which transport the signal from the centrally located vasomotor center to the target organs, the arteries. In the present study, $\alpha_{2}$-adrenoceptor agonists decreased the activity of the central vasomotor center for four weeks. This was confirmed by plasma catecholamine concentrations measured at the end of the treatment. Furthermore, some of the animals were treated with an $\alpha_{1}$-adrenoceptor antagonist, prazosin, that blocks the sympathetic control at the 
target organ side.

After four weeks the antihypertensive effect was gone, which in our simplified model means that the signal transporters and/or target organs must have been modified. One possibility is that the number of transporters (nerves) had increased or that they become more efficient. The same thing may have happened at the target organs: perhaps the signals transported by the nerves were processed more efficiently (increased sensitivity, receptor type changes) or the target organ itself may have become more efficient (increased contractibility). As a third option, inhibiting systems may have become less active, the netto effect being an increased vascular tone.

We investigated the sympathetic nerves (signal transporters) and arteries (target organs) in an attempt to find the missing link or links responsible for the transient effect of several types of antihypertensive drugs.

To begin with, let us focus on the arterial properties. The decreased sympathetic tone, i.e., the decreased noradrenaline release, was followed by increased arterial response which may have been caused by several variables. Firstly, the smooth muscle contractibility may have increased, implying more contraction with less excitation. However, the maximal responses to high potassium Krebs solution were the same in controls and treated animals, so we may conclude that no changes developed in the contractile apparatus. Secondly, the arteries may have become more sensitive. It is known that changes in the number or affinity of adrenoceptors (Michel et al., 1989; 1990) can be related to observed changes of the sympathetic nervous system in hypertensives (Aprigliano \& Hermsmeyer, 1977; Abboud, 1982; de Champlain, 1990; Esler et al., 1990; Michel et al., 1990; Mark, 1991). The $\alpha$-adrenoceptor population seems to become less sensitive in response to decreased stimuli. The opposite has been found in the $\beta$-adrenoceptor population, where increased stimulation resulted in a rapid down-regulation (Jacobsson, 1984; Sibley \& Lefkowitz, 1985). A possible change in sensitivity was investigated by constructing concentration response curves for various agonists and by determining the affinity of $\alpha_{1}$-adrenoceptors with the aid of radioligand binding studies. Our reactivity study showed no changes in $\alpha$ - or $\beta$-adrenoceptors. Changes in $\beta$-adrenoceptor responses in the renal resistance artery were not expected, since no post-junctional $\beta$-adrenoceptors are present in these arteries (Heesen \& De Mey, 1990; Eerdmans et al., 1991). The receptor binding study only showed a changed $\alpha_{1}$-adrenoceptor affinity in the prazosin treated animals, which may have been caused by traces of prazosin remaining after the treatment. 
Thirdly, the changes in vascular tone could be explained by changes in $\alpha$ adrenoceptor subtypes. Several studies have suggested the existence of multiple $\alpha_{1}$-adrenoceptor subtypes (Daly et al., 1988a; Minneman, 1988; Muramatsu et al., 1990a; b; Ruffolo et al., 1991). Furthermore, different relations between subtypes have been found in the various types of arteries (Flavahan \& Vanhoutte, 1987). The $\alpha_{1}$-adrenoceptor subtypes differ in their amino acid sequence, tissue distribution and affinity for competitive antagonists. In the present study we investigated the relation between $\alpha_{1 \mathrm{~A}^{-}}$and $\alpha_{1 \mathrm{~B}}$-adrenoceptors in the various types of arteries and in the kidney. To discriminate between the two subtypes chloroethylclonidine was used. The aorta harbors a large population of $\alpha_{1 \mathrm{~B}}$-adrenoceptors. Proceeding down the vascular tree, the population of $\alpha_{1 \mathrm{~A}}$-adrenoceptors increases while that of $\alpha_{1 \mathrm{~B}}$-adrenoceptors decreases. The aorta is not innervated, and innervation increases as one follows the vascular tree. This suggests a relation between less innervation (sympathetic activity) and more $\alpha_{1 \mathrm{~B}}$-adrenoceptors. In the present study, a decreased sympathetic tone was not followed by an increase in the number of $\alpha_{1 B}$-adrenoceptors. Furthermore, concentration response curves with $\alpha$ adrenoceptor agonists in arteries with or without CEC treatment did not reveal any functional changes, and the number of $\alpha_{1 \mathrm{~A}, \mathrm{~B}}$-adrenoceptors in the kidney, as determined in a receptor binding study, did not change due to the treatments.

Fourthly, vascular tone is partially regulated by contraction inhibiting systems. Endothelial cells have the ability to release endothelium-derived relaxing factor (EDRF), which has been identified as nitric oxide (Palmer et al., 1987), and endothelium hyperpolarizing factor (EDHF) (Chen et al., 1988; Taylor \& Weston, 1988; Furchgott \& Vanhoutte, 1989; Brayden, 1991; Garland \& McPherson, 1992; Hayakawa et al., 1993), both of which cause a relaxation of the artery (Furchgott \& Zawadski, 1980; De Mey \& Gray, 1985). Reduction of endothelium-dependent relaxations and enhancement of agonistinduced contractions, normally negatively modulated by endothelium, have been found to occur in hypertensive patients and animal models (Van de Voorde \& Leusen, 1986; Luscher et al., 1987; Jameson et al., 1990; Panza et al., 1990; Nakamura \& Prewitt, 1991). A possible reduction of endotheliumdependent relaxations was evaluated using acetylcholine. The experiments showed that the aorta and the superior mesenteric artery, but not the resistance arteries, of the animals treated with prazosin and rilmenidine were significantly less sensitive to acetylcholine. One possible explanation for these different responses from large and resistance arteries can be found in changes in EDRF and EDHF release. Large vessel endothelium releases EDRF, while that of 
smaller arteries releases both EDRF and EDHF (Hayakawa et al., 1993). The decreased EDRF release found in the large arteries may be followed by increased EDHF release in the resistance arteries.

If we rule out arterial modifications, it may be changes in nerve properties which explain the lack of efficacy of the antihypertensive drugs. The following changes could re-adjust the excitation of the artery so as to increase blood pressure to pre-treatment level: i) increased noradrenaline exposure due to increased innervation or noradrenaline release; ii) decreased activity from inhibiting systems like petidergic nerves, resulting in increased vascular tone.

Noradrenaline concentrations in the femoral artery were not different for the four treatments. The method we used cannot differentiate between the number of nerves and the noradrenaline content of these nerves. However, it did not indicate increased noradrenaline release due to increased density. Using electrical nerve stimulation, it was possible to excite sympathetic but also nonadrenergic nerves (peptidergic nerves). In addition to noradrenaline, the sympathetic nerve also releases co-transmitters such as neuropeptide Y (NPY) and purines (Mulvany \& Halpern, 1977; Ekblad et al., 1983; Edvinsson et al., 1984; Lundberg et al., 1985; Wahlestedt et al., 1985; Burnstock, 1987). The postsynaptic actions of these co-transmitters can be mediated through specific receptors or by alteration of the sensitivity of adrenergic receptors (NPY). Furthermore, peptidergic nerves can contribute to a non-adrenergic component of vascular control (Kawasaki et al., 1988). Electrical nerve stimulation revealed increased sensitivity of the mesenteric resistance artery in the three treatment groups. No changes were found in the larger superior mesenteric artery or the renal resistance artery. This increased sensitivity was not caused by changes in noradrenaline re-uptake or changes in noradrenaline sensitivity of the artery. Increased sensitivity during the whole frequency response curve ruled out NPY, since enhancement by NPY only occurs at high frequency (Lundberg et al., 1990). Post-synaptic modulation by $\alpha_{2}$ - and $\beta$-adrenoceptors can also be excluded, since the curves were constructed while those receptors were hlucked. What is left is increased innervation of the mesenteric resistance artery or a role for non-adrenergic nerves. The latter could explain the difference in electrical nerve stimulation between the two types of resistance arteries. In earlier studies we investigated the presence of non-adrenergic, capsaicin-sensitive nerves in mesenteric and renal resistance arteries. As has also been found by other groups (Barja et al., 1983), renal resistance arteries lack capsaicin-sensitive, peptidergic nerves. Changes in peptidergic nerve properties (decreased activity) in the mesenteric resistance artery could explain 
the difference in electrical field stimulation between the two resistance arteries.

In conclusion, treatment for four weeks with prazosin, rilmenidine or azepexole did not lead to long-term blood pressure reduction. This was not due to changes in contractile properties or adrenoceptor populations of the arteries investigated. Endothelium-induced relaxing properties of the large arteries may play a role, but more important are the alterations seen in the mesenteric resistance artery. Since the mesenteric arterial bed is very large, increased vascular tone will result in increased blood pressure. Future investigations should pay more attention to the effect of antihypertensive drugs on secondary control mechanisms such as non-adrenergic nerve systems. 


\section{References}

Abboud F.M. (1982). The sympathetic system in hypertension, Hypertension., 4, II208II 225 .

Angus J.A., Broughton A. \& Mulvany M.J. (1988). Role of $\alpha$-adrenoceptors in constrictor responses of rat, guinea-pig and rabbit small arteries to neural activation, J. Physiol., 403, 495-510.

Aprigliano O. \& Hermsmeyer K. (1977). Trophic influences of the sympathetic nervous system on the rat portal vein, Circ. Res., 41, 198-206.

Barja F., Mathison R. \& Huggel H. (1983)., Cell and tissue research, 229, 411.

Bjorklund A., Lindvall O. \& Svensson L.A. (1972). Mechanisms of fluorophore formation in the histochemical glyoxylic acid method for monoamines, histochemie, 32, 113-131.

Boonen H.C.M. \& De Mey J.G.R. (1990). Increased calcium sensitivity in isolated resistance aneries from spontaneously hypertensive rats: effects of dihydropyridines, Eur. J. Pharmacol., 179, 403-412.

Boonen H.C.M. \& De Mey J.G.R. (1991). Effects of a phorbol ester and staurosporine on electro- and pharmacomechanical coupling in a resistance artery, Eur. J. Pharmacol., $202,25-32$.

Brayden J.E. (1991). Hyperpolarization and relaxation of resistance arteries in response to adenosine diphosphate. Distribution and mechanisms of action, Circ. Res., 69, 14151420.

Burnstock G. (1987). Mechanisms of interaction of peptide and non-peptide vascular neurotransmitter system, Cardiovasc. Pharmacol., 10 (suppl 12), S74-S81.

de Champlain J. (1990). Pre- and postsynaptic adrenergic dysfunctions in hypertension, J. Hypertension., 8, S77-S85.

Chen G., Suzuki H. \& Weston A.H. (1988). Acetylcholine releases endothelium-derived hyperpolarizing factor and EDRF from rat blood vessels, Br. J. Pharmacol., 95, 11651174.

Cotecchia S., Schwinn S.D., Randall R.R., Lefkowitz R.J., Caron M.G. \& Koblika B.K. (1988). Molecular cloning and expression and expression of the cDNA for the hamster alpha1-adrenergic receptor, Proc. Natl. Acad. Sci. USA., 85, 7159-7163.

Cowen T. \& Burnstock G. (1980). Quantitative analysis of the density and pattern of adrenergic innervation of blood vessels, Histochem., 66, 19-34.

Daly C.J., Dunn W.R., McGrath J.C. \& Wilson V.G. (1988a). An attempt at selective protection from phenoxybenzamine of postjunctional alpha-adrenoceptor subtypes mediating contractions to noradrenaline in the rabbit isolated saphenous vein, $\mathrm{Br}$. J. Pharmacol., 95, 505-511.

Daly C.J., McGrath J.C. \& Wilson V.G. (1988b). An examination of the postjunctional $\alpha$ adrenoceptor subtypes for (-)-noradrenaline in several isolated blood vessels from the rabbit. Br. J. Pharmacol., 95, 473-484.

De Mey J.G.R. \& Gray V.S.D. (1985). Endothelium dependent reactivity in resistance vessels, Prog. Appl. Microcirc., 8, 181-187.

De Mey J.G.R. \& Vanhoutte P.M. (1981). Uneven distribution of postjunctional $\alpha_{1}$ and $\alpha_{2}$ - like adrenoceptors in canine arterial and venous smooth muscle, Circ. Res., 48, 875884. 
De Mey J.G.R. \& Vanhoutte P.M. (1982). Heterogeneous behavior of the canine arterial and venous wall. Importance of the endothelium, Circ. Res., 51, 439-447.

DeMcyts P. (1976). Cooperative properties of hormone receptors in cell membranes, J. Supramol. Struct., 4, 241-258.

Drew G.W. \& Whiting S.B. (1979). Evidence for two distinct types of postsynapticadrenoceptors in vascular smooth muscle in vivo, Br. J. Pharmacol., 67, 207-215.

Edvinsson L., Ekblad E., Hakanson R. \& Wahlestedt C. (1984). Neuropeptide Y potentiates the effect of various vasoconstrictor agents on rabbit blood vessels, $\mathrm{Br}$. $\mathrm{J}$. Pharmacol., 83, 519-525.

Eerdmans P.H.A., Heesen B.J., Struijker Boudier H.A.J. \& De Mey J.G.R., 1991. Sympathetic heterogeneity in mesenteric and renal resistance arteries, in: Resistance Arteries. Structure and Function, Mulvany M.J., Aalkjaer C., Heagerty A.M., Nyborg N.C.B. \& Strandgaard S., Excerpta Medica, Amsterdam, The Netherlands, 156-159.

Ekblad E., Edvinsson L., Wahlestedt R., Uddman R., Hakanson R. \& Sundler F. (1983). Neuropeptide $\mathrm{Y}$ co-exists and cooperates with noradrenaline in perivascular nerve fibres, Reg. Peptides., 8, 225-235.

Epand R.M. \& Lester D.S. (1990). The role of membrane piophysical properties in the regulation of protein kinase-C activity, TIPS, 11, 317-320.

Esler M., Lambert G. \& Jennings G. (1990). Increased regional sympathetic nervous activity in human hypertension: causes and consequences, J. Hypertension., 8, S53-S.57

Feng F., Abel P.W., Scofield M., Liu F., Wolff D.W. \& Jeffrics W.B. (1993). Heterogenous expression of alphal-adrenoceptor subtypes among rat nephon segments. Mol. Pharmacol., 44, 926-933.

Flavahan N.A. \& Vanhoutte P.M., 1987, Heterogeneity of alpha-adrenergic responsiveness in vascular smooth muscle : Role of receptor subtype and receptor reserve, in: The alpha-1 adrenergic receptors, Ruffolo Jr. R.R. Humana Press, Clition. New Jerscy. 351-403.

Furchgott R.F. \& Vanhoutte P.M. (1989). Endothelium-derived relaxing and contracting factors, Faseb. J., 3, 2007-2018.

Furchgott R.F. \& Zawadski J.V. (1980). The obligatory role of endothelial cells in the relaxation of anterial smooth muscle by acetylcholine, Nature., 288, 373-376.

Garland C.J. \& McPherson G.A. (1992). Evidence that nitric oxide does not mediate the hyperpolarization and relaxation to acetylcholine in the rat small mesenteric artery, $\mathrm{Br}, \mathrm{J}$. Pharmacol., 105, 429-435.

Han C. \& Minneman K.P. (1991). Interaction of subtype-selective antagonists with $\alpha_{1}$ adrenergic receptor binding sites in rat tissues, J. Pharmacol. Exp. Therap., 40, 531538.

Hayakawa H., Hirata Y.. Suzuki E.. Sugimoto T., Matsuoka H., Kikuchi K.. Nagano T., Hirobe M. \& Sugimoto T. (1993). Mechanisms for altered endothelium-dependent vasorelaxation in isolated kidneys from experimental hypertensive rats. Am. J. Physiol., 264, H1535-H1541

Heesen B.J. \& De Mey J.G.R. (1990). Effects of cyclic AMP-affecting agents on contractile reactivity of isolated mesenteric and renal resistance arteries of the rat, $\mathrm{Br} . \mathrm{J}$. Pharmacol., 101, 859-864. 
Jackson C.A., Michel M.C. \& Insel P.A. (1992). Expression of renal $\alpha_{1}$-adrenergic receptor subtypes in established hypertension, J. Cardiovasc. Pharmacol., 19, 857-862.

Jacobsson B. (1984). A modern view on the pharmacology of the adrenoceptor, In: Adrenergic blood pressure regulation, Ed. W.H. Birkenhager et al., ISBN 0-444-90408$5,168-173$.

Jameson M., Luscher T., Skopec J., Diederich A. \& Diederich D. (1990). Impaired endothelium dependent relaxation in mesenteric resistance arteries of prehypertensive SHR rat, Kidney. Int., 37, 387.

Kawasaki H., Takasaki K., Saito A. \& Goto K. (1988). Calcitonin gene-related peptide acts as a novel vasodilator neurotransmitter in mesenteric resistance vessels of the rat, Nature., 335, 164-167.

Langer S.Z. (1974). Presynaptic regulation of catecholamine release, Biochem. Pharmacol., 23, 1793-1800.

Lundberg J.M., Torssell L., Sollevi A., Pernow J., Norheim E.T., Anggard A. \& Hamberger B. (1985). Neuropeptide $Y$ and sympathetic vascular control in man, Reg. Peptides., 13, 41-52.

Lundberg J.M., Franco-Cereda A., Hemsen A., Lacroix J.S. \& Pernow J. (1990). Pharmacology of noradrenaline and neuropeptide tyrosine (NPY)-mediated sympathetic cotransmission, Fund. Clin. Pharmacol., 4, 373-391.

Luscher T.F., Raij L. \& Vanhoutte P.M. (1987). Endothelium-dependent vascular responses in normotensive and hypertensive Dahl rats, Hypertension., 9, 157-163.

Mark A.L. (1991). Sympathetic neural contribution to Salt-induced hypertension in Dahl rats, Hypertension., 17, I86-190.

Merz W.A. (1967). Die streckenmessung an gerichteten strukturen im mikroskop und ihre anwendung zur bestimmung von oberflachen-volumen-relationen im knochengewebe, Mikroskopie, 22, 132.

Michel M.C., Insel P.A. \& Brodde O.E. (1989). Renal $\alpha$-adrenergic receptor alterations: a cause of essential hypertension, Faseb. J., 3, 139-144.

Michel M.C., Brodde O.E. \& Insel P.A. (1990). Peripheral adrenergic receptors in hypertension, Hypertension., 16, 107-120.

Michel M.C., Hanft G. \& Gross G. (1994). Radioligand binding studies of $\alpha_{1}$-adrenoceptor subtypes in rat heart, $\mathrm{Br}$. J. Pharmacol., 111, 533-538.

Minneman K.P. (1988). $\alpha_{1}$-Adrenergic receptor subtypes, inositol phosphates and sources of cell calcium, Pharmacol. Rev., 40, 87-119.

Mulvany M.J. \& Halpern W. (1977). Contractile properties of small arterial resistance vessels in spontaneously hypertensive and normotensive rats, Circ. Res., 41, 19-26.

Muramatsu I., Kigoshi S. \& Oshita M. (1990a). Two distinct $\alpha_{1}$-adrenoceptor subtypes involved in noradrenaline contraction of the rabbit thoracic aorta, $\mathrm{Br}$. J. Pharmacol., 101, 662-666.

Muramatsu I., Ohmura T., Kigoshi T., Hashimoto S. \& Oshita M. (1990b). Pharmacological subclassification of $\alpha_{1}$-adrenoceptors in vascular smooth muscle, $\mathrm{Br}$. J. Pharmacol., 99, 197-201.

Nakamura T. \& Prewitt R.L. (1991). Effect of Ng-monomethyl-L-arginine an arcade arterioles of rat spinotrapezius muscles, Am. J. Physiol., 261, H46-H52. 
Nilsson H. (1985). Adrenergic nervous control of resistance and capacitance vessels, Acta. Physiol. Scand., 124(suppl 541), 1-34.

Nilsson H., Goldstein M. \& Nilsson O. (1986). Adrenergic innervation and neurogenic response in large and small arteries and veins from the rat, Acta. Physiol. Scand., 126, 121-133.

Owen M.P. (1993). Functional characterization of $\alpha$-adrenoceptors on rabbit intrarenal arteries in vitro, J. Pharmacol. Exp. Therap., 265, 807-812.

Palmer R.M.J., Ferrige A.G. \& Moncada S. (1987). Nitric-oxide release accounts for the biological activity of endothelium derived relaxing factor, Nature., 327, 524-526.

Panza J.A., Quyyumi A.A., Brush J.E. \& Epstein S.E. (1990). Abnormal endothelium. dependent vascular relaxation in patients with essential hypertension, New. Engl. J. Med., 323, 22-27.

Perez D.M., Piascik M.T. \& Graham R.M. (1991). Solution-phase library screening for the identification of rare clones: isolation of an alphalD receptor cDNA, Mol. Pharmacol., $40,876-883$

Pettinger W.A., Umemura. Smyth D.D. \& Jeffries W.B. (1987). Renal $\alpha_{2}$-adrenoceptors and the adenylate cyclase-cAMP system: biochemical and physiological interactions, Am. J. Physiol., 252, F199-F208.

Piascik M.T., Butler B.T. \& Pruitt T.A. (1990). The role of $\alpha_{1}$-adrenoceptor subtypes in the regulation of arterial blood pressure, Eur. J. Pharmacol., 180, 381-386.

Piascik M.T., Sparks M.S. \& Pruitt T.A. (1993). Effect of chloroethylclonidine on arterial blood pressure and heart rate, J. Pharmacol. Exp. Therap., 262, 901-906.

Ruffolo R.R., Nichols A.J., Stadel J.M. \& Hieble J.P. (1991). Structure and function of \& $x$ adrenoceptors, Pharmacol. Rev., 43, 475-505.

Schwinn D.A., Page S.O., Middleton J.P., Lorenz W., Liggett S.B., Yamamoto K., Lapetina E.G., Caron M.G., Lefkowitz R.J. \& Cotecchia S. (1991). The $\alpha_{1 c}$-adrenergic receptor: characterization of signal transduction pathways and mammalian tissue heterogeneity, J. Pharmacol. Exp. Therap., 40, 619-626.

Sibley D.R. \& Lefkowitz R.J. (1985). Molecular mechanisms of receptor desensitization using the beta-adrenergic receptor-coupled adenylate cyclase system as a model, Nature., $317,124-129$.

Taylor S.G. \& Weston A.H. (1988). Endothelium derived hyperpolarizing factor: a new endogenous inhibitor from the vascular endothelium, TIPS, 9, 272-274.

Van de Voorde J. \& Leusen I. (1986). Endothelium dependent and independent relaxation of aortic rings from hypertensive rats, Am. J. Physiol., 250, H711-H717.

Vanhoutte P.M. \& Miller V.M. (1989). $\alpha_{2}$-adrenoceptors and endothelium-derived relaxing factor, Am. J. Med., 87, 1S-5S.

Vanhoutte P.M., Verbeuren T.J. \& Webb R.C. (1981). Local modulation of adrenergic neuroeffector interaction in the blood vessel wall. Physiol. Rev., 61, 151-218.

Van Zwieten P.A., Thoolen M.J.M.C., Jonkman F.A.M., Wilffert B., De Jonge A. \& Timmermans P.B.M.W.M. (1986). Central and peripheral effects of S 3341 [(Ndicyclopropylmethyl)-amino-2-oxazoline] in animal models, Arch. Int. Pharmacodyn. Ther., 279, 130-149. 
Wahlestedt C., Edvinsson L., Ekblad E. \& Hakanson R. (1985). Neuropeptide Y potentiates noradrenaline-evoked vasoconstriction: mode of action, J. Pharmacol. Exp. Therap., 214, 735-741.

Wallenstein S., Zucker C.L. \& Fleiss J.L. (1980). Some statistical methods useful in circulation research, Circ. Res., 47, 1-9.

Weibel E.R. (1989). Stereological Methods. Vol 1. Practical methods for biological morphometry, academic Press Inc., ISBN 0-12-742201-3, 122-123. 
Structure and reactivity of rat peripheral arteries 4 weeks after myocardial infarction

\author{
P.H.A. Eerdmans, G.E. Fazzi, H. v.d. Heijden, \\ P. Leenders, P. Schiffers and J.G.R. De Mey
}





\section{Abstract}

After a myocardial infarction (MI) the sympathetic nervous system and various other neurohumoral mechanisms are activated to engage mechanisms in the remaining myocardium, the peripheral vasculature and the kidneys that may help to maintain systemic perfusion pressure. We evaluated whether after a MI, peripheral arteries in rats are modified on the long run. The experiments involved the thoracic aorta, the superior mesenteric artery and mesenteric resistance-sized arteries of rats with a four week old myocardial infarction and of sham-operated control rats. The mean infarction size was $45.6 \%$ of the left ventricle. In the investigated arteries no significant alterations of lumen diameter, media thickness and media cross-sectional area were observed. No changes in maximal responses and sensitivity to adrenergic and non-adrenergic contractile stimuli were found in the aorta and superior mesenteric artery. Also active wall stress of these vessels did not differ between sham and MI. Furthermore no changes were found in relaxing responses to acetylcholine or isoprenaline in either type of artery. In contrast, in the mesenteric resistance arteries a significant reduction of maximal contractile responses to potassium, noradrenaline and serotonin was observed. Active wall stress was not altered in these vessels. These observations indicate that following $\mathrm{MI}$ in the rat the contractile reactivity of mesenteric resistance arteries is chronically and nonselectively reduced. Such an alteration may contribute to the development of decompensated heart failure.

\section{Introduction}

Following necrotizing injury to the myocardium such as myocardial infarction, arterial blood pressure may initially be maintained under resting conditions (Drexler et al., 1986; Schlant \& Alexander, 1994). This has been attributed to the activation of neurohumoral mechanisms that stimulate compensatory mechanisms in the remaining myocardium, the peripheral vasculature and the kidneys (Esler et al., 1984; Laragh, 1986; Leimbach et al., 1986; Fyhrquist \& Tikkanen, 1988; Jennings \& Esler, 1990; Sigurdsson et al., 1993). However, on the long run, congestive heart failure may develop.

The neurohumoral mechanisms that are activated after myocardial infarction include the sympathetic nervous system (Esler et al., 1984; Hasking et al., 1986; Jennings \& Esler, 1990; Sigurdsson et al., 1993 ). Neurogenic and circulating catecholamines promote the contractility of the rest myocardium and elevate total peripheral resistance and thereby help to maintain perfusion 
pressure (Remme, 1986). Experiments in vitro and in vivo, that involved chronic exposure to natural and synthetic adrenergic agonists, indicated, however, that catecholamines can chronically alter cardiac and vascular structure (Lee et al., 1987; Mangiarua \& Lee, 1992) and that effector systems may adapt (become tolerant) to increased sympathetic input (Sibley \& Lefkowitz, 1985; Leeb-Lundberg et al., 1987; Forster et al., 1989; 1992; Vatner et al., 1989; Hausdorff et al., 1990; Lohse et al., 1990; Raymond et al., 1990; Kiuchi et al., 1992; Teerlink et al., 1993). This process, which has been elaborated in great molecular detail for $\beta$-adrenoceptors, may be responsible for the reduced $\beta$-adrenergic responsiveness and $\beta$-adrenoceptor density in the heart of heart failure patients and of experimental models of heart failure (for review see Brodde, 1991). Less is known about changes in the peripheral vasculature in heart failure in general and with respect to adrenergic mechanisms in particular which are primarily $\alpha$-adrenergic in this system. In a recent study of subcutaneous resistance arteries, isolated from congestive heart failure patients, a non-selective reduction of contractile responses was noted along with a reduction of endothelium-dependent relaxing responses (Kiuchi et al., 1993). However, the patients and controls in this study obviously differed not only with respect to heart failure but also with respect to drug therapy which included diuretics, nitrates, and cardiac glycosides.

In the present study we evaluated the structure and reactivity of peripheral arteries in rats with a 4 week old left ventricular infarction (MI) (Fishbein et al., 1978; Pfeffer et al., 1979) that had not been subjected to any drug treatment. The experiments were performed in both MI-rats and sham-operated controls and involved the thoracic aorta, the superior mesenteric artery and mesenteric resistance-sized arteries. These vessels differ not only with respect to their location along the arterial tree, but also with respect to the density of sympathetic nerves (De Mey \& Vanhoutte, 1982 ) and with respect to the type of postjunctional $\alpha 1$-adrenoceptors (Nilsson et al., 1986; Eerdmans et al., 1991; Feng et al., 1993) and of the signal transduction pathway which they engage (Han et al., 1987; Daly et al., 1990; Michel et al., 1990b; Wilson \& Minneman, 1990). 


\section{Materials \& methods}

\section{Animals}

Experiments were performed in 16 week old male specific pathogen-free Wistar rats. The animals were maintained on a 12 hour dark - 12 hour light cycle and had free access to standard lab food and tap water. Myocardial infarction $(n=7)$ was produced by ligation of the left coronary artery using a modification of the method of Fishbein et al (Fishbein et al., 1978; Pfeffer et al., 1979). In short, animals were anaesthetized with pentobarbital $(60 \mathrm{mg} / \mathrm{kg}$ i.p.) and the trachea was intubated (PE-240). Skin and muscles overlying the 4th left intercostal space were separated and cut. The thorax was opened after starting positive pressure respiration and the heart was carefully pushed to the left or exteriorized by applying pressure to the right side of the thorax. A silk suture (6-0) was looped around the left descending coronary artery. In sham animals $(n=8)$, the suture was looped through the myocardium next to the left descending coronary artery. When the heart was returned to its normal position, the suture was tied and ribs were pulled together with 3-0 silk. When closing the thorax a silastic drain was inserted to restore the sub-atmospheric pressure.

\section{Tissue preparation}

Four weeks after inducing myocardial infarction or sham operation the rats were killed by a sharp blow on the back of the head and exsanguination. From each rat the thoracic aorta, superior mesenteric artery, mesentery, left kidney and heart were isolated. The kidney and heart were cleaned of adhering connective tissue and their wet weight was determined.

From the aorta and superior mesenteric artery segments of approximately 2 $\mathrm{mm}$ were cut. The mesentery was pinned out on a petri dish coated with Silgard (Dow Corning Corp.) and fourth order resistance-sized side branches of the superior mesenteric artery (diameter approximately $200 \mu \mathrm{m}$ ) were dissected.

\section{Plasma catecholamine concentrations}

In separate groups of sham and MI rats, equipped with an intra-arterial catheter, plasma catecholamine concentrations were determined. From conscious undisturbed animals a $2 \mathrm{ml}$ arterial blood sample was collected in chilled heparinized tubes containing $12 \mathrm{mg}$ of glutathione. Tubes were centrifuged at 3000 rotations per minute at $4^{\circ} \mathrm{C}$ for 15 minutes and plasma was stored at $-20^{\circ} \mathrm{C}$ until use. High performance liquid chromatography (HPLC) 
with fluorometric detection according to the method of Van der Hoorn (Hoorn van der et al., 1989) was used to determine the plasma catecholamines concentrations using $\alpha$-methylnoradrenaline as an internal standard.

\section{Infarct size determination}

The hearts were fixed with phosphate buffered formalin $(\mathrm{pH}=7.4)$ and cut in $2.2 \mathrm{~mm}$ thin slices. The slices were stained with an azan staining. In summary; the slices were incubated for 30 minutes in Azan I solution $(0.5 \mathrm{~g}$ Azocarmine $\mathrm{G}, 1 \mathrm{ml}$ concentrated acetic acid and $100 \mathrm{ml}$ aqua dest), rinsed and incubated for 45 minutes in 5\% phosphotungstic acid, rinsed and incubated for 5-15 minutes in Azan II solution (Anilineblue $0.5 \mathrm{~g}$, Orange G 2 $\mathrm{g}, 8 \mathrm{ml}$ concentrated acetic acid) rinsed and embedded. Slices of $2.2 \mathrm{~mm}$ were cut starting from the apex of the heart. The third slice was used to determine the infarction size as described by Pfeffer et al (Pfeffer et al., 1985).

\section{Myograph experiments}

The isolated arteries were mounted in a myograph (JP Trading Corp., Risskov, Denmark) (Mulvany \& Halpern, 1977; Heesen \& De Mey, 1990). In the myograph the vessels are mounted horizontally in an organ chamber between an isometric force transducer (Statham UC3 and Kistler Morse DSC6 for large and small vessels, respectively) and a displacement device using 2 stainless steel wires (diameter $0.04 \mathrm{~mm}$ ). The organ chamber was filled with Krebs-Ringer bicarbonate solution (KRB, 25 and $10 \mathrm{ml}$ for large and small vessels, respectively) that was maintained at $37^{\circ} \mathrm{C}$ and aerated with $95 \% \mathrm{O}_{2}$ and $5 \% \mathrm{CO}_{2}$. Prior to experimentation the internal diameter of the thoracic aorta and superior mesenteric artery segments were set at 1675 and $1020 \mu \mathrm{m}$ respectively, which was observed in preliminary experiments to yield strong and reproducible contractile responses. Mesenteric resistance arteries were stretched to their individual optimal internal circumference for isometric force development by an active length-tension protocol (Boonen \& De Mey, 1990; 1991; Heesen \& De Mey, 1990; Eerdmans et al., 1991). Therefore their internal circumference was increased by $60 \mu \mathrm{m}$ every $5 \mathrm{~min}$, with intermittent exposure to $10 \mu \mathrm{M}$ noradrenaline. This length-tension protocol was continued until maximal contractile responses were obtained.

Contractile responses were induced with high potassium solution and with the agonists, noradrenaline, phenylephrine, 5-hydroxytryptamine and Argvasopressin. Relaxing responses to isoproterenol or acetylcholine were induced after the preparations had been made to contract with $10 \mu \mathrm{M}$ phenylephrine. To rule out effects of $\beta$ - and $\alpha_{2}$-adrenoceptor stimulation all agonist 
concentration-response curves, except the concentration response curve for isoproterenol, were constructed in the presence of $1 \mu \mathrm{M}$ propranolol and $1 \mu \mathrm{M}$ yohimbine.

All agents were tested in the same vessels but the order of testing was randomized to exclude that responses to a given agonist were influenced by pretreatment with another agent. To stimulate the sympathetic nerves in the mesenteric resistance arteries, 2 platinum electrodes connected to a constant current source (amplitude $85 \mathrm{~mA}$ ) were placed longitudinally across the mounted vessel segments and frequency response curves (1 to $32 \mathrm{~Hz}$, pulse duration $2 \mathrm{msec}$ ) were constructed (Nilsson, 1985; Eerdmans et al., 1991). The experiments in the isolated aorta, superior mesenteric artery and mesenteric resistance artery segments took approximately 6 hours to perform.

\section{Morphology}

Arteries were fixed in the myograph at their working diameter with phosphate buffered formalin $\left(\mathrm{pH}=7.4,37^{\circ} \mathrm{C}\right.$ ) for thirty minutes. The fixed arterial segments were dehydrated and embedded in paraffin (Paraplast, Sherwood, St. Louis, USA), and cross sections of $4 \mu \mathrm{m}$ (microtome type 820, American Optical, USA) were cut. Quantitative morphology was performed on the preparations after staining with Lawson's solution, a staining which highlights the elastic laminae. Measurements were performed using video images generated by a Zeiss Axioscope (Zeiss, Germany), a standard CCD camera (Stemmer, Germany) and commercial software (JAVA; Jandel Scientific Video Analysis Software, Jandel Scientific, Corte Madera, CA, USA). The internal circumference (IC), (the length of the internal elastic lamina) was determined along with the cross sectional area of the tunica media (CSA), (the area enclosed between the internal and external elastic lamina). From IC, the lumen radius ( $r$ ) was calculated assuming a circular configuration $(r=I C / 2 \pi)$. Mean media thickness (Mt) was obtained from the formula CSA $=\pi(r+M t)^{2}$ $\pi r^{2}$.

\section{Drugs and Solutions.}

During dissection, mounting and experimentation the arterial preparations were immersed in a Krebs bicarbonate buffered physiological salt solution (KRB). $\mathrm{KRB}$ had the following millimolar composition: $\mathrm{NaCl} 118.3, \mathrm{KCl} 4.7, \mathrm{CaCl}_{2}$ 2.5, $\mathrm{MgSO}_{4} .7 \mathrm{H}_{2} \mathrm{O}$ 1.2, $\mathrm{KH}_{2} \mathrm{PO}_{4}$ 1.2, $\mathrm{NaHCO}_{3} 25.0$, glucose 11.1. High potassium solution (K-KRB) was prepared by replacing all $\mathrm{NaCl}$ in normal $\mathrm{KRB}$ with an equimolar amount of $\mathrm{KCl}$. L-isoproterenol hydrochloride, Lnoradrenaline hydrochloride, L-phenylephrine hydrochloride, DL-propranolol 
hydrochloride, $\alpha$-methylnoradrenaline, bicine, 1,2-diphenylethylenediamine, orange $\mathrm{G}$ and azacarmine $\mathrm{G}$ were obtained from Sigma Chemical Co (Saint Louis, Mo USA). Acetylcholine hydrochloride, serotonin creatinine sulphate monohydrate and potassium ferricyanide were purchased from Janssen Chimica (Beerse, Belgium) and Arg-vasopressin from Sandoz (Basel, Switzerland). Yohimbine was purchased from Boehringer Ingelheim, lidocaine from Braun Melsungen AG (Germany). Phosphotungstic acid was purchased from Aldrich and aniline bleu from Clin-Tech limited (Essex, England). Hydrochloric acid, 1-octanol, acetic acid, ammonia-ammonium chloride was purchased from Merck, n-haptene from J.T. Baker (The Netherlands), Acetonitrile from Fisons (England).

\section{Data Analysis.}

Contractile responses of isolated blood vessels to agonists were expressed as increases in wall tension (increases in isometric force divided by twice the segment length) as increases in wall stress (active wall tension divided by media thickness) and relative to the amplitude of the contraction induced by $125 \mathrm{mM}$ potassium $+10 \mu \mathrm{M}$ noradrenaline in the same preparation. Sensitivity for the contractile effects of agonists or nerve stimulation was determined by interpolation on a least square sigmoidal curve fit of the individual concentration response curves (Inplot, GraphPad, San Diego, Ca, USA). Data are shown as mean \pm SEM. Statistical significance of effects and of differences between treatment groups was evaluated by Student's t-test for paired observations, Student's t-test for unpaired observations or analysis of variance followed by Bonferroni's t-test or Student's t-test where appropriate (Wallenstein et al., 1980) using commercially available software (Crunch, Software Corp., San Francisco, Ca USA).

\section{Results}

\section{General and structural findings}

On average permanent ligation of the left coronary artery resulted in infarction of $45.6 \pm 2.5 \%$ of the left ventricle (free left ventricular wall + septum).

4 weeks after myocardial infarction the bodyweight of the MI rats was significantly lower than that of the shams (table 1). The heart weight was significantly increased in the MI rats while the kidney weight was reduced. In table 2 plasma noradrenaline and adrenaline concentrations at week 1 and week 5 are summarised. A significant increase of plasma adrenaline was found 
at 1 week after myocardial infarction. After 5 weeks no differences of plasma noradrenaline or adrenaline concentrations were noted.

In table 3 effects of the myocardial infarction on the structure of the thoracic aorta, superior mesenteric artery and mesenteric resistance arteries are summarised. Media cross sectional area was not changed in the thoracic aorta, superior mesenteric artery or in the mesenteric resistance artery of the MI rats. Furthermore, in the mesenteric resistance artery radius, cross sectional area, media thickness and wall to lumen ratio were not changed at 4 weeks post MI.

Table 1

\begin{tabular}{lll}
\hline & sham & myocardial infarction \\
\hline $\mathrm{n}$ & 8 & 7 \\
bodyweight at end $(\mathrm{g})$ & $363 \pm 9$ & $337 \pm 10^{*}$ \\
bodyweight increase $(\%)$ & $26.2 \pm 2.5$ & $14.9 \pm 4 *$ \\
heart weight $(\mathrm{g})$ & $1.38 \pm .07$ & $1.89 \pm .18^{*}$ \\
heart/body ratio $(\mathrm{mg} / \mathrm{g})$ & $3.8 \pm .18$ & $5.6 \pm .5^{*}$ \\
kidney weight $(\mathrm{g})$ & $1.36 \pm .04$ & $1.18 \pm .05 *$ \\
kidney/body ratio $(\mathrm{mg} / \mathrm{g})$ & $3.8 \pm .1$ & $3.5 \pm .13$
\end{tabular}

Total bodyweight increase, heart weight and relative heart and kidney weight of sham and myocardial infarction rats. Bodyweight was measured directly before scarifying the animals. Values are means \pm SEM. (* $P<0.05)$.

Table 2

\begin{tabular}{llc}
\hline $\begin{array}{l}\text { n } \\
\text { week l } \\
\text { noradrenaline }(\mathrm{pg} / \mathrm{ml})\end{array}$ & sham & myocardial infarction \\
$\begin{array}{l}\text { adrenaline }(\mathrm{pg} / \mathrm{ml}) \\
\text { week 5 }\end{array}$ & 10 & $178.6 \pm 22.5$ \\
$\begin{array}{l}\text { noradrenaline }(\mathrm{pg} / \mathrm{ml}) \\
\text { adrenaline }(\mathrm{pg} / \mathrm{ml})\end{array}$ & $55.9 \pm 6.8$ & $104.0 \pm 30.6 *$ \\
& $169.6 \pm 31.2$ & $164.9 \pm 27.8$ \\
& $65.9 \pm 20.2$ & $69.7 \pm 14.0$
\end{tabular}

Plasma concentrations of noradrenaline and adrenaline from sham and MI rats were determined 1 week after the sham or myocardial infarction operation and after 5 weeks. Values are means $\pm S E M$. (* $\mathrm{P}<0.05)$. 
Table 3

Aarta

\begin{tabular}{lll} 
& sham & MI \\
$\mathrm{n}$ & 7 & 8 \\
CSA $\left(\mathrm{mm}^{2 *} 1000\right)$ & $514 \pm 21$ & $460 \pm 20$ \\
Superior mesenteric artery & & \\
& sham & MI \\
n & 8 & 7 \\
CSA $\left(\mathrm{mm}^{2 * 1000)}\right.$ & $128 \pm 8$ & $116 \pm 5$ \\
Mesenteric resistance artery & \\
\multicolumn{1}{l}{} & sham & MI \\
n & 8 & 7 \\
CSA $\left(\mathrm{mm}^{2 *} 1000\right)$ & $7.3 \pm .8$ & $7.6 \pm .3$ \\
Radius $(\mu \mathrm{m})$ & $123 \pm 5$ & $125 \pm 3$ \\
M $(\mu \mathrm{m})$ & $8.9 \pm .7$ & $9.3 \pm .4$ \\
W/L $(* 1000)$ & $72 \pm 4$ & $75 \pm 5$
\end{tabular}

Morphological properties, radius, media cross sectional area (CSA), media thickness $\left(\mathrm{M}_{\mathrm{U}}\right)$ and wall to lumen ratio ( $\mathrm{W} / \mathrm{L}=\mathrm{M}_{\mathrm{t}} /$ radius) of large and small arteries from sham and 4 weeks old MI-rats. Values are mean \pm SEM

\section{Vascular Reactivity}

\section{Thoracic Aorta}

Contractile responses were induced in the aorta with the use of $125 \mathrm{mM}$ potassium, noradrenaline, serotonin and Arg-vasopressin (table 4). The maximal increases in wall tension and wall stress induced by these stimuli did not differ between the two groups (figure 1 and table 3). Also the sensitivity to the vasoconstrictor agents was not altered after MI. Relaxing responses to isoproterenol, in terms of maximal response and sensitivity, did not differ between aorta's of MI rats and controls (data not shown).

Table 4

\begin{tabular}{llc}
\hline & sham & myocardial infarction \\
\hline $\mathrm{n}$ & 8 & 7 \\
$125 \mathrm{mM} \mathrm{K}-\mathrm{KRB}(\mathrm{mN} / \mathrm{mm})$ & $2.75 \pm .46$ & $3.05 \pm .58$ \\
$30 \mathrm{nM} \mathrm{AVP}(\mathrm{mN} / \mathrm{mm})$ & $2.63 \pm 1.0$ & $1.75 \pm .94$ \\
$10 \mu \mathrm{M} \mathrm{NA}(\mathrm{mN} / \mathrm{mm})$ & $4.08 \pm .74$ & $4.54 \pm .48$ \\
$\mathrm{pD}_{2}$ & $6.37 \pm .21$ & $6.68 \pm .24$ \\
$10 \mu \mathrm{M} 5-\mathrm{HT}(\mathrm{mN} / \mathrm{mm})$ & $2.19 \pm .72$ & $2.08 \pm .77$ \\
$\mathrm{pD}$ & $5.59 \pm .47$ & $5.24 \pm .14$
\end{tabular}

Contractile properties of the aorta from sham rats and MI rats. Maximal contractile, non-receptor induced. contractions were obtained with high potassium krebs solution (125 mM K-KRB). Maxinal response for noradrenaline (NA), serotonine (5-HT) and Arg-vasopressin (AVP) were conducted Furthermore $\mathrm{pD}_{2}$ was calculated from dose response curves constructed for noradrenaline and 5-HT

* indicate significance of difference to sham (t-test $P<0.05$ ). Values are mean $\pm S E M$. 

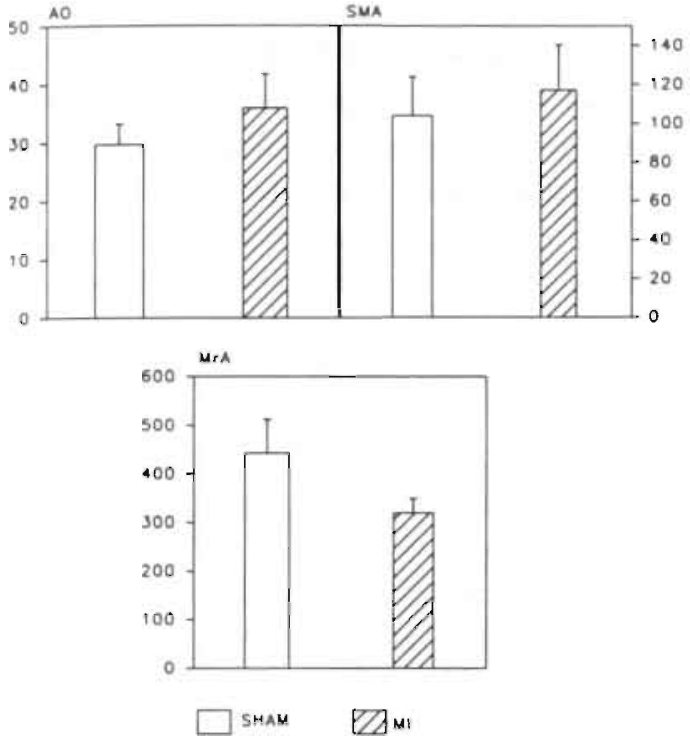

Figure 1

Maximal active wall stress in aorta, superior mesenteric artery and mesenteric resistance artery at 4 weeks after Myocardial Infarction (MI).

Wall stress $\left(\mathrm{mN} / \mathrm{mm}^{2}\right.$; $=$ wall tension / media thickness) was calculated in all types of arteries. In all arteries active wall tension was induced with $125 \mathrm{mM}$ potassium. Bars are mean \pm SEM.

Superior mesenteric artery

In superior mesenteric arteries contractile responses to $125 \mathrm{mM}$ potassium, noradrenaline, noradrenaline in the presence of $3 \mu \mathrm{M}$ cocaine, phenylephrine, serotonin and Arg-vasopressin were recorded (table 5). No significant changes in maximal responses between sham and MI rats were found with either stimulus.

\section{Table 5}

\begin{tabular}{lll} 
& sham & myocardial infarction \\
\hline $\mathrm{n}$ & 8 & 7 \\
$125 \mathrm{mM} \mathrm{K}-\mathrm{KRB}(\mathrm{mN} / \mathrm{mm})$ & $4.51 \pm .81$ & $4.84 \pm .1 .01$ \\
$30 \mathrm{nM} \mathrm{AVP}(\mathrm{mN} / \mathrm{mm})$ & $0.97 \pm .25$ & $1.32 \pm .0 .50$ \\
$10 \mu \mathrm{M} \mathrm{NA}(\mathrm{mN} / \mathrm{mm})$ & $5.87 \pm 1.08$ & $5.99 \pm 1.29$ \\
$\mathrm{pD}_{2}$ & $6.11 \pm .15$ & $6.21 \pm .25$ \\
$10 \mu \mathrm{M} \mathrm{NA}+\mathrm{COC}(\mathrm{mN} / \mathrm{mm})$ & $6.01 \pm 1.22$ & $5.76 \pm 1.32$ \\
$\mathrm{pD}_{2}$ & $6.31 \pm .14$ & $6.18 \pm .24$ \\
$100 \mu \mathrm{M} \mathrm{PHE}(\mathrm{mN} / \mathrm{mm})$ & $3.88 \pm .78$ & $4.79 \pm 1.11$ \\
$\mathrm{pD}_{2}$ & $5.65 \pm .19$ & $6.30 \pm .25 *$ \\
$10 \mu \mathrm{M} \mathrm{5-HT}(\mathrm{mN} / \mathrm{mm})$ & $3.83 \pm .62$ & $4.09 \pm 1.14$ \\
$\mathrm{pD}_{2}$ & $5.99 \pm .19$ & $5.60 \pm .38$
\end{tabular}

Maximal contractile responses were constructed with $125 \mathrm{mM}$ potassium, noradrenaline (NA), noradrenaline with $3 \mu \mathrm{M}$ cocaine (NA+COC), phenylephrine (PHE), serotonine (5 HT) and Argvasopressin (AVP) in sham and MI rats. Furthermore $\mathrm{pD}_{2}$ for NA, PHE and 5-HT were calculated from dose response curves of those drugs. Values are mean $\pm S E M$. * indicate significance of difference to sham (t-test $\mathrm{P}<0.05)$. 
Furthermore no differences in maximal active wall stress between the sham and MI group were noted (figure 1). The sensitivity for phenylephrine was significantly higher in vessels from MI rats than in those from sham controls. For the other stimuli differences in sensitivity were no statistically significant (table 5). Endothelium-dependent relaxing responses to acetylcholine (figure 3) did not differ between sham and MI.

\section{Mesenteric resistance artery}

In mesenteric resistance arteries of the MI rats significantly reduced contractile responses were seen during exposure to $125 \mathrm{mM}$ potassium $+10 \mu \mathrm{M}$ noradrenaline, $10 \mu \mathrm{M}$ noradrenaline in the presence of $3 \mu \mathrm{M}$ cocaine and to $10 \mu \mathrm{M}$ serotonin (table 6). Also maximal responses to noradrenaline and Argvasopressin were reduced, albeit not statistically significant. The maximal active wall stress response to $125 \mathrm{mM}$ potassium $+10 \mu \mathrm{M}$ noradrenaline obtained in resistance arteries of MI rats tended to be lower than that in vessels of sham control. The difference did, however, not reach statistical significance (figure 1). Sensitivities for the various stimuli were not altered in the MI-rats (table 6).

\section{Table 6}

Contractile properties of the mesenteric resistance artery.

\begin{tabular}{lll}
\hline & sham & inyocardial infarcion \\
\hline $\mathrm{n}$ & 8 & 7 \\
$\mathrm{ID}(\mu \mathrm{m})$ & $237 \pm 10$ & $235 \pm 11$ \\
$\mathrm{~K}-\mathrm{KRB}(\mathrm{mN} / \mathrm{mm})$ & $3.70 \pm .44$ & $2.99 \pm .37$ \\
$\mathrm{~K}-\mathrm{KRB}+10 \mu \mathrm{M} \mathrm{NA}(\mathrm{mN} / \mathrm{mm})$ & $4.93 \pm .66$ & $3.64 \pm .40^{*}$ \\
$30 \mathrm{nM} \mathrm{AVP}(\mathrm{mN} / \mathrm{mm})$ & $3.71 \pm .71$ & $3.16 \pm .37$ \\
$10 \mu \mathrm{M} \mathrm{NA}(\mathrm{mN} / \mathrm{mm})$ & $4.52 \pm .61$ & $3.42 \pm .55$ \\
$\mathrm{pD}$ & $5.77 \pm .07$ & $5.66 \pm .14$ \\
$10 \mu \mathrm{M} \mathrm{NA}+\mathrm{COC}(\mathrm{mN} / \mathrm{mm})$ & $4.88 \pm .72$ & $3.50 \pm .43 *$ \\
$\mathrm{pD}$ & $6.19 \pm .17$ & $6.18 \pm .19$ \\
$10 \mu \mathrm{M} \mathrm{PHE}(\mathrm{mN} / \mathrm{mm})$ & $4.32 \pm .75$ & $3.05 \pm .22$ \\
$\mathrm{pD}_{2}$ & $5.71 \pm .16$ & $5.86 \pm .20$ \\
$10 \mu \mathrm{M} 5-\mathrm{HT}(\mathrm{mN} / \mathrm{mm})$ & $2.99 \pm .53$ & $1.57 \pm .41^{*}$ \\
$\mathrm{pD}_{2}$ & $6.41 \pm .16$ & $6.43 \pm .23$
\end{tabular}

Contractile properties of mesenteric resistance arteries from sham rats and MI rats. The arteries are stretched to their individual optimal diameter, (ID, internal diameter). Maximal contractile responses were conducted with high potassium krebs solution (K-KRB), high potassium krebs solution +10 $\mu \mathrm{M}$ noradrenaline $(\mathrm{K}-\mathrm{KRB}+\mathrm{NA})$, noradrenaline (NA), noradrenaline + cocaine (NA + COC), serotonine (5-HT) and Arg-vasopressin (AVP). Values are mean \pm SEM. * indicate significance of difference compared to sham (t-test $\mathrm{P}<0.05$ ). 
Concentration response curves for noradrenaline in the absence or presence of cocaine, concentration response curves for phenylephrine and frequency (1-32 $\mathrm{Hz}$ ) response curves for electrical field stimulations of periarterial nerves are shown in figure 2 . Combined, these observations suggest that at 4 weeks after MI no qualitative alterations of the adrenergic neuroeffector interaction are present at the postjunctional or prejunctional level in the mesenteric resistance arteries. Endothelium-dependent relaxing responses, as evaluated with acetylcholine, did not differ between mesenteric resistance arteries of sham and MI rats (figure 3).
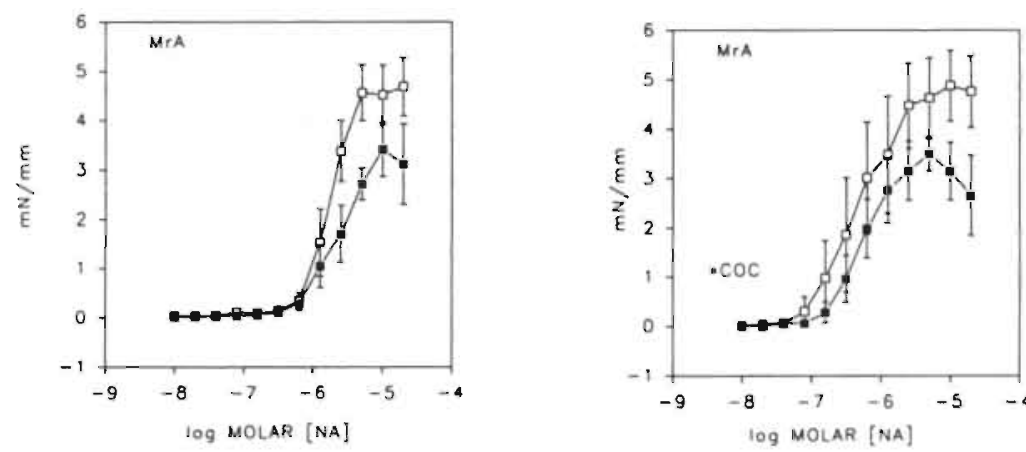

D SHAM

- MI
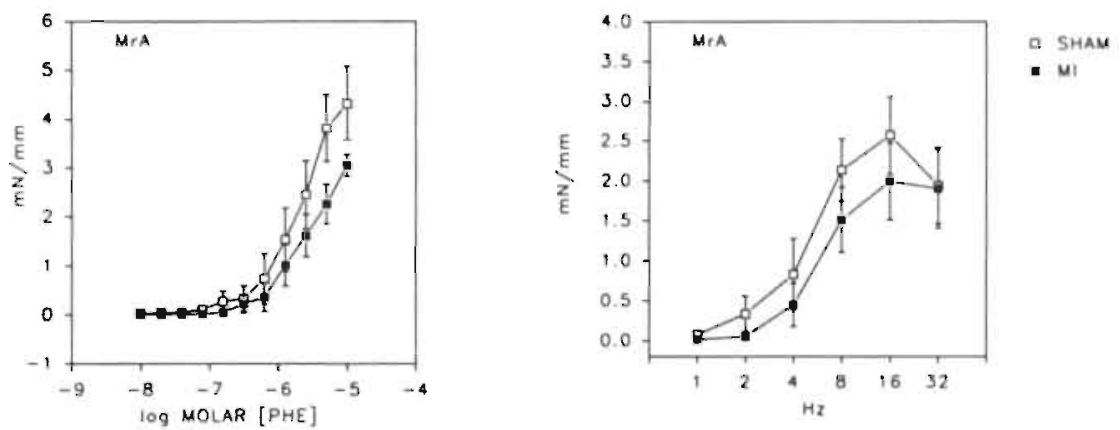

\section{Figure 2}

Frequency and concentration response curves for noradrenaline and phenylephrine in mesenteric resistance arteries. Noradrenaline concentration response curves in the absence (left) or presence of $3 \mu \mathrm{M}$ cocaine (COC, right) obtained in mesenteric resistance arteries of sham rats and rats with a 4 week old myocardial infarction (MI). Furthermore concentration response curves of phenylephrine [PHE] (hottom left) and frequency response curves (bottom right) were constructed. Data are shown as mean \pm SEM. 

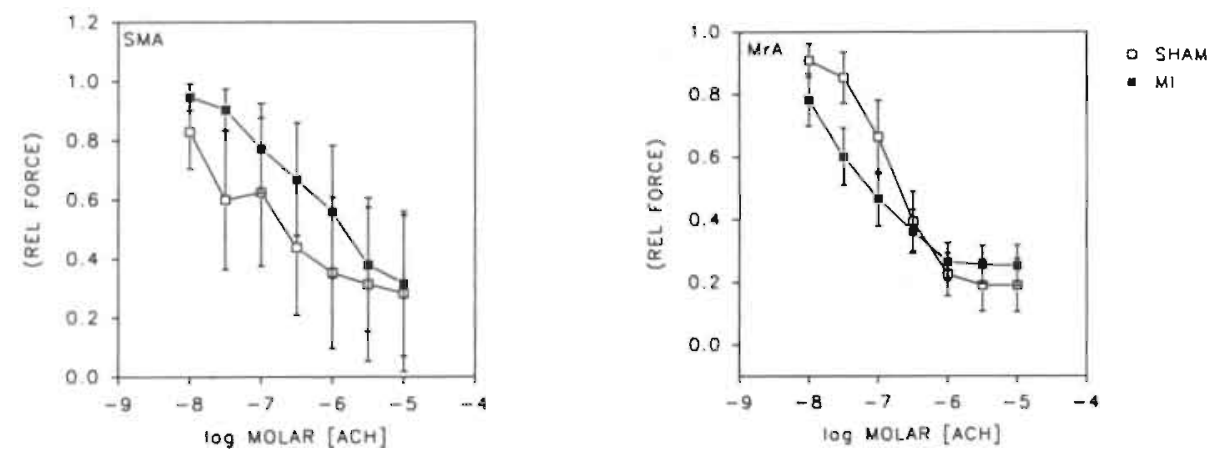

Figure 3

Concentration response curves of acetylcholine $(\mathrm{ACH})$ were obtained in superior mesenteric arteries (SMA), precontracted with Arg-vasopressin and of mesenteric resistance arteries precontracted with phenylephrine. Data are shown as mean \pm SEM.

\section{Discussion}

At 4 weeks after myocardial infarction in the rat, the structure and reactivity of the thoracic aorta and superior mesenteric artery were not significantly modified. In small mesenteric resistance-sized arteries, on the other hand, responses to vasoconstrictor agonists were reduced and this reduction did not seem to involve an alteration of resistance arterial structure or of the sensitivity to the stimuli.

In rats, ligation of the left coronary artery leads to an infarction of most of the free left ventricular wall and hypertrophy of the septum and right ventricle (Fishbein et al., 1978; Pfeffer et al., 1979). In the animals that survive this intervention, maximal cardiac output is reduced and total peripheral resistance is elevated (Pfeffer et al., 1979). This has been attributed to the activation of several neurohumoral systems such as the sympathetic nervous system (Meerson, 1983; Esler et al., 1984; Remme, 1986; Jennings \& Esler, 1990), the renin-angiotensin-aldosterone system (Sigurdsson et al., 1993), vasopressin (Remme, 1986; Dzau, 1987; Hodsman et al., 1988) and endothelin (Fu et al., 1993). These signs, along with the pulmonary congestion noted in these animals, are comparable to those in heart failure patients. Despite growing insights in the pathogenesis of heart failure and advances in its therapy 
(Rutherford \& Braunwald, 1992), the long term prognosis of heart failure patients in general and of post-infarction patients in particular remains poor (Grobbee \& Hofman, 1989). It has been proposed that compensated heart failure may evolve into decompensated or congestive heart failure (Ruggie, 1986; Braunwald, 1988), as a chronic response to the systems that initially help to maintain adequate systemic perfusion. We tested this hypothesis with respect to the effects of the sympathetic nervous system on the peripheral vasculature.

In both infarcted rats and heart failure patients, the activity of the sympathetic nervous system and the plasma catecholamine levels are initially increased (Thomas \& Marks, 1978; Cohn et al., 1984) which contributes to peripheral vasoconstriction. Chronic maintenance of this state of sympathetic hyperactivity may be anticipated to lead to adverse adaptive changes in the vasculature. For instance, catecholamines and sympathetic nerves have been shown to exert an hypertrophic action on the vascular wall (Bevan, 1975; Froneck et al., 1978; Bevan \& Tsuru, 1981; Bevan et al., 1983; Froneck, 1983; Branco et al., 1984; Azevedo \& Osswald, 1986: Dimitriadou et al., 1988). In heart failure this could be amplified by the increased levels of other potential mitogens. On the other hand, the vascular smooth muscle cells may progressively adapt their responsiveness to increased supply of neurotransmitter. In general such a mechanism of "down-regulation" and "desensitisation" is well established for the $\beta$-adrenergic reactivity of the myocardium (for review see Lefkowitz et al (Sibley \& Lefkowitz, 1985)) and has been shown to participate in the altered cardiac function in heart failure patients and in experimental heart failure (Kiuchi et al., 1993)(for review see Brodde (Brodde, 1991)). It is, however, less clear for the $\alpha$-adrenergic processes that govern vascular responses to catecholamines (Michel et al., 1990a; Kiuchi et al., 1992). In this respect conflicting findings were reported concerning vascular responses in experimental heart failure. In a dog model of pacing-induced heart failure Forster et al (Forster et al., 1992) noted a marked and selective increase of the $\alpha_{1}$-adrenergic responses in dorsal pedal artery and saphenous vein. On the other hand, Teerlink et al (Teerlink et al., 1994) observed that at 1 week after myocardial infarction in the rat, the thoracic aortic smooth muscle was less responsive to $\alpha_{1}$-adrenergic stimulation.

We evaluated changes at 4 weeks after induction of myocardial infarction to concentrate on more long term adaptations than in most previous studies. Although coronary artery ligation had resulted in marked left ventricular infarction, cardiac hypertrophy and elevation of plasma adrenaline levels, no differences were observed between thoracic aortae and superior mesenteric 
arteries isolated from infarcted rats and sham-operated controls. Neither media mass nor maximal contractile reactivity or sensitivity to adrenergic and nonadrenergic stimuli were modified. The absence of arterial hypertrophy despite elevation of several candidate mitogens in this model, has been noted before. Heeneman et al. (Heeneman et al., 1995) reported that up to 12 weeks after myocardial infarction in the rat, no hypertrophy could be detected in systemic arteries. They raised the possibility that hypertrophic effects were counteracted by atrial natriuretic factor. This ANF inhibits vascular growth responses (De Mey et al., 1987) and is persistently elevated in heart failure patients (Munzel et al., 1992; Svanegaard et al., 1993) and in infarcted rats (Drexler et al., 1987). An alternative explanation may be found in the rather transient nature of the sympathetic hyperactivity in the model. Though plasma adrenaline was initially elevated, it was normalised after a couple of weeks. In view of this, an early alteration of large artery responses to catecholamines such as described by Teerlink et al. (Teerlink et al., 1994) may have been reversed as well.

While no significant changes had developed or were rapidly reversed in the thoracic aorta or superior mesenteric arteries, mesenteric resistance-sized arteries were hyporeactive to vasoconstrictor stimuli at 4 weeks after myocardial infarction. Reduced maximal responses were observed to a variety of vasoconstrictor stimuli including besides noradrenaline, serotonin, high potassium and even the mixture of high potassium and noradrenaline. This and the lack of changes in sensitivity for either of the agonists makes it unlikely that a specific receptor type or signal transduction pathway would be selectively involved. Also a reduction of muscle mass does not seem to contribute, because media cross sectional area, thickness or wall:lumen did not differ significantly between resistance arteries of infarcted- and control rats. Although not statistically significant, the observation that maximal active wall stress is reduced suggests that the contractility of the individual resistance arterial smooth muscle cells is in general and non-selectively reduced. We have previously reached a similar conclusion in experiments in which intact rats had been continuously infused during 4 days with the $\alpha_{1}$-adrenoceptor agonist phenylephrine (Boonen et al., 1993). Also in this case, no homologous desensitisation was observed but rather a non-selective heterologous reduction of vasoconstrictor responses was noted. At present in can only be speculated why such a change would develop in the mesenteric resistance arteries and not in the larger vessels. All vessels are exposed to the altered plasma concentrations of vasoactive agents that accompany myocardial infarction. Consequences of altered nerve activity would, however, be restricted to 
vessels such as the mesenteric resistance arteries, that in contrast to aorta and superior mesenteric artery, are densely innervated. More comparative analyses of different types of blood vessels and drug-intervention studies will be required to establish the role of the perivascular sympathetic nerves in the observed resistance artery changes.

Reduced resistance arterial contractility after myocardial infarction contrasts to observations in peripheral large arteries and veins of dogs with pacing-induced heart failure (Forster et al., 1992). It is, however, in line with what was noted in subcutaneous resistance arteries isolated from patients with congestive heart failure (Angus et al., 1993). This suggests that in the patients the alteration is not due to treatment with cardiac glycosides, vasodilator drugs and diuretics, but more likely part of the pathology. Depending on the regional distribution of such alteration, the following hemodynamic consequences may be anticipated. When present in vascular beds that play a major role in the control of total peripheral resistance, progressive deterioration of resistance artery function may compromise maintenance of elevated resistance in face of a reduced cardiac output and thus contribute to the transition from compensated to decompensated failure. When on the other hand limited to a vascular bed such as the splanchnic area, it may limit recruitment of blood flow during muscular activity and thus reduce exercise tolerance which is a common feature of heart failure patients (Poole-Wilson et al., 1988). Future regional vascular studies in infarcted rats may not only help to elucidate the mechanisms that are responsible for the vascular changes they may also help to determine the hemodynamic consequences.

In summary, we observed that after myocardial infarction in the rat, peripheral vascular reactivity is modified. The changes which we observed at 4 weeks after the infarction consisted of a general reduction of the contractility of mesenteric resistance arteries. This alteration was not observed in the thoracic aorta and superior mesenteric artery of the same animals and did not seem to have a structural basis. 


\section{References}

Angus J.A., Ferrier C.P., Sudhir K., Kaye D.M. \& Jennings G.L. (1993). Impaired contraction and relaxation in skin resistance arteries from patients with congestive hear failure, Cardiovasc. Res., 27, 204-210.

Azevedo I. \& Osswald W. (1986). Trophic role of the sympathetic innervation, Joumal de Pharmacologie 17, SupplII, 30.

Bevan R.D. (1975). Effect of sympathetic denervation on smooth muscle cell proliferation in the growing rabbit ear artery, Circ. Res., 37, 14-19.

Bevan R.D. \& Tsuru H. (1981). Functional and structural changes in the rabbit ear artery after sympathetic denervation, Circ. Res., 49, 478-485.

Bevan R.D., Tsuru H. \& Bevan J.A. (1983). Cerebral artery mass in the rabbit is reduced by chronic sympathetic denervation, stroke, 14, 393-396.

Boonen H.C.M. \& De Mey J.G.R. (1990). Increased calcium sensitivity in isolated resistance arteries from spontaneously hypertensive rats: effects of dihydropyridines, Eur. J. Pharmacol., 179, 403-412.

Boonen H.C.M. \& De Mey J.G.R. (1991). Effects of a phorbol ester and staurosporine on electro- and pharmacomechanical coupling in a resistance artery, Eur. J. Pharmacol., 202, 25-32.

Boonen H.C.M., Daemen M.J.A.P., Eerdmans P.E., Fazzi G.E., van Kleef E., Schiffers P.M.H. \& De Mey J.G.R. (1993). Mesenteric small artery changes following vasoconstrictor infusion in young rats, J. Cardiovasc. Pharmacol., 22, 388-395.

Brancu D., Albino-Teixeira A.. Azevedo I. \& Osswald W. (1984). Structural and functional alterations caused at the extraneuronal level by sympathetic denervation of blood vessels, Naunyn. Schmiedeberg's. Arch. Pharmacol., 326, 302-312.

Braunwald E. (1988). Pathophysiology of heart failure, Heart disease, a textbook of cardiovascular medicine., Philadelphia: W.B. Saunders, 426-448.

Brodde O.E. (1991). Beta-1 and beta-2 adrenoceptors in the human heart: properties, function, and alterations in chronic heart failure, Pharmacol. Rev., 43, 203-242.

Cohn J.N., Levin T.B., Olivari M.T., Garberg V., Lura D., Francis G.S., Simon A.B. \& Rector T. (1984). Plasma norepinephrine as a guide to prognosis in patients with chronic congestive heart failure, New. Engl. J. Med., 311, 819-823.

Daly C.J., Dunn W.R., McGrath J.C., Miller D.J. \& Wilson V.G. (1990). An examination of the sources of calcium for contractions mediated by postjunctional $\alpha 1-$ and $\alpha 2$ adrenoceptors in several blood vessels isolated from the rabbit, Br. J. Pharmacol., 99, 253-260.

De Mey J.G.R. \& Vanhoutte P.M. (1982). Heterogeneous behavior of the canine arterial and venous wall. Importance of the endothelium, Circ. Res., 51, 439-447.

De Mey J.G.R., Lenaers A., Defreyn G., Calderon P. \& Roba J. (1987). Arterial reactivity, blood pressure, and plasma levels of atrial natriuretic peptides in normotensive and hypertensive rats: effects of acute and chronic administration of atriopeptin III, J. Cardiovasc. Pharmacol., 9, 525-535.

De Mey J.G.R., Dijkstra E.H. \& Vrijdag M.J.J.F. (1991). Endothelium reduces DNA synthesis in isolated arteries, Am. J. Physiol., 260, H1128-H1134. 
Dimitriadou V., Aubineau P., Taxi J. \& Seylaz J. (1988). Ultrastructural changes in the cerebral artery wall induced by long-term sympathetic denervation. Blood. Vessels., 25, 122-143.

Drexler H., Flaim S.F., Toggart E.J., Glick M.R. \& Zelis R. (1986). Cardiocirculatory adjustments to exercise following myocardial infarction in rats. Basic. Res. Cardiol., 81, 350-360.

Drexler H., Finkh M., Hoing S., Toth M., Just H. \& Lang R.E. (1987). Systemic and regional vascular effects of atrial natriuretic peptide in a rat model of chronic heart failure, Basic. Res. Cardiol., 82, 517-529.

Dzau V.J. (1987). Renal and circulatory mechanisms in congestive heart failure, Kidney. Int., 31, 1402-1415.

Eerdmans P.H.A., Heesen B.J., Struijker Boudier H.A.J. \& De Mey J.G.R., 1991, Sympathetic heterogeneity in mesenteric and renal resistance arteries, in: Resistance Arteries. Structure and Function, Mulvany M.J., Aalkjaer C., Heagerty A.M., Nyborg N.C.B. \& Strandgaard S., Excerpta Medica, Amsterdam, The Netherlands, 156-159.

Esler M., Jennings G., Korner P., Blombery P., Sacharias N. \& Leonard P. (1984). Measurement of total and organ-specific noradrenaline kinetics in humans, Am. J. Physiol., 247, E21-E28.

Feng F., Abel P.W., Scofield M., Liu F., Wolff D.W. \& Jeffries W.B. (1993). Heterogenous expression of alpha1-adrenoceptor subtypes among rat nephon segments, Mol. Pharmacol., 44, 926-933.

Fishbein M.C., Maclean D. \& Maroko P.R. (1978). Experimental myocardial infarction in the rat; qualitative and quantitative changes during pathological evolution, Am. J. Pathol., 90, 57-70.

Forster C., Carter S. \& Armstrong P. (1989). Vascular smooth muscle responsiveness to noradrenaline and phenylephrine following experimental heart failure in dogs, Cardiovasc. Res., 23, 489-497.

Forster C., Campbell P.M. \& Armstrong P.W. (1992). Temporal alterations in peripheral vascular responsiveness during both the development and recovery from pacing-induced heart failure, J. Cardiovasc. Pharmacol., 20, 206-215.

Froneck K. (1983). Trophic effects of the sympathetic vervous system on vascular smooth muscle, An. Biomed. Engin., 11, 607-615.

Froneck K., Bloor C.M., Amiel D. \& Chvapil M. (1978). Effect of long term sympathectomy on the arterial wall in rabbits and rats, Exp. Mol. Pathol., 28, 279-289.

Fu L.-X., Sun X.-Y., Hedner T., Feng Q.-P., Liang Q.-M., Hoebeke J. \& Hjalmarson A. (1993). Decreased density of mesenteric arteries but not of myocardial endothelin receptors and function in rats with chronic heart failure, J. Cardiovasc. Pharmacol., 22, 177-182.

Fyhrquist F. \& Tikkanen I. (1988). Atrial natriuretic peptide in congestive heart failure, Am. J. Cardiol., 62, 20A-24A.

Grobbee D.E. \& Hofman A. (1989). Epidemiologie van ziekten in Nederland, Wetenschappelijke uitgeverij Bunge, Utrecht, The Netherlands, .

Han C., Abel P.W. \& Minneman K.P. (1987). $\alpha 1$-Adrenoceptor subtypes linked to different mechanisms for increasing intracellular Ca2 + in smooth muscle, Nature., 329 , 333-335. 
Hasking G.J., Esler M.D.. Jennings G.L., Burton D., Johns J.A. \& Korner P.I. (1986). Noradrenaline spillover to plasma in congestive heart failure: evidence of increased cardiorenal and total sympathetic nerve activity, Circulation., 73, 615-621.

Hausdorff W.P., Caron M.G. \& Lefkowitz R.J. (1990). Tuming off the signal: desensitization of beta-adrenergic receptor function, Faseb. J., 4, 2881-2889.

Heteneman S., Leenders P.J.A., Aarts P.J.J.W., Smits J.F.M., Arends J.W. \& Daemen M.J.A.P. (1995). Peripheral vascular alterations during experimental heart failure in the rat. Do they Exist?, Arterioscler. Throm. Vasc. Biol., 15, 1503-1511.

Heesen B.J. \& De Mey J.G.R. (1990). Effects of cyclic AMP-affecting agents on cuntractile reactivity of isolated mesenteric and renal resistance arteries of the rat, Br. J. Pharmacol., 101, 859-864.

Hodsman G.P., Kohzuki m, Howes L.G., Sumithran E., Tsunoda K. \& Johnston C.I. (1988). Neurohumoral responses in chronic myocardial infarction in rats, Circulation., $78,376-381$.

Hoorn van der F.A.J., Boomsma F., Man in 't Veld A.J. \& Schalekamp M.A.D.H. (1989). Determination of catecholamines in human plasma by high-performance liquid chromotography: comparison between a new method with fluorescence detection and an established method with electrochemical detection, J. Chrom., 487, 17-28.

Jennings G.L. \& Esler M.D. (1990). Circulatory regulation at rest and exercise and the functional assessment of patients with congestive heart failure, Circulation., 81, II5-II13

Kiuchi K., Vatner D.E., Uemura N., Bigaud M., Hasebe N., Hempel D.M., Graham R.M. \& Vatner S.F. (1992). Mechanisms of alphal-adrenergic vascular desensitization in conscious dogs, Circ. Res., 71, 1185-1199.

Kiuchi K., Sato N., Shannon R.P., Vatner D.E., Morgan K. \& Vatner S.F. (1993). Depressed beta-adrenergic receptor- and endothelium-mediated vasodilation in conscious dogs with heart failure, Circ. Res., 73, 1013-1023.

Kiuchi K., Sato N., Shannon R., Vatner D.E., Morgan K. \& Vatner S.F. (1993). Depressed $\beta$-adrenergic receptor- and endothelium-mediated vasodilation in conscious dogs with heart failure, Circ. Res., 73, 1013-1023.

Laragh J.H. (1986). Endocrine mechanisms in congestive cardiac failure renin, aldosterone and atrial natriuretic hormone, Drugs., 32, 1-12.

Lee R.M.K.W., Triggle C.R., Cheung D.W.T. \& Coughlin M.D. (1987). Structural and functional consequences of neonatal sympathectomy on the blood vessels of spontaneously hypertensive rats, Hypertension., 10, 328-338.

I.eeb-Lundberg L.M.F., Cotecchia S., DeBlasi A., Caron M.C. \& Lefkowitz R.J. (1987). Regulation of adrenergic receptor function by phosphorylation, J. Biol. Chem., 262, 3098-3105.

Leimbach W.N., Wallin G., Victor R.G., Aylward P.E., Sundlof G. \& Mark A.L. (1986). Direct evidence from intraneuronal recordings for increased central sympathetic outflow in patients with heart failure, Circulation., 73, 913-919.

Lohse M.J., Benovic J.L., Caron M.G. \& Lefkowitz R.J. (1990). Multiple pathways of rapid beta2-adrenergic receptor desensitization, J. Biol. Chem., 265, 3202-3209.

Mangiarua E.I. \& Lee R.M.K.W. (1992). Morphometric study of cerebral arteries from spontaneously hypertensive stroke-prone hypertensive rats, J. Hypertension., 10, 1183 1190 
Meerson F.Z. (1983). The failing heart: adaption and de-adaption,, Raven Press, New York,

Michel M.C., Brodde O.E. \& Insel P.A. (1990a). Peripheral adrenergic receptors in hypertension, Hypertension., 16, 107-120.

Michel M.C., Hanft G. \& Gross G. (1990b). Alpha1-B but not alpha1-A adrenoceptors mediate inositol phosphate generation, Naunyn. Schmiedeberg's. Arch. Pharmacol., 341, 385-387.

Mulvany M.J. \& Halpern W. (1977). Contractile properties of small anterial resistance vessels in spontaneously hypertensive and normotensive rats, Circ. Res., 41, 19-26.

Munzel T., Kurz S., Holtz J., Busse R., Steinhauer H., Just H. \& Drexler H. (1992). Neurohumoral inhibition and hemodynamic unloading during prolonged inhibition of ANF degradation in patients with severe chronic heart failure, Circulation., 86, 10891098.

Nilsson H. (1985). Adrenergic nervous control of resistance and capacitance vessels, Acta. Physiol. Scand., 124(suppl 541), 1-34.

Nilsson H., Goldstein M. \& Nilsson O. (1986). Adrenergic innervation and neurogenic response in large and small areries and veins from the rat, Acta. Physiol. Scand, 126, 121-133.

Pfeffer M.A., Pfeffer J.M., Fishbein M.C., Fletcher P.J., Spadaro J., Kloner R.A. \& Braunwald E. (1979). Myocardial infarct size and ventricular function in rats, Circ. Res., 44, 503-512.

Pfeffer M.A., Pfeffer J.M., Steinberg C. \& Finn P. (1985). Survival after an experimental myocardial infarction: beneficial effects of long-term therapy with captopril. Circulation. . 72, 406-412.

Poole-Wilson P.A., Buller N.P. \& Lipkin D.P. (1988). Regional blood flow, muscle strenght and skeletal muscle histology in severe congestive heart failure, Am. J. Cardiol., 62, 49E-52E.

Raymond J.R., Hnatowich M., Lefkowitz R.J. \& Caron M.G. (1990). Adrenergic receptors: Models for regulation of signal transduction processes, Hypertension., 15. 119-131.

Remme W.J. (1986). Congestive heart failure. Pathophysiology and medical treatment, J. Cardiovasc. Pharmacol., 8, S36-S52.

Ruggie N. (1986). Congestive hean failure, Med Clin North Am, 70, 829-851.

Rutherford J.D. \& Braunwald E. (1992). Chronic ischemic heart disease, In: Heart disease: a textbook of cardiovascular medicine., W.B. Saunders Company, Philadelphia, 13021316.

Schlant R.C. \& Alexander R.W. (1994). The heart, McGraw-Hill, edition eight, ISBN 007-055418-8, 1114.

Sibley D.R. \& Lefkowitz R.J. (1985). Molecular mechanisms of receptor desensitization using the beta-adrenergic receptor-coupled adenylate cyclase system as a model, Nature., $317,124-129$.

Sigurdsson A., Held P. \& Swedberg K. (1993). Short- and long-term neurohormonal activation following acute myocardial infarction, Am. Heart. J., 126 (5), 1068-1076.

Svanegaard J., Johansen J.B., Thayssen P. \& Haghfelt T. (1993). Neurohormonal systems during heart failure: a review, cardiology, 83, 21-29. 
Teerlink J.R., Clozel M., Fischli W. \& Clozel J.P. (1993). Temporal evolution of endothelial dysfunction in a rat model of chronic hear failure, J. Am. Coll. Cardiol., 22, 615-620.

Teerlink J.R., Gillian G.A., Clozel M. \& Clozel J.P. (1994). Increased vascular responsiveness to norepinephrine in rats with heart failure is endothelium dependent, Circulation., 89, 393-401.

Thomas J.A. \& Marks B.H. (1978). Plasma norepinephrine in congestive heart failure, Am. J. Cardiol., 41, 233-243.

Vatner D.E., Vatner S.F., Nejima J., Llemura N., Susanni E.E., Hintze T.H. \& Homcy C.J. (1989). Chronic norepinephrine elicits desensitisation by uncoupling the B-receptor, J. Clin. Invest., 84, 1741-1748.

Wallenstein S., Zucker C.L. \& Fleiss J.L. (1980). Some statistical methods useful in circulation research, Circ. Res., 47, 1-9.

Wilson K.M. \& Minneman K.P. (1990). Different pathways of 3H inositol phosphate formation mediated by $\alpha_{1 \mathrm{~A}}$-adrenergic and $\alpha \mathrm{lB}$-adrenergic receptors, J. Biol. Chem., $265,17601-17606$. 


\section{Impaired arterial reactivity following cytomegalovirus infection in the immunosuppressed rat}

Pedro H.A. Eerdmans, Maike C.J. Persoons ${ }^{1}$, Sjaak J. M. Debets, Harry A.J. Struijker Boudier, Jos F.M. Smits, Catrien A. Bruggeman', Jo G.R. De Mey

Departments of Pharmacology and Medical Microbiology ${ }^{1}$, Cardiovascular Research Institute Maastricht, University Maastricht, Maastricht, The Netherlands 



\section{Abstract}

Cytomegalovirus (CMV) is a major pathogen in immunocompromised individuals and may participate in the pathogenesis of atherosclerosis in the general population. We evaluated whether $\mathrm{CMV}$-infection alters the function of arterial smooth muscle.

Blood pressure (BP) and arterial reactivity were recorded in immunosuppressed rats that had been infected with $\mathrm{CMV}\left(10^{5}\right.$ plaque forming units i.p.). Furthermore, the reactivity of isolated arteries was compared between CMV-infected rats and rats injected with bacterial endotoxin (LPS).

Initially resting $\mathrm{BP}$ and heart rate (HR) were not modified in CMV-infected rats, but baroreflex control of HR was impaired. By the eighth day post-CMV, BP dropped precipitously and could no longer be raised by phenylephrine (PHE). In mesenteric resistance arteries, isolated at this stage from CMVinfected rats, contractile responses to nerve stimulation, noradrenaline, PHE and serotonin (5-HT) were virtually absent while those to high potassium and vasopressin (AVP) were not modified. In aorta of CMV-infected rats, responses to 5-HT and AVP were impaired while those to PHE or potassium were hardly affected. Reduced contractile responses could not be restored by $\mathrm{N}^{\mathrm{G}}$-nitro-l-arginine methyl ester (L-NAME). Continuous treatment of CMVinfected rats with prazosin $\left(0.1 \mathrm{mg} \cdot \mathrm{kg}^{-1}\right.$.day $\left.{ }^{-1}\right)$ prevented blood pressure lowering and resistance artery changes. Observations in arteries of LPS-treated rats (5-10 mg. $\mathrm{kg}^{-1}$ i.p.) differed markedly from those in vessels of CMVinfected animals. The contractile reactivity of their mesenteric resistance arteries was not altered while in their aorta responses to PHE, 5-HT and AVP were reduced. With the exception of the AVP responses, this was more pronounced in the presence of L-arginine and reversed by L-NAME. These findings indicate that $\mathrm{CMV}$-infection results in a reduction of resistance artery reactivity and hypotonia. This seems not to involve cytokine-mediated induction of NO synthase in the vascular wall but may be due to alterations of excitation-contraction coupling in arterial smooth muscle in response to increased sympathetic nervous input. 


\section{Introduction}

Latent cytomegalovirus (CMV, a betaherpes virus) is present in a major portion of the human population. In immunologically compromised individuals, including those with acquired immunodeficiency, CMV is the cause of serious disease (Abe et al., 1983; Tyms et al., 1989). In the general population CMV may participate in the pathogenesis of atherosclerosis (Bruggeman \& van Dam-Mieras, 1991; Hajjar, 1991; Persoons et al., 1994). The virus is found more frequently in arteries of patients exhibiting grade III atherosclerosis than in those of young trauma victims (Hendrix et al., 1989) and the development of atherosclerosis in heart-transplants has been observed to correlate with the presence of CMV (Grattan et al., 1989; McDonald et al., 1989). The mechanism of CMV's contribution to atherogenesis remains unclear. Both in vitro and in vivo, CMV increases adherence of monocytes and leucocytes to vascular endothelium (Span et al., 1991b). This is mediated by interleukin 1 (IL1) (Span et al., 1991a). Whether CMV also affects arterial smooth muscle cells, another participant in the formation of atherosclerotic lesions and a major determinant of blood pressure, is largely unknown. In addition to potential direct effects of CMV on arterial smooth muscle cells, arterial responses to cytokines produced during $\mathrm{CMV}$-infection may be considered. Cytokines such as interleukin 1 and tumor necrosis factor have been shown to induce NO synthase activity in vascular smooth muscle (Moncada et al., 1989; Moncada \& Higgs, 1991; Schini et al., 1992). This seems to underlay hypotonic shock (Lin et al., 1994) during bacterial endotoxemia. Endotoxin would stimulate cytokine production and subsequently elevate intravascular levels of NO leading to profound vasodilation (JulouSchaeffer et al., 1990; Moncada \& Higgs, 1991; Wakabayashi et al., 1991; Mombouli \& Vanhoutte, 1995). This is accompanied by marked baroreflexmediated stimulation of sympathetic nerve traffic to the heart and blood vessels (Groeneveld et al., 1986). With time the reflex may adapt (Salgado \& Krieger, 1978) which could result in the precipitous uncontrolled fall of blood pressure that characterizes septic shock (Groeneveld et al., 1986; Julou-Schaeffer et al., 1990; Wakabayashi et al.. 1991).

In the present study we evaluated whether CMV-infection influences arterial contractile reactivity and whether cytokine-mediated induction of NO synthase or adaptation to elevated sympathetic tone are involved herein. For this purpose we recorded blood pressure, pressor responses to phenylephrine and contractile reactivity of isolated blood vessels. Rat cytomegalovirus (Bruggeman et al., 1985) was used to infect rats that had been immunosup- 
pressed by irradiation to promote and accelerate infection. Part of the experiments were performed during continuous treatment with prazosin, in an attempt to protect the vasculature against the effects of increased exposure to noradrenaline. Observations were compared to those in sham-infected irradiated rats and in rats injected with bacterial endotoxin as a positive control for hypotonic shock due to cytokine-induced NO synthase expression in the vasculature (Julou-Schaeffer et al., 1990; Rengasamy \& Johns. 1991).

\section{Materials \& methods}

Experiments were performed in 8 week old male specific pathogen-free Wistar Kyoto rats (Central Animal Facilities; University of Limburg, Maastricht, The Netherlands) and were approved by the local animal welfare committee. The animals were maintained on 12 hour dark - 12 hour light cycles and had free access to standard lab food and tap water. Four groups of animals $(n=10$ each) were defined: 1) untreated rats (control), 2) rats treated with bacterial endotoxin (LPS-treated), 3) immunosuppressed untreated rats (CMV-control) and 4) immunosuppressed rats that were infected with cytomegalovirus (CMVinfected). Treatment with LPS consisted of i.p. injection of $5 \mathrm{mg} \cdot \mathrm{kg}^{-1}$ endotoxin of Escherichia coli. Immunosuppression was achieved by 6 Gray total-body gamma irradiation. Twenty four hours later part of the animals were i.p. injected with 100,000 plaque forming units (PFU) of rat cytomegalovirus from a pad of homogenized salivary glands of acutely infected rats (Bruggeman et al., 1985). CMV-controls received sterile phosphate buffered saline.

\section{Blood Pressure Measurement}

Ten CMV-control rats and ten CMV-infected rats were equipped with an intravenous and an intraarterial catheter for i.v. administration of agents and recording of blood pressure, respectively (Struijker Boudier et al., 1982). Surgery was performed under ketamine/xylazine (5 and $1 \mathrm{mg}^{-k^{-1}}$ i.m. respectively) anaesthesia three days prior to immunosuppression. Polyethylene tubing (PE 10) was inserted from a femoral artery into the abdominal aorta and from a femoral vein into the vena cava. The catheters were guided under the dorsal skin, exteriorized and sutured to the neck musculature. 
The animals were injected on three consecutive days with an antibiotic (ampiciline 0.1 g.day $^{-1}$ s.c.).

The arterial catheter was connected to a miniature low volume displacement pressure transducer (CP-01, Century Technology Co, Inglewood Ca, USA) and the signal recorded on a polygraph (Grass model 7D; Grass Instruments, Quincy MA, USA). Heart rate was determined from the pulsatile signal by a tachograph (Grass Instruments). Mean blood pressure, heart rate and dose response curves for the vasopressor effect of i.v. infused L-phenylephrine, were determined in conscious freely moving animals on days $1,3,5,7,8,9$, and 10 after CMV- or sham-infection. Phenylephrine infusion were started at $0.1 \mu \mathrm{g} \cdot \mathrm{min}^{-1}$, the infusion rate was increased $(0.2,0.3,0.4,0.5,0.6,0.7$, $\left.0.8,0.9,1.0,2.0 \mu \mathrm{g} \cdot \mathrm{min}^{-1}\right)$ when a stable pressure was reached.

Similar experiments were performed in rats that were continuously treated with $0.1 \mathrm{mg} \cdot \mathrm{kg}^{-1} \cdot \mathrm{day}^{-1}$ prazosin. During placement of the catheters, these rats were also subcutaneously implanted with an osmotic minipump (Alzet 2ML2; Alza Co, Palo Alto, Ca USA) filled with prazosin dissolved in $50 \%$ DMSO in $\mathrm{H}_{2} 0$. In a previous study (van Kleef et al., 1992) this dose of prazosin was observed to produce an 80 -fold shift of the dose-response curve for the pressor action of phenylephrine, indicating significant $\alpha_{1}$-adrenoceptor antagonism. Up to 14 days of treatment with the solvent did, however, not affect blood pressure, pressor responses to phenylephrine or the reactivity of isolated blood vessels. Three days after initiation of the prazosin-treatment the rats were irradiated. Twenty four hours later part of them were infected with CMV $(n=10)$ and part of them were sham-infected $(n=10)$.

\section{Contractile Reactivity of Isolated Blood Vessels.}

Rats were sacrificed by abdominal aorta puncture under ether anaesthesia 48 to 72 hours after LPS treatment, ten days after sham-infection or seven to ten days after $\mathrm{CMV}$-infection. The decision to sacrifice CMV-infected rats was based on their blood pressure and overall appearance. Furthermore, 8 untreated control animals were used. From each rat the thoracic aorta and the mesentery were isolated. From the latter a fourth order resistance-sized side branch of the superior mesenteric artery (diameter approximately $200 \mu \mathrm{m}$ ) was dissected. Aorta segments and mesenteric small artery segments (length $2 \mathrm{~mm}$ ) were mounted horizontally in an organ chamber between a isometric force transducer (Statham UC3 and Kistler Morse DSC6 for large and small vessels, respectively) and a displacement device (Boonen \& De Mey, 1990a; 1991; Eerdmans et al., 1991). The organ chamber was filled with Krebs-Ringer bicarbonate solution (KRB, 25 and $10 \mathrm{ml}$ for large and small vessels, 
respectively) that was maintained at $37^{\circ} \mathrm{C}$ and aerated with $95 \% \quad \mathrm{O}_{2}$ and $5 \%$ $\mathrm{CO}_{2}$. Prior to experimentation the internal circumference of the thoracic aorta segments was set at $4.25 \mathrm{~mm}$, which was observed in preliminary experiments to yield strong and reproducible contractile responses. Mesenteric resistance arteries were stretched to their individual optimal internal circumference for isometric force development (Boonen \& De Mey, 1990a; 1990b; 1991; Eerdmans et al., 1991). Their circumference was increased by $60 \mu \mathrm{m}$ every 5 min. with intermittent exposure to high potassium solution $\left(125 \mathrm{mM} \mathrm{K}^{+}\right.$; KRB in which all $\mathrm{NaCl}$ had been replaced by an equimolar amount of $\mathrm{KCl}$ ). This length-tension protocol was continued until maximal contractile responses to the depolarising stimulus were obtained. Further experimentation was performed at this optimal internal circumference. Contractile responses were induced with potassium, noradrenaline, phenylephrine, 5-hydroxytryptamine or Arg-vasopressin and relaxing responses to isoproterenol or acetylcholine were induced after the preparations had been made to contract with $30 \mathrm{nM}$ Argvasopressin. These agents were tested in the same vessels but the order of testing was randomized to exclude that responses to a given agonist were influenced by pretreatment with another agent. Part of the experiments were repeated in the presence of $1 \mathrm{mM} \mathrm{L}$-arginine or of $0.1 \mathrm{mM} \mathrm{N} \mathrm{N}^{(i}$-nitro-l-arginine methyl ester (L-NAME), a substrate and an inhibitor of NO synthase, respectively (Moncada et al., 1989). Preparations were preincubated with these agents for at least $30 \mathrm{~min}$ before exposure to contractile or relaxing agonists. Also the order of exposure to L-arginine and L-NAME was randomized. This did not affect the results. To stimulate sympathetic nerves in mesenteric resistance arteries, 2 platinum electrodes connected to a constant current source (amplitude $85 \mathrm{~mA}$ ) were placed longitudinally across the mounted vessel segments and frequency response curves (1 to $32 \mathrm{~Hz}$, pulse duration 2 msec) were constructed (Nilsson, 1985; Eerdmans et al., 1991). The experiments were performed in parallel in isolated aorta and resistance artery segments and took approximately 6 hours to perform. It has previously been demonstrated that long term incubation of blood vessels in vitro may be accompanied by the induction of additional NO synthesis (Moncada et al., 1989; Moncada \& Higgs, 1991). In the present experiments, however, the sensitivity for vasocontrictor agonists and the effects of L-arginine and LNAME on contractile responses to agonists did not differ when evaluated after 1 and 6 hours of incubation of preparations of control rats $(n=6)$. Therefore, the interpretation of the present findings is not likely to be complicated by the induction of NO synthase during the in vitro experimentation. 


\section{Drugs and Solutions}

$\mathrm{KRB}$ had the following millimolar composition: $\mathrm{NaCl} 118.3, \mathrm{KCl} 4.7, \mathrm{CaCl}_{2}$ 2.5, $\mathrm{MgSO}_{4} .7 \mathrm{H}_{2} 01.2, \mathrm{KH}_{2} \mathrm{PO}_{4}$ 1.2, $\mathrm{NaHCO}_{3} 25.0$, glucose 11.1. L-arginine hydrochloride, $\mathrm{N}^{\mathrm{G}}$-nitro-L-arginine methyl ester, L-isoproterenol hydrochloride, LPS from Escherichia coli, L-noradrenaline hydrochloride, Lphenylephrine hydrochloride, L-prazosin hydrochloride, and DL-propranolol hydrochloride were obtained from Sigma Chemical Co (Saint Louis, Mo USA). Acetylcholine hydrochloride and serotonin creatinine sulphate monohydrate were purchased from Janssen Chimica (Beerse, Belgium) and Arg-vasopressin from Sandoz (Basel, Switzerland).

\section{Data Analysis}

Contractile responses of isolated blood vessels to agonists were expressed as increases in wall tension (increases in isometric force divided by twice the segment length) and relative to the amplitude of the contraction induced by $125 \mathrm{mM}$ potassium in the same preparation. Sensitivity for the pressor action of phenylephrine in vivo and for the contractile effect of agonists in vitro was determined by interpolation on a least square sigmoidal curve fit of the concentration response curves (Inplot, GraphPad, San Diego, Ca, USA). Data are shown as mean \pm s.e.mean. Statistical significance of effects and of differences between treatment groups was evaluated by Student's t-test for paired observations, Student's t-test for unpaired observations or analysis of variance followed by Bonferroni's t-test or Student's t-test where appropriate (Wallenstein et al., 1980) using commercially available software (Crunch, Software Corp., San Francisco, Ca USA). 


\section{Results}

\section{Blood Pressure and Heart Rate}

In irradiated rats that had been sham-infected, basal mean arterial pressure (MAP) and heart rate (HR), the sensitivity and maximal pressor response to i.v. infused phenylephrine (PHE) and the bradycardia accompanying the elicited pressure elevation, did not change significantly during the study period (table 1, figure 1 and figure 2).

\section{Table 1}

Effect of phenylephrine on blood pressure in sham-infected and CMV-infected rats.

\begin{tabular}{|l|l|l|l|l||}
\multicolumn{2}{c}{ Sham-infected } & \multicolumn{3}{c|}{ CMV-infected } \\
\hline & $\begin{array}{l}\mathrm{ED}_{50} \\
\left(\mu \mathrm{g} \cdot \mathrm{min}^{-1}\right)\end{array}$ & $\begin{array}{l}\mathrm{E}_{\max } \\
(\mathrm{mmHg})\end{array}$ & $\begin{array}{l}\mathrm{ED}_{50} \\
\left(\mu \mathrm{g} \cdot \mathrm{min}^{-1}\right)\end{array}$ & $\begin{array}{l}\mathrm{E}_{\max } \\
(\mathrm{mmHg})\end{array}$ \\
\hline Day 1 & $0.16 \pm 0.03$ & $51 \pm 7$ & $0.22 \pm 0.03$ & $46 \pm 8$ \\
\hline Day 3 & $0.20 \pm 0.02$ & $64 \pm 5$ & $0.21 \pm 0.03$ & $68 \pm 4$ \\
\hline Day 5 & $0.22 \pm 0.03$ & $64 \pm 3$ & $0.22 \pm 0.07$ & $58 \pm 4$ \\
\hline Day 7 & $0.14 \pm 0.01$ & $61 \pm 2$ & $0.55 \pm 0.17$ & $47 \pm 8$ \\
\hline Day 8 & $0.22 \pm 0.02$ & $69 \pm 4$ & $>2$ & $9 \pm 4 *$ \\
\hline \hline
\end{tabular}

Irradiated rats were i.p. injected with $10^{5} \mathrm{PFU}$ of CMV or sham-infected on Day 0 . Cumulative concentration response curves for the pressor effect of phenylephrine $\left(0.1-2 \mu \mathrm{g} \cdot \mathrm{min}^{-1}\right)$ were constructed by iv infusion of the agonist in conscious unrestrained animals. Data were expressed as the dose required to induce a half maximal response $\left(E D_{s_{0}}\right)$ and as the maximal increase in mean arterial blood pressure $\left(E_{m a x}\right)$, and are shown as mean \pm s.e.mean $(n=7-10)$. "The difference from sham-infected animals is statistically significant $(p<0.05)$.

One day after CMV-infection the recorded variables did not differ from those in sham-infected rats. Three days following CMV-infection, MAP was not altered but HR significantly reduced (figure 1). The sensitivity and maximal pressor response to PHE were not modified at this stage (table 1, figure 2). 

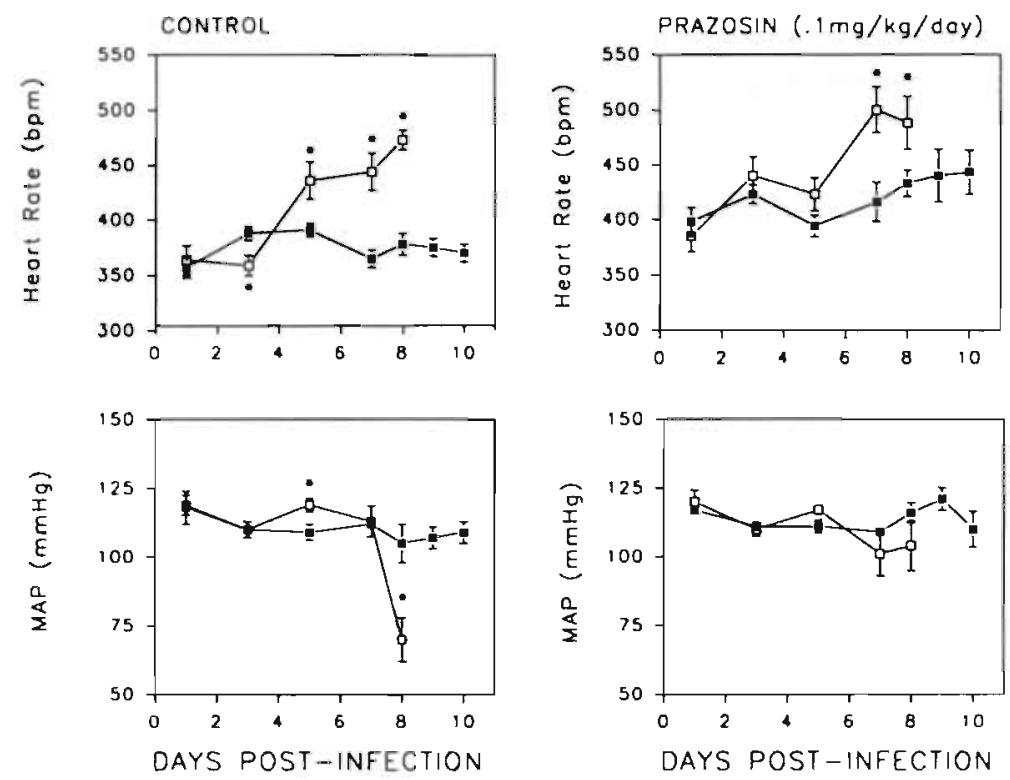

Figure 1

Basal heart rate (HR, top) and mean arterial pressure (MAP, bottom) in conscious unrestrained irradiated rats that had been i.p. injected on day 0 with $10^{5}$ PFU rat cytomegalovirus (CMV, open symbols) or sham-infected (closed symbols) without (left) and with (right) continuous treatment with $0.1 \mathrm{mg} \cdot \mathrm{kg}^{-1}$. day ${ }^{-1}$ prazosin initiated at day -3 . Data are shown as mean \pm s.e.mean $(\mathbf{n}=7-10) .{ }^{*}$. the difference from sham-infected animals is statistically significant $(p<0.05)$.

The baroreflex, as reflected by heart rate changes during pharmacologically induced pressure elevation was, however, impaired (figure 2). The relationship between changes in heartperiod and changes in MAP was less pronounced in CMV-infected rats (correlation coefficient, $\mathrm{r}^{2} .271$ ) than in shams $\left(\mathrm{r}^{2} .508\right)$ and was more shallow (slope $.712 \pm .179 \mathrm{msec}^{\mathrm{mmHg}}{ }^{-1}$ versus $1.653 \pm .217$ msec. $\mathrm{mmHg}^{-1}$ in shams). By day 5 , both MAP and HR were significantly elevated (figure1). The sensitivity and maximal pressor response to PHE were not altered (table 1). The baroreflex was restored but seemed to be operating around a higher heart rate (figure 2). At the 7th day after CMV-infection, basal HR remained elevated while MAP was comparable to that in shams. The animals had become less sensitive to the pressor action of PHE (table 1), but still displayed bradycardia in response to pressure elevation (figure 2). Although the range of pressure and heart rate changes was narrower, the relationship between MAP and HR was shifted as observed on day 5 post- 
CMV. On day 8, CMV-infected rats displayed very low MAP and high HR (figure 1 and figure 2). At this stage even high doses of PHE had minimal effects on blood pressure.
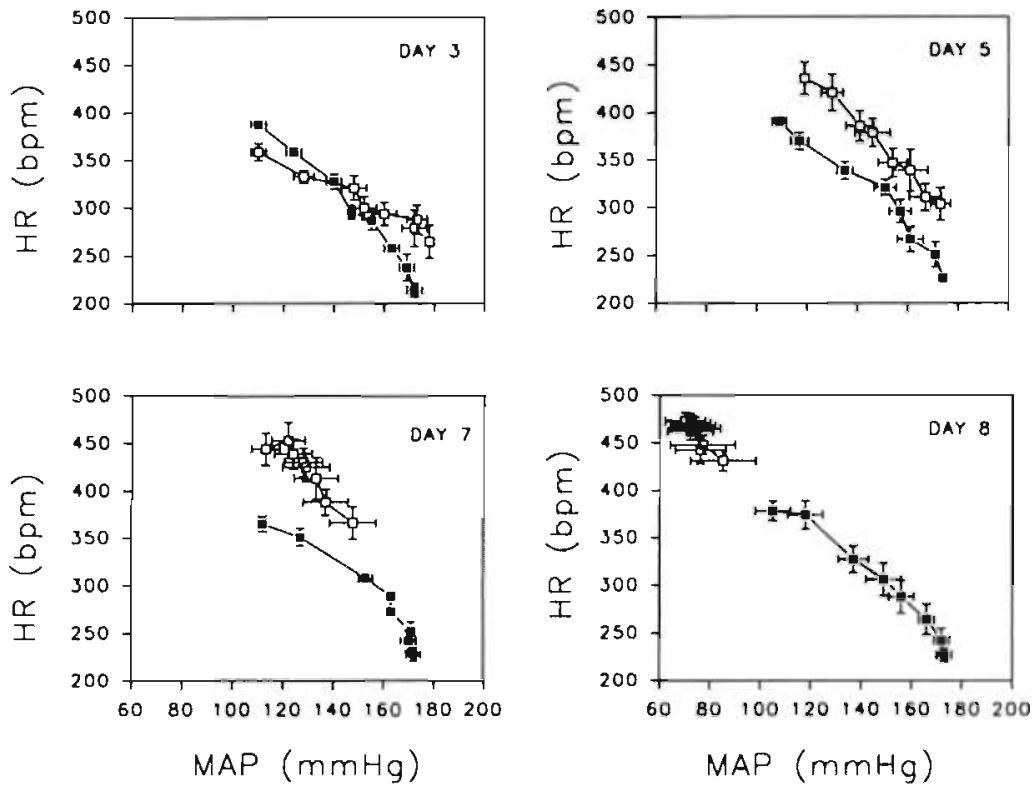

Figure 2

Relationship between hear rate (HR) and mean arterial pressure (MAP) before and during i.v. infusion of phenylephrine ( 0.1 to $\left.2.0 \mu \mathrm{g} \cdot \mathrm{min}^{-1}\right)$ in conscious unrestrained irradiated rats that had been infected with CMV (open symbols) or sham-infected (closed symbols) on day 0. For sensitivity and maximal pressor responses to the agonist see table 1 . Data are shown as mean \pm s.e. mean $(n=$ 7-10).

Blood pressure and heart rate were recorded in additional animals that were infected with CMV or sham-infected during continuous treatment with 0.1 mg.kg-1.day ${ }^{-1}$ prazosin. The long-term treatment with the $\alpha_{1}$-adrenoceptor antagonist did not modify MAP but tended to increase HR (figure 1). In prazosin-treated animals the development of tachycardia during CMV-infection was delayed and no precipitous fall of blood pressure was noted on the 8th day (figure 1). In a separate experiment it was observed that 6 out of 10 prazosintreated rats survived the $\mathrm{CMV}$-infection for at least ten days, while this was the case for only 3 out of $10 \mathrm{CMV}$-infected animals, that were not treated with prazosin. 


\section{Isolated Blood Vessels}

\section{Thoracic aorta}

Eight days following $\mathrm{CMV}$-infection, contractile responses of thoracic aorta segments to $125 \mathrm{mM}$ potassium were not significantly modified. They averaged $3.8 \pm 0.5 \mathrm{mN} / \mathrm{mm}$ compared to $4.8 \pm 0.2 \mathrm{mN} / \mathrm{mm}$ in aorta of shaminfected rats. The sensitivity of the aorta to PHE was decreased and contractile responses to 1-10 $\mu \mathrm{M}$ serotonin (5-HT) and those to $30 \mathrm{nM}$ Arg-vasopressin (AVP) were markedly reduced (figure 3 ). These differences between the aorta of CMV-infected and sham-infected rats were not accentuated in the presence of $1 \mathrm{mM} \mathrm{L}$-arginine and were not abolished by $0.1 \mathrm{mM} \mathrm{L-NAME}$ (figure 3 ).
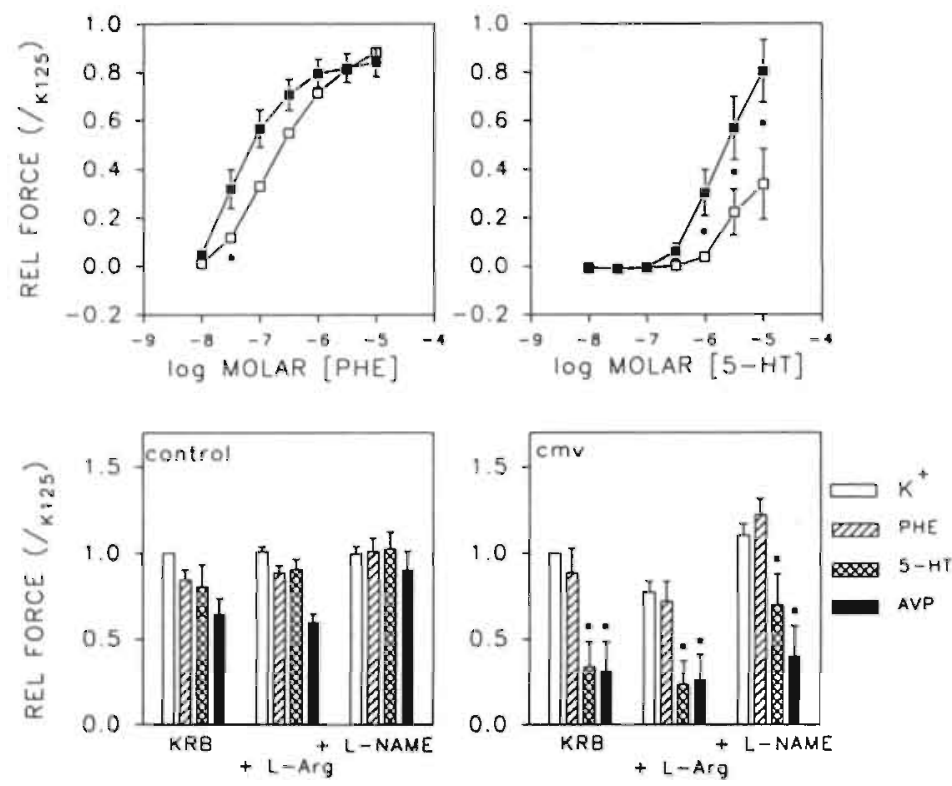

\section{Figure 3}

Contractile reactivity of aorta segments isolated 8 days after CMV- or sham-infection. Shown are concentration response curves (top) for phenylephrine (PHE) and serotonin (5-HT; sham, closed symbols; CMV, open symbols) along with the amplitude of contractile responses to $125 \mathrm{mM}$ potassium. $10 \mu \mathrm{M}$ phenylephrine, $10 \mu \mathrm{M}$ serotonin and $30 \mathrm{nM}$ Arg-vaso-pressin in the absence (KRB) or presence of $1 \mathrm{mM} \mathrm{L}$-arginine (L-Arg) or $0.1 \mathrm{mM}$ L-NAME. The data were expressed as fraction of the contractile response to $125 \mathrm{mM}$ potassium in drug-free solution $(4.8 \pm 0.2$ and 3.8 $\pm 0.5 \mathrm{mN} / \mathrm{mm}$ for control and CMV-rats, respectively) and are shown as mean \pm s.e.mean ( $\mathrm{n}=$ 8). * the difference from sham-infected rats is statistically significant $(P<0.05)$. 
Mesenteric resistance arteries

Eight Days after CMV-infection the size of the mesenteric resistance arteries was not modified and the amplitude of their responses to $125 \mathrm{mM}$ potassium and $30 \mathrm{nM}$ AVP was not altered (table 1). Mesenteric small arteries ohtained from CMV-infected rats failed, however, to contract to adrenergic stimulation (figure 4). Virtually no contractile responses were obtained in response to nerve stimulation or exogenous noradrenaline. The $\beta$-adrenoceptor blocking agent propranolol $(1 \mu \mathrm{M})$ did not unmask responses to these interventions (data not shown, $\mathrm{n}=8$ ) and also the selective $\alpha_{1}$-adrenergic agonist PHE failed to induce contraction (figure 4). Furthermore, responses to 5-HT were significantly smaller in mesenteric resistance arteries of CMV-infected than in those of sham-infected rats (figure 4). The sensitivity $\left(\mathrm{pD}_{2}: 6.7 \pm 0.4\right.$ versus

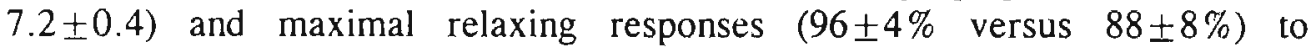
isoproterenol, administered during AVP-induced contraction, were not altered in small arteries of CMV-infected rats (figure 5). In resistance arteries of rats that had been exposed to the virus, the maximal relaxing response to acetylcholine $(54 \pm 17 \%$ versus $90 \pm 3 \%)$ was significantly reduced but the sensitivity to the endothelium-dependent agonist was not modified $\left(\mathrm{pD}_{2}\right.$ : $7.1 \pm 0.2$ versus $6.9 \pm 0.3$ ) (figure 5).

Pretreatment with L-NAME, or administration of the inhibitor during exposure to agonists, did not unmask contractile responses to noradrenaline or PHE and did not enhance contractile responses to 5-HT in mesenteric resistance arteries of CMV-infected rats (not shown). 

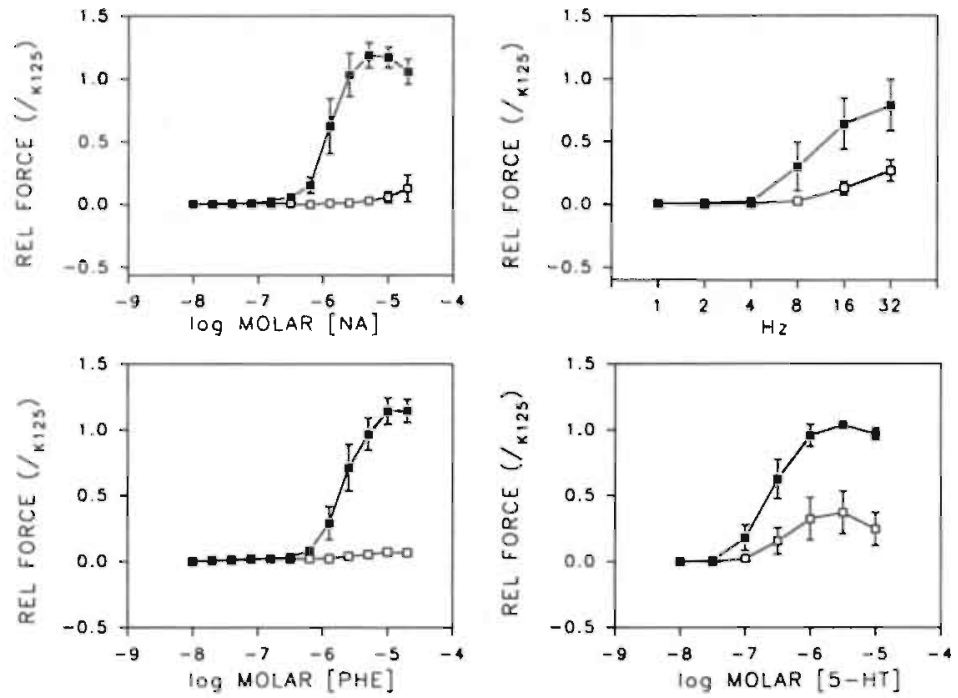

Figure 4

Contractile responses in mesenteric small artery segments isolated 8 days after CMV- (open symbols) or sham-infection (closed symbols). Concentration-response curves for norepinephrine (NE), phenylephrine (PHE) and serotonin (5-HT) are shown along with frequency-response curves for electrical field stimulation of perivascular nerves (EFS). The data were expressed relative to the amplitude of contractile responses to $125 \mathrm{mM}$ potassium (for absolute values see table 2) and are shown as mean \pm s.e.mean $(n=7-10)$. The differences between both groups are statistically significant.

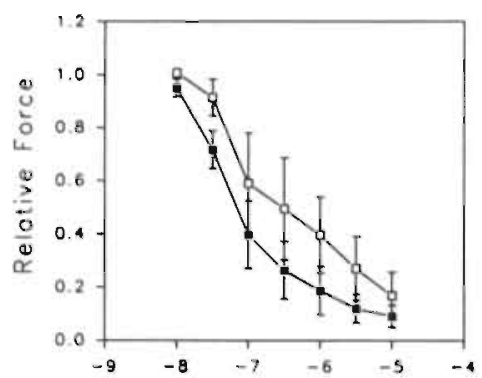

$\log$ MOLAR [ISOP]

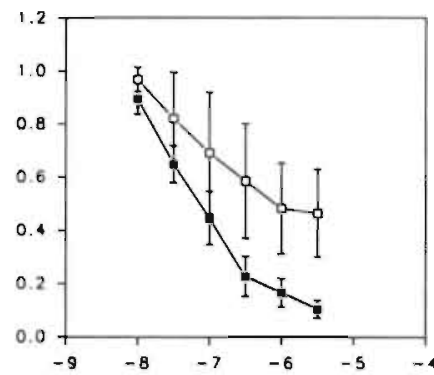

$\log$ MOLAR [ACh]

Figure 5

Relaxing responses in mesenteric small artery segments isolated 8 days after CMV- (open symbols) or sham-infection (closed symbols). Concentration-response curves for isoproterenol (ISOP) and acethylcholine (Ach) were constructed during contraction induced by $30 \mathrm{nM}$ Arg-vasopressin. The data were expressed as fraction of the tone ubserved before addition of the relaxing agent and are shown as mean \pm s.e. mean $(n=7-10)$ 

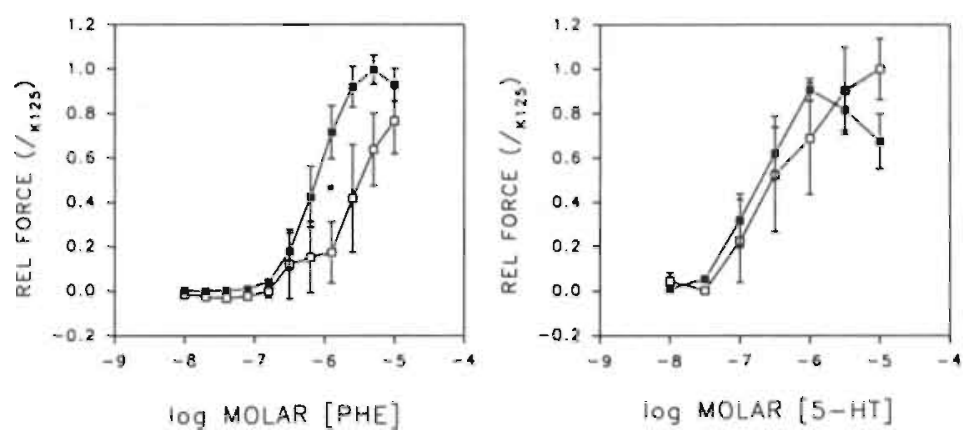

Figure 6

Contractile responses in mesenteric small artery segments isolated 8 days after CMV- (open symbols) or sham-infection (closed symbols) during continuous treatment in vivo with 0.1 $\mathrm{mg} / \mathrm{kg} /$ day prazosin. Concentration-response curves for phenylephrine (PHE) and serotonin (5-HT) are shown. The data were expressed relative to the amplitude of contractile responses to $125 \mathrm{mM}$ potassium (for absolute values see table 2 ) and are shown as mean \pm s.e.mean $(n=7-10)$.

* The difference between CMV-and sham-infected rats is statistically significant.

Figure 6 illustrates responses to vasoconstrictors in mesenteric resistance arteries obtained from rats that had been sham- or CMV-infected during continuous treatment with $0.1 \mathrm{mg} \cdot \mathrm{kg}^{-1}$.day ${ }^{-1}$ prazosin. As was observed for the untreated animals, the optimal diameter and the amplitude of responses to 125 $\mathrm{mM}$ potassium and $30 \mathrm{nM}$ AVP did not differ between vessels of the shamand the CMV-infected rats (table 2). 
Table 2

Maximal contractile responses to agonists in mesenteric resistance-sized arteries of rats infected with cytomegalovirus (CMV)

\begin{tabular}{|l|l|l|l|l|l|}
\hline & $\begin{array}{l}\text { OID } \\
(\mu \mathrm{m})\end{array}$ & $\begin{array}{l}\mathrm{K}^{+} \\
\left(\mathrm{mN} \cdot \mathrm{mm}^{-1}\right)\end{array}$ & $\begin{array}{l}\text { AVP } \\
\left(\mathrm{mN} \cdot \mathrm{mm}^{-1}\right)\end{array}$ & $\begin{array}{l}\text { NA } \\
\left(\mathrm{mN} \cdot \mathrm{mm}^{-1}\right)\end{array}$ & $\begin{array}{l}\text { 5-HT } \\
\left(\mathrm{mN} \cdot \mathrm{mm}^{-1}\right)\end{array}$ \\
\hline Untreated \\
\hline Sham-infected & $201 \pm 9$ & $2.6 \pm .4$ & $2.6 \pm .3$ & $3.0 \pm .4$ & $2.6 \pm .02$ \\
\hline CMV-infected & $193 \pm 12$ & $2.8 \pm .3$ & $2.4 \pm .3$ & $0.1 \pm .05^{*}$ & $0.6 \pm .06^{*}$ \\
\hline 0.1mg.kg-1.day & prazosin \\
\hline Sham-infected & $200 \pm 11$ & $3.3 \pm .4$ & $2.6 \pm .5$ & $3.3 \pm .3$ & $2.1 \pm .3$ \\
\hline CMV-infected & $242 \pm 28$ & $2.6 \pm .3$ & $3.2 \pm .3$ & $1.3 \pm .9^{*}$ & $2.7 \pm .7$ \\
\hline
\end{tabular}

Small arteries were isolated from the mesentery of irradiated rats 8 days after sham- or CMVinfection with and without continuous treatment with prazosin. The vessels were stretched to their individual optimal internal diameter (OID) for isometric force development. The amplitude of contractile responses to $125 \mathrm{mM}$ potassium $\left(\mathrm{K}^{+}\right), 30 \mathrm{nM}$ Arg-vasopressin (AVP), $10 \mu \mathrm{M}$ noradrenaline (NA) and $10 \mu \mathrm{M}$ serotonin (5-HT) were expressed as increases in wall tension and are shown as mean \pm s.e.mean $(n=7-10)$. The difference from sham-infected animals is statistically significant $(p<0.05)$.

But unlike observed for untreated rats, the responsiveness to 5-HT in mesenteric small arteries isolated from prazosin-treated CMV-infected rats was comparable to that in small vessels of prazosin-treated sham-infected animals (figure 6). Furthermore, sensitivity but not maximal responses to PHE were reduced in mesenteric resistance arteries of rats infected with CMV during continuous treatment with prazosin (figure 6, table 2).

\section{Vessels of LPS-treated Rats}

Compared to controls and sham-infected immunosuppressed rats, the contractile reactivity of thoracic aorta segments of LPS-treated rats was markedly altered. The amplitude of contractile responses to PHE, 5-HT and AVP was significantly reduced (figure 7). Furthermore, in aorta of LPS treated rats, $1 \mathrm{mM}$ L-arginine reduced contractile responses and $0.1 \mathrm{mM} \mathrm{L}$ NAME increased contractile responses to PHE and 5-HT (figure 7). In the aorta of control rats, the effects of L-arginine and L-NAME were not statistically significant.

In contrast to the thoracic aorta, the contractile reactivity of mesenteric 
resistance arteries obtained from the same LPS-treated rats, did not differ from that of small arteries isolated from control animals (figure 7). The amplitude of maximal contractile responses to potassium, PHE, 5-HT and AVP were not altered following administration of LPS. Furthermore, the presence of $1 \mathrm{mM}$ L-arginine or $0.1 \mathrm{mM}$ L-NAME did not unmask differences between resistance arteries of LPS-treated and control rats (figure 7).
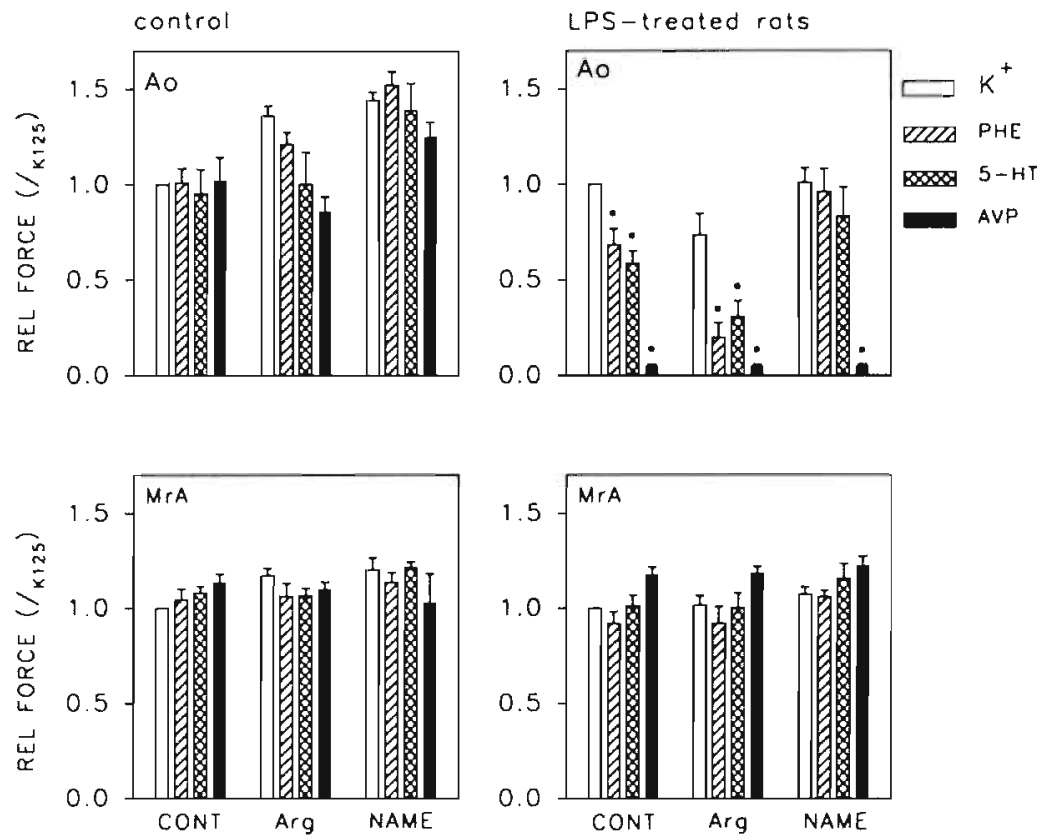

\section{Figure 7}

Effects of L-arginine (L-Arg) and L-N $\mathrm{N}^{\mathrm{G}}$-arginine monomethyl ester (L-NAME) on contractile responses of thoracic aorta segments (top) and mesenteric resistance artery segments (bottom) of rats that had been injected $48-72$ hours earlier with $5-10 \mathrm{mg} / \mathrm{kg}$ LPS (right) and untreated controls (left). Contractions were induced with $125 \mathrm{mM}$ potassium, $10 \mu \mathrm{M}$ phenylephrine, $10 \mu \mathrm{M}$ serotonin and 30 $\mathrm{nM}$ Arg-vasopressin in drug-free solution (KRB) at 45 and $15 \mathrm{~min}$ interval in aorta and small artery preparations, respectively. They were then repeated in the continuous presence of $1 \mathrm{mM} \mathrm{L}$-arginine and thereafter in the presence of $100 \mu \mathrm{M}$ L-NAME. Contractions were expressed as fraction of the response to $\mathrm{K}^{+}$in $\mathrm{KRB}\left(3.5 \pm 0.6\right.$ and $2.9 \pm 0.5 \mathrm{mN} \cdot \mathrm{mm}^{-1}$ for control and LPS-treated aorta, respectively, and $2.9 \pm 0.3$ and $3.2 \pm 0.3 \mathrm{mN} \cdot \mathrm{mm}^{-1}$ for control and LPS-treated mesenteric small artery, respectively). The data are shown as mean \pm s.e.mean $(n=8)$. * the difference from control rats is statistically significant; $\#$, the effect of L-Arg or L-NAME is statistically significant. 


\section{Discussion}

In immunosuppressed rats, CMV infection was found to alter heart rate, blood pressure and arterial reactivity. The arterial changes were more marked in small arteries than in the aorta and differed from those observed following LPS. They could not be reversed by L-NAME but were prevented by prazosin treatment. This suggests that CMV resulted in vascular failure independently of NO synthase, but through activation of the sympathetic nervous system.

Herpes virusses, including cytomegalovirus are widespread in the general population and have been suggested to be involved in the pathogenesis of atherosclerosis (Bruggeman \& van Dam-Mieras, 1991; Hajjar, 1991; Persoons et al., 1994). CMV was observed to promote integrin production and adhesion of monocytes and leucocytes to endothelium (Span et al., 1991a; 1991b). This is mediated by cytokines such as IL1 (Span et al., 1991a). The goal of the present study was to evaluate whether CMV-infection in vivo also influences the function of arterial smooth muscle. The experiments were performed following immunosuppression by irradiation because like human CMV, rat CMV is pathogenic almost exclusively under immunocompromised conditions (Bruggeman et al., 1985). Observations with respect to blood pressure and arterial reactivity in immunosuppressed sham-infected rats were comparable to those in control age-matched rats (Struijker Boudier et al., 1982; Boonen \& De Mey, 1990a; 1991; Eerdmans et al., 1991).

CMV-infected rats ultimately displayed tachycardia, low blood pressure and impaired pressor responses to PHE, reminiscent of hypotonic shock during bacterial sepsis (Groeneveld et al., 1986; Julou-Schaeffer et al., 1990). Observations in mesenteric small arteries indicate that this was due to extensive peripheral vasodilatation. These resistance-sized arteries were markedly hyporesponsive to sympathetic nerve stimulation and $\alpha_{1}$-adrenergic stimulation by exogenous noradrenaline or PHE. Also during bacterial sepsis, extensive peripheral vasodilatation underlies the precipitous fall in blood pressure (Groeneveld et al., 1986; Julou-Schaeffer et al., 1990). Regional- and agonist-selectivity of the changes suggest, however, that the mechanisms differ from those engaged following administration of LPS. Selective alterations were found in small mesenteric arteries. They consisted of drastically impaired responses to $\alpha_{1}$ adrenergic and serotonergic stimulation, despite maintenance of responses to potassium and vasopressin. This can not be attributed to induction of NO synthase because (i) small artery responses to phenylephrine, serotonin and vasopressin are equally sensitive to NO (Eerdmans and De Mey, unpublished observations), (ii) the NO synthase inhibitor L-NAME did not 
restore responses and because (iii) LPS-treatment, which has been shown to result in cytokine-mediate induction of NO synthase in the vascular wall (Moncada et al., 1989; Julou-Schaeffer et al., 1990; Moncada \& Higgs, 1991), altered the reactivity of the aorta but not that of small resistance vessels. It is more likely that a selective alteration of signal-transduction developed in small artery smooth muscle during the course of the CMVinfection. We previously suggested that small artery responses to $\alpha_{1}$-adrenergic stimulation and serotonin are mediated by pertussis toxin sensitive G-proteins affecting voltage-operated calcium channels (Boonen \& De Mey, 1990a; $1990 \mathrm{~b} ; 1991)$. Depolarisation directly opens these channels while vasopressin most likely induces contraction through phospholipase C (Boonen \& De Mey, $1990 \mathrm{a} ; 1990 \mathrm{~b} ; 1991)$. Furthermore, contractile responses of the rat aorta to PHE are rather insensitive to pertussis toxin and calcium channel blockers (Nichols et al., 1989; Oriowo \& Ruffolo, 1992). Thus, the observed regionaland agonist selectivity suggest changes at the level of pertussis toxin sensitive G-proteins, but this remains to be firmly established.

That mechanisms other than induction of NO synthase would be involved in vascular changes following $\mathrm{CMV}$-infection is suggested by their resistance to arginine and arginine-analogues and by their regional distribution which differs from that observed following LPS. We observed that 2 days after bolus administration of LPS, contractile reactivity was reduced in aorta but not resistance vessels and that exogenous arginine caused relaxation in aorta but not resistance vessels. This large artery selectivity contrasts with observations of reduced coronary resistance and relaxation of resistance arteries induced by arginine in rabbit hearts and rat mesenteries 4-6 hours after injected i.p. with $20 \mathrm{mg} / \mathrm{kg}$ LPS (Smith et al., 1991). This discrepancy may be due to differences in concentration- and time-dependency of responses to LPS and cytokines in large and small arteries. In the present study we deliberately used a low concentration of LPS and a long "incubation" time in an attempt to mimic the progressive nature of the changes following CMV-infection.

Prior to changes in vasopressor responsiveness to PHE, CMV-infected rats displayed changes in basal heart rate and in heart rate regulation. Upon elevation of blood pressure with PHE, heart rate is normally reduced through a decrease of sympathetic and an increase of parasympathetic outflow. Three days after $\mathrm{CMV}$-infection the capacity to reduce heart rate in response to pressure elevation was impaired. Although the reflex recovered, it was apparently shifted to a higher set-point. Thereafter basal heart rate increased even further. It is of interest that even at 8 days post-infection, when high heart rate and low blood pressure were observed, administration of the $\beta$ - 
adrenoceptor antagonist propranolol ( $1 \mathrm{mg} \cdot \mathrm{kg}^{-1}$ i.v.) reduced heart rate (unpublished observations). Combined these data suggest that increased sympathetic output was maintained for several days after CMV-infection.

Several days were needed before arterial reactivity changed following CMVinfection. This may be indicative of an indirect mechanism. Our findings with prazosin suggest a possible contribution of sympathetic nervous input to the vascular alterations. Because $\mathrm{CMV}$-infection ultimately resulted in hypotonic shock preceded by tachycardia, we anticipated that prazosin-treatment would accelerate the development of the precipitous fall of blood pressure. Surprisingly it rather delayed the changes in heart rate and blood pressure. Furthermore, it protected small arteries against the selective reactivity changes. From this we suggest that excessive $\alpha_{1}$-adrenergic stimulation of arterial smooth muscle contributes to the selective alteration of excitationcontraction coupling. Through a more or less classical down-regulation process it would primarily affect the action of postjunctional $\alpha_{1}$-adrenoceptors and that of other agonists, such as serotonin, that share the same signalling mechanisms in the vasculature (Boonen \& De Mey, 1990a; 1990b; 1991). It would not affect vascular $\beta$-adrenergic responses, because we have previously shown that in mesenteric small arteries postjunctional $\beta$-adrenoceptors are situated beyond the reach of neuronally released noradrenaline (Eerdmans et al., 1991). Furthermore, $\alpha_{1}$-adrenergic responses of the aorta could escape from this process because, in the adult rat, this vessel is not innervated.

In summary, we observed that CMV-infection of irradiated rats resulted in altered heart rate regulation, tachycardia, changes in arterial reactivity and marked reduction of blood pressure. The changes in vascular function were agonist- and regionally selective. They differed from those observed following administration of endotoxin. Alterations of excitation-contraction coupling in blood vessels are more likely to be involved than cytokine-mediated induction of NO synthase. $\alpha_{1}$-Adrenoceptors may participate in the initiation of these changes. 


\section{References}

Abe M., Reichert C.M., Straus S.E., Longo D.L., Parillo J., Lane C., Fauci A.S., Rook A.H., Manischewitz J.F. \& Quinnan G.V. (1983). Death in the AIDS patient: role of cytomegalovirus, New. Engl. J. Med., December 8, 1454.

Boonen H.C.M. \& De Mey J.G.R. (1990a). G-proteins are involved in contractile responses of isolated mesenteric resistance arteries to agonists, Naunyn. Schmiedeberg's. Arch. Pharmacol., 342, 462-468.

Boonen H.C.M. \& De Mey J.G.R. (1990b). Increased calcium sensitivity in isolated resistance arteries from spontaneously hypertensive rats: effects of dihydropyridines, Eur. J. Pharmacol., 179, 403-412.

Boonen H.C.M. \& De Mey J.G.R. (1991). Effects of a phorbol ester and staurosporine on electro- and pharmacomechanical coupling in a resistance artery, Eur. J. Pharmacol, 202, 25-32.

Bruggeman C.A. \& Van Dam-Mieras M.C.E. (1991). The possible role of cytomegalovirus in atherogenesis, Prog. Med. Virol., 38, 1-26.

Bruggeman C.A., Meyer H., Bosman F. \& Van Boven C.P.A. (1985). Biology of rat cytomegalovirus, Intervirology, 14, 1-9.

Eerdmans P.H.A., Heesen B.J., Struijker Boudier H.A.J. \& De Mey J.G.R., 1991, Sympathetic heterogeneity in mesenteric and renal resistance arteries, in: Resistance Arteries. Structure and Function, ed. Mulvany M.J., Aalkjaer C., Heagerty A.M., Nyborg N.C.B. \& Strandgaard S. pp. 156-159. Amsterdam: Excerpta Medica.

Grattan M.T., Moreno-Cabral C.E., Starnes V.A., Oyer P., Stinson E.B. \& Shumway N.E. (1989). Cytomegalovirus infection is associated with cardiac allograft rejection and atherosclerosis, JAMA, 261, 3561-3566

Groeneveld A.B.J., Bronsveld W. \& Thijs L.G. (1986). Hemodynamic determinants of mortality in human septic shock, Surgery, 99, 140-152.

Hajjar D.P. (1991). Viral pathogenesis of atherosclerosis, Am. J. Pathol., 139, 1195-1211. Hendrix M.G.R., Dormans P.H.J., Kitslaar P., Bosman F. \& Bruggeman C.A. (1989). The presence of cytomegalovirus nucleic acids in arterial walls of atherosclerotic and normosclerotic patients, Am. J. Pathol., 134, 1151-1157.

Julou-Schaeffer G., Gray G.A., Fleming I., Schott C., Parratt J.R. \& Stoclet J.-C. (1990). Loss of vascular responsiveness induced by endotoxin involves L-arginine pathway, Am. J. Physiol., 259, H1038-H1043.

Lin P.J., Chang C.H. \& Chang J.P. (1994). Reversal of refractory hypotension in septic shock by inhibitor of nitric oxide synthase, Chest., 106, 626-629.

Mcdonald K., Rector T.S., Braunlin E.A., Kubo S.H. \& Olivari M.T. (1989). Association of coronary artery disease in cardiac transplant recipients with cytomegalovirus infection, Am. J. Pathol., 64, 359-362.

Mombouli J.V. \& Vanhoutte P.M. (1995). Kinins and endothelial control of vascular smooth muscle, Ann. Rev. Pharmacol. Toxicol., 35, 679-705.

Moncada S. \& Higgs E.A. (1991). Endogenous nitric oxide: physiology, pathology and clinical relevance, Eur. J. Clin. Invest., 21, 361-374.

Moncada S., Palmer R.M.J. \& Higgs E.A. (1989). Biosynthesis of nitric oxide from Larginine. A pathway for the regulation of cell function and communication, Biochem. Pharmacol., 38, 1709-1715. 
Nichols A.J., Motley E.D. \& Ruffolo R.R. (1989). Effect of pertussis toxin treatment on postjunctional $\alpha 1$ - and $\alpha 2$-adrenoceptor function in the cardiovascular system of the pithed rat, J. Pharmacol. Exp. Therap., 249, 203-209.

Nilsson H. (1985). Adrenergic nervous control of resistance and capacitance vessels, Acta. Physiol. Scand., 124 (suppl 541), 1-34.

Oriowo M.A. \& Ruffolo R.R. (1992). Heterogeneity of postjunctional $\alpha 1$-adrenoceptors in mamalian aortae: subclassification based on chloroethylclonidine, WB 4101 and nifedipine, J. Vasc. Res, 29, 33-40.

Persoons M.C., Daemen M.J., Bruning J.H. \& Bruggeman C.A. (1994). Active cytomegalovirus infection of arterial smooth muscle cells in immunocompromised rats. A clue to herpesvirus-associated atherogenesis ?, Circ. Res., 75, 214-220.

Rengasamy A. \& Johns R.A. (1991). Characterization of endothelium-derived relaxing factor / nitric oxide synthase from bovine cerebellum and mechanism of modulation by high and low oxygen tensions, J. Pharmacol. Exp. Therap., 259, 310-316.

Salgado H.O. \& Krieger E.M. (1978). Time-course of baroreceptor resetting in short-term hypotension in the rat, Am. J. Physiol., 234, H552-H556.

Schini V.B., Durante W., Elizondo E., Scott-Burden T., Junquero D.C., Schafer A.I. \& Vanhoutte P.M. (1992). The induction of nitric oxide synthase activity is inhibited by TGF- $\beta 1$, PDGF-AB and PDGF-BB in vascular smooth muscle cells, Eur. J. Pharmacol., 216, 379-383.

Smith R.E.A., Palmer R.M.J. \& Moncada S. (1991). Coronary vasodilatation induced by endotoxin in the rabbit isolated perfused heart is nitric oxide-dependent and inhibited by dexamethasone, Br. J. Pharmacol., 104, 5-6.

Span A.H.M., Mullers W., Miltenburg A.M.M. \& Bruggeman C.A. (1991a). Cytomegalovirus induced PMN adherence in relation to an ELAM-1 antigen present on infected endothelial cell monolayers, Immunology., 72, 355-360.

Span A.H.M., Van Dam-Mieras M.C.E., Mullers W., Endert J., Muller A.D. \& Bruggeman C.A. (1991b). The effect of virus infection on adherence of leukocytes or platelets to endothelial cells, Eur. J. Clin. Invest., 21, 721-731.

Struijker Boudier H.A.J., Evenwel R.T., Smits J.F.M. \& Van Essen H. (1982). Baroreflex sensitivity during the development of spontaneous hypertension in rats, Clin. Sci., 62 , 589-594.

Tyms A.S., Taylor D.L. \& Parkin J.M. (1989). Cytomegalovirus and acquired immunodeficiency syndrome. J. Antimicrob. Chemother. 23 (suppl A), 89-105.

Van Kleef E.M., Smits J.F.M., De Mey J.G.R., Cleutjens J.P.M., Lombardi D.M., Schwartz S.M. \& Daemen M.J.A.P. (1992). $\alpha_{1}$-Adrenoceptor blockade reduces the angiotensin II-induced vascular smooth muscle cell DNA synthesis in the rat thoracic aorta and carotid artery, Circ. Res., 70, 1122-1127.

Wakabayashi G., Gelfand J.A., Burke J.F., Thompson R.C. \& Dinarello C.A. (1991). A specific receptor antagonist for interleukin 1 prevents escherichia coli-induced shock in rabbits, Faseb. J., 5, 338-343.

Wallenstein S., Zucker C.L. \& Fleiss J.L. (1980). Some statistical methods useful in circulation research, Circ. Res., 47, 1-9. 
Summary and conclusions 



\section{Background}

Harvey, who discovered the basic principles of the circulation of the blood, was so impressed by its complexity that he stated in the first chapter of his classic book Exercitatio Anatomica de Motu Cordis et Sanguinis in Animalibus (1628) that he almost felt that the motion of the heart and blood was to be comprehended only by God.

Indeed the control of the cardiovascular system seems to be very complex. An important control systems in relation to blood pressure control is the sympathetic nervous system. Claude Bernard (1851) recognized that integration of the function of the cardiovascular system depends mainly on the nervous system. The exploration of the sympathetic nervous system started in 1897 when noradrenaline, the main sympathetic neurotransmitter, was identified (Abel \& Crawford, 1897). In 1905 (Elliot, 1905) the relation between noradrenaline and the sympathetic nervous system was first mentioned. The link between noradrenaline, the sympathetic nervous system and the cardiovascular system was first described in 1921 (Loewi, 1921). Classically two acute sympathetic mechanisms are proposed in relation to blood pressure regulation: i) vascular and cardiac control by sympathetic nerves using noradrenaline as prime neurotransmitter and ii) control of the heart and vasculature by circulating noradrenaline and adrenaline released by the adrenal medulla. Cardiovascular effects of other aspects of the sympathetic nervous system became increasingly clear during the last 25 years.

In chapter 1 of this thesis it is described that besides noradrenaline various other transmitters (cotransmitters) can be released by sympathetic nerves. The release of neurotransmitters is controlled locally by feedback systems (for example pre-synaptic $\alpha_{2^{-}}$and $\beta$-adrenoceptors), hormones (for example angiotensin II) or transmitters from peptidergic nerve endings.

Furthermore, it became clear that several types and subtypes of adrenoceptors exist and that these adrenoceptors are not uniformly distributed along the vascular tree (De Mey \& Vanhoutte, 1981; Daly et al., 1988; Faber, 1988b; Heesen \& De Mey, 1990; Messing et al., 1990; Piascik et al., 1990; Aantaa et al., 1995; Hieble et al., 1995; Michel et al., 1995; Graham et al., 1996). The latter can also be said about the sympathetic nerves. Large arteries like the aorta are sparsely innervated. In general, nerve density increases with increasing branching of the vascular tree but marked differences exist between vascular beds. A second important finding of the last decades is the dynamics of the adrenoceptors. Adrenoceptor populations change depending on the levels of stimulation, increased stimulation leading to reduction of the density of at 
least certain (sub)types of receptors (down-regulation) and vice versa (Sibley \& Lefkowitz, 1985; Brodde, 1991; Kiuchi et al., 1993).

Knowledge on the functional significance of the sympathetic nervous system has also evolved. The sympathetic nervous system is not only an acute blood pressure regulating system, but can also alter blood pressure in a chronic manner. Evidence has been presented for a trophic influence of the sympathetic nervous system on the heart and vasculature (see chapter 1) (Bevan \& Tsuru, 1979; 1981; Bevan et al., 1983; Blaes \& Boissel, 1983; Yamori et al., 1987; Nakaki et al., 1990). The structural changes caused by the sympathetic nervous system can contribute to increased vascular resistance and blood pressure as observed in hypertension.

In summary, on the one hand the sympathetic nervous system plays a pivotal role in normal cardiovascular control. On the other hand, many investigators (see chapter 1 for a review) believe that abnormalities in sympathetic activity may underlie the pathogenesis of certain diseases. The aim of this thesis was to investigate the long-term consequences of altered sympathetic activity on especially the resistance part of the vascular system. In particular the next research questions were stipulated;

- what are the alterations in vascular adrenergic reactivity in experimental models of chronically increased or decreased sympathetic activity?

- what are the structural vascular alterations in experimental models of chronically increased or decreased sympathetic activity?

In order to answer these questions we studied a range of arteries from different vascular beds of rats. We focused on resistance sized arteries in view of the important role these arteries play in resistance, and hence blood pressure, control. In chapter 1 the choice of the experimental models we used was motivated.

\section{What are the results and what is their interpretation?}

Chapters 2 and 3 were aimed at a precise definition of the pharmacological tools to be used in the vascular $\alpha$-adrenoceptor studies in this thesis. In chapter 2 we investigated the role of $\alpha_{1}$-adrenoceptor subtypes in isolated large and small arteries of the rat. We evaluated effects of the $\alpha_{1 \mathrm{~B}}+\alpha_{1 \mathrm{D}}$ adrenoceptor blocking agent $\mathrm{CEC}$ on $\left[{ }^{3} \mathrm{H}\right]$-prazosin binding and on responses and affinity to 
noradrenaline and $\alpha_{1}$-adrenoceptor antagonists in isolated rat thoracic aorta, superior mesenteric artery, and mesenteric resistance arteries. Pretreatment with $C E C$ reduced the number of prazosin binding sites and the sensitivity for the contractile effect of noradrenaline more markedly in large arteries than in small resistance-sized arteries of the rat. Yet, pretreatment with CEC did not modify some aspects of the regional heterogeneity of arterial $\alpha_{1}$-adrenergic responses such as differences in susceptibility of agonist responses to the inhibitory action of phenoxybenzamine and $\mathrm{Na}$-nitroprusside. The findings suggest that (i) $\alpha_{1 \mathrm{~A}}$-adrenoceptors are more prominent in small arteries than in large resistance arteries of the rat and (ii) regional heterogeneity of $\alpha_{1}$ adrenergic responses in blood vessels is not solely due to differences in the distribution of $\alpha_{1}$-adrenoceptor subtypes. Furthermore in mesenteric resistance arteries, pretreatment with $\mathrm{CEC}$ reduced the number of prazosin binding sites but did not affect maximal contractile responses to noradrenaline despite the absence of a significant receptor reserve. CEC, however, reduced the contractile response of the mesenteric resistance artery to noradrenaline in the absence of extracellular calcium. This suggests that in mesenteric resistance

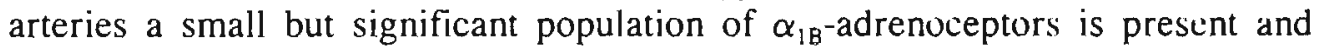
coupled to an intracellular calcium pool. These $\alpha_{1 \mathrm{~B}}$-adrenoceptors contribute, however, minimally to sustained responses to noradrenaline which seem to be mediated primarily by $\alpha_{1 \mathrm{~A}}$-adrenoceptors.

In chapter 3 we furthermore investigated the acute effects of 3 different $\alpha_{2}$ adrenoceptor agonists, azepexole, clonidine and rilmenidine in mesenteric and renal resistance arteries. The $\alpha_{2}$-adrenoceptor agonists differ in several respects: two $\alpha_{2}$-adrenoceptor agonists with centrally acting hypotensive properties, azepexole and clonidine and furthermore rilmenidine, an $\mathrm{N}$ substituted oxazoline, with high affinity for both $\alpha_{2}$-adrenoceptors and imidazoline receptors were used. Azepexole and rilmenidine did not modify (i) basal tone, (ii) contractile responses to $30 \mathrm{mM}$ potassium, (iii) contractile responses to 0.1 to $20 \mu \mathrm{M}$ phenylephrine and (iv) relaxing responses to isoproterenol $1 \mathrm{nM}$ to $10 \mu \mathrm{M}$. At $10 \mu \mathrm{M}$ rilmenidine, but not azepexole, increased the sensitivity of mesenteric vessels to nerve stimulation. Clonidine on the other hand increased contractile responses to $30 \mathrm{mM}$ potassium and reduced contractile responses to phenylephrine. Contractile effects of clonidine in partly depolarised preparations could be antagonised by $1 \mu \mathrm{M}$ prazosin. It was concluded that $\alpha_{2}$-adrenoceptor stimulation failed to influence resistance artery contractile reactivity and both rilmenidine and clonidine elicited effects that can not be attributed to $\alpha_{2}$-adrenoceptor stimulation. For rilmenidine this 
may involve an effect on sensory-motor nerves; in the case of clonidine partial $\alpha_{1}$-adrenoceptor agonism seems to play a major role. The lack of clear cut effects of $\alpha_{2}$-adrenoceptor stimulation be it through direct activation of excitation-contraction coupling or through inhibition of adenylate cyclase, contrasts with the earlier demonstration of both pre- and postjunctional $\alpha_{2}{ }^{-}$ adrenergic binding sites in this tissue.

Chapters 4 and 5 were aimed at an analysis of vascular reactivity and structural alterations in chronic hypertension. The studies were performed in SHR, an experimental model characterized by hyperinnervation of blood vessels and by a sympathetic hyperactivity during the early stages of the development of hypertension (see chapter 1). In the two chapters we compared non-treated SHR with animals that received postsynaptic $\alpha_{1}$-adrenoceptor blocking drugs or centrally acting drugs that reduce sympathetic activity. The (4 weeks) treatment of the 8 weeks old spontaneously hypertensive rats were the following; $0.1 \mathrm{mg} / \mathrm{kg} /$ day prazosin, $6 \mathrm{mg} / \mathrm{kg} /$ day rilmenidine or 60 $\mathrm{mg} / \mathrm{kg} /$ day azepexole.

In chapter 4 the emphasis was put on the blood pressure and vascular structural alterations following the treatment. Azepexole and rilmenidine transiently lowered blood pressure and heart rate but caused a persistent reduction of plasma noradrenaline levels. Prazosin on the other hand did not modify blood pressure, heart rate or plasma noradrenaline levels. The lack of chronic antihypertensive action of the drugs causing reduced sympathetic activity is in contrast with the observations by ourselves and others (Christensen et al., 1988; Linz et al., 1989; Eerdmans et al., 1991; Harrap, 1991) that ACE inhibitors, hydralazine or other vasodilators can persistently lower blood pressure chronically in SHR. The discrepancy suggests that the sympathetic nervous system has a more important role in acute than in longterm control of blood pressure. This is in agreement with the view expressed by Guyton and co-workers (see introduction) that nervous control of the cardiovascular system primarily serves a short-term function.

After the four weeks treatment structural properties and maximal contractile responses were determined in thoracic aorta, superior mesenteric artery, mesenteric and renal resistance arteries. Findings differed considerably between different types of vessels. It was found that prazosin treatment resulted in a significant reduction of media cross sectional area (CSAm) in aorta but not in the other vessels. Azepexole on the other hand caused a significant increase of CSAm of the mesenteric resistance arteries. Rilmenidine treatment had no effect on the vascular structure. Maximal active wall tension 
and maximal active wall stress of the several types of artery were not modified by prazosin or azepexole. However, rilmenidine treatment resulted in a significant increase of active wall tension and stress in the aorta and the opposite in the mesenteric resistance artery. In a previous study (Boonen et al., 1993) we found a lack of structural effects on small mesenteric arteries after 4 day phenylephrine infusion at doses that did cause blood pressure elevation, whereas contractile reactivity decreased. Taken together, these data do not support a generalized arterial structural effect of the sympathetic nervous system. There may be regionally selective changes in arterial structure and function, whereas at least part of the effect of azepexole and rilmenidine may not at all depend on their interference with $\alpha_{2}$-adrenoceptors. Some of the lack of long term arterial structural effects seen in this study may contribute to the limited anti-hypertensive potential of the applied drugs in the SHR.

In chapter 5 we described the effect of 4 weeks treatment with $0.1 \mathrm{mg} / \mathrm{kg} / \mathrm{day}$ prazosin, $6 \mathrm{mg} / \mathrm{kg} /$ day rilmenidine or $60 \mathrm{mg} / \mathrm{kg} / \mathrm{day}$ azepexole on vascular reactivity as investigated in the thoracic aorta, superior mesenteric artery, mesenteric resistance arteries and renal resistance arteries. Furthermore, changes in $\alpha$-adrenoceptor subtypes were evaluated in receptor binding studies of the kidney. In the latter only a changed $\alpha_{1}$-adrenoceptor affinity of the prazosin treated animals was found which may be due to the presence of prazosin following its 4 week treatment. Electrical nerve stimulation revealed an increased sensitivity in the mesenteric resistance artery in the three treatment groups. No changes were found in the larger superior mesenteric artery or renal resistance artery. This increased sensitivity was not caused by changes in noradrenaline re-uptake or changes in the sensitivity of the arterial smooth muscle for noradrenaline. Furthermore the aorta and superior mesenteric artery, but not resistance arteries, of the animals treated with prazosin and rilmenidine were significantly less sensitive to acetylcholine. From the observed findings we concluded that no changes in contractile properties or adrenoceptor populations of the investigated arteries developed due to the 4 weeks treatment to decrease sympathetic activity. The changes in the endothelium induced relaxing properties of the large arteries and the alterations seen in the mesenteric resistance artery can play a role in the lack of antihypertensive effects of the used treatments.

Although these studies (chapter 4 and 5) do not disclaim a potential role for sympathetic hyperactivity in the early postnatal period of SHR, they suggest that in the later stages ( $>3$ months) hypertension is not dependent on sympathetic activity (see figure 1). 


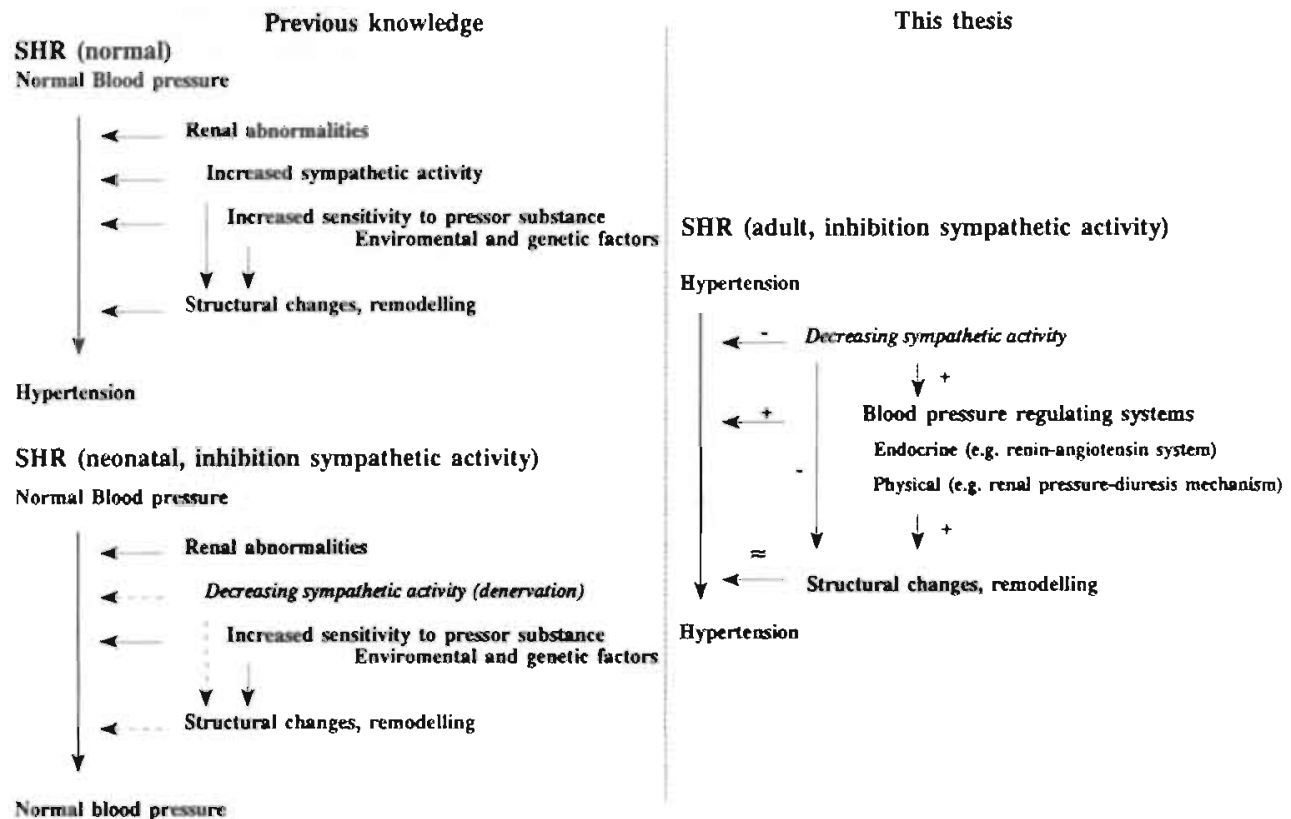

\section{Figure 1}

Schematic representation of the variables responsible for the development of hypertension, the findings in neonatal SH-rats and the observations from this thesis. When decreasing sympathetic activity in neonatal rats no structural changes or hypertension develop. In this thesis we evaluated the effect of a decreased sympathetic activity in the adult rat (right side). The (negative) effects of decreased sympathetic activity, pressure decrease and structural alterations, were overridden hy other blood pressure regulating systems (positive effects)

We suggest that the increased vascular resistance is due to structural vascular alterations, overruling any potential chronic effect of decreased sympathetic activity on blood pressure. This hypothesis is in agreement with that of others (see introduction) who regard the sympathetic nervous system primarily as a short-term controller of blood pressure.

In chapter 6 we described the effect of another pathological condition, heart failure due to myocardial infarction, on vascular reactivity. The myocardial infarction model can be seen as an increased sympathetic activity model (see chapter 1). The thoracic aorta, the superior mesenteric artery and mesenteric resistance-sized arteries of rats with a four week old myocardial infarction and of sham-operated control rats were investigated. The mean infarction size was $45.6 \%$ of the left ventricle. Structural evaluation of the investigated arteries 
showed no significant alterations of lumen diameter, media thickness and media cross-sectional area. Furthermore no changes in maximal responses, sensitivity to adrenergic and non-adrenergic contractile stimuli or active wall stress were found in the aorta and superior mesenteric artery. Also no changes were found in relaxing responses to acetylcholine or isoprenaline in either type of artery. In the mesenteric resistance arteries, however, a significant reduction of maximal contractile responses to potassium, noradrenaline and serotonin was found. It was concluded that following $\mathrm{MI}$ in the rat the contractile reactivity of mesenteric resistance arteries is chronically and nonselectively reduced (figure 2). The decreased contractility of the mesenteric resistance artery may contribute to the development of decompensated heart failure. The studies again show a marked regional heterogeneity. In addition, the studies point in the direction of an intriguing phenomenon: in the course of the development of heart failure in this rat model resistance vessels lose their contractility. This may suggest a more common mechanism underlying cardiac and vascular failure in this pathology. Future research should be aimed at the signal transduction mechanisms that dysfunction in this condition.

In chapter 7 a third experimental model of increased sympathetic activity is described. The cytomegalovirus infection rat model can be seen as a sepsis model in which increased sympathetic activity developed to maintain adequate blood pressure. Blood pressure and arterial reactivity were recorded in immunosuppressed rats that had been infected with CMV $\left(10^{5} \mathrm{PFU}\right.$ ip). In reactivity studies of isolated arteries the effect of $\mathrm{CMV}$-infection and injections with bacterial endotoxin (LPS) were evaluated. Initially, resting blood pressure and heart rate were not modified in CMV-infected rats, but baroreflex control of heart rate was impaired. By the eighth day post-CMV, blood pressure dropped precipitously and could no longer be raised by phenylephrine. In mesenteric resistance arteries of those rats contractile responses to nerve stimulation, noradrenaline, phenylephrine and serotonin were virtually absent, high potassium and vasopressin induced contractions were not modified.In the aorta, responses to serotonin and vasopressin were impaired, whereas phenylephrine or potassium induced contractions were hardly affected. In addition, a group of CMV-infected rats were treated continuously with prazosin $(0.1 \mathrm{mg} / \mathrm{kg}$.day). The treatment prevented blood pressure lowering and resistance artery changes.

In arteries of LPS-treated rats $(10 \mathrm{mg} / \mathrm{kg}$.day) only differences in contractile abilities of the aorta were found: responses to phenylephrine, serotonin and arg-vasopressin responses were reduced. 
Previous knowledge

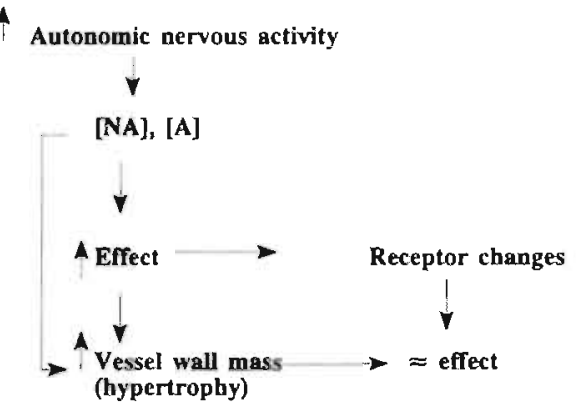

This thesis

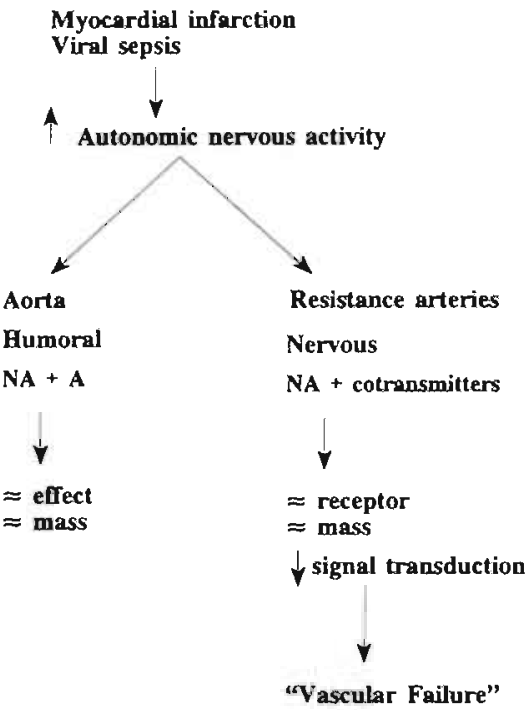

Figure 2

Schematic representation of the classical model of the effect of increased sympathetic tone on the vasculature (left) and of the model distilled from this thesis. Increased sympathetic activity will lead to an increased concentration of noradrenaline and adrenaline $([\mathrm{NA}]+[\mathrm{A}])$. This results in a constriction of the arteries. The arteries reacts on this in two way; i) a hypertrophy develops and ii) down regulation, decreased sensitivity of the adrenoceptors. Furthermore a direct hypertrophic effect of noradrenaline has been observed. The changes in mass and receptor population will counteract the effects of an increased catecholamine concentrations and the baseline situation returns. In this thesis, we investigated the role of an increased sympathetic activity with the use of two experimental models (myocardial infarction and viral sepsis). Two pathways exists, humoral (non-innervated arteries) and nervous (innervated arteries). In the humoral pathway no changes in receptor populations or vascular structure were found, the latter was also observed in the nervous pathway. However, significant alterations were observed in signal transduction pathways causing in decreasing sympathetic control leading to vascular failure.

These changes, however, could be reversed by L-NAME which was not the case after CMV infection. It was concluded that CMV-infection results in a selective reduction of resistance artery reactivity and hypotonia (figure 2). These changes were not caused by cytokine-mediated induction of NO synthase in the vascular wall as seen after LPS-injections. The increased sympathetic activity seems to play an important role, since blocking adrenergic input by prazosin prevented changes in contractility after CMV-infection. Selective alterations of excitation-contraction coupling, signal transduction 
systems, of arterial smooth muscle cells may play a role herein. These data are in agreement with our previous observations (Boonen et al., 1993) that show an altered signal transduction in mesenteric small arteries following a 4-day phenylephrine infusion.

\section{General conclusions}

What are the alterations in vascular adrenoceptor reactivity in experimental models for increased and decreased sympathetic activity?

Cardiovascular control depends heavily on sympathetic activity both under physiological and pathological conditions. However, the reaction of the target organs to sympathetic input seems to be a dynamic phenomenon. We focused on the arterial system as the target organ. Due to nerve and adrenoceptor heterogeneity the effect of sympathetic hypo- and hyperactivity differ from one arterial bed to the other. From research by our own group and others a picture emerges of heterogeneous distribution of $\alpha$-adrenoceptor subtypes along the vascular tree (Testa et al., 1995). The aorta and elastic arteries are only poorly innervated and the predominant $\alpha_{1}$-adrenoceptor subtypes seems to be the $\alpha_{1 \mathrm{~B}}$ and $\alpha_{1 \mathrm{D}}$. Descending along the vascular tree there is an increasing innervation and a shift from $\alpha_{1 \mathrm{~B}}$ and $\alpha_{1 \mathrm{D}}$ to $\alpha_{1 \mathrm{~A}}$ adrenoceptors. Furthermore postjunctional $\alpha_{2}$-adrenoceptors seem to have a predominant localization in the smaller arteries and arterioles of the microcirculation. This heterogeneous distribution suggests a differential role of $\alpha_{1}$-adrenoceptor subtypes in the elastic and resistive properties of the arterial system and may provide a basis for a more selective pharmacological interference with these important properties of the arterial system. Modulations in innervation and adrenoceptor population ( inor decreased sensitivity, up/down regulation, shift in subtypes) can have major hemodynamic consequences. Functional changes like postsynaptic desensitized $\alpha_{2}$-adrenoceptors and hypersensitive presynaptic $\beta_{2}$-adrenoceptors have been described in hypertensive disease (Tsuda et al., 1987; de Champlain, 1990).

$\beta$-Adrenoceptor down regulation has been firmly established in heart failure, where reduced $\beta$-adrenergic responsiveness and $\beta$-adrenoceptor density in the heart and peripheral vasculature has been observed (for review see Brodde, 1991). Increased sensitivity to adrenergic stimuli has been described to play a role in the development of hypertension (Lais \& Brody, 1978; Mulvany, 1983; Aqel et al., 1987; Akbar et al., 1989; Kishi \& Inoue, 1990; Kong et al., 1991; Hayashi et al., 1992). Changes in adrenergic responses could at least in part 
explain the vascular failure often occurring after myocardial infarction and sepsis.

Down regulation of vascular $\alpha_{1}$-adrenoceptors did not occur in the models of increased sympathetic activity we investigated. The decreased contractile responses to noradrenaline and serotonin in the myocardial infarction model and CMV-infected animals seem to be caused by changes in signal transduction pathways rather than in receptor density. Small artery responses to $\alpha_{1}$-adrenergic stimulation and serotonin are mediated by pertussis toxin sensitive G-proteins affecting voltage-operated calcium channels (Boonen \& De Mey, 1990a; b; 1991). Depolarisation directly opens these channels while Argvasopressin most likely induces contraction through phospholipase $\mathrm{C}$ (Boonen \& De Mey, 1990a; b; 1991). Furthermore, contractile responses of the rat aorta to PHE are rather insensitive to pertussis toxin and calcium channel blockers (Nichols et al., 1989; Oriowo \& Ruffolo, 1992) which explains the normal responses in our study. Thus, the observed regional- and agonist selectivity of vascular alterations following myocardial infarction and CMVinfection indirectly suggest changes at the level of pertussis toxin sensitive Gproteins.

The lack of $\alpha_{1}$-adrenoceptor up or down regulation during long term increased stimulation allows the sympathetic nervous system to maintain its vascular control in normal and pathological situations. However, the signal transduction systems further down the road seem to fail, causing hyporeactivity to various vasocontrictor agonists and thus causes major hemodynamic problems as seen during sepsis and congestive heart failure.

What are the structural vascular alterations in experimental models for increased or decreased sympathetic activity?

In addition to its acute effects, the sympathetic nervous system seems to play an important chronic role in vascular function. Especially hypertrophic effects of the sympathetic nervous system are thought to play a key role in the structural alterations found in hypertension. The SHR model has often be used to investigated the relation between hypertension, sympathetic activity and structural vascular changes. Neonatal immunosympathectomy with anti-nerve growth factor (NGF) and guanethidine prevents the development of high blood pressure in SHR and SHRSP (stroke-prone SHR) (Lee et al., 1987; Mangiarua \& Lee, 1992). Structural changes, increased wall to lumen ratio and media thickness in the SH rats have been described in several studies (Lee \& Smeda, 1985; Mangiarua \& Lee, 1992). 
Two models were used to evaluate the role of the sympathetic nervous system in relation to structural vascular alterations. A normal pressure model with among others increased sympathetic tone, the MI-model, and an increased pressure model with a decreased sympathetic tone, SHR treated with central $\alpha_{2}$-agonists. In the MI-model with chronically increased sympathetic activity no structural vascular changes were seen. In the azepexole treated SHR-rats mesenteric resistance artery alterations were found in the form of increased cross sectional area, media thickness and wall to lumen ratio. This can be due to locally increased blood pressure, since azepexole causes a vasoconstriction of the arteriolar vasculature (Faber, 1988a) and small venules (De Mey \& Vanhoutte, 1981; Messing, 1992) distal from the mesenteric resistance arteries. From this we can conclude that increased/decreased sympathetic activity by itself will not alter vascular structure in an adult, fully developed vascular system. The sympathetic nervous system may be an important modulator of vascular structure in young, growing tissue. In more advanced stages, other -mechanical- factors may be a more important determinant of vascular structure (Daemen \& De Mey, 1995). Increased blood pressure, the result from an increased sympathetic tone can be an important modulator of structural alterations. In this view structural vascular alterations are adaptive processes contributing to the maintenance of normal physical vessel wall properties in the face of an elevated pressure.

In conclusion, the sympathetic nervous system plays an important role in blood pressure regulation and during acute situations of hemodynamic disorders. The role of the sympathetic nervous system in chronically maintaining increased blood pressure levels in spontaneous hypertension seems to be minor. In longterm arterial pressure control it is not the only player. Other systems of endocrine (e.g. renin-angiotensin system) or physical (e.g. renal pressurediuresis mechanism) nature may be more dominant in long-term arterial pressure control. Sympathetic activity may affect vascular structure in developing, young vessels. In more mature vessels other factors of again endocrine or physical nature seem to offset any potential structural effect of the sympathetic nervous system.

$\alpha_{1}$-Adrenoceptors seems not to fit in the classical model of homologous receptor up and down regulation. Rather, a malfunctioning signal transduction system seems to be the underlying cause of the vascular failure in septic shock after CMV-infection or congestive heart failure following MI. Future experiments should focus on the role of chronic sympathetic hyperactivity in the development of these forms of vascular failure. 


\section{References}

Aantaa R., Marjamaki A. \& Scheinin M. (1995). Molecular pharmacology of $\alpha_{2}$ adrenoceptor subtypes, Ann. Med., 27, 439-449.

Abel J.J. \& Crawford A.C. (1897). On the blood pressure raising constituent of the suprarenal capsule, Bull Johns Hopkins Hosp, 8, 151.

Akbar H., Chen N.Y., Fossen D.V. \& Wallace D. (1989). Increased vascular contractile sensitivity to serotonin in spontaneously hypertensive rats is linked with increased turnover of phosphoinositide, Life. Sci., 45, 577-583.

Aqel M.B., Sharma R.V. \& Bhalla R.C. (1987). Increased norepinephrine sensitive intracellular $\mathrm{Ca} 2+$ pool in the caudal artery of spontaneously hypertensive rats. J. Hypertension., 5, 249-253.

Bevan R.D. \& Tsuru H. (1979). Long term denervation of vascular smooth muscle causes not only functional but structural change, Blood. Vessels., 16, 109-112.

Bevan R.D. \& Tsuru H. (1981). Functional and structural changes in the rabbit ear artery after sympathetic denervation, Circ. Res., 49, 478-485.

Bevan R.D., Tsuru H. \& Bevan J.A. (1983). Cerebral artery mass in the rabbit is reduced by chronic sympathetic denervation, stroke, 14, 393-396.

Blaes N. \& Boissel J.P. (1983). Growth-stimulating effect of cathecholamines on rat aortic smooth muscle cells in culture, J. Cell. Physiol., 116, 167-172.

Boonen H.C.M. \& De Mey J.G.R. (1990a). G-proteins are involved in contractile responses of isolated mesenteric resistance arteries to agonists, Naunyn. Schmiedeberg's. Arch. Pharmacol., 342, 462-468.

Boonen H.C.M. \& De Mey J.G.R. (1990b). Increased calcium sensitivity in isolated resistance arteries from spontaneously hypertensive rats: effects of dihydropyridines, Eur. J. Pharmacol., 179, 403-412.

Boonen H.C.M. \& De Mey J.G.R. (1991). Effects of a phorbol ester and staurosporine on electro- and pharmacomechanical coupling in a resistance artery, Eur. J. Pharmacol., $202,25-32$.

Boonen H.C.M., Daemen M.J.A.P., Eerdmans P.E., Fazzi G.E., van Kleef E., Schiffers P.M.H. \& De Mey J.G.R. (1993). Mesenteric small artery changes following vasoconstrictor infusion in young rats, J. Cardiovasc. Pharmacol., 22, 388-395.

Brodde O.E. (1991). $\beta_{1}$ and $\beta_{2}$ adrenoceptors in the human heart: properties, function, and alterations in chronic heart failure, Pharmacol. Rev., 43, 203-242.

de Champlain J. (1990). Pre- and postsynaptic adrenergic dysfunctions in hypertension, J. Hypertension., 8, S77-S85.

Christensen H.R.L., Nielsen H., Christensen K.L., Baandrup U., Jespersen J.T. \& Mulvany M.J. (1988). Long-term hypotensive effects of an angiotensin converting enzyme inhibitor in spontaneously hypertensive rats: is there a role for vascular structure?. J. Hypertension., 6 (suppl 3), s27-s31.

Daly C.J., McGrath J.C. \& Wilson V.G. (1988). An examination of the postjunctional $\alpha$ adrenoceptor subtypes for (-)-noradrenaline in several isolated blood vessels from the rabbit, Br. J. Pharmacol., 95, 473-484.

Daemen M.J.A.P. \& De Mey J.G.R. (1995). Regional heterogeneity of arterial structural changes, Hypertension, 25, 464-473. 
De Mey J.G.R. \& Vanhoutte P.M. (1981). Uneven distribution of postjunctional $\alpha_{1}-$ and $\alpha_{2}$ - like adrenoceptors in canine arterial and vennus smooth muscle, Circ. Res., 48. 875884 .

Eerdmans P.H.A., Struijker Boudier H.A.J. \& De Mey J.G.R. (1991). Contractile reactivity of isolated resistance arteries after 4 weeks of treatment with rilmenidine, clonidine or hydralazine in spontaneously hypertensive rats, J. Hypertension., 9, S348S349.

Elliot T.R. (1905). The action of adrenalin, J. Physiol., 32, 401.

Faber J.E. (1988a). Effect of local tissue cooling on microvascular smooth muscle and postjunctional $\alpha 2$-adrenoceptors, Am. J. Physiol., 255, h121-H130.

Faber J.E. (1988b). In situ analysis of $\alpha$-adrenoceptors on arteriolar and venular smooth muscle in rat skeletal muscle microcirculation, Circ. Res., 62, 37-50.

Graham R.M., Perez D.M., Hwa J. \& Piascik M.T. (1996). $\alpha_{1}$-adrenergic receptor subtypes. Molecular structure, function, and signaling, Circ. Res., 78, 737-749.

Harrap S.B. (1991). Angiotensin converting enzyme inhibitors, regional vascular hemodynamics, and the development and prevention of experimental genetic hypertension, Am. J. Hypertension., 4, 212S-216S

Hayashi K., Epstein M. \& Loutzenhiser R. (1992). Enhanced myogenic responsiveness of renal interlobular arteries in spontaneously hypertensive rats, Hypertension., 19[suppl II], 153-160.

Heesen B.J. \& De Mey J.G.R. (1990). Effects of cyclic AMP-affecting agents on contractile reactivity of isolated mesenteric and renal resistance arteries of the rat, $\mathrm{Br}$. J. Pharmacol.. 101, 859-864.

Hieble J.P., Bylund D.B., Clarke D.E., Eikenburg D.C., Langer S.Z., Lefkowitz R.J., Minneman K.P. \& Ruffolo R.R. (1995). International union of Pharmacology. X. Recommendation for nomenclature of alpha 1 adrenoceptors: consensus update, Pharmacol. Rev., 47. 267-270.

Kishi K. \& Inoue T. (1990). Possible mechanisms of abnormal norepinephrine sensitivity and reactivity of resistance vessels and the development of hypertension in spontaneously hypertensive rats. A hypothesis, Am. J. Hypertension., 3, 202S-205S.

Kiuchi K., Sato N., Shannon R., Vatner D.E., Morgan K. \& Vatner S.F. (1993).

Depressed $\beta$-adrenergic receptor- and endothelium-mediated vasodilation in conscious dogs with heart failure, Circ. Res., 73, 1013-1023.

Kong J.Q., Taylor A. \& Fleming W.W. (1991). Mesenteric vascular responses of young spontaneously hypertensive rats, J. Phannacol. Exp. Therap., 258, 13-17.

Korner P., Bobik A., Oddie C. \& Friberg P. (1993). Sympathoadrenal system is critical for structural changes in genetic hypertension, Hypertension., 22, 243-252.

Lais L.T. \& Brody M.J. (1978). Vasoconstrictor hyperresponsiveness: an early pathogenic mechanism in the spontaneously hypertensive rat, Eur. J. Pharmacol., 47, 177-189.

Lee R.M.K.W. \& Smeda J.S. (1985). Primary versus secondary strucrural changes of the blood vessels in hypertension, Can. J. Physiol. Pharmacol., 63, 392-401.

Lee R.M.K.W., Triggle C.R., Cheung D.W.T. \& Coughlin M.D. (1987). Structural and functional consequences of neonatal sympathectomy on the blood vessels of spontaneously hypertensive rats, Hypertension., 10, 328-338. 
Lee R.M.K.W., Borokowski K.R., Leenen F.H.H., Tsoporis J. \& Coughlin M. (1991). Combined effect of neonatal sympathectomy and adrenal demedullation on blood pressure and vascular changes in spontaneously hypertensive rats, Circ. Res., 69, 714-721.

Linz. W., Scholkens B.A. \& Ganten D. (1989). Converting enzyme inhibition specifically prevents the development and induces regression of cardiac hypertrophy in rats, Clin. Exp. Hypertension., A11, 1325-1350.

Loewi O. (1921). Uber humorale ubertragbarkeit der herznervenwirkung, Pfluegers Arch, 189, 239.

Mangiarua E.I. \& Lee R.M.K.W. (1992). Morphometric study of cerebral arteries from spontaneously hypertensive stroke-prone hypertensive rats, J. Hypertension., 10, 11831190.

Messing M.W.J. (1992). Antihypertensive drugs and the microcirculation, UPM, ISBN 90 90050957, , 64-72.

Messing M.W.J., van Essen H. \& Struijker Boudier H.A.J. (1990). Effects of $\alpha$ adrenoceptor antagonists on striated muscle microcirculation of conscious rats, Drugs., 40, 31-33.

Michel M.C., Kenny B. \& Schwinn D.A. (1995). Classification of $\alpha_{1}$ adrenoceptor subtypes, Naunyn. Schmiedeberg's. Arch. Pharmacol., 352, 1-10.

Mulvany M.J. (1983). Do resistance vessel abnormalities contribute to the elevated blood pressure of spontaneously-hypertensive rats?, Blood. Vessels., 20, 1-22.

Nakaki T., Nakayama M., Yamamoto S. \& Kato R. (1990). $\alpha_{1}$-Adrenergic stimulation and $\beta_{2}$-adrenergic inhibition of DNA synthesis in vascular smooth muscle cells, Mol. Pharmacol., 37, 30-36.

Nichols A.J., Motley E.D. \& Ruffolo R.R. (1989). Effect of pertussis toxin treatment on pistjunctional $\alpha 1$ - and $\alpha 2$-adrenoceptor function in the cardiovascular system of the pithed rat, J. Pharmacol. Exp. Therap., 249. 203-209.

Oriowo M.A. \& Ruffolo R.R. (1992). Heterogeneity of postjunctional $\alpha_{1}$-adrenoceptors in mamalian aortae: subclassification based on chloroethylclonidine, WB 4101 and nifedipine, J. Vasc. Res, 29, 33-40.

Piascik M.T., Butler B.T. \& Pruitt T.A. (1990). The role of $\alpha_{1}$-adrenoceptor subtypes in the regulation of arterial blood pressure, Eur. J. Pharmacol., 180, 381-386.

Sibley D.R. \& Lefkowitz R.J. (1985). Molecular mechanisms of receptor desensitization using the beta-adrenergic receptor-coupled adenylate cyclase system as a model, Nature., 317, 124-129.

Testa R., Destefani C., Guarneri L., Poggesi E., Simonazzi I., Taddei C. \& Leonardi A. (1995). The $\alpha_{1 \mathrm{D}}$ adrenoceptor subtype is involved in the noradrenaline induced contractions of rat aorta, Life. Sci., 57, PL153-163.

Tsuda K., Kuchii M., Nishio L. \& Masuyama Y. (1987). Presynaptic $\alpha_{2}$-adrenoceptors mediated regulation of norepinephrine release in perfused mesenteric vasculatures in young and adult spontaneously hypertensive rats, Jpn. Circ. J., 51, 25-32.

Yamori Y.. Mano M., Nara Y. \& Horie R. (1987). Catecholamine induced polyploidization in vascular smooth muscle cells, Circulation., 75, 192-195. 
Samenvatting 



\section{Samenvatting}

Een wetenschappelijke samenvatting van dit proefschrift is gegeven in hoofdstuk 8 . Deze nederlandstalige samenvatting is geschreven voor een breder publiek van geïnteresseerde lezers.

De invloed van het sympatisch zenuwstelsel op de bloedsomloop bestaat uit twee componenten. Ten eerste uit het controleren van hartfunctie en vaatwandspanning door middel van het vrijmaken van boodschapperstoffen uit de sympatische zenuwuiteinden. Ten tweede door het rechtstreeks vrijmaken van hormonen in de bloedbaan. Deze boodschapperstoffen en hormonen (catecholaminen) gaan een interactie aan met receptoren in het hart en in de bloedvaten met als resultaat een verandering van hartfunctie of bloedvatdiameter. Aangezien er grote verschillen kunnen bestaan in soorten en hoeveelheden receptoren en in dichtheid van sympatische zenuwen in de diverse bloedvaten kunnen de vrijgekomen hormonen heel verschillende effecten hebben.

Het sympatisch zenuwstelsel speelt een belangrijke rol bij het handhaven van een adequate doorbloeding van het lichaam in pathologische omstandigheden zoals o.a. hart problemen (pompfunctie stoornissen) en infecties. Toch leiden deze ziekten regelmatig tot ernstige problemen met uiteindelijk de dood tot gevolg. Of dit door het falen van het sympatisch zenuwstelsel komt is nog niet duidelijk.

Uit experimenteel onderzoek naar het ontstaan van hypertensie (hoge bloeddruk) blijkt dat het sympatisch zenuwstelsel tevens een belangrijke rol kan spelen bij de ontwikkeling van deze aandoening. Zo blijken mensen met een verhoogde bloeddruk regelmatig ook een verhoogde sympatische activiteit te hebben. Bij hypertensie vindt men behalve hoge arteriële drukken ook veranderingen in vaatwandstruktuur en receptor eigenschappen. Of deze ontstaan door veranderingen in sympatische activiteit is nog onduidelijk.

Het doel van dit proefschrift was om de gevolgen van een veranderde sympatische activiteit gedurende lange perioden te bestuderen in grote en kleine bloedvaten. De volgende twee vragen zijn getracht te beantwoorden door middel van verschillende dierexperimentele modellen:

- ontstaan er veranderingen in de gevoeligheid van bloedvaten bij de verschillende experimentele modellen van verhoogde of verlaagde sympatische activiteit?

- ontstaan er veranderingen in de structuur van de vaatwand bij de verschillende experimentele modellen van verhoogde of verlaagde sympatische activiteit? 
Er is gebruik gemaakt van verschillende diermodellen. De spontaan hypertensieve rat (SHR) heeft een verhoogde sympatische activiteit. Hetzelfde geldt voor het myocard infarct model tijdens de eerste weken na het ontstaan van het infarct. Ook tijdens een cytomegalovirus (CMV) infectie zien we een verhoogde sympatische activiteit met als doel de bloed voorziening op peil te houden. Door de ratten te behandelen met centraal werkende $\alpha_{2}$-adrenoceptor agonisten werd het mogelijk de sympatische activiteit te verlagen. De sympatische invloed op het vaatstelsel werd tevens verlaagd door gebruik te maken van de $\alpha_{1}$-adrenoceptor antagonist prazosine.

In hoofdstuk 2 en 3 van het proefschrift werd de aard van de $\alpha$-adrenoceptoren in de diverse arteriën onderzocht. De grote arteriën zoals de aorta blijken vooral $\alpha_{1 \mathrm{~B}}$ en

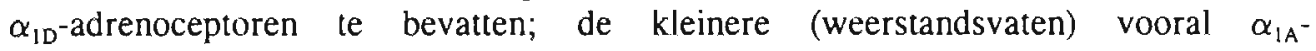
adrenoceptoren. De grote vaten hebben bijna geen sympatische zenuwuiteinden, hoe kleiner de arteriën hoe groter het aantal zenuwuiteinden. Veranderingen in $\alpha$ adrenoceptor populaties werden niet gevonden in de gebruikte experimentele modellen van verhoogde of verlaagde sympatische activiteit (hoofdstuk 5). Veranderingen in gevoeligheid voor catecholaminen zoals gezien bij het myocard infarct (hoofdstuk 6) en CMV model (hoofdstuk 7) blijken te berusten op veranderingen in signaal transductie systemen: systemen die de verbinding leggen tussen de receptor en het inwendige van de cel.

Het sympatisch zenuwstelsel blijkt een belangrijke rol te spelen in het ontstaan van strukturele vaatveranderingen in de spontaan hypertensieve rat. Het uitschakelen van de sympatisch activiteit bij de pasgeboren rat voorkomt de ontwikkeling van hypertensie. Uit dit proefschrift blijkt dat het verlagen of verhogen van de sympatische activiteit bij de volwassen rat niet leidt tot struktuur veranderingen (hoofdstuk 4). De strukturele veranderingen bij hypertensie worden dus niet in stand gehouden door verhoogde sympatische activiteit maar moeten meer gezien worden als aanpassing van de vaatwand aan de verhoogde druk.

Concluderend kunnen we zeggen dat het sympatisch zenuwstelsel geen doorslaggevende rol speelt in het onderhouden van de verhoogde bloeddruk bij experimentele hypertensie. Veranderingen in de vaatfunctie zijn niet het gevolg van veranderingen in adrenoceptor eigenschappen maar in veranderingen in signaal transductie systemen. Het falen van het onderhouden van adequate doorbloeding bij hartfalen en CMV infectie blijkt niet te berusten op langdurige veranderingen in de werking van het sympatisch zenuwstelsel. Veeleer lijkt hierbij een falen van het vaatstelsel voorop te staan. 


\section{CURRICULUM VITAE}

$\begin{array}{lll}\begin{array}{l}\text { Name } \\ \text { Christian names } \\ \text { Date of birth }\end{array} & \begin{array}{l}\text { : Eerdmans. } \\ : \text { Pedro Henry Alfred. } \\ : 23-11-1961 .\end{array} \\ \text { Education } & : 1982-1987 & \begin{array}{l}\text { Medicine Study. } \\ 1988-1990\end{array} \\ & \begin{array}{l}\text { Master in the Medical and Pharmaceutical } \\ \text { Research Study (University of Brussels, Belgium) } \\ \text { Experimental pharmacology, PhD project, } \\ \text { Department of Pharmacology, University of } \\ \text { Limburg, The Netherlands. }\end{array}\end{array}$

$\begin{array}{lll}\text { Diplomas } & 1987 & \text { Master in Medicine. (docteraal geneeskunde) } \\ 1988 & \text { Cell and tissue culture (Boerhaave, Leiden) } \\ 1988 & \text { Radiation Safety Expert, Level 5B } \\ 1989 & \text { Article 9 degree, (animal experiments) } \\ 1990 & \text { Master in the Medical and Pharmaceutical Research. }\end{array}$

Positions

present

: 1993- Head Trialbureau Urology, Department of L'rology. University Hospital Maastricht (azM), The Netherlands.

prior
: 1987 - 1989 Medical doctor in research (AIO), Orthopaedics Department, University Hospital Maastricht, The Netherlands.
1989 - 1993 Experimental pharmacologist (OIO), Pharmacology Department, University of Limburg, The Netherlands.




\section{Publications}

\section{Ahistracts}

P.H.A. Ferdmans, G.H.I.M. Walenkamp, S.K. Bulstra, A.J. van der Linden. Effect van gentamicine op gewrichtskraakbeen. NTVG 1990;134,nr 3, blz 147-148.

P.H.A. Eerdmans, G.H.I.M. Walenkamp, S.K. Bulstra en A.J. van de Bogaard. Een septische-artritismodel met staphylococcus aureus bij de rat. NTVG 1990;134,27, 1330.

P.H.A. Eerdmans, J.G.R. De Mey. $\alpha_{1}$-adrenergic effects of clonidine on contractile reactivity of isolated mesenteric and renal resistance arteries of spontaneously hypertensive rats. In: Blood Vessels, 27, no 1, 35, 1990.

P.H.A. Eerdmans, J.G.R. De Mey. Acute effects of $\alpha_{2}$ agonists in isolated mesenteric and intra-renal resistance arteries of 12 weeks old spontaneously hypertensive rats. European journal of Pharnacology, 183/3, 831-832, 1990.

P.H.A. Eerdmans, H.A.J. Struyker Boudier, J.G.R. De Mey. Contractile reactivity of isolated resistance arteries after 4 week treatment with rilmenidine, clonidine or hydralazine in spontaneously hypertensive rats. Ricerca Scientifica ed educazione permanente suppl. N.90, 1991

P.H.A. Eerdmans, H.A.J. Struyker Boudier, J.G.R. De Mey. Components involved in resistance arterial responses to electrical field stimulation. Blood Vessels, vol 28, no 4, blz 286-287, 1991.

P.H.A. Eerdmans, J.J.M. Debets, J.F.M. Smits, J.G.R. De Mey. Reduced responsiveness to sympathetic nerve stimulation in peripheral resistance arteries following myocardial infarction. Pharmaceutisch Weekblad, suppl, H, h5, 1991.

P.H.A. Lerdmans, M.C.J. Persoons, C.A. Bruggeman, J.G.R. De Mey. Effect of cytomegalovirus infection in vivo on the reactivity of isolated resistance-sized arteries of the rat. The FASEB Journal, vol 6, no 4, part I, A1039, 1992.

F. Weil, P. Eerdmans, E. van Waalwijk van Doom, G. Ralph, R. Janknegt. The effect of the $\alpha_{1}$-adrenoceptor selective agonist midodrine on mild to moderate female stressincontinence. Neurourology and Urodynamics, vol 13, no 4, 446-447, 1994.

E.H.J. Weil, P.H.A. Eerdmans, R.A. Janknegt. A new randomized study on neuromodulation versus conventional treatment for incontinence or dysfunctional voiding patterns; a preliminary report. Neurourology and Urodynamics, vol 15, no 4, 284-285, 1996.

R.A. Janknegt, F.H.J. Weil, P.H.A. Eerdmans. Two stage neuromodulation implant for refractory voiding dysfunctions: an attempt to improve the PNE testing score Neurourology and Irodynamics, vol 15, no 4, 403-404, 1996.

Ernest H.J. Weil, Pedro H.A. Eerdmans, Ruud A. Janknegt. 5 year treatment of patients with severe voiding disorders, so called urological cripples, by neuromodulation. The facts. European Urology, vol 30, no S2, 236, 1996

R. Janknegt, E. Weil, P. Ferdmans. Improvement neuromodulation results for urge, urge incontinence and retention by two stage implant. European Urology, vol 30, no S2, 236, 1996

E.H.J. Weil, P.H.A. Eerdmans, R.A. Janknegt. Significant positive urodynamic changes 6 months after neuromodulation in 21 patients with urge-incontinence. European Urology, vol 30, no S2, 238, 1996 
P.H.A. Eerdmans, H.A.J. Struyker Boudier, J.G.R. De Mey. Sympathetic heterogeneity in mesenteric and renal resistance arteries. Resistance arteries, structure and function, ed. Mulvany et al, 156-159, 1991.

P.H.A. Eerdmans, H.A.J. Struyker Boudier, J.G.R. De Mey. Contractile realctivity of isolated resistance arteries after 4 week treatment with rilmenidine, clonidine or hydralazine in spontaneously hypertensive rats. Journal of Hypertension, 9 (suppl 6), s348-s349, 1991.

Pedro H. A. Eerdmans, Harry A. J. Struyker Boudier and Jo G. R. De Mey. Fffect of nerve stimulation on isolated mesenteric and intra-renal resistance arteries, shr versus wky. Genetic Hypertension. Ed. J. Sassard, 85-87, 1992.

Harrie C.M. boonen, Mat J.A.P. Daemen, Pedro H.A. Eerdmans, Gregorio E. Fazzi, Ellen M. van Kleef, Paul M. H. Schiffers, and Jo G.R. De Mey. Mesenteric small artery changes after vasocontrictor infusion in young rats. Journal of Cardiovascular Pharmacology, 22, blz 388-395, 1993.

S.K. Bulstra, R. Kuijer, P. Eerdmans, A.J. van der Linden. The effect in vitro of irrigating solutions on intact rat articular cartilage. J. Bone Joint Surg. 76-B, 468-470, 1994.

Ben J.A. Janssen, Pedro H.A. Eerdmans, Jos F.M. Smits. Mechanisms of renal vasoconstriction following furosemide in conscious rats. Naunyn-Schmiedeberg's Arch Pharmacol, 349, 528-537, 1994.

Pedro H.A. Eerdmans, Maike C.J. Persoons, Sjaak J. M. Debets, Harry A.J. Struijker Boudier, Jos F.M. Smits, Catrien A. Bruggeman, Jo G.R. De Mey. Impaired arterial reactivity following cytomegalovirus Infection in the immunosuppressed rat. British journal of Pharmacology, 119, 637-646, 1996

R.A. Janknegt, E.H.J. Weil, P.H.A. Eerdmans. Improving neuromodulation technique for refractory voiding dysfunctions: Two stage implant. Urology, In press. 



\section{Dankwoord}

Ik denk nog met veel plezier terug aan de "lezingen" van Harry tijdens mijn studenten periode. Het was altijd een genot om zijn verhaal, dat uitblonk in eenvoud en duidelijkheid, te beluisteren. De keuze farmacologie was door mij dan ook snel gemaakt hetgeen resulteerde in een keuzeblok in het tweede jaar en een wetenschapsstage farmacologie in 1987. De stage was mijn eerste kennismaking met Jo en het enthousiasme voor zijn vakgebied maakte direct een diepe indruk op me. Het heeft mij dan ook weinig tijd gekost om in 1989 naar Jo te stappen toen ik hoorde dat er een vacature voor een OIO-plaats vrijkwam. Het meeste heb ik genoten van de "experimentele" vrijheid die ik had bij Jo. Ieder idee kon uitgewerkt worden, het introduceren van nieuwe technieken werd toegejuicht. Deze vrijheid heeft er voor gezorgd dat mijn proefschrift zeer divers is geworden. Het moeilijk kunnen overzien van al deze verschillende data is echter ook een van de redenen dat mijn proefschrift "lang" op zich heeft laten wachten. Ook tijdens de post-farmacologie periode hebben Jo en Harry een groot aandeel gehad in het afronden van mijn experimenteel werk middels dit proefschrift waarvoor mijn dank.

Het uitvoeren van experimenten is meestal iets wat men niet alleen kan doen. Om goed te kunnen presteren ben je vaak afhankelijk van derden. Dit was zeer zeker ook bij mij het geval.

Door de diversiteit van mijn proefschrift, - in vivo/in vitro modellen, operatie technieken (myocard infarct, invasieve bloeddruk metingen), receptor binding studies en histologie (zenuwkleuring, morfometrie) - heb ik vaak om raad en daad moeten vragen bij mij collega's. Jos, bedankt voor je adviezen tijdens de myocard infarct en CMV experimenten. Paul en zijn lab wil ik bedanken voor het meten van de catecholaminen bepalingen. Sjaak, Helma, Peter en Elsbeth wil ik bedanken voor het maken van myocard infarct dieren en het helpen met de bloeddrukmetingen. Ger wil ik bedanken voor alle receptorbinding studies die hij onverstoord voor mij heeft uitgevoerd. Veel heb ik ook te danken aan Gregorio die menig vaatje voor mij gekleurd en gemeten heeft. Dorrette voor het meten van zenuwdichtheden in de femoraal arterie, ik zie haar nog de duizenden puntjes zetten. Harrie Boonen, Frank en Harry van der Heijden wil ik bedanken voor de myograaf hulp tijdens weer eens een overvol protocol.

I would like to thank Holger and Nina for their help which made electrical nerve stimulation possible in our lab. De instrumentele dienst wil ik bedanken voor hun ondersteuning bij het ontwikkelen en verder verbeteren van de zenuw stimulatie apparatuur. 
Veel heb ik ook te danken aan de witte Sony radio die het lab regelmatig omtoverde in een discotheek maar het werk o zo veel aangenamer maakte.

Caroline komt veel eer toe, eerst als analiste (bloeddruk metingen, osmotische minipompjes etc), daarna als partner. Menig vrij uurtje, weekend, heeft zij Patrick bezig gehouden of sociale verplichtingen vervuld zodat ik rustig aan mijn proefschrift kon werken.

Ten laatste bedank ik de leden van de beoordelingscommissie:

Prof. dr. R.A. Janknegt, Prof. dr. C. Bruggeman, Prof. dr. S. de Lange, Prof. dr. M.C. Michel en Dr. M. Pfaffendorf voor de kritische evaluatie en positieve beoordeling van mijn proefschrift. 
